\title{
A Prominent Couple
}

Citation for published version (APA):

Ratz, L. (2017). A Prominent Couple: the TMPRSS2:ERG Gene Fusion in Aggressive Prostate Cancer . [Doctoral Thesis, Maastricht University]. Datawyse / Universitaire Pers Maastricht.

https://doi.org/10.26481/dis.20171215lr

Document status and date:

Published: 01/01/2017

DOI:

10.26481/dis.20171215lr

Document Version:

Publisher's PDF, also known as Version of record

\section{Please check the document version of this publication:}

- A submitted manuscript is the version of the article upon submission and before peer-review. There can be important differences between the submitted version and the official published version of record.

People interested in the research are advised to contact the author for the final version of the publication, or visit the DOI to the publisher's website.

- The final author version and the galley proof are versions of the publication after peer review.

- The final published version features the final layout of the paper including the volume, issue and page numbers.

Link to publication

\footnotetext{
General rights rights.

- You may freely distribute the URL identifying the publication in the public portal. please follow below link for the End User Agreement:

www.umlib.nl/taverne-license

Take down policy

If you believe that this document breaches copyright please contact us at:

repository@maastrichtuniversity.nl

providing details and we will investigate your claim.
}

Copyright and moral rights for the publications made accessible in the public portal are retained by the authors and/or other copyright owners and it is a condition of accessing publications that users recognise and abide by the legal requirements associated with these

- Users may download and print one copy of any publication from the public portal for the purpose of private study or research.

- You may not further distribute the material or use it for any profit-making activity or commercial gain

If the publication is distributed under the terms of Article $25 \mathrm{fa}$ of the Dutch Copyright Act, indicated by the "Taverne" license above, 


\section{A Prominent Couple}

\section{The TMPRSS2:ERG Gene Fusion in}

Aggressive Prostate Cancer 


\section{A Prominent Couple - The TMPRSS2:ERG Gene Fusion in Aggressive Prostate Cancer Leonie Ratz}

ISBN 9789461597762

Cover design and layout by Leonie Ratz

Printed by Datawyse | Universitaire Pers Maastricht

Copyright (C) Leonie Ratz, Cologne 2017

All rights reserved. No parts of this thesis may be reproduced, stored or transmitted in any form or by any means without prior written permission of the author.

Cover illustration: collection of silhouettes of men (from shutterstock.inc) 


\title{
A Prominent Couple
}

\section{The TMPRSS2:ERG Gene Fusion in Aggressive Prostate Cancer}

\author{
DISSERTATION \\ to obtain the degree of Doctor at Maastricht University, \\ on the authority of the Rector Magnificus, Prof. Dr. Rianne M. Letschert \\ in accordance with the decision of the Board of Deans, \\ to be defended in public \\ on Friday, $15^{\text {th }}$ of December 2017, at 13:30 hours \\ by \\ Leonie Ratz \\ born on $23^{\text {rd }}$ of March 1987 in Cologne
}




\section{SUPERVISORS}

Prof. Dr. F. C. S. Ramaekers

Prof. Dr. H. Sültmann (German Cancer Research Center and National Center of Tumor

Diseases, Heidelberg)

\section{CO-SUPERVISORS}

Privatdozentin Dr. S. M. Klauck (German Cancer Research Center, Heidelberg)

Prof. Dr. P. Altevogt (German Cancer Research Center, Heidelberg)

\section{ASSESSMENT COMMITTEE}

Prof. Dr. M. van Engeland (chair)

Prof. Dr. J. Schalken (Radboud University Medical Center, Nijmegen)

Prof. Dr. S. Pahernik (Nuremberg General Hospital, Paracelsus Medical University, Nuremberg)

Prof. Dr. M. Vooijs

\section{FUNDING}

This project was supported through intramural funding by the German Cancer Research Center. 
CONTENTS

List of abbreviations $\quad 6$

General introduction $\quad 9$

Chapter 1 The biology of aggressive prostate cancer:

Implications for innovative diagnostics and therapy

Chapter 2 TMPRSS2:ERG gene fusion variants induce TGF- $\beta$ signaling and epithelial to mesenchymal transition in

human prostate cancer cells

Chapter 3 TMPRSS2:ERG overexpression induces changes in the epigenetic signature of human prostate cancer cells: Hypomethylation correlates with upregulation of FZD4 and HLA-DMB

Chapter $4 \quad$ INSM1 induces a neuroendocrine phenotype in prostate cancer cells

Chapter 5 General discussion

Valorisation

Summary

Nederlandse samenvatting

Deutsche Zusammenfassung

Acknowledgements

Curriculum vitae 201

Publication list 


\section{LIST OF ABBREVIATIONS}

\begin{tabular}{|c|c|}
\hline ACPP & acid phosphatase, prostate \\
\hline ADT & androgen deprivation therapy \\
\hline AKT & AKT serine/threonine kinase 1 \\
\hline ALK1 & activin receptor like kinase 1 \\
\hline AMACR & alpha-methylacyl-CoA racemase \\
\hline$A R$ & androgen receptor \\
\hline AR-V7 & androgen receptor splice variant 7 \\
\hline ASCL1 & achaete-scute homolog 1 \\
\hline BAMBI & BMP and activin membrane-bound inhibitor \\
\hline BCA & bicinchoninic acid \\
\hline BMP & bone morphogenetic protein \\
\hline $\mathrm{bp}$ & base pair \\
\hline $\mathrm{BPH}$ & benign prostate hyperplasia \\
\hline BSA & bovine serum albumin \\
\hline CD24 & cluster of differentiation 24 \\
\hline $\mathrm{CDH} 1$ & E-cadherin \\
\hline $\mathrm{CDH} 2$ & $\mathrm{~N}$-cadherin \\
\hline CDK1 & cyclin-dependent kinase 1 \\
\hline cDNA & complementary DNA \\
\hline CFU & colony forming units \\
\hline CHD1 & chromodomain helicase DNA binding protein 1 \\
\hline CHGA and $B$ & chromogranin $\mathrm{A}$ and $\mathrm{B}$ \\
\hline CK & cytokeratin \\
\hline CNA & Copy number alteration \\
\hline $\mathrm{Cp}$ & crossing point \\
\hline CRPC & castration-resistant prostate cancer \\
\hline CTC & circulating tumor cell \\
\hline DHT & dihydrotestosterone \\
\hline DMSO & dimethyl sulfoxide \\
\hline DNA & deoxyribonucleic acid \\
\hline DNase & deoxyribunuclease \\
\hline DNMT & DNA methyltransferase \\
\hline Dox & doxycycline \\
\hline EGFR & epidermal growth factor receptor \\
\hline EMT & epithelial-to-mesenchymal transition \\
\hline ERG & V-ets erythroblastosis virus E26 homolog (avian) \\
\hline ERK2 & extracellular signal-regulated kinases, alias of MAPK1 \\
\hline Ev & empty vector \\
\hline
\end{tabular}




\begin{tabular}{|c|c|}
\hline FC & fold change \\
\hline FN1 & fibronectin 1 \\
\hline FPKM & fragments per kilobase of exon per million fragments mapped \\
\hline FZD4 & frizzled 4 \\
\hline GAPDH & glyceraldehyde-3-phosphate dehydrogenase \\
\hline GO & gene ontology \\
\hline HGPIN & high-grade prostatic intraepithelial neoplasia \\
\hline HLA-DMB & major histocompatibility complex, class II, DM beta \\
\hline ICGC-EOPC & International Cancer Genome Consortium-Early Onset PCa project \\
\hline ID1 and 2 & inhibitor of differentiation (1 and 2) \\
\hline IGP & NGFN IG Prostate Cancer project \\
\hline INSM1 & insulinoma associated-1 \\
\hline IPA & Ingenuity Pathway Analysis \\
\hline JNK & c-Jun N-terminal kinases \\
\hline L1CAM & L1 cell adhesion molecule \\
\hline LRP5 and 6 & low-density lipoprotein receptor-related protein 5 and 6 \\
\hline MAPK & mitogen-activated protein kinase \\
\hline MET & mesenchymal-to-epithelial transition \\
\hline $\operatorname{miR}$ & micro-RNA \\
\hline MMP & matrix metalloproteinase \\
\hline MSMB & microseminoprotein beta \\
\hline MYCN & $\mathrm{N}$-myc proto-oncogene \\
\hline NCAM & neuronal cell adhesion molecule \\
\hline NED & neuroendocrine differentiation \\
\hline NEPC & neuroendocrine prostate cancer \\
\hline NSE & neuron specific enolase \\
\hline ORF & open reading frame \\
\hline p38 & alias of MAPK14, mitogen-activated protein kinase 14 \\
\hline PAKT & phospho-AKT \\
\hline PAP & prostatic acid phosphatase \\
\hline $\mathrm{PCa}$ & prostate cancer \\
\hline PI3K & phosphatidylinositol 3-kinase \\
\hline PIN & prostatic intraepithelial neoplasia \\
\hline PLA1A & phospholipase A1 member A \\
\hline PLAT & plasminogen activator, tissue type \\
\hline p-p38 & phospho-p38 \\
\hline PSA & prostate specific antigen \\
\hline pSMAD & phospho-SMAD \\
\hline qPCR & quantitative reverse transcription PCR \\
\hline RELN & reelin \\
\hline
\end{tabular}




$\begin{array}{ll}\text { REST } & \text { RE-1 silencing transcription factor/neuron-restrictive silencer factor } \\ \text { rhALK1 } & \text { (NRSF) } \\ \text { rhFZD4 } & \text { recombinant decoy receptor ALK1 } \\ \text { RPKM } & \text { reads per kilobase per million mapped reads } \\ \text { RT-PCR } & \text { reverse transcription PCR } \\ \text { SCG3 } & \text { secretogranin III } \\ \text { SiRNA } & \text { small interfering RNA } \\ \text { SLC45A3 } & \text { solute carrier family 45 member 3 } \\ \text { SMAD } & \text { SMAD family protein } \\ \text { SNAI2 } & \text { snail family transcriptional repressor 2 } \\ \text { SYP } & \text { synaptophysin } \\ \text { TCF7L2 } & \text { T cell factor/lymphoid enhancer 2 } \\ \text { TCF/LEF-1 } & \text { transcription factor/lymphoid enhancer binding factor 1 } \\ \text { TCGA } & \text { The Cancer Genome Atlas } \\ \text { TDRD1 } & \text { tudor domain containing 1 } \\ \text { T/E } & \text { TMPRSS:ERG } \\ \text { TGF- } \beta & \text { transforming growth factor beta } \\ \text { TGFB1 and 2 } & \text { TGF- } \beta \text { 1 and 2 } \\ \text { TMPRSS2 } & \text { transmembrane protease, serine 2 } \\ \text { TUBB3 } & \text { tubulin beta 3 } \\ \text { VIM } & \text { vimentin } \\ \text { VTN } & \text { vitronectin } \\ \text { WNT } & \text { wingless-type family member } \\ \text { ZEB1 } & \text { zinc finger E-box binding homeobox 1 } \\ \end{array}$


General introduction 


\section{THE EPIDEMIOLOGY OF PROSTATE CANCER}

Prostate cancer ( $\mathrm{PCa}$ ) is the most prevalent non-cutaneous malignancy accounting for $15 \%$ of the cancers diagnosed in men [1]. It is the second leading cause of cancerrelated death in men in Western countries with 417,000 new cases and 92,000 deaths in 2012 in Europe [1, 2]. Only few risk determinants for the development of PCa have been defined, such as increasing age, ethnic or geographical origin, and family history, while the influence of lifestyle factors is less well-established [3-5]. Increasing age is by far the most important risk factor. Only $30 \%$ of all cases are diagnosed under the age of 65 years in the US [6]. The 10-years risk to develop PCa for men aged 30 years is $0.01 \%$, increases to $4.77 \%$ for men aged 60 years and to $5.50 \%$ for men aged 70 years [6].

In 2014, the highest incidence rates for PCa in the US were in the age group of 65-74 years, while between 1975-1995 the incidence rates were in the group of 75 years or older indicating that the diagnosis is currently made at younger age [7]. The incidence rates for PCa are highly variable between different geographical areas, with highest incidence in industrialized countries [6]. Since autopsy-based detection of PCa revealed similar prevalence rates among different geographical areas, the increasing incidence is significantly associated with the widespread implementation of PSA testing leading to elevated biopsy-based detection rates in asymptomatic patients [8, 9]. The mortality pattern has largely remained unchanged and shows less variation worldwide, as PSA testing has a greater impact on incidence than on mortality $[6,8]$. Family history is an important contributing factor for the incidence of PCa (men with affected first-degree relatives are diagnosed 2.48 times (95\% confidence interval: 2.25-2.74) more often compared to men with unaffected relatives), and has a higher impact on the incidence rate for men aged $<65$ years [10].

\section{THE PROSTATIC GLAND}

The adult prostatic tissue consists of pseudostratified epithelium with basal, luminal and neuroendocrine (NE) cells, together forming the glandular acini surrounded by a fibromuscular stromal network. The basal cell layer forms the proliferating compartment characterized by high expression of p63, cytokeratin (CK) 5, 6, 14, 19, glutathione-Stransferase-pi (GSTpi), B-cell lymphoma 2 (Bcl-2), and epidermal growth factor receptor (EGFR) $[11,12]$. The basal layer also contains pluripotent stem cells or transit amplifying (TA) cells with limited proliferative capacity that can differentiate into the functional distinct cell types of the prostate and give rise to phenotypically intermediate cells representing different states in the differentiation process $[11,12]$. Pluripotent stem cells are maintained by different signaling mechanisms including Notch/Delta, TGF- $\beta$ and integrin signaling [13]. The differentiation compartment contains secretory luminal 
cells, which are the major cell type of the prostate, characterized by expression of CK8 and CK18 [12]. Luminal cells are positive for prostate specific antigen (PSA) and prostatic acid phosphatase (PAP) and show high expression of androgen receptor (AR). The NE cells, that are assumed to derive from the periurogenital paraganglia from the neural crest and invade the developing prostate by week 10 of gestational age, are localized disseminated throughout the prostate epithelium and display dendritic-like extensions $[14,15]$. Electron microscopic analysis has revealed a granular morphology of NE cells correlating with the detection of various neurosecretory products including serotonin, histamine and members of the chromogranin/secretogranin peptide family, as well as the NE markers synaptophysin and CD56 (NCAM) [16, 17].

The development of the prostatic gland depends on AR signaling. In the absence of androgens, AR, a steroid hormone receptor, is sequestered in the cytoplasm and bound to a heat shock protein chaperone complex that protects it from proteolysis and maintains a conformational state that is accessible to ligand binding [18]. Androgen signaling is initiated by entering of testosterone into the cell and its conversion to the more potent dihydrotestosterone (DHT) by the enzyme $5 \alpha$-reductase [19]. Upon binding of DHT to the AR ligand-binding domain, receptor dissociation from the heat shock protein complex, phosphorylation and translocation to the nucleus is induced. Translocation enables binding of the nuclear receptor to androgen response elements (ARE) within target genes by its DNA-binding domain and subsequent recruitment of co-regulatory transcription factors, including histone modifiers (e.g. CBP/p300, NCoR) [20], transcription regulators (e.g. TRAP/DRIP/ARC) and DNA structural modifiers (e.g. SWI/SNF/BRG1) [21]. Assembly of the transcriptional complex initiates gene expression of $A R$ target genes including PSA [22]. Under physiologic conditions, AR signaling is terminated by cyclic assembly/disassembly of the AR-transcription factor complex mediated by the heat shock protein complex [18].

\section{CHALLENGES IN CURRENT DIAGNOSTIC AND THERAPEUTIC MANAGEMENT OF PROSTATE CANCER}

PCa is usually suspected based on an elevated PSA value and abnormal digital rectal examination (DRE), but PSA level is not a direct surrogate for tumor stage. Definitive diagnosis requires histopathological evaluation of prostate specimens obtained by systematic transrectal ultrasound (TRUS)-guided biopsy cores [23] (Figure 1). The sensitivity of this technique is limited to $53 \%$ and repeat biopsy is recommended to one third of patients with a persistently suspected PCa, which can be very stressful to patients [24, 25]. Prostate biopsies are classified according to the Gleason grading system based on glandular architectural pattern, scored from 1 to 5 with decreasing differentiation, and combining primary and secondary patterns taking into account the morphologic hete- 
rogeneity of PCa [26]. The dilemma with the Gleason score is that different histological foci can harbor distinct genetic aberrations leading to heterogeneous clinical outcomes among patients with the same histological pattern [27].

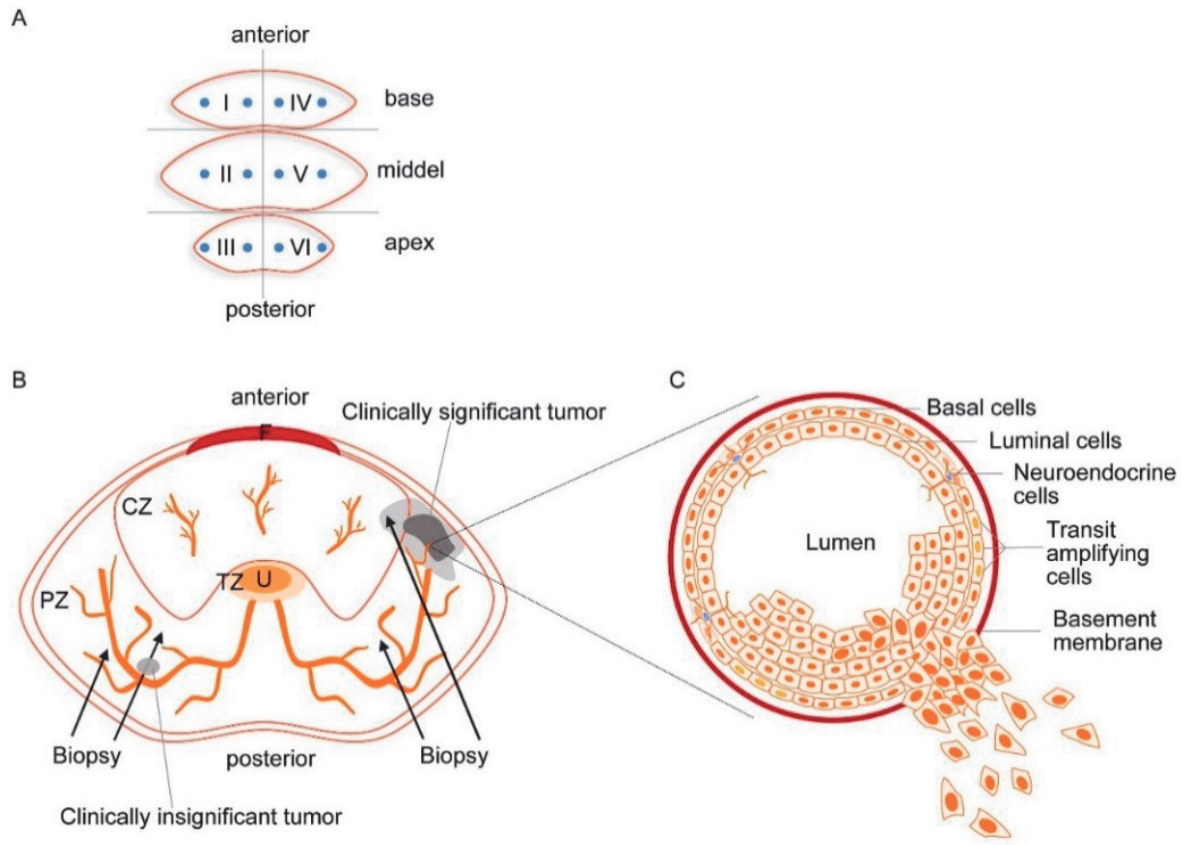

Figure 1: Schematic illustration of the prostate gland. (A) Scheme of prostate biopsy practice. The most commonly used biopsy scheme includes 12 systematically obtained tissue cores covering all parts of the prostate gland. Blue dots represent biopsy cores. (B) Axial cross-section of the prostate. Black arrows indicating ultrasound-guided biopsy. Thirty percent of patients undergoing prostate biopsy will have positive results, of the remaining $70 \%$ with negative biopsy $20-30 \%$ will have false-negative biopsy due to the systematically yet random biopsy pattern that may miss a clinically significant tumor. In $15 \%$ of cases random biopsy cores underscore the tumor grade by detecting clinically insignificant lesion with low Gleason score or by missing the actual extent of the aggressive lesion leading to understaging of the disease. (C) Different cell types within a prostatic duct displaying invading metastatic cancer cells. $\mathrm{U}$ - urethra, $\mathrm{TZ}$ - transitional zone, $\mathrm{CZ}$ - central zone, PZ - peripheral zone, F- fibromuscular stroma.

PCa frequently shows an indolent clinical course with a $2.5-3 \%$ lifetime risk of dying from PCa and risk stratification remains a major clinical question [6]. Patients with histologically confirmed PCa are assigned to risk groups based on stage, grade, and PSA value used to predict the probability of biochemical failure after treatment and determine treatment recommendations. Eighty percent of newly diagnosed PCa cases are detected as clinically local disease that can be effectively treated with surgery and radiotherapy or hormone therapy $[28,29]$. The 5 -year relative survival rate for localized PCa 
is $100 \%$ [6]. Five percent of men are diagnosed at stage IV PCa or will progress after primary therapy to treatment refractory metastatic disease, with a 5-years survival rate of $29.8 \%$ [6]. However, there is uncertainty about the risk of disease progression, since clinicopathologic criteria are insufficient to efficiently distinguish between slow growing and aggressive non-indolent tumors. Identifying biomarkers that predict clinically aggressive PCa and metastatic dissemination is a current challenge for PCa translational research to reduce overtreatment of insignificant disease on the one hand and select patients that are at risk of progressive disease and need aggressive treatment on the other hand.

Characterization of the cancer genome, epigenome and transcriptome of prostate cancer patients can provide important insights into the biological properties of PCa cells. PCa is a genomically complex disease and the molecular mechanisms and implications for disease outcome of distinct genomic aberrations are poorly understood. Identification of the specific molecular profiles that promote tumor aggressiveness is essential to predict the risk of clinically significant disease. Functional characterization of biological processes involved in therapy resistance could identify novel targets to improve therapy management.

\section{AIM AND OUTLINE OF THE THESIS}

My work aims to identify novel molecular mechanisms of aggressive PCa and to functionally characterize promising driver genes. The focus is on the role of the TMPRSS2:ERG gene fusion, the most prevalent genomic alteration in $\mathrm{PCa}$ present in approximately $50 \%$ of all PCa cases. The TMPRSS2:ERG gene fusion, resulting from the fusion of ERG ( $\mathrm{v}$ ets erythroblastosis virus E26 homolog (avian)) to the androgen responsive gene TMPRSS2, leads to upregulation of ERG protein and activation of downstream target genes [30]. The expression of fusion mRNAs from distinct TMPRSS2:ERG variants is associated with clinicopathological parameters, while the underlying molecular processes resulting from expression of $\mathrm{T} / \mathrm{E}$ gene fusion variants remain unclear.

Chapter 1 provides an overview of the diverse molecular alterations that have been identified in the aggressive prostate cancer genome. Further, the progress towards the clinical implementation of selected molecular targets will be highlighted. In chapter 2 , the gene expression and signaling alterations and their functional implications caused by the TMPRSS2:ERG gene fusion will be analysed. Using a doxycycline (Dox)-inducible overexpression cell model, we show that the TGF- $\beta$ /BMP as well as the WNT/ $\beta$-catenin signaling pathways are the molecular determinants underlying TMPRSS2:ERG-mediated epithelial-to-mesenchymal transition (EMT) in PCa cells. The global epigenetic alterations induced by the TMPRSS2:ERG gene fusion will be explored in chapter 3. Hy- 
pomethylation correlates with upregulation of FZD4 and HLA-DMB. In chapter 4, a candidate gene selection approach from expression profiling and RNA-sequencing data of PCa patient tumor samples is used to identify and functionally characterize PCa-relevant genes. The neuronal transcription factor insulinoma-associated 1 (INSM1) is identified as a regulator of a NE network in prostate cancer cell lines. Neuroendocrine prostate cancer (NEPC) is considered as a highly aggressive manifestation of advanced PCa. We show that the TMPRSS2:ERG gene fusion is associated with NE characteristics in prostate cancer cell lines. We further show that a regulatory network of neuronal transcription factors promotes a NE phenotype in PCa cell lines that could be mediated by the Reelin signaling pathway. We suggest that the INSM1 could be an important driver of this NE network and should be considered for future biomarker studies or drug development. 


\section{REFERENCES}

1. Ferlay J, Steliarova-Foucher E, Lortet-Tieulent J, Rosso S, Coebergh JW, Comber H, Forman D and Bray F. Cancer incidence and mortality patterns in Europe: estimates for 40 countries in 2012. Eur J Cancer. 2013; 49(6):1374-1403.

2. Torre LA, Bray F, Siegel RL, Ferlay J, Lortet-Tieulent J and Jemal A. Global cancer statistics, 2012. CA Cancer J Clin. 2015; 65(2):87-108.

3. Cuzick J, Thorat MA, Andriole G, Brawley OW, Brown PH, Culig Z, Eeles RA, Ford LG, Hamdy FC, Holmberg L, Ilic D, Key TJ, La Vecchia C, Lilja H, Marberger M, Meyskens FL, et al. Prevention and early detection of prostate cancer. Lancet Oncol. 2014; 15(11):e484-492.

4. Loeb $S$ and Schaeffer EM. Risk factors, prevention and early detection of prostate cancer. Prim Care. 2009; 36(3):603-621.

5. Williams SB, Salami S, Regan MM, Ankerst DP, Wei JT, Rubin MA, Thompson IM and Sanda MG. Selective detection of histologically aggressive prostate cancer: an Early Detection Research Network Prediction model to reduce unnecessary prostate biopsies with validation in the Prostate Cancer Prevention Trial. Cancer. 2012; 118(10):2651-2658.

6. Howlader N NA, Krapcho M, Miller D, Bishop K, Kosary CL, Yu M, Ruhl J, Tatalovich Z, Mariotto A, Lewis DR, Chen HS, Feuer EJ, Cronin KA (eds). (2017). SEER Cancer Statistics Review, 1975-2014. National Cancer Institute. Bethesda, MD, USA).

7. Stanford JL, Stephenson RA, Coyle LM, Cerhan J, Correa R, Eley JW, Gilliland F, Hankey B, Kolonel LN, Kosary C, Ross R, Severson R and D. W. (1999). Prostate Cancer Trends 1973-1995, SEER Program National Cancer Institute. (Bethesda, USA: National Cancer Institute $(\mathrm{NCI})$ ).

8. Center MM, Jemal A, Lortet-Tieulent J, Ward E, Ferlay J, Brawley O and Bray F. International variation in prostate cancer incidence and mortality rates. Eur Urol. 2012; 61(6):1079-1092.

9. Breslow N, Chan CW, Dhom G, Drury RA, Franks LM, Gellei B, Lee YS, Lundberg S, Sparke B, Sternby NH and Tulinius $\mathrm{H}$. Latent carcinoma of prostate at autopsy in seven areas. The International Agency for Research on Cancer, Lyons, France. Int J Cancer. 1977; 20(5):680-688.

10. Kicinski M, Vangronsveld J and Nawrot TS. An epidemiological reappraisal of the familial aggregation of prostate cancer: a meta-analysis. PLoS One. 2011; 6(10):e27130.

11. Letellier G, Perez MJ, Yacoub M, Levillain P, Cussenot $O$ and Fromont G. Epithelial phenotypes in the developing human prostate. J Histochem Cytochem. 2007; 55(9):885-890.

12. Wang Y, Hayward S, Cao M, Thayer K and Cunha G. Cell differentiation lineage in the prostate. Differentiation. 2001; 68(4-5):270-279.

13. Hudson DL. Epithelial stem cells in human prostate growth and disease. Prostate Cancer Prostatic Dis. 2004; 7(3):188-194.

14. Epstein JI, Amin MB, Beltran H, Lotan TL, Mosquera JM, Reuter VE, Robinson BD, Troncoso P and Rubin MA. Proposed morphologic classification of prostate cancer with neuroendocrine differentiation. Am J Surg Pathol. 2014; 38(6):756-767.

15. Aumuller $G$, Leonhardt M, Janssen M, Konrad L, Bjartell A and Abrahamsson PA. Neurogenic origin of human prostate endocrine cells. Urology. 1999; 53(5):1041-1048.

16. Szczyrba J, Niesen A, Wagner M, Wandernoth PM, Aumuller G and Wennemuth G. Neuroendocrine Cells of the Prostate Derive from the Neural Crest. J Biol Chem. 2017; 292(5):2021-2031.

17. Abbas F, Civantos F, Benedetto P and Soloway MS. Small cell carcinoma of the bladder and prostate. Urology. 1995; 46(5):617-630.

18. Prescott J and Coetzee GA. Molecular chaperones throughout the life cycle of the androgen receptor. Cancer Lett. 2006; 231(1):12-19.

19. Feldman BJ and Feldman D. The development of androgen-independent prostate cancer. Nat Rev Cancer. 2001; 1(1):34-45. 
20. Chakravarti D, LaMorte VJ, Nelson MC, Nakajima T, Schulman IG, Juguilon H, Montminy M and Evans RM. Role of CBP/P300 in nuclear receptor signalling. Nature. 1996; 383(6595):99-103.

21. Chmelar R, Buchanan G, Need EF, Tilley W and Greenberg NM. Androgen receptor coregulators and their involvement in the development and progression of prostate cancer. Int J Cancer. 2007; 120(4):719-733.

22. McKenna NJ, Lanz RB and O'Malley BW. Nuclear receptor coregulators: cellular and molecular biology. Endocr Rev. 1999; 20(3):321-344.

23. Hendriks RJ, van Oort IM and Schalken JA. Blood-based and urinary prostate cancer biomarkers: a review and comparison of novel biomarkers for detection and treatment decisions. Prostate Cancer Prostatic Dis. 2017; 20(1):12-19.

24. Nevoux P, Ouzzane A, Ahmed HU, Emberton M, Montironi R, Presti JC, Jr. and Villers A. Quantitative tissue analyses of prostate cancer foci in an unselected cystoprostatectomy series. BJU Int. 2012; 110(4):517-523.

25. Haas GP, Delongchamps NB, Jones RF, Chandan V, Serio AM, Vickers AJ, Jumbelic M, Threatte G, Korets $\mathrm{R}$, Lilja $\mathrm{H}$ and de la Roza G. Needle biopsies on autopsy prostates: sensitivity of cancer detection based on true prevalence. J Natl Cancer Inst. 2007; 99(19):1484-1489.

26. Gordetsky J and Epstein J. Grading of prostatic adenocarcinoma: current state and prognostic implications. Diagn Pathol. 2016; 11:25.

27. Andreoiu M and Cheng L. Multifocal prostate cancer: biologic, prognostic, and therapeutic implications. Hum Pathol. 2010; 41(6):781-793.

28. Penney KL, Stampfer MJ, Jahn JL, Sinnott JA, Flavin R, Rider JR, Finn S, Giovannucci E, Sesso HD, Loda M, Mucci LA and Fiorentino M. Gleason grade progression is uncommon. Cancer Res. 2013; 73(16):51635168.

29. Miller DC, Hafez KS, Stewart A, Montie JE and Wei JT. Prostate carcinoma presentation, diagnosis, and staging: an update form the National Cancer Data Base. Cancer. 2003; 98(6):1169-1178.

30. Tomlins SA, Laxman B, Varambally S, Cao X, Yu J, Helgeson BE, Cao Q, Prensner JR, Rubin MA, Shah RB, Mehra R and Chinnaiyan AM. Role of the TMPRSS2-ERG gene fusion in prostate cancer. Neoplasia. 2008; 10(2):177-188. 


\section{Chapter 1}

\section{The biology of aggressive prostate cancer: Implications for innovative diagnostics and therapy}

Partly published in:

Novel RNA markers in prostate cancer: functional considerations and clinical translation. Pickl JM, Heckmann D, Ratz L, Klauck SM, Sültmann H. Biomed Res Int. 2014;2014:765207. doi: 10.1155/2014/765207.

In preparation for submission as review by:

Ratz L, Klauck SM, Sültmann H 


\section{THE PATHOGENESIS AND PROGRESSION OF PROSTATE CANCER}

The human prostate can be divided into distinct anatomical zones (peripheral, central, and periurethral transitional zone, and the non-glandular anterior fibromuscular stro$\mathrm{ma}$ ). The histological division of the prostate into the different zones is of clinical relevance since the majority of prostate cancers are located in the peripheral zone (PZ), while benign prostate hyperplasia (BPH), a condition in which proliferation of prostatic cells causes significant discomfort and complications, occurs mainly in the transitional zone (TZ) $[1,2]$. Tumors in the PZ have been found to be less differentiated with higher Gleason scores, and more invasive showing capsule infiltration at a smaller tumor volume [1]. Local variation in intercellular signaling and gene expression might play a role in this zonal occurrence [3].

The majority of prostate cancers are adenocarcinomas arising from multifocal hyperplasia of luminal secretory cells within acinar or ductal structures [4]. Luminal cancerous cells display aberrant morphological characteristics including nuclear enlargement, hyperchromasia, and prominent nucleoli that gradually increase during malignant transition [5]. The continuum of morphological changes, ranging from low-grade dysplasia to carcinoma in situ, are collectively described as prostatic intraepithelial neoplasia (PIN) [6]. High-grade PIN (HGPIN), occurring with increased incidence and severity with increasing age, is considered as a premalignant condition of most prostate adenocarcinomas and was found as histological predictor of PCa [7-9]. The morphological, immunohistochemical and molecular changes observed in HGPIN are similar to those in prostate adenocarcinomas [10], such as staining of luminal cell specific CK7, 8, 18 [11], and alpha-methylacyl-CoA racemase (AMACR) [10], allelic loss of chromosome 8p12-21 [12], loss of telomere length [13], and gain of chromosomes 7, 8, 10, and 12 [14], while the basal cell layer and the basement membrane are mostly preserved. Staining for basal cell specific antigens, such as high molecular weight keratins or p63, is therefore a useful diagnostic tool to distinguish between HGPIN and PCa [15].

PCa is characterized by a complex pathology with multiple histologically heterogeneous foci that are classified according to the Gleason score $[16,17]$. Different histological foci can harbor distinct genetic aberrations reflecting molecular subtypes with independent clonal origin, leading to heterogeneous clinical outcomes among patients with the same histological pattern [18]. PCa frequently shows an indolent clinical course indicating that many cancer foci arise from a pathogenic program that is insufficient to promote aggressiveness [18]. The acquisition of critical activating events may induce aggressive cell characteristics leading to a dominant tumor focus and clinically relevant disease [19]. The presence of multiple genetic aberrations within a tumor focus is challenging for the analysis of tumor promoting mutations and its predictive value [20]. However, the detection of shared molecular aberrations in metastatic tumor samples has led to the 
hypothesis that most metastatic prostate cancers have monoclonal origins arising from a single precursor cancer cell by a selective advantage of individual clones or by therapy-induced selection pressure $[19,21]$.

A complex spectrum of somatic genomic alterations is seen in PCa including point mutations, copy number alterations (CNA), structural rearrangements, and changes in DNA methylation (Table 1.1) [22, 23]. Major signaling pathways that are most commonly altered in PCa, including AR, PTEN-PI3K/AKT, Ras/Raf/MEK/ERK and the retinoblastoma protein (pRB) signaling pathway, are affected in $34-43 \%$ of primary PCa and $74-100 \%$ of metastatic tumors $[23,24]$. In primary $\mathrm{PCa}$, focal genomic deletions are seen, while in metastatic PCa they can affect a large portion of the genome suggesting increased genomic instability with disease progression [25]. Highly altered cancer genomes with extensive CNAs have been associated with higher Gleason score, unfavourable disease prognosis and early biochemical relapse $[23,26]$. Deletion of chromosome 8p21-22 involving $N K X 3-1$ (8p21) is the most frequently reported allelic loss in primary PCa. NKX3-1 is a prostate-specific homeobox gene having growth-suppressive and differentiating effects on prostatic epithelium. Genomic deletion of NKX3-1 occurs early during prostatic carcinogenesis, its loss has been reported in PIN and was suggested to be related to the progression to PCa [27]. Deletions of tumor suppressors such as PTEN (10q23), RB1 (13q14), BRCA2 (13q13), and TP53 (17p31) are recurrently seen in PCa subsets $[23,25]$. Loss of PTEN, an inhibitor of PI3K/AKT signaling and negative regulator of cell migration and cell survival, is considered as a late event in cancer progression, since it is more prevalent in PCa and less frequent in PIN lesions [28]. Gene amplifications including MYC (8q24), NCOA2 (8q13), PIK3CA (3q26), and ELK4 (1q32) are commonly seen in primary and advanced PCa [25], while focal amplification of $A R$ (Xq12) is restricted to metastatic $\mathrm{PCa}$ [23]. 
Table 1.1: Molecular targets for PCa diagnosis. This table encompasses established as well as novel targets in the progression towards aggressive PCa.

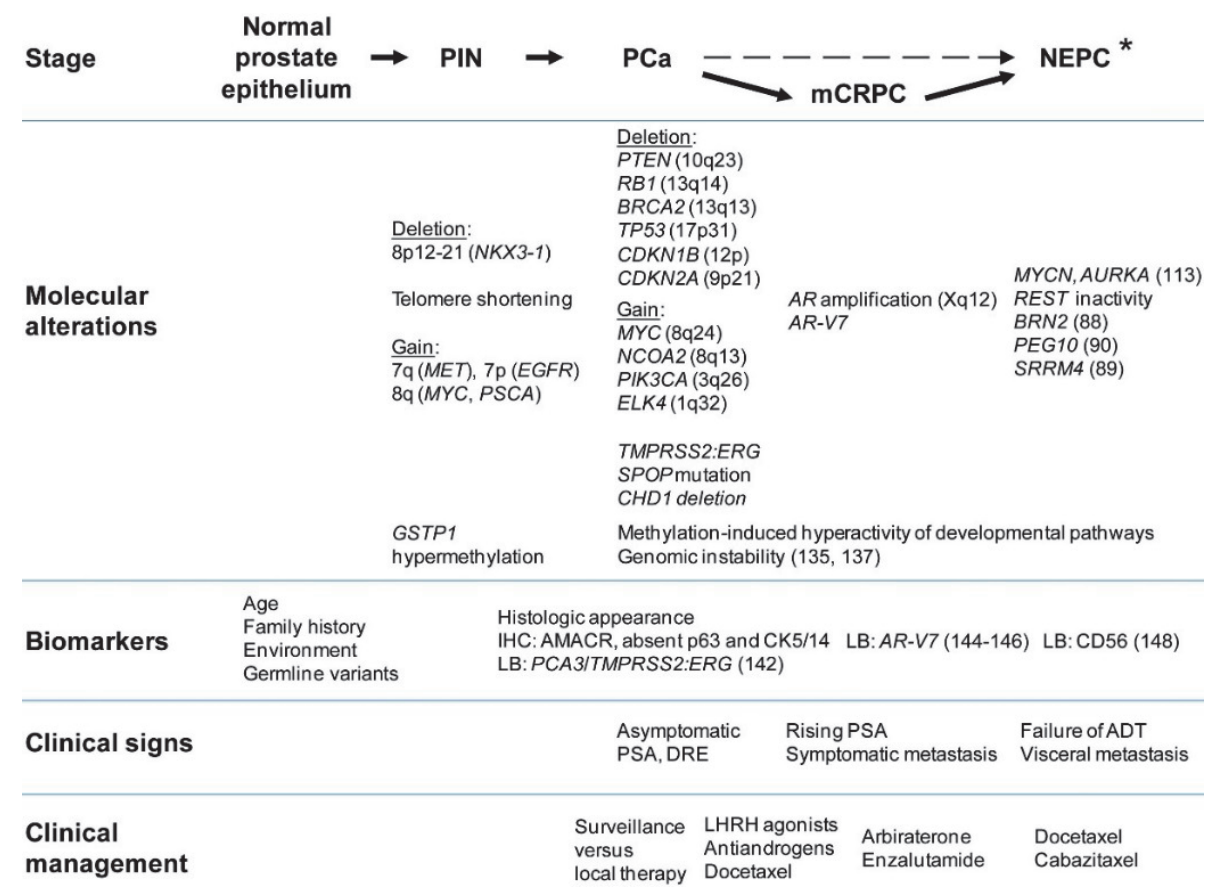

*PIN - prostatic intraepithelial neoplasia, mCRPC - metastatic castration resistant PCa, NEPC - neuroendocrine PCa, IHC - immunohistochemistry, LB - liquid biopsy

Androgens play a central role in PCa development and progression to metastatic disease. Genetic variations and mutations within the AR gene or the androgen biosynthesis and metabolism pathways can affect the response to androgen signaling. The length of polymorphic CAG nucleotide sequence repeats in exon 1 of the $A R$ gene, encoding a polyglutamine chain in the DNA-binding domain, inversely affects the AR-induced transcriptional activity $[29,30]$. In a limited number of studies, ethnicity-based differences in CAG nucleotide repeat length correlated with the ethnical variation in PCa incidence and mortality [31-33].

Long-term AR signaling can induce DNA double-strand breaks driving the generation of chromosomal rearrangements [34]. Chromosomal translocations involving the ETS transcription factor family (e.g. ERG, ETV1, ETV4, and ETV5) are high-frequency rearrangement events in PCa [35]. The AR-responsive protease TMPRSS2 is the most frequent fusion partner, but SLC45A3 and NDRG1 among others have also been reported as partner genes [36, 37]. The TMPRSS2:ERG gene fusion is the most prevalent genomic 
alteration in PCa resulting from the fusion of ERG to TMPRSS2 by intrachromosomal deletion and translocation events, leading to overexpression of the transcription factor from the androgen-regulated TMPRSS2 promoter [38, 39]. The ETS gene family is the largest group of transcriptional regulators consisting of 28 members in the human genome and can be further subclassified based on sequence similarities in the ETS DNA binding domain [40]. ETS proteins can act as activator or repressor of transcription by regulating genes that are involved in cellular architecture, migration, invasion, and permeability. Therefore, ETS transcription factors play a role in embryogenesis, vasculogenesis, angiogenesis, haematopoiesis and neuronal development in a wide range of tissues [41]. During development, ERG is involved in the formation of the vascular system, the urogenital tract, in bone development, and in migration of embryonic neural crest cells [41]. In adult tissue, ERG expression is found in endothelial cells of various tissues maintaining vascular integrity and regulating vascular inflammatory response by regulating VE-cadherin, von Willebrand factor, endoglin, VEGF, IL8, ICAM-1, and VCAM [41].

AR activity promotes the spatial proximity of distant genomic regions and recruitment of enzymes facilitating double-strand breaks (e.g. TOP2B) and subsequent recombination suggesting a non-random chromosomal rearrangement in PCa [40, 42, 43]. In response to genotoxic stress, AR also recruits activation-induced cytidine deaminase (AID) and the LINE-1 encoded endonuclease ORF2 that promote genomic rearrangements [42]. Exposure of androgen-sensitive fusion-negative LNCaP cells to DHT and irradiation, etoposide or doxorubicin, led to the induction of TMPRSS2:ERG and TMPRSS2:ETV1 gene fusions that corresponded to the identified gene fusion variants in PCa tissue [42]. Regarding the role of $A R$ signaling in the development of gene fusion events, the TMPRSS2:ERG rearrangement is considered as an early event in PCa development [34]. Bastus et al. found shorter length of the CAG repeat in the $A R$ gene in fusion-positive cases $(n=20)$ compared to fusion-negative cases $(n=20)$, however, this finding was not statistically significant [44].

Blocking of the AR signaling pathway by androgen deprivation therapy (ADT) in combination with chemotherapy belongs to the initial treatment options of advanced-stage PCa $[45,46]$. ADT is achieved by luteinizing hormone-releasing hormone (LHRH) analoga or LHRH antagonists, combined with antiandrogens such as bicalutamide. However, most cancers will relapse and progress to castration-resistant prostate cancer (CRPC), a condition in which PCa cells do not respond to ADT [45], defined by low serum testosterone together with rising PSA levels or radiological progression of metastatic lesions on ADT [47]. Increasing PSA level is a significant predictor of survival in patients who have newly diagnosed, metastatic PCa treated with continuous ADT [48]. CRPC can initially be treated by blocking AR signaling activity with the second-generation AR antagonist enzalutamide, and androgen synthesis inhibitors such as abiraterone $[49,50]$. The development of CRPC is driven by the genomic instability of PCa cells and multiple me- 
chanisms lead to the aberrant reactivation of AR signaling, including receptor promiscuity allowing alternative ligand binding, $A R$ gene amplification $[51,52]$, recruitment of alternating transcriptional coregulators [53-56] and $A R$ splice variants. C-terminal truncated splice variants constitutively drive AR signaling under castrate conditions $[57,58]$. Of note is that $A R$ splice variants were shown to regulate a distinct transcriptional program [59]. The most commonly expressed $A R$ splice variant is $A R-V 7$, resulting from splicing of exon 3 to a cryptic exon in the intron between exon 3 and 4 generating a truncated AR protein lacking the ligand-binding domain, but retaining transcriptional activity $[60,61]$. AR-V7 could be detected in primary untreated PCa at low levels, but showed an increased ratio relative to full length $A R$ in metastatic CRPC (MCRPC) [24, $62]$. $A R-V 7$ has been implicated in abiraterone and enzalutamide resistance and correlated to disease progression and mortality $[24,62,63]$. In VCaP cells, androgen deprivation using enzalutamide induced expression of $A R-V 7$ [64]. The molecular effects of ADT using a second-generation $A R$ antagonist are also under investigation with respect to neuroendocrine differentiation and increased immune check-point signaling, highlighting the diverse mutational complexity of $\operatorname{CRPC}[65,66]$.

\section{NEUROENDOCRINE PROSTATE CANCER}

Among patients with advanced disease, manifestation of a high-grade neuroendocrine PCa (NEPC) phenotype is detected, distinguished from prostatic acinar carcinoma by unique clinical and ultrastructural characteristics and immunohistochemical staining for various neuroendocrine elements and polypeptide hormones [67]. NE cells containing neurosecretory granules by electron microscopy, are immunohistochemically detected by positive staining for synaptophysin (SYP) (Figure 1.1A), chromogranins $A$ and $B$ (CHGA, CHGB), neuron-specific enolase (NSE/ENO2), or neuronal cell adhesion molecule (NCAM1/CD56) [67] [68]. NEPC is the most significant histological subtype of PCa compared to other rare categories such as ductal adenocarcinoma, mucinous carcinoma, and signet ring carcinoma [69].

Clinically, NEPC appears as a highly aggressive variant of advanced CRPC defined by unresponsiveness to hormone therapy, rapid disease progression, poor prognosis, lytic bone lesions, visceral metastases, and marked prostatic enlargement [70, 71]. Absent AR expression and disproportional low PSA levels are hallmarks of NEPC [70, 71]. NE foci exist within virtually all human prostate adenocarcinomas, reported incidence rates range from $25-90 \%[67,72,73]$. It was suggested that the different morphologic manifestations of NEPC, i.e. carcinoid tumors, large cell neuroendocrine carcinomas and small cell carcinomas, represent a continuum characterized by gradual expression of molecular aberrations [74]. Small cell carcinoma of the prostate (Figure 1.1B), the most 
aggressive form of NEPC, where transformation towards a predominantly neuroendocrine histology occurred, is rare with a reported frequency of less than $1 \%$ [72].
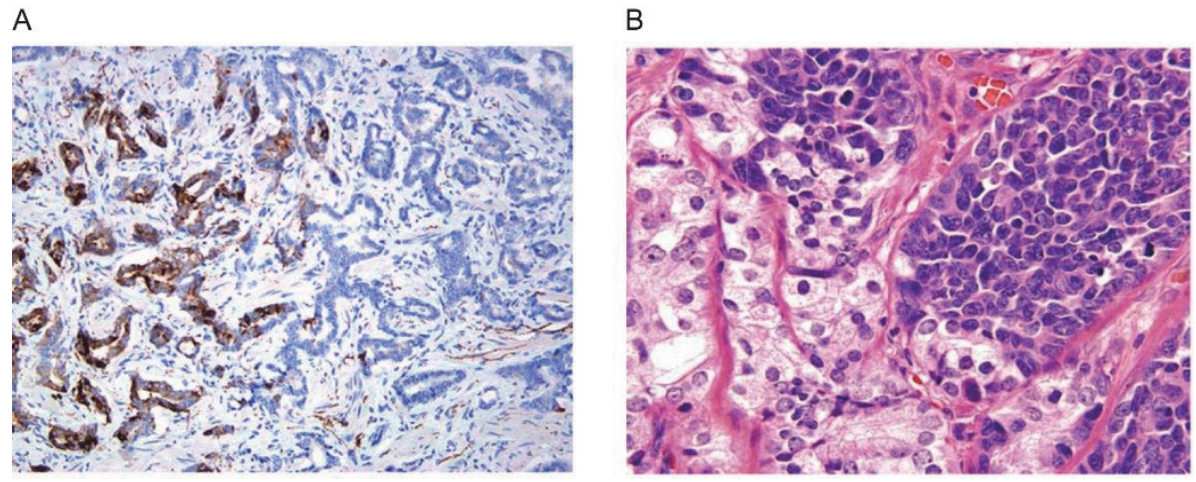

Figure 1.1: Prostate cancer biopsy core with NE differentiation. (A) Adenocarcinoma of the prostate Gleason score $3+3=6$. Areas with positive SYP staining (left) showing same glandular morphology as negative stained SYP areas (right). (B) Mixed usual adenocarcinoma of the prostate (left) with small cell carcinoma (right) (adapted from Epstein et al. [67]).

The increasing incidence of NEPC (about 6.8\% per year between 2004-2011) can be partly attributed to prolonged patients' life expectancy and aggressive rebiopsy practice of metastatic CRPC $[71,75]$. The median survival rate after NEPC diagnosis is 7 months [70] and the 5-years survival rates are low (17\%), mirroring the lack of a specific detection method and effective therapy for NEPC [76]. NEPC can arise de novo, however, it is more prevalent in previously treated adenocarcinomas. There is a growing body of evidence that the extent of neuroendocrine differentiation (NED) correlates with exposure to ADT and represents an adaptive clinical phenotype, which is of special significance regarding the advent of novel highly potent AR-targeted therapies [75, 77-86]. Androgen-deprived culture conditions were shown to induce a neuronal morphology and expression of NSE and CHGA in LNCaP cells [87]. Intriguing molecular mechanisms of ADT-induced NED in PCa have recently been elucidated (Table 1.1). On enzalutamide treatment, AR-targeted inhibition in vitro released the repressive activity of AR signaling on the neuronal transcription factor $B R N 2$, thereby enabling induction of a NE program and promoting tumor aggressiveness [88]. Overexpression of the RNA splicing factor SRRM4 in prostate tumors was found to drive progression to NEPC by regulating splicing of the RE-1 silencing transcription factor (REST) and reducing functional REST protein [89]. REST is known to mediate restriction of neuronal gene expression and is involved in AR-mediated control of cell differentiation [65]. Androgen deprivation reduced the expression of REST that coincided with increased expression of CHGA and a NE-like morphology in LNCaP cells [65]. Loss of REST in NEPC in association with a NE phenotype was a crucial discovery in the emerging mechanisms of NEPC [81]. By identifying an additive effect of SRRM4 and AR pathway inhibition to induce NEPC, the researchers 
proposed a role for ADT as prerequisite condition to release a lineage-specific differentiation program and preparing transformation to NEPC [89]. The placental gene PEG10 was identified as driver of NEPC in a dynamic progression xenograft model revealing a biphasic expression pattern during distinct stages of NEPC development [90]. PEG10 expression increased during enzalutamide-mediated AR inhibition in the initial progression phase. A second increase was detected at the emergence of NEPC promoting cell cycle progression in the context of RB1 and TP53 loss, and triggering invasion by increased SNAIL expression via TGF- $\beta$ signaling [90].

It was initially assumed that NEPC developed from outgrowth of normal prostatic NE cells, promoted by the selective pressure of androgen-independent growth [91]. Current evidence suggests a common origin of adenocarcinoma and NEPC supported by concordant molecular alterations, involving TMPRSS2:ERG gene fusion and TP53 mutations [92-94]. This concept assumes evolution of NED from adenocarcinoma cells into NE cells, underpinned by the detection of epithelial characteristics in NE cells such as expression of CK8, CK18, and AMACR [84, 95, 96]. Several signaling mediators have been implicated in NED including neuropeptides (bombesin/gastrin-releasing peptide, calcitonin, serotonin, and vasoactive intestinal peptide) [97], cytokines (IL-6, IL-1B, IL-8) [98-100], ionizing irradiation [101], and stimuli elevating intra-cellular cAMP (such as forskolin) [102]. LNCaP cells cultured with cAMP or charcoal-stripped fetal bovine serum acquired a NE phenotype $[103,104]$. CAMP further induced G1 growth arrest in LNCaP cell [104] and synergized with IL-6, a prominent inducer of NED [105]. IL-6 triggered REST repression and STAT3-induced NED in LNCaP cells [106-108]. Neuropeptides and IL-8 activated the nonreceptor tyrosine kinases ETK, SrC and FAK resulting in androgenindependent $A R$ activation $[100,109]$. In a transgenic adenocarcinoma of the mouse prostate (TRAMP) model, cooperativity between the NE-specific forkhead transcription factor FoxA2 and the hypoxia-induced transcription factor HIF1 $\alpha$ induced target genes that were required for a NE phenotype in PCa [110]. FoxA2/HIF1 $\alpha$ complex formation was promoted by the ubiquitin ligase Siah2 that regulated HIF1 $\alpha$ activity thus enabling complexation with FoxA2 [110]. Hypoxia-mediated NED of LNCaP cells was shown to be facilitated by decreased Notch signaling, which is known for its role in cell fate and differentiation by inhibiting neurogenesis and maintaining a progenitor cell state [111].

Amplification of Aurora kinase A (AURKA) and N-myc (MYCN), also frequently occurring in neuroblastoma and small cell lung cancer, was identified in $40 \%$ of patients that clinically had developed NEPC $[112,113]$. AURKA, involved in G2-to-M transition during the cell cycle, and the transcription factor $\mathrm{N}$-myc were shown to physically interact and function in reciprocal stabilization [112]. Overexpression of either AURKA or MYCN in RWPE-1 cells induced expression of the NE markers NSE and SYP [112]. MYCN overexpression in LNCaP cells revealed direct binding of N-myc to the promoter of NSE and SYP [112]. AURKA inhibition led to a reduced cell viability in MYCN-overexpressing LNCaP and NCl-H660 cells, and induced tumor shrinkage by $50-87 \%$ in NE-tumor xeno- 
graft models accompanied by reduced SYP expression [112]. In a mouse model transplanted with $\mathrm{N}$-myc overexpressing human prostate basal epithelial cells, activated AKT1 downstream of N-myc was sufficient to induce NEPC detected by histological NE attributes and positive IHC stain for NE markers (CHGA, SYP, NCAM1, NSE), accompanied by negative AR stain [114]. Detection of AURKA amplification and overexpression in primary PCa specimens suggested its role as marker to identify patients that are more likely to develop NEPC [112]. Together, these finding indicate molecular parallels to the well-studied NE tumor models of neuroblastoma and small cell lung cancer and announce a crucial step towards a better understanding of the molecular pathogenesis of NEPC promoting the development of therapeutic strategies and identification of potential biomarkers [112-115].

\section{MOLECULAR TARGETS AND NOVEL APPROACHES TO DIAGNOSIS AND TREATMENT}

The majority of PCa is diagnosed as locoregional disease [116, 117]. Since clinicopathologic criteria are insufficient to efficiently discriminate between slow growing versus non-indolent biologically aggressive tumors, there is uncertainty about the risk of disease progression. Although Gleason scoring together with clinical data is used for stratification of treatment modalities according to risk category today, genomic features rather than histopathological grading may determine the clinical course of the disease in future. Molecular subtypes may determine distinct genomic pathways of progression. At a molecular level, $74 \%$ of primary PCa could be assigned to a mutational subtype defined by distinct oncogenic drivers involving SPOP, FOXA1, and IDH1 or gene fusions involving ERG, ETV1, ETV4 or FLI1 [118]. Deletion of three genomic regions have been shown to co-occur with the TMPRSS2:ERG fusion spanning the PTEN and TP53 locus, and a multigenic region located at 3p14 including FOXP1 [23]. PTEN deletion is associated with advanced PCa, decreased time to metastasis and poor prognosis [119]. TMPRSS2:ERG expression can be used for confirmation of PCa diagnosis in morphologically suspicious biopsy cores [120]. Its detection also discriminates between NE tumors of the prostate and small cell carcinoma of other organs [121]. The stratification of molecular subtypes may further have important treatment implications. The enzyme poly [ADP-ribose] polymerase 1 (PARP1) is a required cofactor for ERG, and PARP1 inhibition induced increased vulnerability of PCa cells to low-dose radiation $[122,123]$ suggesting that tumors may respond to treatment by PARP1-inhibitors. Recent studies showed that PCa patients with inherited mutations in BRCA1/2 and ataxia-telangiectasia mutated (ATM), who have a shorter survival time, clinically respond to the PARP1 inhibitor olaparib [124, 125]. SPOP (Speckle-type POZ protein), a substrate recognition component of an E3 ubiquitin ligase, is the gene with the most common point mutations in primary PCa. However, the occurrence of SPOP mutations was not further increased in 
CRPC [24]. Tumors of the SPOP mutant subtype were recently demonstrated to activate PI3K and AR signaling, suggesting a mechanism of signaling convergence between SPOP mutant and TMPRSS2:ERG positive tumors with potential implications for androgentargeting therapy [126]. SPOP-mutant tumors often show deletion of the CHD1 locus (5q21), encoding the chromodomain helicase DNA binding protein 1, a tumor suppressor functioning in genome stability and maintenance of chromatin architecture. SPOPmutation and CHD1-deletion sensitizes tumors to increased genomic instability by deficient DNA mismatch repair processes [127]. Functional studies suggest a synergistic effect of SPOP-mutant and CHD1-deleted tumors [128]. SPOP-mutant tumors are further characterized by recurrent overexpression of SPINK1 (a serine peptidase inhibitor Kazal type 1), that occurred mutually exclusive from ERG rearrangements $[129,130]$. SPINK1 overexpression was shown to be associated with earlier clinical recurrence [129]. Due to its high homology with the epidermal growth factor receptor (EGFR), SPINK1 overexpressing tumors could respond to cetuximab, a monoclonal antibody against EGFR currently tested in the preclinical setting [131].

The genomic alterations within these molecular subtypes also showed an association with altered DNA methylation, potentially representing different epigenetic mechanisms between these subtypes with yet unresolved functional consequences suggesting DNA methylation as biomarker in PCa [26]. Promoter-associated hypermethylated $\mathrm{CpG}$ islands were highly enriched for differentiation and developmental processes, and associated with reduced gene expression (e.g. PTEN, TP53, GSTP1), suggesting that DNA hypermethylation may change differentiation states and activity of carcinogenic pathways $[132,133]$. CPG island hypermethylation of a gene-panel (GSTP1, APC, RASSF1A, PTGS2, MDR1) could discriminate primary PCa from benign prostate tissue [134]. Hypermethylation of the transcriptional elongation regulator (TCERG1L) in combination with other genomic markers could predict disease relapse in localized PCa [135]. The DNA methylation profile has also been found to be subject specific and maintained within metastatic subclones, suggesting a role as longitudinal marker $[132,136]$.

Genomic instability leading to complex rearrangements are frequently found in PCa [135] [137]. Chromothripsis, the extensive DNA rearrangement involving few chromosomal loci, occurring most likely by an initial error in chromosome segregation of incompletely replicated DNA during mitosis, has been proposed as marker of an aggressive non-indolent course in initially localized PCa that requires aggressive treatment [135, 137-139]. Chained genomic rearrangements, called chromoplexy, were frequently found in $E R G$ fusion-positive genomes and affect regions that are highly expressed in $P C a$, suggesting an association with AR-driven transcriptional processes [137]. Chromoplexy induced deletion of PTEN, NKX3-1, CDKN1B, TP53, and RB1, and may thereby simultaneously deregulate $\mathrm{PCa}$ pathways, potentially leading to a rapid punctuated progression of PCa [137]. 
PCa is usually suspected based on PSA value and digital rectal examination (DRE), but PSA level is not a direct surrogate for tumor stage. Definitive diagnosis requires histopathological confirmation of the disease on prostate biopsy [140]. Tumor heterogeneity often precludes precise staging and histopathological grading and therefore weakens the power of current diagnostic management in PCa. Analysis of genetic changes evolving within metastatic PCa is challenged by the poor availability of samples from bone metastases, the major location of PCa dissemination. Liquid biopsies, circulating genetic material or proteins detected in different body fluids, could provide a highly valuable easily accessible source of tumor markers to detect clinically significant PCa and to obtain a faithful representation of tumor aggressiveness that could lead to an improved therapy decision. Several blood-based and urinary prostate cancer biomarkers are currently evaluated. The Prostate Health Index (PHI) is a test recently approved by the US Food and Drug Administration (FDA) using serum PSA isoforms in men with PSA levels ranging from 4-10 $\mathrm{ng} / \mathrm{mL}$ to support decision-making regarding prostate biopsies [141]. The diagnostic and prognostic value of the prostate cancer gene 3 (PCA3), a non-coding RNA highly overexpressed in PCa, and the TMPRSS2:ERG gene fusion in liquid biopsies are under investigation in different trials (reviewed in [140]). The detection of urinary PCA3 could potentially reduce the number of biopsies in men with increased PSA level (>10 ng/mL). The combined detection of PCA3 and TMPRSS2:ERG in urinary exosomes was used for improved risk stratification of men with elevated serum PSA levels to guide further disease management [142]. Exosomes are nanosized (40-100nm) extracellular vesicles secreted from cells via the endosomal pathway. Tumor cells release exosomes at increased levels, which are then detectable in different body fluids. Exosomal cargo reflects the genetic and proteomic signature of the tumor rendering them as suitable target for biomarker detection in PCa [143]. Exosomes and circulating tumor cells (CTCS) could overcome the shortcoming of metastatic biopsies in PCa to obtain insights in aggressive mechanisms with implications for treatment adjustment. Detection of $A R$ splice variant $A R-V 7$ in exosomes and CTCS from CRPC patients was shown to be a predictive biomarker of resistance to AR-targeting agents [58, 144-146]. Molecular profiling of CTCS was demonstrated as dynamic approach to monitor AR signaling during treatment and to predict response to arbiraterone [147]. For the histologic evaluation of small cell neuroendocrine PCa, rebiopsy often reveals mixed features of both adenocarcinoma and neuroendocrine carcinoma and the diagnosis of NEPC is predominantly based on clinical characteristics. CTCs in blood samples from patients with confirmed small cell carcinoma were shown to be positive for CD56 and were of smaller size than CTCs from CRPC patients. This study highlights the phenotypic similarities between tumor and CTCS and suggests potential use of CTCs in the early detection of PCa transforming towards NEPC [148]. However, so far only increased CTC count was prospectively validated in two phase III randomized trials, showing association with reduced overall survival [149, 150]. 
Blood mRNA signatures are also investigated as biomarker source. Two studies suggested the detection of transcript levels of selected mRNAs in whole-blood samples of patients with CRPC as improved prognostic markers [151, 152]: a panel consisting of six circulating mRNA markers (ABL2, C1QA, SEMA4D, TIMP1, ITGAL, and CDKN1A) predicted survival in CRPC patients [151]. Poor overall survival of patients with CRPC was associated with a nine-gene model (RHAG, CA1, HEPACAM2, SNCA, HEMGN, SOX6, TMEM56, OSBP2, and RHD) [152]. However, the biological relevance of these gene signatures remains unresolved.

\section{SUMMARY}

At the time of diagnosis, PCa will frequently present as organ-confined disease and most tumors will persist as indolent clinical conditions $[116,117]$. The individual risk to develop clinically significant, and potentially lethal disease is not recognized by histological grading alone. The heterogeneous clinical course that is observed among PCa cases is determined by complex and dynamic genomic aberrations. Novel markers for refined risk stratification of progressive disease outcome and prediction of treatment response are needed. Several tissue-based multigene expression assays for the prediction of aggressive PCa are available for clinical application [153, 154]. Their routine implementation is currently hampered by intrinsic challenges of PCa research, such as heterogeneity, multifocality, and a small sample volume in prostate biopsy. Genetic instability increases the complexity of somatic genomic alterations leading to a specific combination of driver mutations in a tumor. However, molecular pathology is an emerging field in PCa as a growing number of targets with known correlation to tumor biology are recognized, such as $A R$ splice variants (Table 1.1). Further, differentiation markers of neuroendocrine manifestation may predict poor responsiveness to ADT. Individual genetic aberrations could be interrogated by next generation sequencing and may find application for a personalized approach in clinical practice. Molecular and genetic analysis of biopsy cores is currently not included in the PCa guidelines. In future, it may complement the diagnosis of PCa as it has already been implemented in other tumor entities, such as breast cancer, melanoma and, most recently, lung cancer [155-157]. Simultaneously, a broader spectrum of therapeutic targets in addition to ADT is required to improve the clinical management of metastatic PCa [158]. The functional and mechanistic evaluation of genetic markers is the basis for the development of novel drug targets and treatment strategies, and could guide the emphasis of future research. 


\section{REFERENCES}

1. Greene DR, Wheeler TM, Egawa S, Dunn JK and Scardino PT. A comparison of the morphological features of cancer arising in the transition zone and in the peripheral zone of the prostate. J Urol. 1991; 146(4):1069-1076.

2. McNeal JE, Redwine EA, Freiha FS and Stamey TA. Zonal distribution of prostatic adenocarcinoma. Correlation with histologic pattern and direction of spread. Am J Surg Pathol. 1988; 12(12):897-906.

3. Sinnott JA, Rider JR, Carlsson J, Gerke T, Tyekucheva S, Penney KL, Sesso HD, Loda M, Fall K, Stampfer MJ, Mucci LA, Pawitan Y, Andersson SO and Andren O. Molecular differences in transition zone and peripheral zone prostate tumors. Carcinogenesis. 2015; 36(6):632-638.

4. Kendal WS and Mai KT. Histological subtypes of prostatic cancer: a comparative survival study. Can J Urol. 2010; 17(5):5355-5359.

5. Ayala AG and Ro JY. Prostatic intraepithelial neoplasia: recent advances. Arch Pathol Lab Med. 2007; 131(8):1257-1266.

6. Bostwick DG and Brawer MK. Prostatic intra-epithelial neoplasia and early invasion in prostate cancer. Cancer. 1987; 59(4):788-794.

7. McNeal JE and Bostwick DG. Intraductal dysplasia: a premalignant lesion of the prostate. Hum Pathol. 1986; 17(1):64-71.

8. Kronz JD, Allan $\mathrm{CH}$, Shaikh AA and Epstein JI. Predicting cancer following a diagnosis of high-grade prostatic intraepithelial neoplasia on needle biopsy: data on men with more than one follow-up biopsy. Am J Surg Pathol. 2001; 25(8):1079-1085.

9. Davidson D, Bostwick DG, Qian J, Wollan PC, Oesterling JE, Rudders RA, Siroky M and Stilmant M. Prostatic intraepithelial neoplasia is a risk factor for adenocarcinoma: predictive accuracy in needle biopsies. J Urol. 1995; 154(4):1295-1299.

10. Zynger DL and Yang X. High-grade prostatic intraepithelial neoplasia of the prostate: the precursor lesion of prostate cancer. Int J Clin Exp Pathol. 2009; 2(4):327-338.

11. Brawer MK, Peehl DM, Stamey TA and Bostwick DG. Keratin immunoreactivity in the benign and neoplastic human prostate. Cancer Res. 1985; 45(8):3663-3667.

12. Emmert-Buck MR, Vocke CD, Pozzatti RO, Duray PH, Jennings SB, Florence CD, Zhuang Z, Bostwick DG, Liotta LA and Linehan WM. Allelic loss on chromosome 8p12-21 in microdissected prostatic intraepithelial neoplasia. Cancer Res. 1995; 55(14):2959-2962.

13. Vukovic B, Park PC, Al-Maghrabi J, Beheshti B, Sweet J, Evans A, Trachtenberg J and Squire J. Evidence of multifocality of telomere erosion in high-grade prostatic intraepithelial neoplasia (HPIN) and concurrent carcinoma. Oncogene. 2003; 22(13):1978-1987.

14. Bostwick DG and Qian J. Atypical adenomatous hyperplasia of the prostate. Relationship with carcinoma in 217 whole-mount radical prostatectomies. Am J Surg Pathol. 1995; 19(5):506-518.

15. Novis DA, Zarbo RJ and Valenstein PA. Diagnostic uncertainty expressed in prostate needle biopsies. A College of American Pathologists Q-probes Study of 15,753 prostate needle biopsies in 332 institutions. Arch Pathol Lab Med. 1999; 123(8):687-692.

16. Gordetsky J and Epstein J. Grading of prostatic adenocarcinoma: current state and prognostic implications. Diagn Pathol. 2016; 11:25.

17. Arora R, Koch MO, Eble JN, Ulbright TM, Li L and Cheng L. Heterogeneity of Gleason grade in multifocal adenocarcinoma of the prostate. Cancer. 2004; 100(11):2362-2366.

18. Andreoiu M and Cheng L. Multifocal prostate cancer: biologic, prognostic, and therapeutic implications. Hum Pathol. 2010; 41(6):781-793.

19. Shen MM and Abate-Shen C. Molecular genetics of prostate cancer: new prospects for old challenges. Genes Dev. 2010; 24(18):1967-2000.

20. Verhagen PC, Tilanus MG, de Weger RA, van Moorselaar RJ, van den Tweel JG and Boon TA. Prognostic factors in localised prostate cancer with emphasis on the application of molecular techniques. Eur Urol. 2002; 41(4):363-371. 
21. Liu W, Laitinen S, Khan S, Vihinen M, Kowalski J, Yu G, Chen L, Ewing CM, Eisenberger MA, Carducci MA, Nelson WG, Yegnasubramanian S, Luo J, Wang Y, Xu J, Isaacs WB, et al. Copy number analysis indicates monoclonal origin of lethal metastatic prostate cancer. Nat Med. 2009; 15(5):559-565.

22. Beroukhim R, Mermel CH, Porter D, Wei G, Raychaudhuri S, Donovan J, Barretina J, Boehm JS, Dobson J, Urashima M, Mc Henry KT, Pinchback RM, Ligon AH, Cho YJ, Haery L, Greulich H, et al. The landscape of somatic copy-number alteration across human cancers. Nature. 2010; 463(7283):899-905.

23. Taylor BS, Schultz N, Hieronymus H, Gopalan A, Xiao Y, Carver BS, Arora VK, Kaushik P, Cerami E, Reva B, Antipin Y, Mitsiades N, Landers T, Dolgalev I, Major JE, Wilson M, et al. Integrative genomic profiling of human prostate cancer. Cancer Cell. 2010; 18(1):11-22.

24. Robinson D, Van Allen EM, Wu YM, Schultz N, Lonigro RJ, Mosquera JM, Montgomery B, Taplin ME, Pritchard CC, Attard G, Beltran H, Abida W, Bradley RK, Vinson J, Cao X, Vats P, et al. Integrative clinical genomics of advanced prostate cancer. Cell. 2015; 161(5):1215-1228.

25. Schoenborn JR, Nelson P and Fang M. Genomic profiling defines subtypes of prostate cancer with the potential for therapeutic stratification. Clin Cancer Res. 2013; 19(15):4058-4066.

26. Cancer Genome Atlas Research N. The Molecular Taxonomy of Primary Prostate Cancer. Cell. 2015; 163(4):1011-1025.

27. Bowen C, Bubendorf L, Voeller HJ, Slack R, Willi N, Sauter G, Gasser TC, Koivisto P, Lack EE, Kononen J, Kallioniemi OP and Gelmann EP. Loss of NKX3.1 expression in human prostate cancers correlates with tumor progression. Cancer Res. 2000; 60(21):6111-6115.

28. Morais CL, Han JS, Gordetsky J, Nagar MS, Anderson AE, Lee S, Hicks JL, Zhou M, Magi-Galluzzi C, Shah RB, Epstein JI, De Marzo AM and Lotan TL. Utility of PTEN and ERG immunostaining for distinguishing high-grade PIN from intraductal carcinoma of the prostate on needle biopsy. Am J Surg Pathol. 2015; 39(2):169-178.

29. Chamberlain NL, Driver ED and Miesfeld RL. The length and location of CAG trinucleotide repeats in the androgen receptor $\mathrm{N}$-terminal domain affect transactivation function. Nucleic Acids Res. 1994; 22(15):3181-3186.

30. La Spada AR, Wilson EM, Lubahn DB, Harding AE and Fischbeck KH. Androgen receptor gene mutations in X-linked spinal and bulbar muscular atrophy. Nature. 1991; 352(6330):77-79.

31. Giovannucci E, Stampfer MJ, Krithivas K, Brown M, Dahl D, Brufsky A, Talcott J, Hennekens CH and Kantoff PW. The CAG repeat within the androgen receptor gene and its relationship to prostate cancer. Proc Natl Acad Sci U S A. 1997; 94(7):3320-3323.

32. Bennett CL, Price DK, Kim S, Liu D, Jovanovic BD, Nathan D, Johnson ME, Montgomery JS, Cude K, Brockbank JC, Sartor O and Figg WD. Racial variation in CAG repeat lengths within the androgen receptor gene among prostate cancer patients of lower socioeconomic status. J Clin Oncol. 2002; 20(17):3599-3604.

33. Buchanan G, Irvine RA, Coetzee GA and Tilley WD. Contribution of the androgen receptor to prostate cancer predisposition and progression. Cancer Metastasis Rev. 2001; 20(3-4):207-223.

34. Bastus NC, Boyd LK, Mao X, Stankiewicz E, Kudahetti SC, Oliver RT, Berney DM and Lu YJ. Androgeninduced TMPRSS2:ERG fusion in nonmalignant prostate epithelial cells. Cancer Res. 2010; 70(23):95449548.

35. Tomlins SA, Rhodes DR, Perner S, Dhanasekaran SM, Mehra R, Sun XW, Varambally S, Cao X, Tchinda J, Kuefer R, Lee C, Montie JE, Shah RB, Pienta KJ, Rubin MA and Chinnaiyan AM. Recurrent fusion of TMPRSS2 and ETS transcription factor genes in prostate cancer. Science. 2005; 310(5748):644-648.

36. Esgueva R, Perner S, C JL, Scheble V, Stephan C, Lein M, Fritzsche FR, Dietel M, Kristiansen G and Rubin MA. Prevalence of TMPRSS2-ERG and SLC45A3-ERG gene fusions in a large prostatectomy cohort. Mod Pathol. 2010; 23(4):539-546.

37. Pflueger D, Rickman DS, Sboner A, Perner S, LaFargue CJ, Svensson MA, Moss BJ, Kitabayashi N, Pan Y, de la Taille A, Kuefer R, Tewari AK, Demichelis F, Chee MS, Gerstein MB and Rubin MA. N-myc downstream regulated gene 1 (NDRG1) is fused to ERG in prostate cancer. Neoplasia. 2009; 11(8):804-811.

38. Perner S, Demichelis F, Beroukhim R, Schmidt FH, Mosquera JM, Setlur S, Tchinda J, Tomlins SA, Hofer MD, Pienta KG, Kuefer R, Vessella R, Sun XW, Meyerson M, Lee C, Sellers WR, et al. TMPRSS2:ERG fusion- 
associated deletions provide insight into the heterogeneity of prostate cancer. Cancer Res. 2006; 66(17):8337-8341.

39. Attard G, Clark J, Ambroisine L, Fisher G, Kovacs G, Flohr P, Berney D, Foster CS, Fletcher A, Gerald WL, Moller H, Reuter V, De Bono JS, Scardino P, Cuzick J, Cooper CS, et al. Duplication of the fusion of TMPRSS2 to ERG sequences identifies fatal human prostate cancer. Oncogene. 2008; 27(3):253-263.

40. Sharrocks AD. The ETS-domain transcription factor family. Nat Rev Mol Cell Biol. 2001; 2(11):827-837.

41. Adamo P and Ladomery MR. The oncogene ERG: a key factor in prostate cancer. Oncogene. 2016; 35(4):403-414.

42. Lin C, Yang L, Tanasa B, Hutt K, Ju BG, Ohgi K, Zhang J, Rose DW, Fu XD, Glass CK and Rosenfeld MG. Nuclear receptor-induced chromosomal proximity and DNA breaks underlie specific translocations in cancer. Cell. 2009; 139(6):1069-1083.

43. Haffner MC, Aryee MJ, Toubaji A, Esopi DM, Albadine R, Gurel B, Isaacs WB, Bova GS, Liu W, Xu J, Meeker AK, Netto G, De Marzo AM, Nelson WG and Yegnasubramanian S. Androgen-induced TOP2Bmediated double-strand breaks and prostate cancer gene rearrangements. Nat Genet. 2010; 42(8):668675.

44. Mangelsdorf PC and Galinat WC. The Tunicate Locus in Maize Dissected and Reconstituted. Proc Natl Acad Sci U S A. 1964; 51(2):147-150.

45. Nouri M, Ratther E, Stylianou N, Nelson CC, Hollier BG and Williams ED. Androgen-targeted therapyinduced epithelial mesenchymal plasticity and neuroendocrine transdifferentiation in prostate cancer: an opportunity for intervention. Front Oncol. 2014; 4:370.

46. Huggins $\mathrm{C}$ and Hodges CV. Studies on prostatic cancer. I. The effect of castration, of estrogen and androgen injection on serum phosphatases in metastatic carcinoma of the prostate. CA Cancer J Clin. 1972; 22(4):232-240.

47. Mottet N, Bellmunt J, Bolla M, Briers E, Cumberbatch MG, De Santis M, Fossati N, Gross T, Henry AM, Joniau S, Lam TB, Mason MD, Matveev VB, Moldovan PC, van den Bergh RC, Van den Broeck T, et al. EAU-ESTRO-SIOG Guidelines on Prostate Cancer. Part 1: Screening, Diagnosis, and Local Treatment with Curative Intent. Eur Urol. 2017; 71(4):618-629.

48. Hussain M, Goldman B, Tangen C, Higano CS, Petrylak DP, Wilding G, Akdas AM, Small EJ, Donnelly BJ, Sundram SK, Burch PA, Dipaola RS and Crawford ED. Prostate-specific antigen progression predicts overall survival in patients with metastatic prostate cancer: data from Southwest Oncology Group Trials 9346 (Intergroup Study 0162) and 9916. J Clin Oncol. 2009; 27(15):2450-2456.

49. Wadosky KM and Koochekpour S. Therapeutic Rationales, Progresses, Failures, and Future Directions for Advanced Prostate Cancer. Int J Biol Sci. 2016; 12(4):409-426.

50. Massard C and Fizazi K. Targeting continued androgen receptor signaling in prostate cancer. Clin Cancer Res. 2011; 17(12):3876-3883.

51. Visakorpi T, Hyytinen E, Koivisto P, Tanner M, Keinanen R, Palmberg C, Palotie A, Tammela T, Isola J and Kallioniemi OP. In vivo amplification of the androgen receptor gene and progression of human prostate cancer. Nat Genet. 1995; 9(4):401-406.

52. Urbanucci A, Sahu B, Seppala J, Larjo A, Latonen LM, Waltering KK, Tammela TL, Vessella RL, Lahdesmaki $\mathrm{H}$, Janne OA and Visakorpi T. Overexpression of androgen receptor enhances the binding of the receptor to the chromatin in prostate cancer. Oncogene. 2012; 31(17):2153-2163.

53. Chen CD, Welsbie DS, Tran C, Baek SH, Chen R, Vessella R, Rosenfeld MG and Sawyers CL. Molecular determinants of resistance to antiandrogen therapy. Nat Med. 2004; 10(1):33-39.

54. Han G, Buchanan G, Ittmann M, Harris JM, Yu X, Demayo FJ, Tilley W and Greenberg NM. Mutation of the androgen receptor causes oncogenic transformation of the prostate. Proc Natl Acad Sci U S A. 2005; 102(4):1151-1156.

55. Shah S and Small E. Emerging biological observations in prostate cancer. Expert Rev Anticancer Ther. 2010; 10(1):89-101.

56. Feldman BJ and Feldman D. The development of androgen-independent prostate cancer. Nat Rev Cancer. 2001; 1(1):34-45. 
57. Dehm SM, Schmidt LJ, Heemers HV, Vessella RL and Tindall DJ. Splicing of a novel androgen receptor exon generates a constitutively active androgen receptor that mediates prostate cancer therapy resistance. Cancer Res. 2008; 68(13):5469-5477.

58. Antonarakis ES, Lu C, Wang H, Luber B, Nakazawa M, Roeser JC, Chen Y, Mohammad TA, Chen Y, Fedor $\mathrm{HL}$, Lotan TL, Zheng $\mathrm{Q}$, De Marzo AM, Isaacs JT, Isaacs WB, Nadal R, et al. AR-V7 and resistance to enzalutamide and abiraterone in prostate cancer. N Engl J Med. 2014; 371(11):1028-1038.

59. Hu R, Lu C, Mostaghel EA, Yegnasubramanian S, Gurel M, Tannahill C, Edwards J, Isaacs WB, Nelson PS, Bluemn E, Plymate SR and Luo J. Distinct transcriptional programs mediated by the ligand-dependent full-length androgen receptor and its splice variants in castration-resistant prostate cancer. Cancer Res. 2012; 72(14):3457-3462.

60. Hu R, Dunn TA, Wei S, Isharwal S, Veltri RW, Humphreys E, Han M, Partin AW, Vessella RL, Isaacs WB, Bova GS and Luo J. Ligand-independent androgen receptor variants derived from splicing of cryptic exons signify hormone-refractory prostate cancer. Cancer Res. 2009; 69(1):16-22.

61. Guo Z, Yang X, Sun F, Jiang R, Linn DE, Chen H, Chen H, Kong X, Melamed J, Tepper CG, Kung HJ, Brodie AM, Edwards J and Qiu Y. A novel androgen receptor splice variant is up-regulated during prostate cancer progression and promotes androgen depletion-resistant growth. Cancer Res. 2009; 69(6):2305-2313.

62. Sun M and Abdollah F. Re: AR-V7 and Resistance to Enzalutamide and Abiraterone in Prostate Cancer. Eur Urol. 2015; 68(1):162-163.

63. Lokhandwala PM, Riel SL, Haley L, Lu C, Chen Y, Silberstein J, Zhu Y, Zheng G, Lin MT, Gocke CD, Partin AW, Antonarakis ES, Luo J and Eshleman JR. Analytical Validation of Androgen Receptor Splice Variant 7 Detection in a Clinical Laboratory Improvement Amendments (CLIA) Laboratory Setting. J Mol Diagn. 2017; 19(1):115-125.

64. Liu LL, Xie N, Sun S, Plymate S, Mostaghel E and Dong X. Mechanisms of the androgen receptor splicing in prostate cancer cells. Oncogene. 2014; 33(24):3140-3150.

65. Svensson C, Ceder J, Iglesias-Gato D, Chuan YC, Pang ST, Bjartell A, Martinez RM, Bott L, Helczynski L, Ulmert D, Wang Y, Niu Y, Collins C and Flores-Morales A. REST mediates androgen receptor actions on gene repression and predicts early recurrence of prostate cancer. Nucleic Acids Res. 2014; 42(2):9991015.

66. Bishop JL, Sio A, Angeles A, Roberts ME, Azad AA, Chi KN and Zoubeidi A. PD-L1 is highly expressed in Enzalutamide resistant prostate cancer. Oncotarget. 2015; 6(1):234-242.

67. Epstein JI, Amin MB, Beltran H, Lotan TL, Mosquera JM, Reuter VE, Robinson BD, Troncoso P and Rubin MA. Proposed morphologic classification of prostate cancer with neuroendocrine differentiation. Am J Surg Pathol. 2014; 38(6):756-767.

68. Qi J, Pellecchia M and Ronai ZA. The Siah2-HIF-FoxA2 axis in prostate cancer - new markers and therapeutic opportunities. Oncotarget. 2010; 1(5):379-385.

69. Grignon DJ. Unusual subtypes of prostate cancer. Mod Pathol. 2004; 17(3):316-327.

70. Wang HT, Yao YH, Li BG, Tang Y, Chang JW and Zhang J. Neuroendocrine Prostate Cancer (NEPC) progressing from conventional prostatic adenocarcinoma: factors associated with time to development of NEPC and survival from NEPC diagnosis-a systematic review and pooled analysis. J Clin Oncol. 2014; 32(30):3383-3390.

71. Gillessen S, Omlin A, Attard G, de Bono JS, Efstathiou E, Fizazi K, Halabi S, Nelson PS, Sartor O, Smith MR, Soule HR, Akaza H, Beer TM, Beltran H, Chinnaiyan AM, Daugaard G, et al. Management of patients with advanced prostate cancer: recommendations of the St Gallen Advanced Prostate Cancer Consensus Conference (APCCC) 2015. Ann Oncol. 2015; 26(8):1589-1604.

72. di Sant'Agnese PA and Cockett AT. Neuroendocrine differentiation in prostatic malignancy. Cancer. 1996; 78(2):357-361.

73. Aparicio A, Logothetis CJ and Maity SN. Understanding the lethal variant of prostate cancer: power of examining extremes. Cancer Discov. 2011; 1(6):466-468.

74. Tzelepi V, Zhang J, Lu JF, Kleb B, Wu G, Wan X, Hoang A, Efstathiou E, Sircar K, Navone NM, Troncoso P, Liang S, Logothetis CJ, Maity SN and Aparicio AM. Modeling a lethal prostate cancer variant with smallcell carcinoma features. Clin Cancer Res. 2012; 18(3):666-677. 
75. Parimi V, Goyal R, Poropatich K and Yang XJ. Neuroendocrine differentiation of prostate cancer: a review. Am J Clin Exp Urol. 2014; 2(4):273-285.

76. Alanee S, Moore A, Nutt M, Holland B, Dynda D, El-Zawahry A and McVary KT. Contemporary Incidence and Mortality Rates of Neuroendocrine Prostate Cancer. Anticancer Res. 2015; 35(7):4145-4150.

77. Beltran H, Tagawa ST, Park K, MacDonald T, Milowsky MI, Mosquera JM, Rubin MA and Nanus DM. Challenges in recognizing treatment-related neuroendocrine prostate cancer. J Clin Oncol. 2012; 30(36):e386-389.

78. Wright ME, Tsai MJ and Aebersold R. Androgen receptor represses the neuroendocrine transdifferentiation process in prostate cancer cells. Mol Endocrinol. 2003; 17(9):1726-1737.

79. Wang $\mathrm{W}$ and Epstein JI. Small cell carcinoma of the prostate. A morphologic and immunohistochemical study of 95 cases. Am J Surg Pathol. 2008; 32(1):65-71.

80. Guate JL, Escaf S, Menendez CL, del Valle M and Vega JA. Neuroendocrine cells in benign prostatic hyperplasia and prostatic carcinoma: effect of hormonal treatment. Urol Int. 1997; 59(3):149-153.

81. Lapuk AV, Wu C, Wyatt AW, McPherson A, McConeghy BJ, Brahmbhatt S, Mo F, Zoubeidi A, Anderson S, Bell RH, Haegert A, Shukin R, Wang Y, Fazli L, Hurtado-Coll A, Jones EC, et al. From sequence to molecular pathology, and a mechanism driving the neuroendocrine phenotype in prostate cancer. J Pathol. 2012; 227(3):286-297.

82. Miyoshi Y, Uemura H, Kitami K, Satomi Y, Kubota Y and Hosaka M. Neuroendocrine differentiated small cell carcinoma presenting as recurrent prostate cancer after androgen deprivation therapy. BJU Int. 2001; 88(9):982-983.

83. Burchardt T, Burchardt M, Chen MW, Cao Y, de la Taille A, Shabsigh A, Hayek O, Dorai T and Buttyan R. Transdifferentiation of prostate cancer cells to a neuroendocrine cell phenotype in vitro and in vivo. J Urol. 1999; 162(5):1800-1805.

84. Germann M, Wetterwald A, Guzman-Ramirez N, van der Pluijm G, Culig Z, Cecchini MG, Williams ED and Thalmann GN. Stem-like cells with luminal progenitor phenotype survive castration in human prostate cancer. Stem Cells. 2012; 30(6):1076-1086.

85. Stratton M, Evans DJ and Lampert IA. Prostatic adenocarcinoma evolving into carcinoid: selective effect of hormonal treatment? J Clin Pathol. 1986; 39(7):750-756.

86. Sasaki T, Komiya A, Suzuki H, Shimbo M, Ueda T, Akakura K and Ichikawa T. Changes in chromogranin a serum levels during endocrine therapy in metastatic prostate cancer patients. Eur Urol. 2005; 48(2):224229; discussion 229-230.

87. Yuan TC, Veeramani S, Lin FF, Kondrikou D, Zelivianski S, Igawa T, Karan D, Batra SK and Lin MF. Androgen deprivation induces human prostate epithelial neuroendocrine differentiation of androgen-sensitive LNCaP cells. Endocr Relat Cancer. 2006; 13(1):151-167.

88. Bishop JL, Thaper D, Vahid S, Davies A, Ketola K, Kuruma H, Jama R, Nip KM, Angeles A, Johnson F, Wyatt AW, Fazli L, Gleave ME, Lin D, Rubin MA, Collins CC, et al. The Master Neural Transcription Factor BRN2 Is an Androgen Receptor-Suppressed Driver of Neuroendocrine Differentiation in Prostate Cancer. Cancer Discov. 2017; 7(1):54-71.

89. Li Y, Donmez N, Sahinalp C, Xie N, Wang Y, Xue H, Mo F, Beltran H, Gleave M, Wang Y, Collins C and Dong $X$. SRRM4 Drives Neuroendocrine Transdifferentiation of Prostate Adenocarcinoma Under Androgen Receptor Pathway Inhibition. Eur Urol. 2017; 71(1):68-78.

90. Akamatsu S, Wyatt AW, Lin D, Lysakowski S, Zhang F, Kim S, Tse C, Wang K, Mo F, Haegert A, Brahmbhatt S, Bell R, Adomat H, Kawai Y, Xue H, Dong X, et al. The Placental Gene PEG10 Promotes Progression of Neuroendocrine Prostate Cancer. Cell Rep. 2015; 12(6):922-936.

91. Bonkhoff $\mathrm{H}$, Stein $U$ and Remberger K. Endocrine-paracrine cell types in the prostate and prostatic adenocarcinoma are postmitotic cells. Hum Pathol. 1995; 26(2):167-170.

92. Sauer CG, Roemer A and Grobholz R. Genetic analysis of neuroendocrine tumor cells in prostatic carcinoma. Prostate. 2006; 66(3):227-234.

93. Lotan TL, Gupta NS, Wang W, Toubaji A, Haffner MC, Chaux A, Hicks JL, Meeker AK, Bieberich CJ, De Marzo AM, Epstein JI and Netto GJ. ERG gene rearrangements are common in prostatic small cell carcinomas. Mod Pathol. 2011; 24(6):820-828. 
94. Hansel DE, Nakayama M, Luo J, Abukhdeir AM, Park BH, Bieberich CJ, Hicks JL, Eisenberger M, Nelson WG, Mostwin JL and De Marzo AM. Shared TP53 gene mutation in morphologically and phenotypically distinct concurrent primary small cell neuroendocrine carcinoma and adenocarcinoma of the prostate. Prostate. 2009; 69(6):603-609.

95. Huang J, Yao JL, di Sant'Agnese PA, Yang Q, Bourne PA and Na Y. Immunohistochemical characterization of neuroendocrine cells in prostate cancer. Prostate. 2006; 66(13):1399-1406.

96. Bonkhoff $\mathrm{H}$, Stein $\mathrm{U}$ and Remberger K. Multidirectional differentiation in the normal, hyperplastic, and neoplastic human prostate: simultaneous demonstration of cell-specific epithelial markers. Hum Pathol. 1994; 25(1):42-46.

97. Jongsma J, Oomen MH, Noordzij MA, Romijn JC, van Der Kwast TH, Schroder FH and van Steenbrugge GJ. Androgen-independent growth is induced by neuropeptides in human prostate cancer cell lines. Prostate. 2000; 42(1):34-44.

98. Mori S, Murakami-Mori K and Bonavida B. Interleukin-6 induces G1 arrest through induction of p27(Kip1), a cyclin-dependent kinase inhibitor, and neuron-like morphology in LNCaP prostate tumor cells. Biochem Biophys Res Commun. 1999; 257(2):609-614.

99. Albrecht M, Doroszewicz J, Gillen S, Gomes I, Wilhelm B, Stief T and Aumuller G. Proliferation of prostate cancer cells and activity of neutral endopeptidase is regulated by bombesin and IL-1beta with IL-1beta acting as a modulator of cellular differentiation. Prostate. 2004; 58(1):82-94.

100. Lee LF, Louie MC, Desai SJ, Yang J, Chen HW, Evans CP and Kung HJ. Interleukin-8 confers androgenindependent growth and migration of LNCaP: differential effects of tyrosine kinases Src and FAK. Oncogene. 2004; 23(12):2197-2205.

101. Deng X, Liu H, Huang J, Cheng L, Keller ET, Parsons SJ and Hu CD. Ionizing radiation induces prostate cancer neuroendocrine differentiation through interplay of CREB and ATF2: implications for disease progression. Cancer Res. 2008; 68(23):9663-9670.

102. Bang YJ, Pirnia F, Fang WG, Kang WK, Sartor O, Whitesell L, Ha MJ, Tsokos M, Sheahan MD, Nguyen P, Niklinski WT, Myers CE and Trepel JB. Terminal neuroendocrine differentiation of human prostate carcinoma cells in response to increased intracellular cyclic AMP. Proc Natl Acad Sci U S A. 1994; 91(12):5330-5334.

103. Shen R, Dorai $T$, Szaboles M, Katz AE, Olsson CA and Buttyan R. Transdifferentiation of cultured human prostate cancer cells to a neuroendocrine cell phenotype in a hormone-depleted medium. Urol Oncol. 1997; 3(2):67-75.

104. Cox ME, Deeble PD, Lakhani S and Parsons SJ. Acquisition of neuroendocrine characteristics by prostate tumor cells is reversible: implications for prostate cancer progression. Cancer Res. 1999; 59(15):38213830.

105. Deeble PD, Murphy DJ, Parsons SJ and Cox ME. Interleukin-6- and cyclic AMP-mediated signaling potentiates neuroendocrine differentiation of LNCaP prostate tumor cells. Mol Cell Biol. 2001; 21(24):84718482.

106. Zhu Y, Liu C, Cui Y, Nadiminty N, Lou W and Gao AC. Interleukin-6 induces neuroendocrine differentiation (NED) through suppression of RE-1 silencing transcription factor (REST). Prostate. 2014; 74(11):1086-1094.

107. Lou W, Ni Z, Dyer K, Tweardy DJ and Gao AC. Interleukin-6 induces prostate cancer cell growth accompanied by activation of stat3 signaling pathway. Prostate. 2000; 42(3):239-242.

108. Spiotto MT and Chung TD. STAT3 mediates IL-6-induced neuroendocrine differentiation in prostate cancer cells. Prostate. 2000; 42(3):186-195.

109. Lee LF, Guan J, Qiu Y and Kung HJ. Neuropeptide-induced androgen independence in prostate cancer cells: roles of nonreceptor tyrosine kinases Etk/Bmx, Src, and focal adhesion kinase. Mol Cell Biol. 2001; 21(24):8385-8397.

110. Qi J, Nakayama K, Cardiff RD, Borowsky AD, Kaul K, Williams R, Krajewski S, Mercola D, Carpenter PM, Bowtell D and Ronai ZA. Siah2-dependent concerted activity of HIF and FoxA2 regulates formation of neuroendocrine phenotype and neuroendocrine prostate tumors. Cancer Cell. 2010; 18(1):23-38. 
111. Danza G, Di Serio C, Rosati F, Lonetto G, Sturli N, Kacer D, Pennella A, Ventimiglia G, Barucci R, Piscazzi A, Prudovsky I, Landriscina M, Marchionni N and Tarantini F. Notch signaling modulates hypoxia-induced neuroendocrine differentiation of human prostate cancer cells. Mol Cancer Res. 2012; 10(2):230-238.

112. Beltran H, Rickman DS, Park K, Chae SS, Sboner A, MacDonald TY, Wang Y, Sheikh KL, Terry S, Tagawa ST, Dhir R, Nelson JB, de la Taille A, Allory Y, Gerstein MB, Perner S, et al. Molecular characterization of neuroendocrine prostate cancer and identification of new drug targets. Cancer Discov. 2011; 1(6):487-495.

113. Mosquera JM, Beltran H, Park K, MacDonald TY, Robinson BD, Tagawa ST, Perner S, Bismar TA, Erbersdobler A, Dhir R, Nelson JB, Nanus DM and Rubin MA. Concurrent AURKA and MYCN gene amplifications are harbingers of lethal treatment-related neuroendocrine prostate cancer. Neoplasia. 2013; 15(1):1-10.

114. Lee JK, Phillips JW, Smith BA, Park JW, Stoyanova T, McCaffrey EF, Baertsch R, Sokolov A, Meyerowitz JG, Mathis C, Cheng D, Stuart JM, Shokat KM, Gustafson WC, Huang J and Witte ON. N-Myc Drives Neuroendocrine Prostate Cancer Initiated from Human Prostate Epithelial Cells. Cancer Cell. 2016; 29(4):536-547.

115. Tsai H, Morais CL, Alshalalfa M, Tan HL, Haddad Z, Hicks J, Gupta N, Epstein JI, Netto GJ, Isaacs WB, Luo J, Mehra R, Vessella RL, Karnes RJ, Schaeffer EM, Davicioni E, et al. Cyclin D1 Loss Distinguishes Prostatic Small-Cell Carcinoma from Most Prostatic Adenocarcinomas. Clin Cancer Res. 2015; 21(24):5619-5629.

116. Penney KL, Stampfer MJ, Jahn JL, Sinnott JA, Flavin R, Rider JR, Finn S, Giovannucci E, Sesso HD, Loda M, Mucci LA and Fiorentino M. Gleason grade progression is uncommon. Cancer Res. 2013; 73(16):51635168.

117. Miller DC, Hafez KS, Stewart A, Montie JE and Wei JT. Prostate carcinoma presentation, diagnosis, and staging: an update form the National Cancer Data Base. Cancer. 2003; 98(6):1169-1178.

118. Cancer Genome Atlas Research Network. Electronic address scmo and Cancer Genome Atlas Research N. The Molecular Taxonomy of Primary Prostate Cancer. Cell. 2015; 163(4):1011-1025.

119. Yoshimoto M, Cunha IW, Coudry RA, Fonseca FP, Torres CH, Soares FA and Squire JA. FISH analysis of 107 prostate cancers shows that PTEN genomic deletion is associated with poor clinical outcome. $\mathrm{Br} \mathrm{J}$ Cancer. 2007; 97(5):678-685.

120. Tomlins SA, Palanisamy N, Siddiqui J, Chinnaiyan AM and Kunju LP. Antibody-based detection of ERG rearrangements in prostate core biopsies, including diagnostically challenging cases: ERG staining in prostate core biopsies. Arch Pathol Lab Med. 2012; 136(8):935-946.

121. Scheble VJ, Braun M, Wilbertz T, Stiedl AC, Petersen K, Schilling D, Reischl M, Seitz G, Fend F, Kristiansen $G$ and Perner S. ERG rearrangement in small cell prostatic and lung cancer. Histopathology. 2010; 56(7):937-943.

122. Brenner JC, Ateeq B, Li Y, Yocum AK, Cao Q, Asangani IA, Patel S, Wang X, Liang H, Yu J, Palanisamy N, Siddiqui J, Yan W, Cao X, Mehra R, Sabolch A, et al. Mechanistic rationale for inhibition of poly(ADPribose) polymerase in ETS gene fusion-positive prostate cancer. Cancer Cell. 2011; 19(5):664-678.

123. Chatterjee P, Choudhary GS, Sharma A, Singh K, Heston WD, Ciezki J, Klein EA and Almasan A. PARP inhibition sensitizes to low dose-rate radiation TMPRSS2-ERG fusion gene-expressing and PTEN-deficient prostate cancer cells. PLoS One. 2013; 8(4):e60408.

124. Na R, Zheng SL, Han M, Yu H, Jiang D, Shah S, Ewing CM, Zhang L, Novakovic K, Petkewicz J, Gulukota K, Helseth DL, Jr., Quinn M, Humphries E, Wiley KE, Isaacs SD, et al. Germline Mutations in ATM and BRCA1/2 Distinguish Risk for Lethal and Indolent Prostate Cancer and are Associated with Early Age at Death. Eur Urol. 2017; 71(5):740-747.

125. Fong PC, Boss DS, Yap TA, Tutt A, Wu P, Mergui-Roelvink M, Mortimer P, Swaisland H, Lau A, O'Connor MJ, Ashworth A, Carmichael J, Kaye SB, Schellens JH and de Bono JS. Inhibition of poly(ADP-ribose) polymerase in tumors from BRCA mutation carriers. N Engl J Med. 2009; 361(2):123-134.

126. Blattner M, Liu D, Robinson BD, Huang D, Poliakov A, Gao D, Nataraj S, Deonarine LD, Augello MA, Sailer V, Ponnala L, Ittmann M, Chinnaiyan AM, Sboner A, Chen Y, Rubin MA, et al. SPOP Mutation Drives Prostate Tumorigenesis In Vivo through Coordinate Regulation of PI3K/mTOR and AR Signaling. Cancer Cell. 2017; 31(3):436-451. 
127. Boysen G, Barbieri CE, Prandi D, Blattner M, Chae SS, Dahija A, Nataraj S, Huang D, Marotz C, Xu L, Huang J, Lecca P, Chhangawala S, Liu D, Zhou P, Sboner A, et al. SPOP mutation leads to genomic instability in prostate cancer. Elife. 2015; 4.

128. Shenoy TR, Boysen G, Wang MY, Xu QZ, Guo W, Koh FM, Wang C, Zhang LZ, Wang Y, Gil V, Aziz S, Christova R, Rodrigues DN, Crespo M, Rescigno P, Tunariu N, et al. CHD1 loss sensitizes prostate cancer to DNA damaging therapy by promoting error-prone double-strand break repair. Ann Oncol. 2017.

129. Tomlins SA, Rhodes DR, Yu J, Varambally S, Mehra R, Perner S, Demichelis F, Helgeson BE, Laxman B, Morris DS, Cao Q, Cao X, Andren O, Fall K, Johnson L, Wei JT, et al. The role of SPINK1 in ETS rearrangement-negative prostate cancers. Cancer Cell. 2008; 13(6):519-528.

130. Barbieri CE, Baca SC, Lawrence MS, Demichelis F, Blattner M, Theurillat JP, White TA, Stojanov P, Van Allen E, Stransky N, Nickerson E, Chae SS, Boysen G, Auclair D, Onofrio RC, Park K, et al. Exome sequencing identifies recurrent SPOP, FOXA1 and MED12 mutations in prostate cancer. Nat Genet. 2012; 44(6):685-689.

131. Ateeq B, Tomlins SA, Laxman B, Asangani IA, Cao Q, Cao X, Li Y, Wang X, Feng FY, Pienta KJ, Varambally S and Chinnaiyan AM. Therapeutic targeting of SPINK1-positive prostate cancer. Sci Transl Med. 2011; 3(72):72ra17.

132. Aryee MJ, Liu W, Engelmann JC, Nuhn P, Gurel M, Haffner MC, Esopi D, Irizarry RA, Getzenberg RH, Nelson WG, Luo J, Xu J, Isaacs WB, Bova GS and Yegnasubramanian S. DNA methylation alterations exhibit intraindividual stability and interindividual heterogeneity in prostate cancer metastases. Sci Transl Med. 2013; 5(169):169ra110.

133. Brocks D, Assenov Y, Minner S, Bogatyrova O, Simon R, Koop C, Oakes C, Zucknick M, Lipka DB, Weischenfeldt J, Feuerbach L, Cowper-Sal Lari R, Lupien M, Brors B, Korbel J, Schlomm T, et al. Intratumor DNA methylation heterogeneity reflects clonal evolution in aggressive prostate cancer. Cell Rep. 2014; 8(3):798-806.

134. Yegnasubramanian S, Kowalski J, Gonzalgo ML, Zahurak M, Piantadosi S, Walsh PC, Bova GS, De Marzo AM, Isaacs WB and Nelson WG. Hypermethylation of CpG islands in primary and metastatic human prostate cancer. Cancer Res. 2004; 64(6):1975-1986.

135. Fraser M, Sabelnykova VY, Yamaguchi TN, Heisler LE, Livingstone J, Huang V, Shiah YJ, Yousif F, Lin X, Masella AP, Fox NS, Xie M, Prokopec SD, Berlin A, Lalonde E, Ahmed M, et al. Genomic hallmarks of localized, non-indolent prostate cancer. Nature. 2017; 541(7637):359-364.

136. Mundbjerg K, Chopra S, Alemozaffar M, Duymich C, Lakshminarasimhan R, Nichols PW, Aron M, Siegmund KD, Ukimura O, Aron M, Stern M, Gill P, Carpten JD, Orntoft TF, Sorensen KD, Weisenberger DJ, et al. Identifying aggressive prostate cancer foci using a DNA methylation classifier. Genome Biol. 2017; 18(1):3.

137. Baca SC, Prandi D, Lawrence MS, Mosquera JM, Romanel A, Drier Y, Park K, Kitabayashi N, MacDonald TY, Ghandi M, Van Allen E, Kryukov GV, Sboner A, Theurillat JP, Soong TD, Nickerson E, et al. Punctuated evolution of prostate cancer genomes. Cell. 2013; 153(3):666-677.

138. Holland AJ and Cleveland DW. Chromoanagenesis and cancer: mechanisms and consequences of localized, complex chromosomal rearrangements. Nat Med. 2012; 18(11):1630-1638.

139. Wu C, Wyatt AW, McPherson A, Lin D, McConeghy BJ, Mo F, Shukin R, Lapuk AV, Jones SJ, Zhao Y, Marra MA, Gleave ME, Volik SV, Wang Y, Sahinalp SC and Collins CC. Poly-gene fusion transcripts and chromothripsis in prostate cancer. Genes Chromosomes Cancer. 2012; 51(12):1144-1153.

140. Hendriks RJ, van Oort IM and Schalken JA. Blood-based and urinary prostate cancer biomarkers: a review and comparison of novel biomarkers for detection and treatment decisions. Prostate Cancer Prostatic Dis. 2017; 20(1):12-19.

141. Catalona WJ, Partin AW, Sanda MG, Wei JT, Klee GG, Bangma CH, Slawin KM, Marks LS, Loeb S, Broyles DL, Shin SS, Cruz AB, Chan DW, Sokoll LJ, Roberts WL, van Schaik RH, et al. A multicenter study of [2]pro-prostate specific antigen combined with prostate specific antigen and free prostate specific antigen for prostate cancer detection in the 2.0 to $10.0 \mathrm{ng} / \mathrm{ml}$ prostate specific antigen range. J Urol. 2011; 185(5):1650-1655. 
142. Tomlins SA, Aubin SM, Siddiqui J, Lonigro RJ, Sefton-Miller L, Miick S, Williamsen S, Hodge P, Meinke J, Blase A, Penabella Y, Day JR, Varambally R, Han B, Wood D, Wang L, et al. Urine TMPRSS2:ERG fusion transcript stratifies prostate cancer risk in men with elevated serum PSA. Sci Transl Med. 2011; 3(94):94ra72.

143. Minciacchi VR, Zijlstra A, Rubin MA and Di Vizio D. Extracellular vesicles for liquid biopsy in prostate cancer: where are we and where are we headed? Prostate Cancer Prostatic Dis. 2017.

144. Del Re M, Biasco E, Crucitta S, Derosa L, Rofi E, Orlandini C, Miccoli M, Galli L, Falcone A, Jenster GW, van Schaik RH and Danesi R. The Detection of Androgen Receptor Splice Variant 7 in Plasma-derived Exosomal RNA Strongly Predicts Resistance to Hormonal Therapy in Metastatic Prostate Cancer Patients. Eur Urol. 2017; 71(4):680-687.

145. Steinestel J, Luedeke M, Arndt A, Schnoeller TJ, Lennerz JK, Wurm C, Maier C, Cronauer MV, Steinestel K and Schrader AJ. Detecting predictive androgen receptor modifications in circulating prostate cancer cells. Oncotarget. 2015.

146. Scher HI, Lu D, Schreiber NA, Louw J, Graf RP, Vargas HA, Johnson A, Jendrisak A, Bambury R, Danila D, McLaughlin B, Wahl J, Greene SB, Heller G, Marrinucci D, Fleisher M, et al. Association of AR-V7 on Circulating Tumor Cells as a Treatment-Specific Biomarker With Outcomes and Survival in CastrationResistant Prostate Cancer. JAMA Oncol. 2016; 2(11):1441-1449.

147. Miyamoto DT, Lee RJ, Stott SL, Ting DT, Wittner BS, Ulman M, Smas ME, Lord JB, Brannigan BW, Trautwein J, Bander NH, Wu CL, Sequist LV, Smith MR, Ramaswamy S, Toner M, et al. Androgen receptor signaling in circulating tumor cells as a marker of hormonally responsive prostate cancer. Cancer Discov. 2012; 2(11):995-1003.

148. Beltran H, Jendrisak A, Landers M, Mosquera JM, Kossai M, Louw J, Krupa R, Graf RP, Schreiber NA, Nanus DM, Tagawa ST, Marrinucci D, Dittamore R and Scher HI. The Initial Detection and Partial Characterization of Circulating Tumor Cells in Neuroendocrine Prostate Cancer. Clin Cancer Res. 2016; 22(6):1510-1519.

149. Goldkorn A, Ely B, Quinn DI, Tangen CM, Fink LM, Xu T, Twardowski P, Van Veldhuizen PJ, Agarwal N, Carducci MA, Monk JP, 3rd, Datar RH, Garzotto M, Mack PC, Lara P, Jr., Higano CS, et al. Circulating tumor cell counts are prognostic of overall survival in SWOG S0421: a phase III trial of docetaxel with or without atrasentan for metastatic castration-resistant prostate cancer. J Clin Oncol. 2014; 32(11):11361142.

150. Scher HI, Heller G, Molina A, Attard G, Danila DC, Jia X, Peng W, Sandhu SK, Olmos D, Riisnaes R, McCormack R, Burzykowski T, Kheoh T, Fleisher M, Buyse M and de Bono JS. Circulating tumor cell biomarker panel as an individual-level surrogate for survival in metastatic castration-resistant prostate cancer. J Clin Oncol. 2015; 33(12):1348-1355.

151. Ross RW, Galsky MD, Scher HI, Magidson J, Wassmann K, Lee GS, Katz L, Subudhi SK, Anand A, Fleisher M, Kantoff PW and Oh WK. A whole-blood RNA transcript-based prognostic model in men with castration-resistant prostate cancer: a prospective study. Lancet Oncol. 2012; 13(11):1105-1113.

152. Olmos D, Brewer D, Clark J, Danila DC, Parker C, Attard G, Fleisher M, Reid AH, Castro E, Sandhu SK, Barwell L, Oommen NB, Carreira S, Drake CG, Jones R, Cooper CS, et al. Prognostic value of blood mRNA expression signatures in castration-resistant prostate cancer: a prospective, two-stage study. Lancet Oncol. 2012; 13(11):1114-1124.

153. Davis JW. Novel commercially available genomic tests for prostate cancer: a roadmap to understanding their clinical impact. BJU Int. 2014; 114(3):320-322.

154. Alshalalfa $M$, Schliekelman $M$, Shin $H$, Erho $N$ and Davicioni E. Evolving transcriptomic fingerprint based on genome-wide data as prognostic tools in prostate cancer. Biol Cell. 2015; 107(7):232-244.

155. Hagemann IS. Molecular Testing in Breast Cancer: A Guide to Current Practices. Arch Pathol Lab Med. 2016; 140(8):815-824.

156. Jang $\mathrm{S}$ and Atkins MB. Which drug, and when, for patients with BRAF-mutant melanoma? Lancet Oncol. 2013; 14(2):e60-69.

157. Lindeman NI, Cagle PT, Beasley MB, Chitale DA, Dacic S, Giaccone G, Jenkins RB, Kwiatkowski DJ, Saldivar JS, Squire J, Thunnissen E, Ladanyi M, College of American Pathologists International Association for the 
CHAPTER 1

Study of Lung C and Association for Molecular P. Molecular testing guideline for selection of lung cancer patients for EGFR and ALK tyrosine kinase inhibitors: guideline from the College of American Pathologists, International Association for the Study of Lung Cancer, and Association for Molecular Pathology. J Mol Diagn. 2013; 15(4):415-453.

158. Georgi B, Korzeniewski N, Hadaschik B, Grullich C, Roth W, Sultmann H, Pahernik S, Hohenfellner M and Duensing S. Evolving therapeutic concepts in prostate cancer based on genome-wide analyses (review). Int J Oncol. 2014; 45(4):1337-1344. 


\section{Chapter 2}

\section{TMPRSS2:ERG gene fusion variants induce TGF- $\beta$ signaling and epithelial to mesenchymal transition in human prostate cancer cells}

Published as:

Leonie Ratz, Mark Laible, Lukasz A. Kacprzyk, Stephanie M. Wittig-Blaich, Yanis Tolstov, Stefan Duensing, Peter Altevogt, Sabine M. Klauck and Holger Sültmann Oncotarget. 2017; 8(15):25115-25130. doi: 10.18632/oncotarget.15931 


\section{ABSTRACT}

TMPRSS2:ERG (T/E) gene fusions are present in approximately $50 \%$ of all prostate cancer cases. The expression of fusion mRNAs from distinct T/E variants is associated with clinicopathological parameters, while the underlying molecular processes remain unclear. We characterized the molecular mechanisms and functional implications caused by doxycycline (Dox)-inducible overexpression of the frequent T/E III and VI fusion variants in LNCaP cells. Induction of T/E expression resulted in increased cellular migratory and invasive potential, and reduced proliferation caused by accumulation in G1 phase. T/E overexpressing cells showed epithelial-to-mesenchymal transition (EMT), as demonstrated by upregulation of TGF- $\beta$ and WNT pathway genes, mesenchymal markers, and increased phosphorylation of the p38 MAPK. Augmented secretion of TGF- $\beta 1$ and $-\beta 2$, and T/E-mediated regulation of $A L K 1$, a member of the TGF- $\beta$ receptor family, was detected. ALK1 inhibition in T/E overexpressing cells blocked p38 phosphorylation and reduced the expression of the TGF- $\beta$ target genes VIM, MMP1, CDH2, and SNAI2. We found a T/E variant VI-specific induction of miR-503 associated with reduced expression of SMAD7 and CDH1. Overexpression of miR-503 led to increased levels of VIM and MMP1. Our findings indicate that TGF- $\beta$ signaling is a major determinant of EMT in T/E overexpressing LNCaP cells. We provide evidence that T/E VI-specific transcriptional modulation by miR-503 accounts for differences in the activation of EMT pathway genes, promoting the aggressive phenotype of tumors expressing T/E variant VI. We suggest that ALK1-mediated TGF- $\beta$ signaling is a novel oncogenic mechanism in T/E positive PCa. 


\section{INTRODUCTION}

Prostate cancer (PCa) is the most frequently diagnosed cancer among men in Western countries and a major cause of cancer-related mortality [1, 2]. PCa is a heterogeneous disease with several molecular and clinicopathological subtypes. The TMPRSS2:ERG $(T / E)$ gene fusion, resulting from a chromosomal rearrangement of ERG (V-ets erythroblastosis virus E26 homolog (avian)) to the androgen responsive gene TMPRSS2 (transmembrane protease, serine 2), is the most frequent somatic alteration in PCa [3], and detectable in $50 \%$ of the tumors [4]. In those cases, ERG overexpression is driven by the androgen-responsive promoter of TMPRSS2, resulting in upregulation of ERG protein and activation of downstream target genes [5]. Ninety percent of prostate cancers overexpressing ERG harbor T/E fusions [5]. However, no consensus on the prognostic significance of T/E fusion-positive tumors has been reached so far [6, 7]. This may be due to differences in tumor characteristics and multiple T/E isoforms $[6,8,9]$, which have been associated with clinicopathological parameters [10] and progression [11, 12]. The most common fusion mRNA variant III (T/E III), containing exon 1 of TMPRSS2 (1$17 \mathrm{bp})$ and exon $4-11$ of $E R G$ (T1/E4), is present in $86 \%$ of fusion-positive tumors [10]. Since exon 1 of TMPRSS2 is noncoding, this mRNA is translated from an internal ATG site, resulting in a truncated ERG protein. The expression of $T / E V I$, resulting from fusion of exons 1-2 of TMPRSS2 to exons 4-11 of ERG (T2/E4), has been associated with aggressive disease [10]. This mRNA is translated from a start codon within TMPRSS2 exon 2 that is in frame with the ERG ORF. The resulting protein includes the first five amino acids of TMPRSS2 and lacks the first 12 amino acids of the full-length ERG protein.

Previously, we found T/E specific transcriptional upregulation of genes associated with activated TGF- $\beta / B M P$ and WNT signaling in fusion-positive PCa compared to fusionnegative PCa [13]. TGF- $\beta$ and WNT signaling regulate a diverse range of cellular processes related to cancer progression $[14,15]$ and are major inducers of epithelial-to-mesenchymal transition (EMT) [16]. Here, our aim was to characterize the molecular mechanisms and functional implications of $\mathrm{T} / \mathrm{E}$ variant overexpression and their consequences on cellular and molecular phenotypes. We focused on the analysis of T/E III and T/E VI gene fusion variants based on their frequencies of occurrence and their association with clinical and pathological variables. We established LNCaP cells, featuring androgen-independency with high levels of androgen receptor (AR), stably overexpressing the T/E III and VI variants in an inducible promoter system (LNCaP-T/E), and examined the effects of overexpression on cellular properties and signal transduction pathways. To validate the observed transcriptional modulation upon ERG overexpression in LNCaP, the T/E-positive metastatic prostate cancer cell line $\mathrm{NCl}-\mathrm{H} 660$ [17] was employed. This cell line harbors both T/E III and T/E VI fusions [17]. Complementary to the LNCaP-T/E model, ERG was silenced in NCl-H660 cells using an ERG-specific siRNA and mRNA levels of the targets previously measured in LNCaP$T / E$ clones were assessed. Overall, we found a large degree of commonality but also distinct transcriptional effects between T/E III and VI variants. 


\section{MATERIAL AND METHODS}

\section{Cell lines and culturing}

LNCaP (CRL-1740) and NCl-H660 (CRL-5813) cells were purchased from American Type Culture Collection (ATCC, Manassas, VA, USA). Stably transfected acceptor LNCaP cells were maintained in RPMI640 (Thermo Fisher Scientific, Waltham, MA, USA), supplemented with $10 \%$ of Tet System Approved FBS (tet-FBS, Clontech, Göteborg, Sweden) and $80 \mu \mathrm{g} / \mathrm{mL}$ hygromycin B (Thermo Fisher Scientific). NCl-H660 cells were maintained in HITES medium supplemented with $5 \%$ fetal bovine serum according to the provider's instructions. All cell lines were authenticated using Multiplex Cell Authentication by Multiplexion (Heidelberg, Germany) as described recently [61]. The SNP profiles matched known profiles or were unique. The purity of cell lines was validated using the Multiplex cell Contamination Test by Multiplexion (Heidelberg, Germany) as described recently [62]. No Mycoplasma, SMRV or interspecies contamination was detected.

\section{Generation of LNCaP cell models stably expressing T/E variants}

Establishment of the LNCaP-T/E variant cell model including T/E sequences is described in the Supplementary Methods, Supplementary Figure 2.1A and Supplementary Figure 2.2. Transgene expression was induced with $50 \mathrm{ng} / \mathrm{mL}$ Dox (Sigma-Aldrich, Munich, Germany) in RPMI1640 containing 10\% tet-FBS. Medium of the uninduced cells was supplemented with the respective volume of PBS only.

\section{RNA isolation, reverse transcription and quantitative real-time $P C R$}

Total RNA was isolated from cell lines using the miRNeasy Mini Kit (Qiagen, Hilden, Germany) and quality controlled on the 2100 Bioanalyser (Agilent Technologies, Waldbronn, Germany) with RNA 6000 Nano Kit according to manufacturer's protocols. Total RNA was reverse transcribed using the RevertAid H Minus First Strand cDNA Synthesis Kit (Thermo Fisher Scientific). HotStarTaqDNA polymerase (Qiagen) was used for RT-PCR with 50 ng of cDNA template. Relative mRNA levels were assessed by quantitative RTPCR on the Lightcycler 480 (Roche Diagnostics, Mannheim, Germany) using Universal Probe Library (UPL) assays and primers listed in Supplementary Table S2.1. Linear expression levels were normalized to GAPDH using the $2^{(-\Delta \Delta C t)}$ method [63]. For miRNA quantification, TaqMan ${ }^{\circledR}$ Assays (hsa-miR-503, ID: 1048; RNU6B, ID: 1093, Thermo Fisher Scientific) were used according to the manufacturer's instruction.

\section{Microarray gene expression profiling}

RNA was isolated with the RNase-Free DNase Set (Qiagen) according to the manufacturer's protocol. After quality control, 500ng of total RNA with a concentration of 50 $\mathrm{ng} / \mu \mathrm{l}$ were submitted to the DKFZ Genomics and Proteomics Core Facility (GPCF) for Illumina Whole-Genome Expression Beadchip Analysis (Human HT-12 Chip). The raw 
data were quantile-normalized using the Bioconductor package preprocessCore in $\mathrm{R}$. The microarray data reported in this study are available from the NCBI GEO database (GSE78032). Genes showing expression fold changes $>|1.5|$ ( $p$-value $<0.05$ ) were considered as differentially expressed and were analysed with Ingenuity Pathway Analysis (IPA) (see below). Genes involved in relevant biological processes obtained from microarray analysis were validated by qPCR in the same samples that were used for microarray profiling.

\section{Luciferase reporter assay}

Cells seeded in triplicate in 96-well plates at 5000 cells/well were treated with Dox and transfected with 100 ng of either wild-type TOPflash or mutant FOPflash reporter plasmid from the TCF Reporter Plasmid Kit (Merck Millipore, Darmstadt, Germany) using the jetPEI Polyplus transfection reagent (VWR International, Darmstadt, Germany). Firefly luciferase signals were determined $72 \mathrm{~h}$ after transfection using the ONE-GloTM Luciferase Assay System (Promega, Mannheim, Germany). Activation of the WNT/ $\beta$-catenin pathway was calculated by dividing wild-type TOPflash by mutant FOPflash activity.

\section{SiRNA-mediated gene knock-down}

LNCaP-T/E cells were transfected with 20nM siRNA against TGFB1 (Qiagen) using Lipofectamine RNAiMAX (Thermo Fisher Scientific) and OptiMEM ${ }^{\circledR}$ । (Thermo Fisher Scientific) according to the manufacturer's protocol. Cells transfected with nonsilencing AllStars Negative Control siRNA (Qiagen) were used as controls. Cells were treated for 48h, medium was changed, Dox-supplemented medium was added where indicated and siRNA treatment was repeated. Cells were incubated for $72 \mathrm{~h}$ and processed for further analysis.

$\mathrm{NCl}-\mathrm{H} 660$ cells were transfected with 50nM siRNA against ERG (Qiagen) using Lipofectamine RNAiMAX (Thermo Fisher Scientific) and OptiMEM ${ }^{\circledR}$ I (Thermo Fisher Scientific) according to the manufacturer's protocol. Cells transfected with nonsilencing AllStars Negative Control siRNA (Qiagen) were used as controls. Cells were incubated for $72 \mathrm{~h}$ and processed for further analysis.

\section{miRNA transfection}

For transfection, cells were treated with Dox and transfected with hsa-miR-503-5p inhibitor (Exiqon, Vedbaek, Denmark) or hsa-miR-503-5p mimic (GE Healthcare, Rosersberg, Sweden) using Lipofectamine RNAiMAX transfection reagent (Thermo Fisher Scientific).

\section{Pharmacological inhibitors}

The ALK1 inhibitor K02288 (Biomol, Hamburg, Germany) was dissolved at a concentration of $100 \mathrm{mM}$ in DMSO. Further dilutions of K02288 were made in PBS to reduce the 
final concentration of DMSO in the assay. Equal amounts of DMSO added to the cell culture medium served as negative control. RhALK1 (R\&D, Wiesbaden, Germany) was dissolved in PBS at a concentration of $100 \mu \mathrm{g} / \mathrm{mL}$, and rhFZD4 (R\&D) was dissolved in PBS at a concentration of $400 \mu \mathrm{g} / \mathrm{mL}$. Here, PBS was added to the cell culture medium as a negative control. Inhibitors or control solvents were diluted in Dox-containing tetFBS medium and added to the cells for $48 \mathrm{~h}$.

\section{Cell proliferation assay}

Cells were treated with Dox for $48 \mathrm{~h}$ and seeded into 96 -well plates at 5000 cells/well in $90 \mu \mathrm{l} 10 \%$ tet-FBS-containing medium in triplicate. Ten $\mu \mathrm{l}$ of the colorimetric WST-1 reagent (Roche Diagnostics) was added to the medium and incubated at $37^{\circ} \mathrm{C}$ at the indicated time points. Absorbance was measured one hour after addition of WST-1 reagent using a Tecan Infinite ${ }^{\circledR}$ M200 microplate reader (Tecan Group Ltd., Männedorf, Switzerland).

\section{Migration and invasion assays}

In vitro cell migration assays were performed in duplicate using 24-well transwell chambers with $8 \mu \mathrm{m}$ pore size (Merck Millipore). Cells $\left(5 \times 10^{5}\right.$ cells $\left./ \mathrm{mL}\right)$ were seeded in the upper chamber in $200 \mu \mathrm{l}$ serum-free medium. $700 \mu \mathrm{l}$ of medium supplemented with $10 \%$ FBS as chemoattractant was filled into the bottom well. After $48 \mathrm{~h}$ of cultivation in $5 \%$ $\mathrm{CO} 2$ at $37^{\circ} \mathrm{C}$, migrated cells attached to the lower surface of the insert were fixed with $100 \%$ methanol on ice and stained with $0.1 \%$ Crystal Violet (Sigma- Aldrich). Migrated cells were counted in four random fields under a light microscope (10x magnification).

Invasion assays were performed analogously after coating the transwell chambers with $100 \mu$ l Matrigel (BD Biosciences, Heidelberg, Germany) per filter.

\section{Cell cycle analysis}

Twenty-four, 48 and $72 \mathrm{~h}$ after Dox induction, trypsinized cells were fixed with $100 \%$ icecold ethanol and stained with propidium iodide (PI) solution (PBS containing $50 \mu \mathrm{g} / \mathrm{mL}$ $\mathrm{PI}, 0.1 \mathrm{mg} / \mathrm{mL}$ RNase A, 0.05\% (v/v) Triton X-100). PI staining was analysed using a FACSCanto II flow cytometer (BD Biosciences). Data was analysed using the software Cyflogig, version 1.2.1 (CyFlo Ltd., Turku, Finland).

\section{Cell lysis and Western blot analysis}

Whole-cell lysates were prepared in RIPA lysis buffer (50mM Tris- $\mathrm{HCl}$ pH 8.0, $150 \mathrm{mM}$ $\mathrm{NaCl}, 1 \% \mathrm{NP}-40,0.5 \%$ sodium deoxycholate, $0.1 \% \mathrm{SDS}$ ), supplemented with $1 \times \mathrm{cOm}$ plete Mini Protease Inhibitor Cocktail (Roche Diagnostics) and 1x PhosSTOP Phosphatase Inhibitor Cocktail (Roche Diagnostics). Lysates were boiled 5 min at $95^{\circ} \mathrm{C}$ with $4 \mathrm{x}$ reducing Roti-Load protein loading buffer (Roth, Karlsruhe, Germany). Samples were separated on a mini polyacrylamide gel (Bio-Rad, Munich, Germany) and transferred to 
PVDF membranes using the Trans-Blot Turbo semi-dry blotting system (Bio-Rad) at 1.3A, 25V for 7-10 min. After blocking with 5\% BSA in Tween-20/PBS, membranes were probed with primary antibodies prepared in blocking solution overnight at $4^{\circ} \mathrm{C}$ on a roller, followed by incubation with horseradish peroxidase-conjugated secondary antibody in blocking solution for $1 \mathrm{~h}$ at room temperature and ECL detection (Thermo Fisher Scientific) by the ChemiDoc XRS+ system (Bio-Rad). Western blotting was performed using primary antibodies against ERG (Abcam, Cambridge, UK), and SMAD7 (Abcam), AR (Santa Cruz, Dallas, Texas, USA), p-SMAD1/5, SMAD1, p-p38, p38, p-AKT, AKT, CDH1, and GAPDH (all Cell Signaling Technology, Danvers, MA, USA) at 1:1000 dilution. Secondary antibodies used were anti-rabbit-HRP (at 1:25000 dilution; Dianova, Hamburg, Germany) and anti-mouse-HRP (at 1:10000 dilution; Cell Signaling). Quantitative analysis of protein expression relative to GAPDH was done using Image Lab software (BioRad).

\section{Luminex immunoassay}

TGF- $\beta$ signaling pathway components were analysed using the Milliplex Human TGF- $\beta$ signaling 6-plex (Merck Millipore) and the Milliplex Human Multi-pathway 9-plex assay (Merck Millipore). Total TGF- $\beta$ protein expression in cell lysates and cell culture supernatants were measured using the Milliplex Human TGF- $\beta$ 1,2,3 assay (Merck Millipore). For Luminex analysis, the cells were treated with Dox to induce ERG expression. For collection, cell lysates and supernatants were centrifuged ( $15 \mathrm{~min}, 4000 \mathrm{rpm}, 4^{\circ} \mathrm{C}$ ) after $72 \mathrm{~h}$ of induction. Immunoassays using Lumine ${ }^{\circledR} \mathrm{xMAP}^{\circledR}$ technology were performed according to the manufacturer's instructions. The fluorescent reporter signals were analysed by a Bio-Plex 200 reader (Bio-Rad).

\section{Ingenuity Pathway Analysis}

Functional annotation and pathway enrichment of differentially regulated genes were identified using Ingenuity Pathway Analysis (IPA) software (Qiagen). IPA uses the Ingenuity knowledge base, a database of protein and gene interactions integrated from published biomedical literature and 3rd party sources. Analysis using IPA was performed between December 2015 and February 2016 (Ingenuity version 26127183). Genes showing an expression fold change $>|1.5|$ were considered as differentially expressed and included in the analysis.

\section{Functional annotations}

Gene expression changes were categorized into functional annotations of molecular and cellular mechanisms. The Ingenuity knowledge base provides a predicted direction of change for the biological function (downstream effect analysis), represented by an activation z-score, where $z>2.0$ or $<-2.0$ is predictive for activation or reduction of the 
process, respectively. A p-value $<0.05$ indicates a statistically significant association between a set of differentially expressed genes and a given process.

\section{Pathway enrichment analysis}

Ingenuity knowledge base provides an analysis of metabolic and cell signaling pathways that are significantly enriched in the gene expression signature. Significance values were calculated based on Fisher's right tailed exact test and the -log(p-value) by IPA. Pathways meeting the threshold $p$-value $<0.05$ were considered as significant. Using the 'Compare' tool, IPA identified the intersection and unique gene sets among T/E III and $\mathrm{T} / \mathrm{E} \mathrm{VI}$ versus empty vector datasets. Upstream regulator analysis can identify molecules upstream of the genes in the dataset that potentially explain the observed gene expression changes and molecular functions. It is based on prior knowledge of expected effects between transcriptional regulators and their target genes stored in the Ingenuity knowledge base.

\section{Statistical testing}

Expression differences between the induced and uninduced cells were analysed using a paired t-test and between induced cells of T/E III and VI by an unpaired t-test. Statistical significance of t-test depicted as $* p<0.05, * * p<0.01, * * * p<0.001$.

\section{RESULTS}

\section{Characterization of T/E expressing LNCaP cells}

To study the role of the $T / E$ gene fusion variants (Figure 2.1A), we made use of a Flp recombinase based transfection system allowing stable and inducible expression of T/E variants III and VI in LNCaP cells. An empty expression vector served as a control. The expression of T/E variants (LNCaP-T/E) was verified using RT-PCR (Supplementary Figure S1B). QPCR analysis after Dox-induction showed $\sim 50$-fold and $\sim 150$-fold upregulation of $E R G$ in T/E III and T/E VI cells, respectively (Figure 2.1B). Western blot analysis confirmed the expression of ERG protein in Dox-induced LNCaP-T/E cells only (Figure 2.1C). In line with previous reports that $E R G$ expression leads to downregulation of androgen receptor $(A R)$ transcripts [18], both LNCaP-T/E III and VI cell lines showed markedly decreased $A R$ protein after ERG overexpression (Figure 2.1C), indicating that the cell lines faithfully reflect the in vivo situation. Concurrent with reports that lower AR expression is associated with reduced differentiation of PCa cells [19], we noticed morphological changes, including cellular rounding, spindle-like branching, and detachment from adjacent cells (Figure 2.1D), which resembled a fibroblast-like morphology. These results suggested that ERG affects processes controlling the morphology of LNCaP cells. 
A

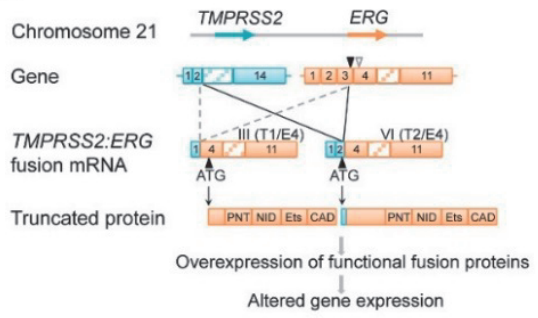

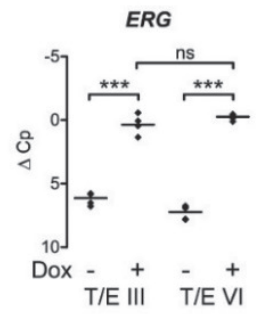

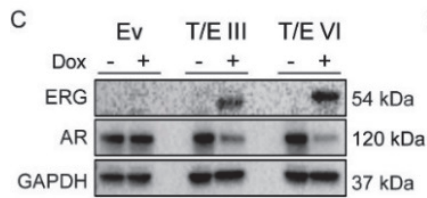

$E$

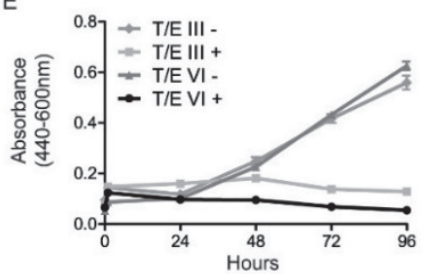

G

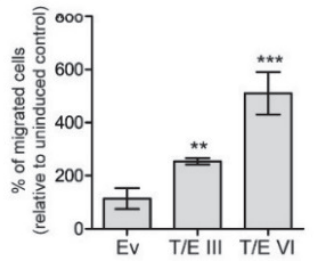

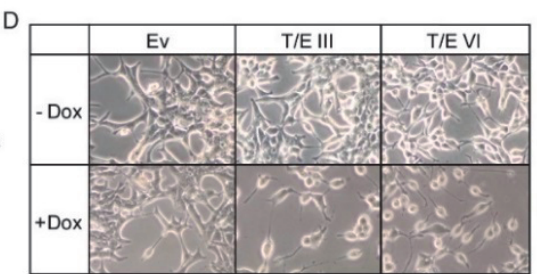

$\mathrm{F}$

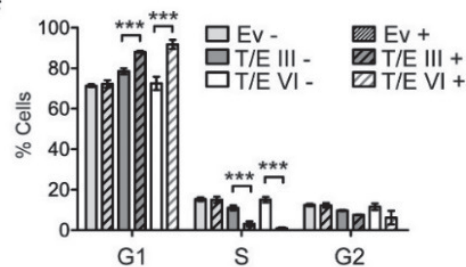

$\mathrm{H}$

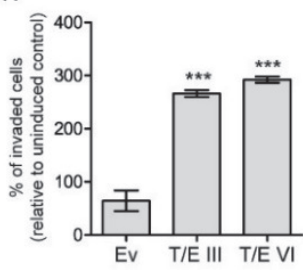

Figure 2.1: Stable T/E variant overexpression in LNCaP cells. (A) Structure of T/E gene fusion variants III and VI; TMPRSS2 (RefSeq NM_005656), ERG (RefSeq NM_004449.4). Downward pointing arrowheads: position of ERG fusion break point in T/E III (white) and T/E VI (black). Upward black pointing arrowhead: translation initiation codon. Protein domains: PNT, pointed domain (a protein-protein interaction site); NID, N-terminal inhibitory domain; Ets, Ets-DNA binding domain; CAD, C-terminal activator domain. (B) qPCR of Dox-induced $E R G$ expression in T/E III and T/E VI compared to uninduced cells. $\triangle C p$ values from three independent experiments are shown relative to GAPDH. (C) Western blot analysis of ERG and AR expression in empty vector (Ev), T/E III and T/E VI LNCaP cells, respectively. GAPDH served as protein loading control. (D) Morphological changes induced by Dox-mediated ERG overexpression in T/E III and T/E VI and control LNCaP cells. Pictures were taken at 20-fold magnification after $72 \mathrm{~h}$ Dox induction. (E) Cell growth was measured by a WST-1 assay at the indicated time points after pre-treatment with Dox (three independent experiments). (F) Cell cycle analysis using flow cytometry with propidium iodide (PI) staining. T/E III, T/E VI and empty vector cells were either not treated (-) or treated with Dox (+) and analysed $72 \mathrm{~h}$ post induction. Data are shown as percent positive staining cells \pm s.d. of three independent experiments. (G-H) Quantification of $(\mathrm{G})$ migrated, and $(\mathrm{H})$ invaded T/E expressing cells with a transwell chamber assay. Eight microscopic fields per treatment were analysed and results of three independent experiments are shown. Ev - Empty vector; ns - not significant. 


\section{T/E overexpression confers oncogenic properties to LNCaP cells}

The impact of T/E overexpression on LNCaP cells was analysed using proliferation, migration and invasion assays. T/E overexpressing cells showed reduced proliferation from $48 \mathrm{~h}$ to $96 \mathrm{~h}$ post induction (Figure 2.1E). After $72 \mathrm{~h}$, a decreased number of cells in S- and G2-phase and an increased number in G1-phase was observed (Figure 2.1F) for both T/E III and VI variants. No apoptotic cells were detectable in the sub-G1 fractions. Thus, T/E overexpression induced cell cycle changes leading to the accumulation of cells in G1 phase and reduced cell proliferation without evidence of apoptosis. T/E expressing LNCaP cells migrated and invaded significantly faster compared to uninduced or empty vector controls (Figure 2.1G and $1 \mathrm{H}$ ). The migration rate was higher in T/E VI compared to T/E III cells (Figure 2.1G).

Overexpression of T/E III and VI variants reveal transcriptional programs associated with TGF-B signaling

The transcriptional programs regulated by T/E overexpression were investigated by microarray expression profiling on 48,107 genes (GEO accession GSE78032). Differentially expressed genes $(>|1.5|$ fold change; $p<0.05)$ compared to empty vector control ( $n=4,429$; Supplementary Table S2.2) were selected for further analysis using the Ingenuity Pathway Analysis (IPA) program. Of the 2,205 genes, which were altered in both T/E III and VI variants (T/E intersection; Supplementary Table S2.2), 94\% showed concordant expression changes, indicating a high degree of accordance between the variants. The number of distinct genes found after T/E III or VI overexpression (T/E III only and T/E VI only) was 418 and 1,806, respectively (Supplementary Table S2.2).

Comparison of differential mRNA expression between LNCaP-T/E cells and T/E-positive ex vivo tumors [13] revealed 30\% (37/126) overlap, including the genes Tudor Domain Containing 1 (TDRD1), Cluster of Differentiation 24 (CD24), BMP And Activin MembraneBound Inhibitor $(B A M B I)$, and Cyclin-Dependent Kinase 1 (CDK1) [13]. Furthermore, transcriptional changes in T/E overexpressing cells were consistent with the expected transcriptional response to $E R G$ overexpression based on previous findings. For example, AR and the androgen-responsive genes TMPRSS2 [5, 18], SLC45A3 [5, 18, 19], $A C P P[19]$, and $M S M B[5,19]$ were downregulated, whereas genes known to be activated by ERG, e.g. PLAT [18], PLA1A [5], and MMP1 [20] were upregulated. These data indicated that our $\mathrm{T} / \mathrm{E}$ expressing cell models faithfully reflected the transcriptional regulation in T/E-positive tumors and are suitable to study the biology of these fusion variants.

GO analysis in IPA using the T/E intersection $(n=2,205)$ showed that genes associated with cell proliferation and interphase were downregulated (Supplementary Table S2.3), which was in agreement with the reduced proliferative ability of LNCaP-T/E cells (Figure 
2.1E). 'Estrogen-mediated S-phase Entry' was identified among the top significantly enriched canonical pathways (Supplementary Table S2.4). This corresponded to the accumulation of the T/E overexpressing cells in G1 phase (Figure 2.1F). Consistent with the increased number of migrated and invaded cells found in the transwell assays (Figure $2.1 \mathrm{G}$ and $2.1 \mathrm{H}$ ), genes belonging to the category 'Cell invasion' were primarily upregulated (Supplementary Table S2.3).
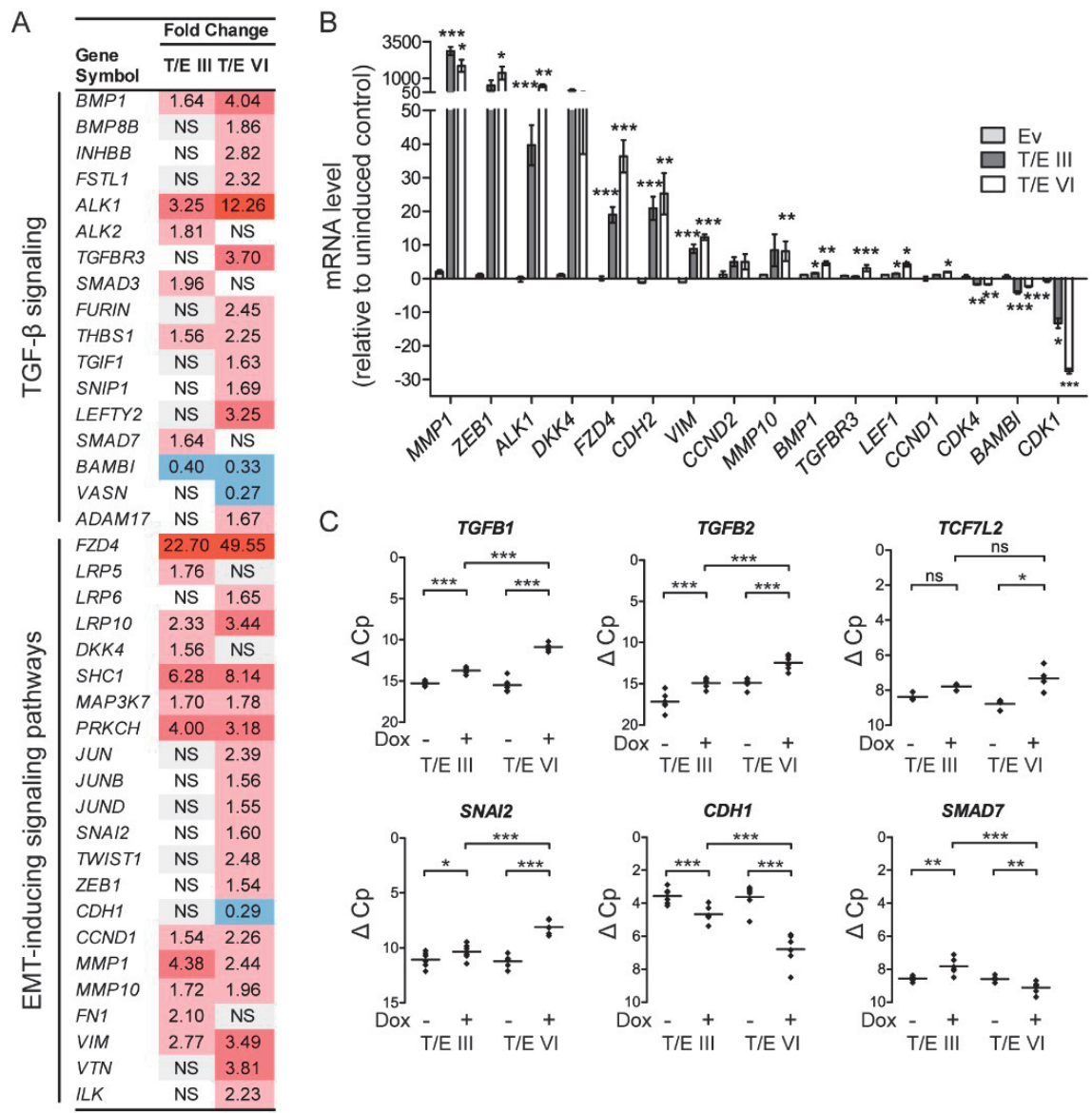

Figure 2.2: Transcriptional modulation in LNCaP-T/E cells. (A) Microarray gene expression data indicating activated TGF- $\beta$ and EMT-inducing signaling pathways in T/E expressing cells. (B-C) qPCR validation of T/Einduced gene expression changes associated with an EMT profile. (B) mRNA expression after T/E induction relative to uninduced controls. (C) mRNA levels of selected targets showing prominent transcriptional modulation in T/E III and VI overexpressing cells. Data are shown as $\triangle \mathrm{Cp}$ values relative to GAPDH measured in the same samples, which had been used for the microarray analysis. Ev - Empty vector; Red - upregulated; blue downregulated; NS - not significant. 
To study potential mechanisms regulating transcriptional changes associated with increased migration and invasion in LNCaP-T/E cells, an upstream regulator analysis was performed with the T/E intersection dataset (Supplementary Table S2.2). The analysis revealed transforming growth factor beta 1 (TGFB1) as an upstream regulator of 284 genes that were directly associated with TGFB1 regulation (Supplementary Table S2.4). These results indicated that TGF- $\beta$ signaling plays a crucial role in T/E overexpressing cells as previously suggested by us [13]. Evidence for activated TGF- $\beta$ signaling in the differentially expressed gene set $(n=4,429)$ was provided by upregulation of several TGF- $\beta$ pathway-specific genes, e.g. bone morphogenetic protein 1 (BMP1), or downregulation of negative regulators of TGF- $\beta$ signaling, such as the pseudoreceptor $B A M B I$ (Figure 2.2A). Activation of noncanonical TGF- $\beta$ signaling was evident by upregulation of SMAD-independent molecules involved in the ERK, JNK/p38 and PI3K/AKT pathways (Figure 2.2A). We also found upregulation of EMT-inducing transcription factors (SNAI2, ZEB1), mesenchymal markers (FN1, VIM, VTN) and matrix metalloproteinases (MMP1, $M M P 10)$, and downregulation of E-cadherin (CDH1) (Figure 2.2A), again supporting our finding that $T / E$ expressing cells lose epithelial characteristics and acquire a mesenchymal phenotype. Of note, the upregulated genes included the type I TGF- $\beta$ receptor Activin A Receptor Like Type 1 (ACVRL1, also known as ALK1) (Figure 2.2A), as well as the WNT receptor Frizzled 4 (FZD4) and its co-receptors $L R P 5$ and LRP6 (Figure 2.2A), suggesting that these receptors might be mediators of transcriptional changes leading to EMT in T/E overexpressing cells.

Validation of the microarray data by GPCR verified the strong upregulation of $A L K 1$ and FZD4 in both LNCaP-T/E variants (Figure 2.2B) as well as upregulation of EMT-inducing components and downregulation of genes negatively associated with TGF- $\beta$ signaling (Figure 2.2B). Notably, the validation confirmed the strong upregulation of the selected EMT inducing ligands (TGFB1, 7.3-fold; TGFB2, 5.5-fold) and downstream effector genes (TCF7L2, 5.1-fold; SNAI2, 4.7-fold) in T/E VI cells, whereas CDH1 (4.3-fold) and SMAD7 (2.3-fold) were downregulated in T/E VI compared to T/E III expressing cells (Figure 2.2C).

\section{Distinct intracellular signaling molecules are regulated in T/E variants}

TGF- $\beta$ signaling is mediated by SMAD-dependent and -independent signaling pathways involving JNK/p38 MAPK and PI3K/AKT [21, 22]. Multiplex protein quantification using Luminex technology and Western blot (Figure 2.3) for TGF- $\beta$ signaling analysis revealed increased phosphorylation of p38 MAPK (T/E VI cells only; Figure 2.3A and 3B), AKT (T/E III cells only; Figure 2.3C, 2.3D and 2.3E), JNK (Figure 2.3F), and SMAD1/5 (Figure 2.3G) upon $\mathrm{T} / \mathrm{E}$ overexpression. Increased levels of $\mathrm{p}-\mathrm{SMAD} 1 / 5$ and $\mathrm{p}-\mathrm{p} 38$ were detectable $4 \mathrm{~h}$ after $\mathrm{T} / \mathrm{E}$ induction, concomitant with increasing ERG levels in T/E III and T/E VI cells. Increased phosphorylation of SMAD2 and 3 was not observed (data not shown). The increased AKT phosphorylation in T/E III, but not in T/E VI, expressing cells (Figure 2.3C, 2.3D and 2.3E) went along with the increasing ERG expression as confirmed by quantitative analysis showing the pAKT/AKT ratio in induced and uninduced cells, albeit this was not significant 
(Figure 2.3E). High basal levels of pAKT were observed in T/E III cells (Figure 2.3D). Activation of survival-associated processes corresponded to the functional annotation of the T/E gene set (Supplementary Table S2.3). TGF- $\beta$-mediated AKT activation has previously been proposed to overcome the growth-inhibitory effects of TGF- $\beta$ in BPH1 tumorigenic sublines [23]. Taken together, these findings provided evidence for increased TGF- $\beta$ signaling in both T/E variants, as well as an activated AKT dependent survival network upon T/E III overexpression, that might act together to induce EMT in this PCa cell model.

A
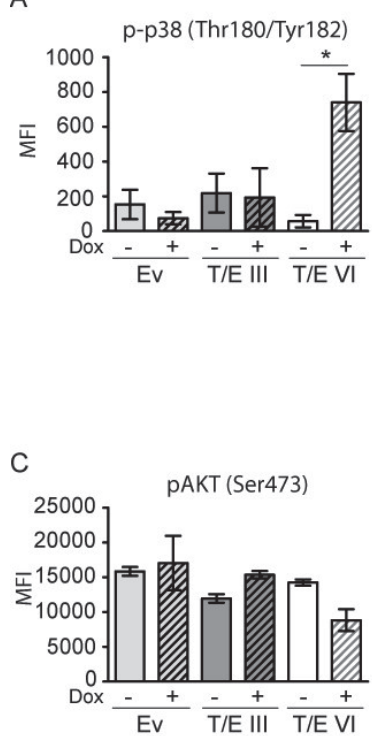

$\mathrm{F}$

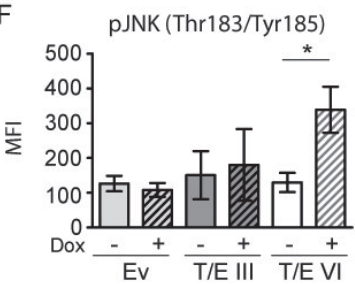

B

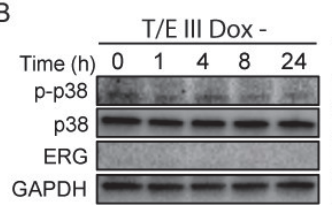

\begin{tabular}{lll} 
T/E III Dox + \\
\hline $14 \quad 8 \quad 24$
\end{tabular}
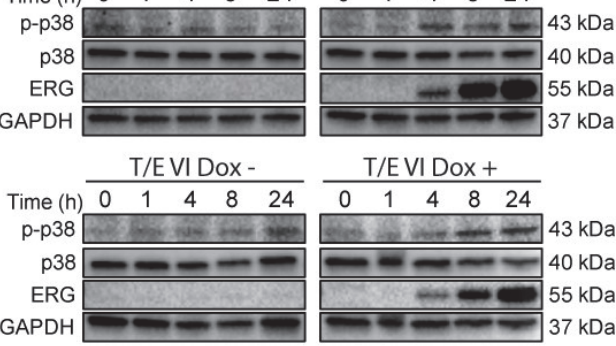

T/E VIDox +

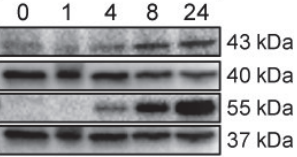

D
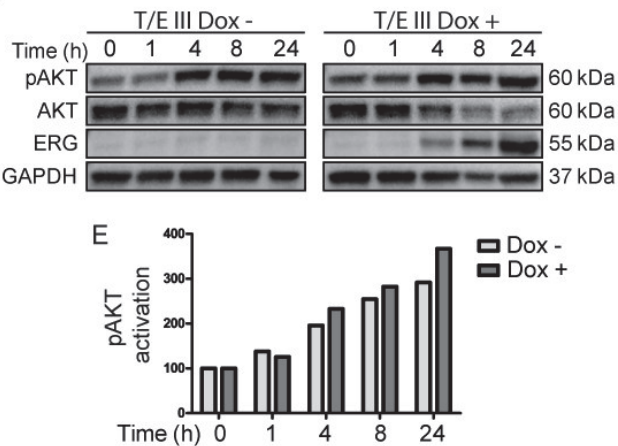

G

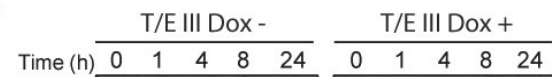

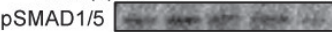

SMAD1

ERG

GAPDH

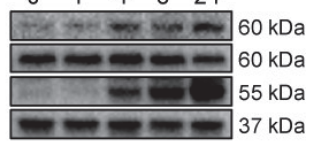

Figure 2.3: Signaling pathways in T/E expressing cells. Activation of signaling molecules ( $p 38, A K T$, JNK, and SMAD1/5) in T/E expressing cells measured by Luminex technology (A, C, F), and Western blot analysis (B, D, $\mathrm{G})$. For Western blot analysis, GAPDH served as loading control. Increased p38 phosphorylation (Thr180/Tyr182) was evident in T/E III (B) and T/E VI (A, B) cells. T/E III cells showed increased AKT phosphorylation (Ser473) (C, D). (E) pAKT/AKT ratios after densitometric analysis of Western blot bands of (D). (F) Increased JNK phosphorylation (Thr183/Tyr185) was revealed in T/E VI cells. Increased pSMAD1/5 phosphorylation (Ser463/465) was evident in (G) T/E III cells. 
Soluble TGF-B is produced by T/E overexpressing cells

Increased TGFB1 and -2 levels in T/E overexpressing cells motivated us to test whether TGF- $\beta$ is secreted to act in an autocrine manner. Active TGF- $\beta$ was measured in cell-free conditioned medium using Luminex immunoassays $72 \mathrm{~h}$ after Dox induction. T/E III and VI overexpressing cells displayed considerably increased TGF- $\beta 1$ (7-fold and 2-fold, respectively) and TGF- $\beta 2$ (6-fold and 3 -fold, respectively) protein compared to controls (Figure 2.4A). Thus, T/E overexpression induced secretion of TGF- $\beta 1$ and TGF- $\beta 2$. SiRNAmediated $E R G$ knockdown in the $\mathrm{NCl}-\mathrm{H} 660 \mathrm{PCa}$ cell line carrying both T/E fusion variants III and VI [17] reduced TGFB1 mRNA levels (Figure 2.5A), further supporting the T/Emediated upregulation of TGF- $\beta$ ligands. Moreover, siRNA-mediated TGFB1 knockdown in T/E III and VI cells led to upregulation of the negative TGF- $\beta$ regulators $B A M B I$ (in T/E III and VI cells) and SMAD7 (only in T/E VI cells, Figure 2.4B and $2.4 \mathrm{C}$ ), indicating that TGFB1 plays a role in T/E-induced TGF- $\beta$ signaling.

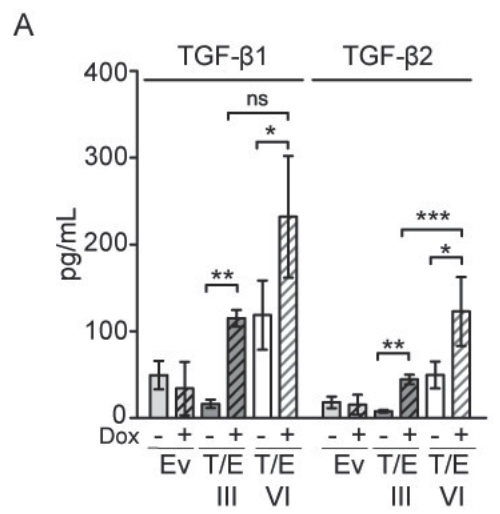

B

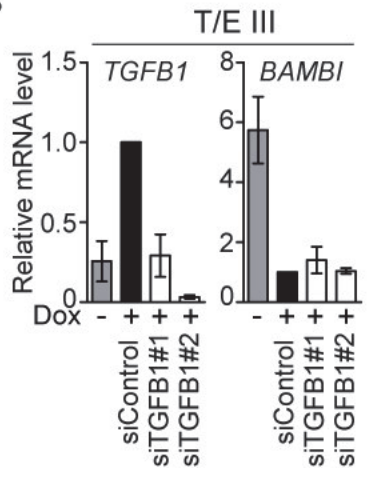

C

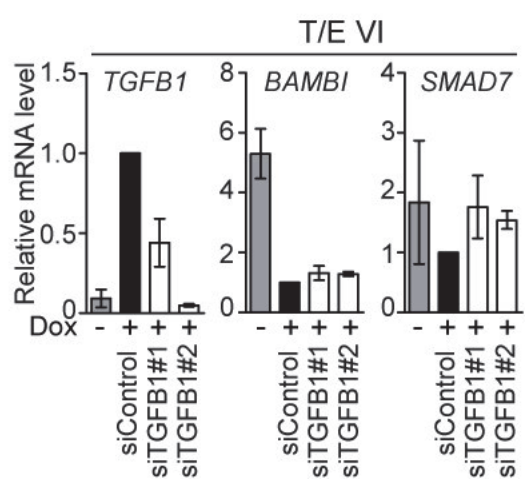

Figure 2.4: TGF- $\beta$ signaling in LNCaP-T/E cells. (A) TGF- $\beta 1$ and TGF- $\beta 2$ released into the medium was determined in cell-free conditioned medium derived from Dox-induced (+) and uninduced (-) LNCaP-T/E cells, respectively. All Luminex results are presented as MFI (mean fluorescent intensity) values \pm s.d. of three independent experiments. Ev - Empty vector. (B-C) siRNA-mediated knockdown of TGFB1 using 20nM siRNA show upregulation of $B A M B I$ in (B) T/E III and (C) T/E VI cells and additionally SMAD7 in T/E VI cells (C) as determined by qPCR. 


\section{ALK1 signaling regulates $p 38$ MAPK and EMT markers}

Since ALK1 mRNA was strongly upregulated in T/E overexpressing cells (40-fold in T/E III and 500-fold in T/E VI cells; Figure 2.2B), we analysed this pathway in more detail. ERG knockdown in $\mathrm{NCl}-\mathrm{H} 660$ cells led to reduced ALK1 mRNA levels (Figure 2.5A) confirming the association between ERG and ALK1 expression. Next, Dox-induced LNCaP-T/E cells were incubated with a human recombinant decoy receptor (rhALK1) [24] or the ALK1 inhibitor K02288 [25]. Disruption of ALK1 signaling using rhALK1 (Figure 2.5B, and 2.5C) or K02288 (Figure 2.5F and 2.5G) resulted in reduced p38 phosphorylation. As expected $[26,27]$, the inhibitor of differentiation 1 (ID1), and ID2 genes were upregulated after ERG induction, but reduced after rhALK1 (Figure 2.5D and 2.5E) or K02288 (Figure 2.5H and 2.5I) treatment. These data suggested that T/E overexpression induces ALK1signaling and supported the concept that ALK1-mediated phosphorylation of p38 confers mesenchymal transformation of PCa cells. In line with this, rhALK1-mediated inhibition of ALK1 signaling led to reduced expression of MMP1 (52\% reduction) in T/E III (Figure 2.5D), and MMP1, VIM, and SNAI2 (39\%, 22\%, and 5\% reduction, respectively) in $\mathrm{T} / \mathrm{E} \mathrm{VI}$ cells (Figure 2.5E). ALK1 inhibition by K02288 also resulted in reduced expression of MMP1 and $C D H 2$ (35\% and 61\% reduction, respectively) in T/E III (Figure 2.5H) and MMP1, CDH2, VIM, and SNAI2 (72\%, 50\%, 40\%, and 48\% reduction, respectively) in T/E $\mathrm{VI}$ overexpressing cells (Figure 2.5I). 

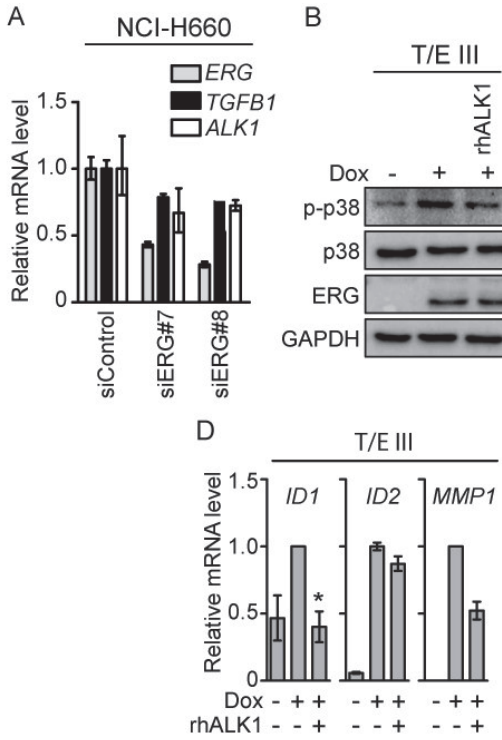

F

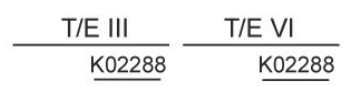

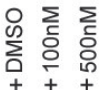

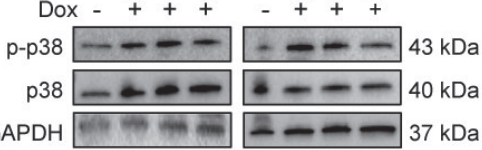

E
C
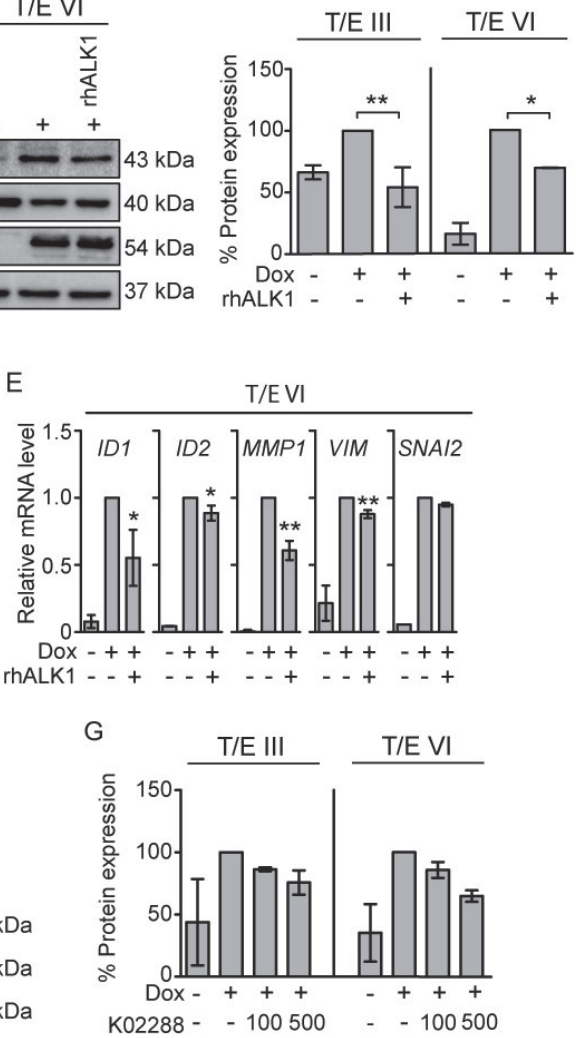

(nM)

I

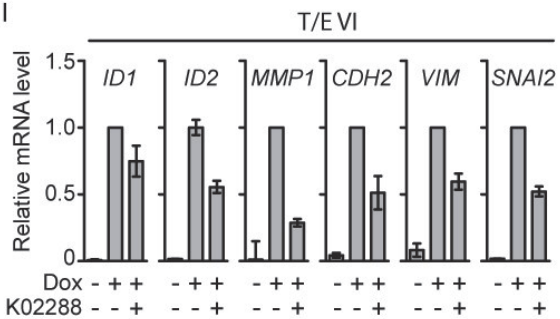

Figure 2.5: ALK1 inhibitors decrease T/E-induced ALK1 signaling. (A) ERG knockdown in NCl-H660 cells (50nM of siRNA) showed reduced levels of TGFB1 and ALK1. (B) Western blot analysis in LNCaP-T/E cells revealed reduced p38 phosphorylation after treatment with rhALK1 $(5 \mu \mathrm{g} / \mathrm{mL})$ compared to PBS-treated control cells. (C) pp38/p38 ratios after densitometric analysis of Western blot bands shown in (B) in T/E III and T/E VI cells, respectively. (D-E) Expression levels of TGF- $\beta$-responsive genes in (D) T/E III and (E) T/E VI expressing cells after rhALK1 treatment $(5 \mu \mathrm{g} / \mathrm{mL})$ determined by qPCR. (F) Western blot analysis of p38 phosphorylation after treatment with $\mathrm{K} 02288$ (at indicated concentrations) compared to DMSO-treated control cells. (G) p-p38/p38 ratios after densitometric analysis of Western blot bands shown in (F) of T/E III and T/E VI cells, respectively. $(\mathrm{H}-\mathrm{I})$ Expression levels of TGF- $\beta$ /BMP-responsive genes in (H) T/E III and (I) T/E VI expressing cells after simultaneous treatment with Dox and K02288 (500nM) were determined by qPCR. 


\section{$T /$ E overexpression activates 6 -catenin signaling in prostate cancer cells}

WNT/ $\beta$-catenin and TGF- $\beta$ signaling pathways share key molecules (p38 MAPK, SNAI1/2, ZEB1/2 [16]) and can synergistically induce changes associated with EMT. Since we had identified an EMT transcriptional signature and upregulation of the WNT/ $\beta$-catenin target genes in T/E overexpressing cells (Figure 2.2A, 2.2B and 2.2C), we characterized signaling downstream of WNT in more detail. Overexpression of both T/E variants led to increased $\beta$-catenin signaling (Figure 2.6A), which was 2.4-fold higher in T/E VI compared to $T / E$ III overexpressing cells. To test whether induction of gene expression was mediated by FZD4 upregulation, we incubated cells with rhFZD4. Disruption of FZD4signaling showed a clear reduction of p38 phosphorylation in T/E III and T/E VI cells by Western blot (Figure 2.6B), and band quantification (Figure 2.6C). Further, we observed reduced MMP1, VIM, and CDH2 levels in T/E III and VI (Figure 2.6D and 2.6E) and additionally reduced SNAI2 in T/E VI cells (Figure 2.6E). These data suggest that FZD4induced oncogenic effects of $\mathrm{T} / \mathrm{E}$ overexpression are mediated by $\mathrm{p} 38$.
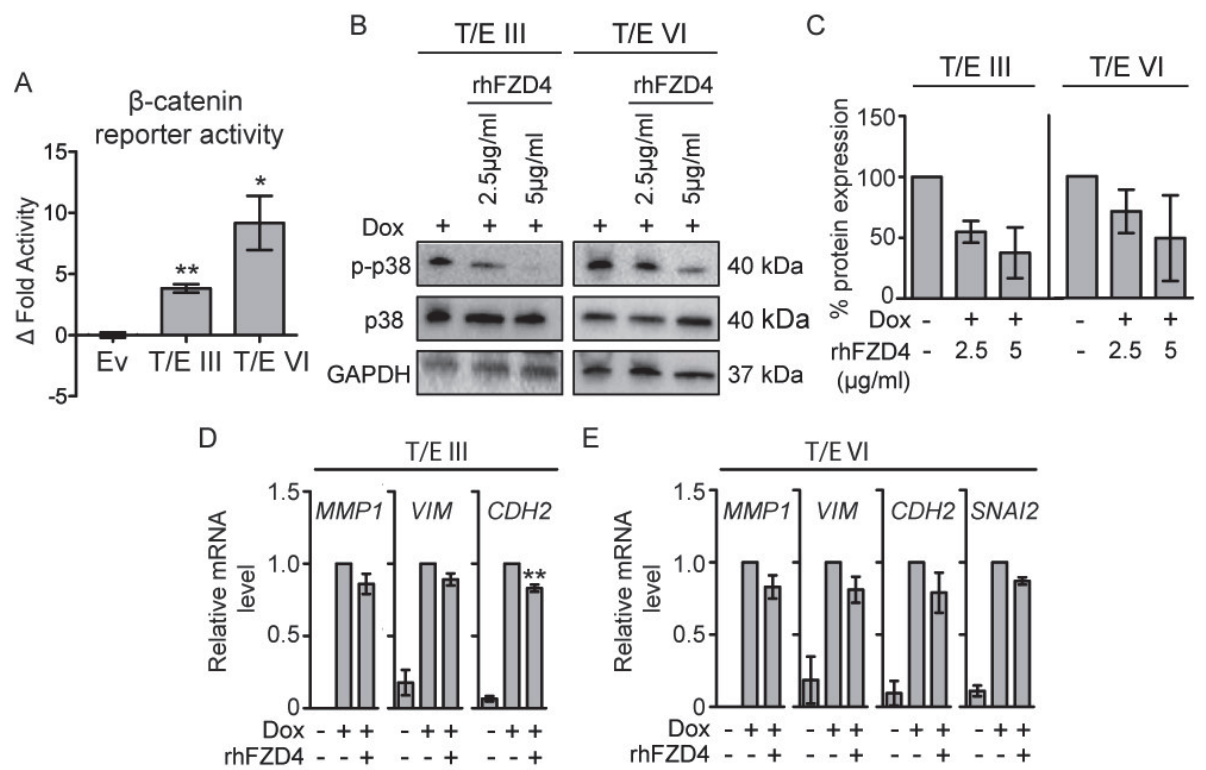

Figure 2.6: T/E expression induces FZD4-mediated $\beta$-catenin signaling in LNCaP cells. (A) TOPflash luciferase activity $72 \mathrm{~h}$ post induction. Mean \pm s.d. of three independent experiments are shown. TOPflash activity was normalized to mutant FOPflash activity and relative to uninduced clones. (B-E) Effects of FZD4-specific inhibition using rhFZD4 for $48 \mathrm{~h}$ compared to PBS-treated control cells. (B) Phosphorylation of $\mathrm{p} 38$ was measured by Western blotting and p-p38/p38 (C) ratio was determined after band analysis of (B). (D-E) EMT target gene expression after rhFZD4 treatment $(5 \mu \mathrm{g} / \mathrm{mL})$ was assessed by qPCR in T/E III (D) and T/E VI (E) cells. Ev Empty vector. 
To dissect the sequence of transcriptional changes upon $E R G$ overexpression, a time course experiment was performed in T/E expressing cells (Figure 2.7). ERG mRNA values showed a rapid increase ( $\sim 10$-fold after $1 \mathrm{~h}, \sim 100$-fold after $4 \mathrm{~h}$ of Dox-induction) in T/E III (Figure 2.7A) and T/E VI cells (Figure 2.7D). A strong increase in ALK1 mRNA, and to a lesser extent FZD4 mRNA, were observed after 8h (Figure 2.7A and 2.7D) suggesting that ERG protein expression, which was detectable after $4 \mathrm{~h}$ (Figure 2.3B, D, G), preceded mRNA expression of those receptors. The expression levels of ZEB1 and MMP1 showed a very strong upregulation after 12h (ZEB1: 450-fold in T/E III and 1500-fold in T/E VI cells; MMP1: 35,000-fold in T/E III and 6,600-fold in T/E VI cells) (Figure 2.7B and 2.7E, respectively). The expression of VIM was induced after $24 \mathrm{~h}$ of Dox-treatment (Figure 2.7A and 2.7D, respectively). These findings indicated that the dynamic transcriptional changes of EMT marker expression were preceded by a first wave of ERG overexpression and a second wave of increased $A L K 1$ and FZD4 expression. Genes, that were negatively associated with TGF- $\beta$ signaling $(B A M B /)$ or associated with epithelial characteristics of LNCaP cells $(A R, C D H 1)$, showed a continuous decrease in expression after $4 \mathrm{~h}$ of Dox-induction (Figure $2.7 \mathrm{C}$ and $2.7 \mathrm{~F}$ ). Of note, in T/E VI cells, BAMBI mRNA levels started to replenish after $48 \mathrm{~h}$ of Dox-induction (Figure $2.7 \mathrm{~F}$ ), together with a declining ALK1 level (Figure 2.7D). A similar effect was observed in T/E III cells, although at a lower level. By integrating the time course regulatory network with the previously modeled end-point measurements (Figure 2.3), we highlighted the dynamics of cellular activity leading to EMT upon ERG overexpression in LNCaP cells.
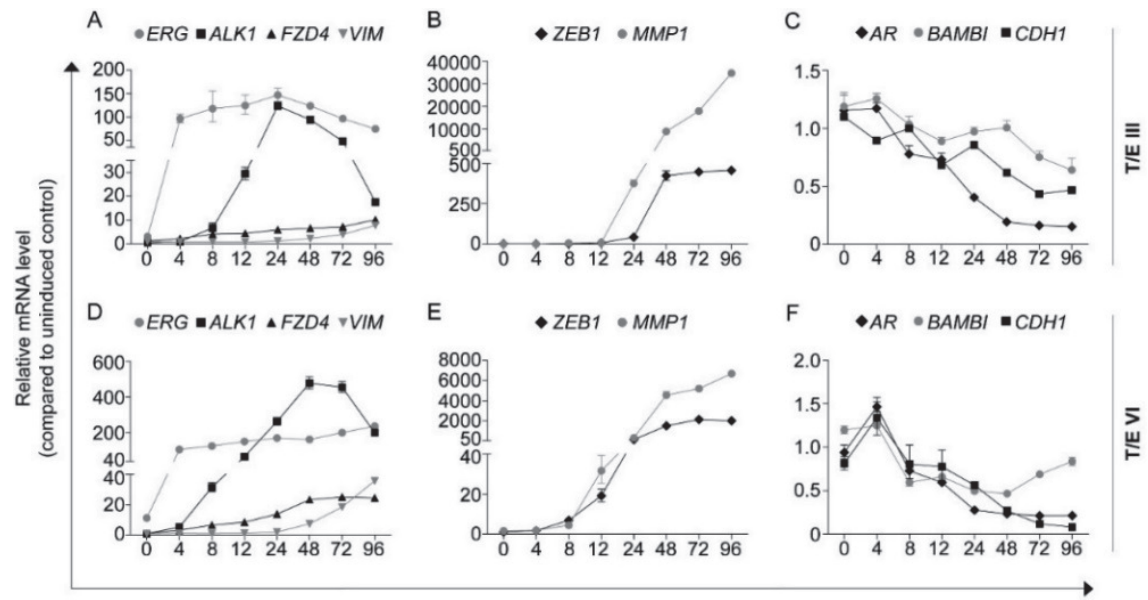

Time (h)

Figure 2.7: Time course experiment of selected ERG downstream targets. (A-C) T/E III and (D-F) T/E VI cells were treated with Dox for the indicated time points (0-96h). Samples were collected and mRNA expression was determined using qPCR. Expression levels are shown relative to uninduced controls at each time point. Upon Dox-induction, ERG mRNA levels show a rapid increase in (A) T/E III and (D) T/E VI cells. Subsequently, an increase in $A L K 1$ and FZD4 mRNA levels are observed after 8h, followed by upregulation of the EMT marker $(A, D) V I M,(B, E) Z E B 1$ and MMP1. Genes that are negatively associated with EMT or TGF- $\beta$ signaling are repressed upon Dox-induced $E R G$ overexpression in (C) T/E III and (F) T/E VI expressing cells. 
Upregulation of miR-503 in T/E VI cells promotes EMT by targeting SMAD7

We further aimed to identify determinants of the stronger activation of EMT regulating pathway genes in T/E VI expressing cells. We focused on miR-503, which was strongly upregulated in the T/E VI only ( 7-fold), but not in the T/E III only microarray dataset (Supplementary Table S2.2). A search for potential miR-503 targets using in silico prediction algorithms showed that miR-503 can target SMAD7 [28], which was downregulated in T/E VI, but upregulated in T/E III cells. We therefore hypothesized that miR-503 might be a candidate modulating the biological activity of the T/E VI fusion variants. To test whether miR-503 could augment EMT, we transiently overexpressed and inhibited miR-503 in T/E III and T/E VI cells using miR-503 mimics and inhibitors, respectively. Only induced T/E VI cells displayed significant upregulation of miR-503, which was further increased by simultaneous miR-503 overexpression (Figure 2.8A). Key EMT markers like VIM and MMP1 were upregulated in T/E-induced cells and were further increased after miR-503 overexpression (Figure 2.8B). Inhibition of miR-503 upon induction of $\mathrm{T} / \mathrm{E} \mathrm{VI}$ expression led to a reduction of VIM (Figure 2.8B). The consequences of miR-503 overexpression, inhibition on SMAD7 and $\mathrm{CDH} 1$ quantities as surrogate for a mesenchymal phenotype, were examined by Western blot analysis. MiR-503 overexpression led to decreased SMAD7 and CDH1 expression in T/E VI cells (Figure 2.8C and 2.8D). These results suggested that T/E VI-mediated overexpression of miR-503 plays an important role in increasing EMT effectors and that miR-503 can promote invasion of T/E $\mathrm{VI}$ expressing cells by affecting CDH1 expression. Furthermore, TGFB1 knockdown in T/E $\mathrm{VI}$ cells showed reduced expression of miR-503 (Figure 2.8E), suggesting that the expression of miR-503 is regulated by TGF- $\beta$, thereby contributing to enhanced TGF- $\beta$ signaling by inhibition of SMAD7 [29]. The varying SMAD7 levels are consistent with the observed differences in TGF- $\beta$ and WNT/ $\beta$-catenin signaling activity between T/E III and T/E VI cells. 
A

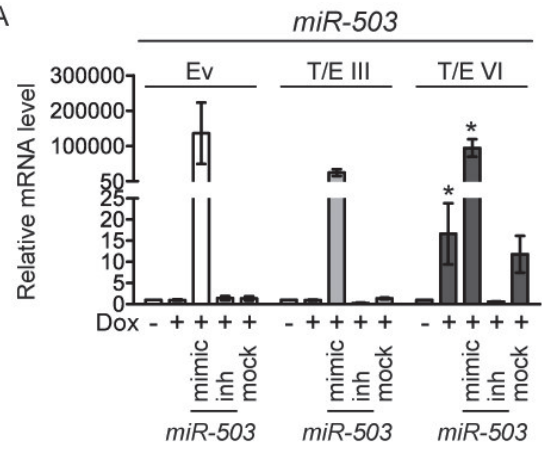

B

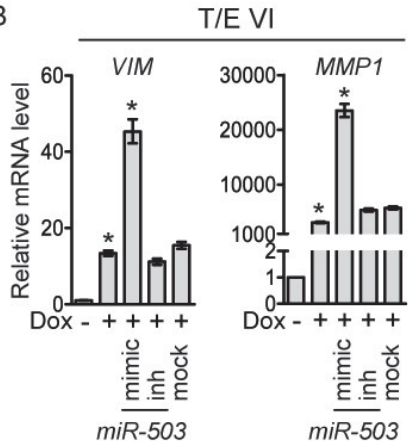

C

\begin{tabular}{|c|c|c|}
\hline Ev & T/E III & T/E VI \\
\hline miR-503 & miR-503 & miR-503 \\
\hline mimic inh mock & mimic inh mock & mimic inh mock \\
\hline
\end{tabular}

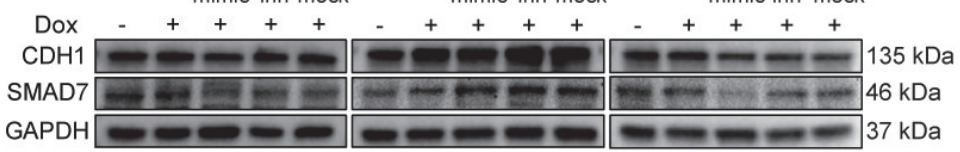

D

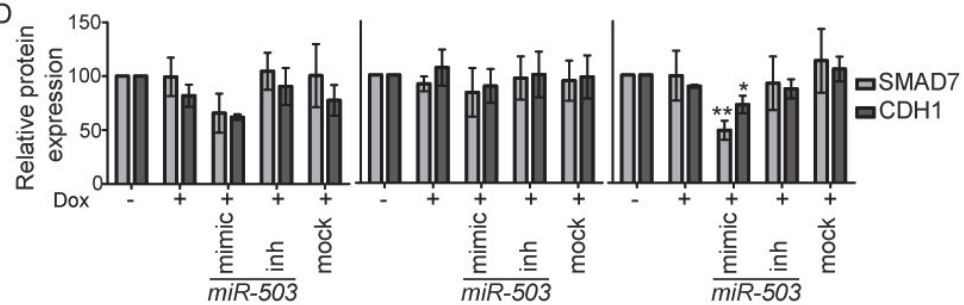

E

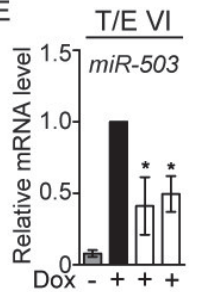

을

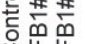

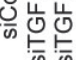

Figure 2.8: MiR-503 overexpression in T/E VI cells inhibits SMAD7 and CDH1. (A) qPCR analysis of miR-503 expression relative to $R N U 6 B$. Values are presented as mean \pm s.d. of three independent experiments. (B) qPCR determination of VIM and MMP1 expression in T/E VI expressing cells relative to GAPDH. (C) Western blot analysis of SMAD7 and CDH1 protein expression in T/E cells. Representative results of three independent Western blot experiments are shown. (D) Quantitative analysis of protein expression relative to GAPDH is presented as mean \pm s.d. of three independent experiments. (E) miR-503 expression upon siRNA-mediated knockdown of TGFB1 (20nM) in T/E VI cells was determined by qPCR. Mimic - hsa-miR-503-5p mimic (used at 10nM), inh - hsa-miR-503-5p inhibitor (used at 100nM).

\section{DISCUSSION}

Previously, we reported that transcriptional changes in T/E-positive tumors are associated with deregulated TGF- $\beta / B M P$ and WNT signaling pathways [13]. Here, by deploying inducible T/E overexpression in LNCaP cell models, we show that overexpression of two distinct $T / E$ variants induce common as well as unique signaling programs that are able to lead the cells into EMT. Upon T/E overexpression, the cells acquire mesenchymal, fibroblast-like morphologies [30]. On the molecular level, this is accompanied 
by downregulation of $A R$, suggesting that $E R G$ disrupts a lineage-specific differentiation program of prostate cells $[18,19]$, and upregulation of EMT effector genes, like MMP1 and VIM, which are correlated with poor PCa tissue differentiation [31] and metastasis formation [32]. Furthermore, upregulated EMT-associated genes included the transcription factors ZEB1 [30] and TCF/LEF-1 [33], as well as TGFB1 and -2 [34]. We also show that $T / E$ overexpression significantly enhances the invasion capability of LNCaP cells. These results are in agreement with the role of T/E overexpression in promoting cell invasion via induction of matrix metalloproteinase and plasminogen activator genes [3, $5,12]$. Global gene expression analysis of $\mathrm{T} / \mathrm{E}$ overexpressing cells led to significantly overrepresented GO categories (proliferation and invasion), which correlated with the observed cellular phenotype. We further found many components of known signaling pathways, including JNK/p38 MAPKs, AKT and SMAD1/5, to be deregulated (Figure 2.9). Importantly, TGFB1 was identified as a regulator gene of T/E-induced transcriptional changes, which again supports our previous ex vivo data [13]. Increased TGF- $\beta$ expression has been shown to induce a tumor-promoting phenotype [35] and metastatic dissemination [36]. TGF- $\beta$ /BMP signaling is well known for its role in bone remodeling and metastasis formation in breast cancer [35] and could therefore play a similar role in PCa. Bone metastasis is common in PCa [37], and expression of TGF- $\beta$ in PCa is correlated to metastasis and survival [38]. Intriguingly, serum TGF- $\beta$ concentrations are elevated in PCa patients with bone metastases [39]. Furthermore, TGF- $\beta$ protein and RNA expression was higher in bone metastases compared to visceral metastases in rapid autopsy specimens of patients who died of metastatic PCa and was associated with a fibroblastlike phenotype [40]. We therefore propose that T/E-induced TGF- $\beta$ secretion could have autocrine effects promoting tumor progression.

The T/E variants III and VI deploy two routes of ERG-mediated oncogenic pathway activation (Figure 2.9). The first route is characterized by strong upregulation of the TGF- $\beta$ receptor $A L K 1$, which can be activated by various BMPs, in addition to TGF- $\beta 1$ and TGF$\beta 3[41,42]$. Inhibition of ALK1 in our model led to reduced phosphorylation of p38, downregulation of the EMT-markers VIM, MMP1, CDH2, and SNAI2, as well as reduced expression of ID1 and ID2, for which induction by ALK1 signaling is known [43]. ALK1induced expression of ID1 promotes tumor cell metastasis [44]. ID1 was shown to be involved in mesenchymal-to-epithelial transition (MET) of breast cancer cells during lung colonization after having undergone TGF- $\beta$-induced EMT [45]. High levels of ALK1 protein in tumor blood vessels can serve as a prognostic marker for metastatic disease in breast cancer patients [45]. In addition, the pharmacological inhibition of ALK1 was able to prevent metastatic dissemination and lung colonization in mouse models of endocrine pancreatic and mammary carcinomas $[45,46]$. The high upregulation of $A L K 1$ in T/E expressing cells in our study was accompanied by augmented levels of TGF- $\beta 1$ and TGF- $\beta 2$ mRNA and protein, suggesting that autocrine TGF- $\beta$ signaling mediates ALK1 pathway activation and phenotypic cellular changes in T/E cells $[47,48]$. 


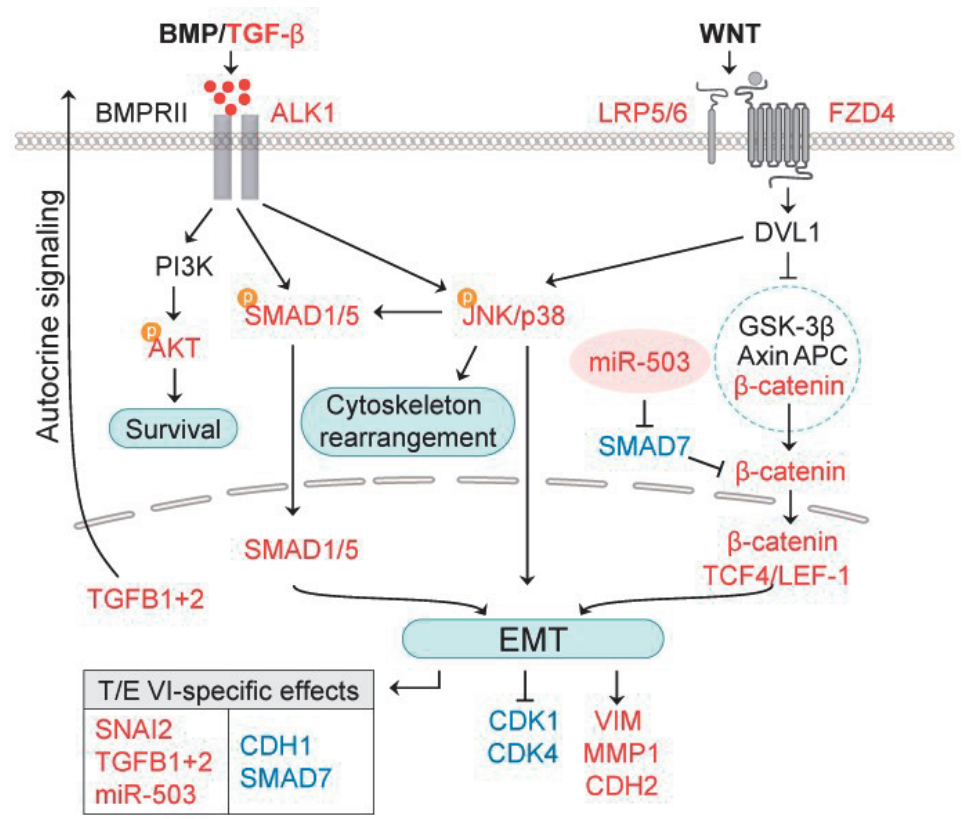

Figure 2.9: Working model for T/E-induced effects on BMP/TGF- $\beta$ and WNT/ $\beta$-catenin signaling pathways. T/E VI variant-specific transcriptional modulation of miR-503 and SMAD7 leads to stronger activation of EMTregulating genes compared to T/E variant III. Red - upregulation; blue - downregulation.

The second route of T/E-induced signaling pointed towards FZD4 receptor-mediated WNT/ $\beta$-catenin signaling as an important element $[49,50]$. Evidence for the role of WNT signaling was seen in the upregulation of transcription factors of the $T$ cell factor/lymphoid enhancer family (TCF7L2, LEF1), increased $\beta$-catenin reporter activity and downregulation of the negative regulator $\mathrm{CDH} 1$ [51]. These effects were more profound in T/E VI, compared to T/E III, expressing cells. Importantly, FZD4 was upregulated upon $T / E$ overexpression, and inhibition of FZD4 led to reduced phosphorylation of p38. These results confirmed reports that loss of cell adhesion and EMT are associated with FZD4-induced activation of WNT signaling [49].

Our results further suggest that variant-specific transcriptional modulation is responsible for the differences in activation of EMT regulating pathway genes. Strikingly, we observed upregulation of miR-503 exclusively in T/E VI overexpressing cells. Overexpression of miR-503 was able to repress SMAD7, a known negative regulator of TGF- $\beta$ and WNT/ $\beta$-catenin signaling [52]. Thus, the miR-503-mediated downregulation of SMAD7 in T/E VI, but not in T/E III cells, explains T/E VI variant-specific transcription. Recently, Li et al. could show that miR-503 downregulates SMAD7 expression and thereby enhances TGF- $\beta$ signaling and the metastatic capability of breast cancer cells 
[28]. SMAD7-mediated stabilization of $\beta$-catenin binding to E-cadherin turned out to increase cell-cell adhesion and formation of adherens junctions [53], thereby potentially blocking metastasis. Reduced expression of SMAD7 might account for the stronger increase of TGF- $\beta$ signaling and $\beta$-catenin reporter activity observed in T/E VI cells. Zhu et al. showed that stimulation of fibroblasts with recombinant TGF- $\beta$ results in a decreased expression of SMAD7 [54]. In agreement with previous reports in MCF-10A breast cancer cells [55], TGFB1 knockdown also decreased miR-503 expression. MiR-503mediated repression of SMAD7 therefore appears to be a way to escape the inhibitory effect of SMAD7 on TGF- $\beta$ and WNT/ $\beta$-catenin signaling. Although miR-503 expression was shown to be lower in metastatic compared to non-metastatic PCa xenografts [56], and several studies reported tumor suppressor properties of miR-503 [57, 58], in the context of T/E-induced TGF- $\beta$ signaling miR-503 overexpression has tumor-promoting effects.

In conclusion, our study identifies the TGF- $\beta / B M P$ and WNT/ $\beta$-catenin signaling pathways as molecular determinants underlying T/E-mediated EMT in PCa cells (Figure 2.9). We confirm that WNT/ $\beta$-catenin signaling in T/E cells is mediated by FZD4 and propose that miR-503 plays a crucial role in augmenting this process. We further demonstrate that TGF- $\beta$-ALK1-p38 signaling promotes EMT in T/E expressing cells. Our findings suggest that autocrine activation of ALK1 plays a role in PCa cells. This could provide a rational basis for ALK1-blocking agents (which are currently already tested in clinical studies in various malignancies $[59,60]$ ) to inhibit progression of T/E fusion-positive PCa. 


\section{ACKNOWLEDGEMENTS}

We thank Sabrina Gerhardt and Simon Ogrodnik for excellent technical assistance and Jan Mollenhauer for providing access to the LNCaP clones with modified Flp-In system. We thank the DKFZ Genomics and Proteomics Core Facility for performing Illumina Whole-Genome Expression Beadchips and associated statistical analyses.

\section{FUNDING}

This project was supported through intramural funding by the German Cancer Research Center.

\section{SUPPLEMENTARY INFORMATION}

Content

1. Supplementary material and methods

1.1. Supplementary Table S2.1

1.2. Supplementary methods

2. Supplementary figures

3. Supplementary tables

1. Supplementary material and methods

1.1. Supplementary Table S2.1: List of primer sequences

List of primers used for cloning

\begin{tabular}{ll}
\hline Name & Sequence $5^{\prime}-\mathbf{3}^{\prime}$ \\
\hline attB1_universal & ggggacaagtttgtacaaaaagcaggctccaccatg \\
attB2_universal & ggggaccactttgtacaagaaagctgggtc \\
ERG_T/E_III_For & ctcagcaggattggctgtct \\
ERG_T/E_III_Rev & tggttgagcagctttcgact \\
ERG_T/E_VI_For & gtgagtgaggaccagtcgtt \\
ERG_T/E_VI_Rev & tgatgcagctggagttggag \\
\hline
\end{tabular}


List of primers used for RT-PCR

\begin{tabular}{ll}
\hline Name & Sequence $5^{\prime}-$ 3' $^{\prime}$ \\
\hline T/E_III_for & ctcagcaggattggctgtct \\
T/E_III_rev & tggttgagcagctttcgact \\
T/E VI_for & gtgagtgaggaccagtcgtt \\
T/E VI_rev & tgatgcagctggagttggag \\
vec_empty_for & gttttgacctccatagaagacac \\
vec_universal_rev & caacagatggctggcaacta \\
\hline
\end{tabular}

List of primer sequences and probes used for qPCR

\begin{tabular}{|c|c|c|c|}
\hline Name & \#UPL probe & Sequence forward $5^{\prime}-3^{\prime}$ & Sequence reverse $5^{\prime}-3^{\prime}$ \\
\hline ACVRL1 & 71 & agacccccaccatcccta & cgcatcatctgagctaggc \\
\hline$B A M B I$ & 71 & cgccactccagctacatctt & cacagtagcatcgaatttcacc \\
\hline$B M P 1$ & 18 & ttcaaggcccacttcttctc & cataactgccgaacgtgttg \\
\hline CCND1 & 17 & gctgtgcatctacaccgaca & ttgagcttgttcaccaggag \\
\hline CCND2 & 49 & ggacatccaaccctacatgc & cgcacttctgttcctcacag \\
\hline $\mathrm{CDH1}$ & 84 & tggaggaattcttgctttgc & cgctctcctccgaagaaac \\
\hline $\mathrm{CDH} 2$ & 59 & tcaacaatgagactggtgacatc & tatgtgggattgccttccat \\
\hline$C D K 1$ & 79 & tggatctgaagaaatacttggattcta & caatcccctgtaggatttgg \\
\hline CDK4 & 25 & gtgcagtcggtggtacctg & ttcgcttgtgtgggttaaaa \\
\hline$D K K 4$ & 37 & aggaggtgccagcgagat & tgcatcttccatcgtagtacaaa \\
\hline$E R G_{-} T / E$ & 64 & ggttaatgcatgctagaaacaca & agatggttgagcagctttcg \\
\hline FZD4 & 19 & aactttcacaccgctcatcc & tgcacattggcacataaaca \\
\hline GAPDH & 60 & agccacatcgctcagacac & gcccaatacgaccaaatcc \\
\hline ID1 & 39 & ccagaaccgcaaggtgag & ggtccctgatgtagtcgatga \\
\hline ID2 & 5 & atatcagcatcctgtccttgc & aaagaaatcatgaacaccgctta \\
\hline$L E F 1$ & 79 & agatcaccccacctcttgg & atgagggatgccagttgtgt \\
\hline MMP1 & 26 & acgaatttgccgacagagat & gtccttggggtatccgtgta \\
\hline MMP1 & 7 & gctaacctttgatgctataactacga & tttgtgcgcatgtagaatctg \\
\hline MMP10 & 61 & gcaaaagaggaggactccaa & tcacatccttttcgaggttgta \\
\hline SMAD7 & 69 & acccgatggattttctcaaa & aggggccagataattcgttc \\
\hline SNAI2 & 73 & acagcgaactggacacacat & gatggggctgtatgctcct \\
\hline TCF7L2 & 10 & acgcctcttatcacgtacagc & gggtaatacggggatatatctgg \\
\hline TGFB1 & 72 & gcagcacgtggagctgta & cagccggttgctgaggta \\
\hline TGFB2 & 67 & ccaaagggtacaatgccaac & cagatgcttctggatttatggtatt \\
\hline TGFBR3 & 82 & gatttcatcttcggcttgaaa & gctcaggaggaatagtgtgga \\
\hline VIM & 13 & tacaggaagctgctggaagg & accagagggagtgaatccag \\
\hline ZEB1 & 3 & cagtgaaagagaagggaatgct & cttcaggccccaggattt \\
\hline
\end{tabular}




\subsection{Supplementary methods}

Generation of LNCaP cell models stably expressing T/E variants

First, CDNA fragments of the two TMPRSS2:ERG variants were amplified by RT-PCR from the ERG ORF plasmid (RefSeq NM_004449.4) (provided by the DKFZ Genomics and Proteomics Core Facility (GPCF)) and cloned into a Gateway entry vector using BP Clonase Enzyme Mix (Thermo Fisher Scientific, Waltham, MA, USA). Sequences of cloning primer pairs are listed in Supplementary Table S5. DNA fragments were transferred from the entry vector to an expression vector carrying the tet repressor gene (tetR) as well as a doxycycline (Dox)-regulated CMV/Tet operator (TetO) promoter by LR Clonase Mix (Thermo Fisher Scientific). In a second step, the LNCaP acceptor clone \#126 was generated by transfection with a vector carrying a Flp recombinase target (FRT) site. The single integration of the vector was verified by Southern blot hybridization, and the cells were selected for successful integration using neomycin resistance and green fluorescence as markers (Supplementary Figure S1A). Finally, LNCaP\#126 cells were cotransfected with a plasmid encoding the Flp recombinase, and the expression vector construct carrying a FRT site and the different target genes under control of the Doxregulated $\mathrm{CMV} /$ Tet operator (TetO) promoter. A HcRed expression construct served as proof for successive integration of transgenes into LNCaP\#126 (Supplementary Figure $\mathrm{S} 1 \mathrm{~A})$ by showing that upon disruption of the EGFP ORF green fluorescence was abolished. Induction of transgene expression by Dox for $72 \mathrm{~h}$ activated the red fluorescence reporter gene in this case, compared to the uninduced state. Subsequently, the target T/E sequence variants III and VI (Supplementary Figure S2), respectively, under control of the Dox-regulated CMV/Tet operator (TetO) promoter were integrated into the LNCaP\#126 cells in the same manner (LNCaP-T/E cells). 


\section{Supplementary Figures}
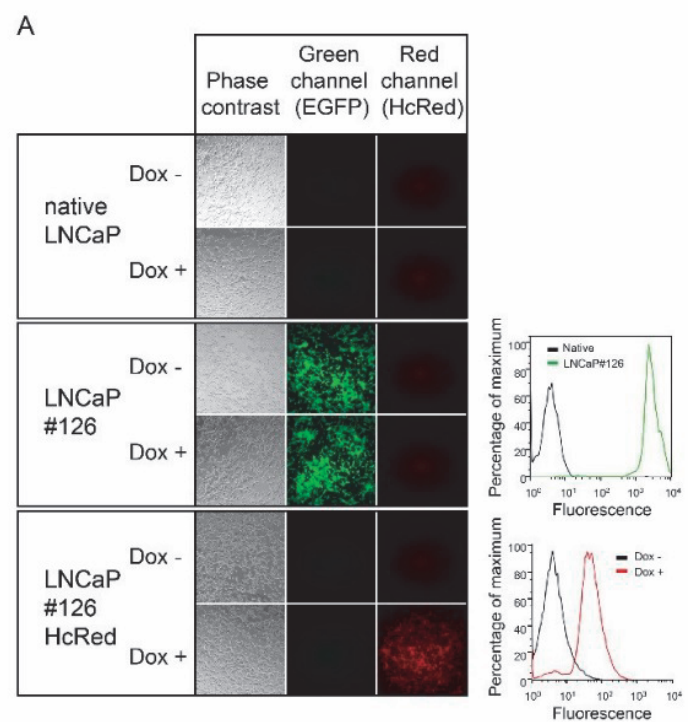

B

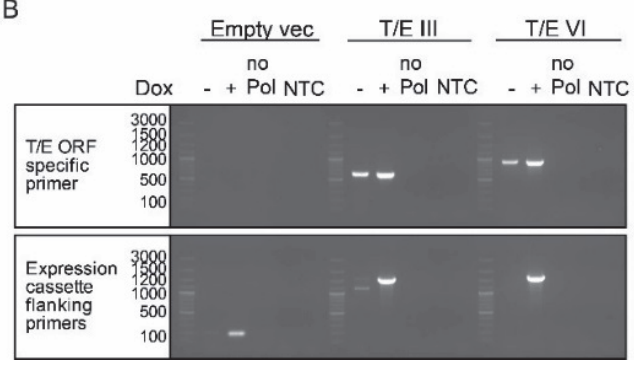

Supplementary Figure S2.1: Site-specific recombination-based system for generation of stably transfected LNCaP cells. (A) Fluorescence microscopy (left) and FACS analysis (right) of recombination events in LNCaP cells. Native LNCaP cells showing no fluorescence in both, green and red, channels (top left panel). LNCaP acceptor clone \#126 after selection for neomycin resistance and green fluorescence: LNCaP cells successfully integrated the acceptor plasmid leading to expression of EGFP independent of Dox (left middle panel and upper right panel). LNCaP cells stably recombined with a HcRed expression plasmid after selection for hygromycin resistance. Successful recombination and integration of the expression plasmid disrupted the EGFP ORF and abolished green fluorescence of the LNCaP acceptor clone. Induction of transgene expression by Dox for $72 \mathrm{~h}$ activated the red fluorescence reporter gene, compared to the uninduced state (left bottom panel). Fluorescence signal after induction depicts a homogeneous expression throughout the whole cell population (bottom right). Microscopic pictures were taken at 10-fold magnification. (B) Agarose gel electrophoresis of RT-PCR products after ERG overexpression in LNCaP empty vector and T/E clones III and VI, respectively. RTPCR products from amplification with T/E specific primers for integrated sequences (upper panel) and from amplification with flanking primers for the complete ORF including parts of the expression cassette (lower panel) from induced (+) and uninduced (-) cells. Expected sizes of T/E specific PCR products are 599bp, and 866bp for the T/E inserts III and VI, respectively. Expected sizes of PCR products from flanking primers are 1481bp, 1559bp and 209bp for T/E III, VI and the empty vector, respectively. no Pol: no Polymerase negative control, NTC: no template negative control. 


\section{T/E III}

ATGACCGCGTCCTCCTCCAGCGACTATGGACAGACTTCCAAGATGAGCCCACGCGTCCCTCAGCAGGATTGGCTGTCTCA ACCCCCAGCCAGGGTCACCATCAAAATGGAATGTAACCCTAGCCAGGTGAATGGCTCAAGGAACTCTCCTGATGAATGC AGTGTGGCCAAAGGCGGGAAGATGGTGGGCAGCCCAGACACCGTTGGGATGAACTACGGCAGCTACATGGAGGAGAA GCACATGCCACCCCCAAACATGACCACGAACGAGCGCAGAGTTATCGTGCCAGCAGATCCTACGCTATGGAGTACAGAC CATGTGCGGCAGTGGCTGGAGTGGGCGGTGAAAGAATATGGCCTTCCAGACGTCAACATCTTGTTATTCCAGAACATCG ATGGGAAGGAACTGTGCAAGATGACCAAGGACGACTTCCAGAGGCTCACCCCCAGCTACAATGCCGACATCCTTCTCTC ACATCTCCACTACCTCAGAGAGACTCCTCTTCCACATTTGACTTCAGATGATGTTGATAAAGCCTTACAAAACTCTCCACG GTTAATGCATGCTAGAAACACAGATTTACCATATGAGCCCCCCAGGAGATCAGCCTGGACCGGTCACGGCCACCCCACG CCCCAGTCGAAAGCTGCTCAACCATCTCCTTCCACAGTGCCCAAAACTGAAGACCAGCGTCCTCAGTTAGATCCTTATCAG ATTCTTGGACCAACAAGTAGCCGCCTTGCAAATCCAGGCAGTGGCCAGATCCAGCTTTGGCAGTTCCTCCTGGAGCTCCT GTCGGACAGCTCCAACTCCAGCTGCATCACCTGGGAAGGCACCAACGGGGAGTTCAAGATGACGGATCCCGACGAGGT GGCCCGGCGCTGGGGAGAGCGGAAGAGCAAACCCAACATGAACTACGATAAGCTCAGCCGCGCCCTCCGTTACTACTA TGACAAGAACATCATGACCAAGGTCCATGGGAAGCGCTACGCCTACAAGTTCGACTTCCACGGGATCGCCCAGGCCCTC CAGCCCCACCCCCCGGAGTCATCTCTGTACAAGTACCCCTCAGACCTCCCGTACATGGGCTCCTATCACGCCCACCCACA GAAGATGAACTTTGTGGCGCCCCACCCTCCAGCCCTCCCCGTGACATCTTCCAGTTTTTTTGGTTGCCCCAAACCCATACTG GAATTCACCAACTGGGGGTATATACCCCAACACTAGGCTCCCCACCAGCCATATGCCTTCTCATCTGGGCACTTACTACTA A

\section{T/E VI}

ATGGCTTTGAACTCAGAAGCCTTATCAGTTGTGAGTGAGGACCAGTCGTTGTTTGAGTGTGCCTACGGAACGCCACACCT GGCTAAGACAGAGATGACCGCGTCCTCCTCCAGCGACTATGGACAGACTTCCAAGATGAGCCCACGCGTCCCTCAGCAG GATTGGCTGTCTCAACCCCCAGCCAGGGTCACCATCAAAATGGAATGTAACCCTAGCCAGGTGAATGGCTCAAGGAACT CTCCTGATGAATGCAGTGTGGCCAAAGGCGGGAAGATGGTGGGCAGCCCAGACACCGTTGGGATGAACTACGGCAGCT ACATGGAGGAGAAGCACATGCCACCCCCAAACATGACCACGAACGAGCGCAGAGTTATCGTGCCAGCAGATCCTACGCT ATGGAGTACAGACCATGTGCGGCAGTGGCTGGAGTGGGCGGTGAAAGAATATGGCCTTCCAGACGTCAACATCTTGTT ATTCCAGAACATCGATGGGAAGGAACTGTGCAAGATGACCAAGGACGACTTCCAGAGGCTCACCCCCAGCTACAATGCC GACATCCTTCTCTCACATCTCCACTACCTCAGAGAGACTCCTCTTCCACATTTGACTTCAGATGATGTTGATAAAGCCTTAC AAAACTCTCCACGGTTAATGCATGCTAGAAACACAGATTTACCATATGAGCCCCCCAGGAGATCAGCCTGGACCGGTCAC GGCCACCCCACGCCCCAGTCGAAAGCTGCTCAACCATCTCCTTCCACAGTGCCCAAAACTGAAGACCAGCGTCCTCAGTT AGATCCTTATCAGATTCTTGGACCAACAAGTAGCCGCCTTGCAAATCCAGGCAGTGGCCAGATCCAGCTTTGGCAGTTCC TCCTGGAGCTCCTGTCGGACAGCTCCAACTCCAGCTGCATCACCTGGGAAGGCACCAACGGGGAGTTCAAGATGACGGA TCCCGACGAGGTGGCCCGGCGCTGGGGAGAGCGGAAGAGCAAACCCAACATGAACTACGATAAGCTCAGCCGCGCCCT CCGTTACTACTATGACAAGAACATCATGACCAAGGTCCATGGGAAGCGCTACGCCTACAAGTTCGACTTCCACGGGATC GCCCAGGCCCTCCAGCCCCACCCCCCCGGAGTCATCTCTGTACAAGTACCCCTCAGACCTCCCGTACATGGGCTCCTATCA CGCCCACCCACAGAAGATGAACTTTGTGGCGCCCCACCCTCCAGCCCTCCCCGTGACATCTTCCAGTTTTTTTGCTGCCCC AAACCCATACTGGAATTCACCAACTGGGGGTATATACCCCAACACTAGGCTCCCCACCAGCCATATGCCTTCTCATCTGG GCACTTACTACTAA

Supplementary Figure S2.2: T/E sequences cloned into the expression vector. Underlined: sequence coding for the first five amino acids of TMPRSS2 in T/E VI. 


\section{Supplementary tables}

\section{Supplementary Table S2.2: List of genes with expression fold change $>|1.5|$ that were used in IPA}

This table can be retrieved from the published version of this chapter, concordant with Supplementary Table 1 in Oncotarget. 2017; 8(15):25115-25130. doi: 10.18632/oncotarget.15931.

Supplementary Table S2.3: Functional annotation of genes differentially regulated upon T/E overexpression

\begin{tabular}{|c|c|c|c|c|}
\hline Functional annotation & Genes & p-value & z-score* & \# Genes ${ }^{\dagger}$ \\
\hline Proliferation of cells & $\begin{array}{l}\text { SET, ATP5G1, STMN1, LILRB1, MYC, } \\
\text { EIF4A1, ACTN4, S100P, LCP1, SCL19A1 }\end{array}$ & $1.63 E-34$ & -2.545 & 768 \\
\hline $\begin{array}{l}\text { Cell proliferation of } \\
\text { tumor cell lines }\end{array}$ & $\begin{array}{l}\text { CD24, IL24, IGFBP3, SLPI, GJA1, PLAT, } \\
\text { SH2D3C, ZFP36, BCL6, SGK1 }\end{array}$ & $9.02 E-28$ & -1.640 & 372 \\
\hline Interphase & $\begin{array}{l}\text { MYC, FBXO5, CDKN1B, ERBB2, E2F2, } \\
\text { PNPT1, BRCA1, CCNE1, BIRC5, CDKN3 }\end{array}$ & $4.10 \mathrm{E}-19$ & -2.287 & 173 \\
\hline Invasion of cells & $\begin{array}{l}\text { CD24, CTNNAL1, GJA1, PLAT, TFF1, CTSK, } \\
\text { SHC1, S100A9, MMP1, ETV6 }\end{array}$ & $3.23 E-13$ & 1.316 & 197 \\
\hline Survival of organism & $\begin{array}{l}\text { PTGER4, PLAT, BCL6, ID2, MCL1, BCL2L1, } \\
\text { CDKN2A, TRAF3IP2, LMNA, NOS3 }\end{array}$ & $8.51 E-05$ & 1.540 & 130 \\
\hline
\end{tabular}

Top 10 differentially expressed genes in our dataset that were annotated to a function. A gene was selected when its annotation to the indicated function was based on at least two findings in the Ingenuity knowledge base. *Activation z-score is a measure of predicted change (increase or decrease) of the process. †Total number of genes supporting a specific functional annotation.

Supplementary Table S2.4: Canonical pathway analysis of genes differentially regulated upon T/E overexpression

\begin{tabular}{lccc}
\hline Ingenuity Canonical Pathways & p-value & z-score* & \# Genes† \\
\hline Cell Cycle: G2/M DNA Damage Checkpoint Regulation & $1.02 \mathrm{E}-07$ & 1.886 & $19(49)$ \\
Molecular Mechanisms of Cancer & $3.79 \mathrm{E}-06$ & $\mathrm{NaN}$ & $65(365)$ \\
Estrogen-mediated S-phase Entry & $7.59 \mathrm{E}-06$ & -2.53 & $11(24)$ \\
Sertoli Cell-Sertoli Cell Junction Signaling & $1.51 \mathrm{E}-05$ & $\mathrm{NaN}$ & $37(178)$ \\
Mitotic Roles of Polo-Like Kinase & $1.75 \mathrm{E}-05$ & -2.138 & $19(66)$ \\
\hline
\end{tabular}

Significantly enriched canonical pathways across the dataset of commonly regulated genes between T/E III and $\mathrm{VI}$ are shown. *Activation z-score is a measure of predicted change (activated or reduced) of the process. $\mathrm{NaN}$ - not a number. +Number of genes in the dataset, which are represented in the pathway. Numbers in brackets depict the total number of genes in the pathway in the reference gene set.

\section{Supplementary Table S2.5: Genes predicted to be regulated by TGF- $\beta$ according to IPA} This table can be retrieved from the published version of this chapter, concordant with Supplementary Table 4 in Oncotarget. 2017; 8(15):25115-25130. doi: 10.18632/oncotarget.15931. 


\section{REFERENCES}

1. Ferlay J, Steliarova-Foucher E, Lortet-Tieulent J, Rosso S, Coebergh JW, Comber H, Forman D and Bray F. Cancer incidence and mortality patterns in Europe: estimates for 40 countries in 2012. Eur J Cancer. 2013; 49(6):1374-1403.

2. Torre LA, Bray F, Siegel RL, Ferlay J, Lortet-Tieulent J and Jemal A. Global cancer statistics, 2012. CA Cancer J Clin. 2015; 65(2):87-108.

3. Tomlins SA, Rhodes DR, Perner S, Dhanasekaran SM, Mehra R, Sun XW, Varambally S, Cao X, Tchinda J, Kuefer R, Lee C, Montie JE, Shah RB, Pienta KJ, Rubin MA and Chinnaiyan AM. Recurrent fusion of TMPRSS2 and ETS transcription factor genes in prostate cancer. Science. 2005; 310(5748):644-648.

4. Tomlins SA, Bjartell A, Chinnaiyan AM, Jenster G, Nam RK, Rubin MA and Schalken JA. ETS gene fusions in prostate cancer: from discovery to daily clinical practice. Eur Urol. 2009; 56(2):275-286.

5. Tomlins SA, Laxman B, Varambally S, Cao X, Yu J, Helgeson BE, Cao Q, Prensner JR, Rubin MA, Shah RB, Mehra R and Chinnaiyan AM. Role of the TMPRSS2-ERG gene fusion in prostate cancer. Neoplasia. 2008; 10(2):177-188.

6. Perner S, Demichelis F, Beroukhim R, Schmidt FH, Mosquera JM, Setlur S, Tchinda J, Tomlins SA, Hofer MD, Pienta KG, Kuefer R, Vessella R, Sun XW, Meyerson M, Lee C, Sellers WR, et al. TMPRSS2:ERG fusionassociated deletions provide insight into the heterogeneity of prostate cancer. Cancer Res. 2006; 66(17):8337-8341.

7. Hu Y, Dobi A, Sreenath T, Cook C, Tadase AY, Ravindranath L, Cullen J, Furusato B, Chen Y, Thangapazham RL, Mohamed A, Sun C, Sesterhenn IA, McLeod DG, Petrovics G and Srivastava S. Delineation of TMPRSS2-ERG splice variants in prostate cancer. Clin Cancer Res. 2008; 14(15):4719-4725.

8. Linn DE, Penney KL, Bronson RT, Mucci LA and Li Z. Deletion of Interstitial Genes between TMPRSS2 and ERG Promotes Prostate Cancer Progression. Cancer Res. 2016.

9. Clark J, Merson S, Jhavar S, Flohr P, Edwards S, Foster CS, Eeles R, Martin FL, Phillips DH, Crundwell M, Christmas T, Thompson A, Fisher C, Kovacs G and Cooper CS. Diversity of TMPRSS2-ERG fusion transcripts in the human prostate. Oncogene. 2007; 26(18):2667-2673.

10. Wang J, Cai Y, Ren C and Ittmann M. Expression of variant TMPRSS2/ERG fusion messenger RNAs is associated with aggressive prostate cancer. Cancer Res. 2006; 66(17):8347-8351.

11. Wang J, Cai Y, Shao LJ, Siddiqui J, Palanisamy N, Li R, Ren C, Ayala G and Ittmann M. Activation of NF\{kappa\}B by TMPRSS2/ERG Fusion Isoforms through Toll-Like Receptor-4. Cancer Res. 2011; 71(4):13251333.

12. Wang J, Cai Y, Yu W, Ren C, Spencer DM and Ittmann M. Pleiotropic biological activities of alternatively spliced TMPRSS2/ERG fusion gene transcripts. Cancer Res. 2008; 68(20):8516-8524.

13. Brase JC, Johannes M, Mannsperger H, Falth M, Metzger J, Kacprzyk LA, Andrasiuk T, Gade S, Meister M, Sirma H, Sauter G, Simon R, Schlomm T, Beissbarth T, Korf U, Kuner R, et al. TMPRSS2-ERG -specific transcriptional modulation is associated with prostate cancer biomarkers and TGF-beta signaling. BMC cancer. 2011; 11:507.

14. Oft $\mathrm{M}$, Heider $\mathrm{KH}$ and Beug $\mathrm{H}$. TGFbeta signaling is necessary for carcinoma cell invasiveness and metastasis. Curr Biol. 1998; 8(23):1243-1252.

15. Komiya $Y$ and Habas R. Wnt signal transduction pathways. Organogenesis. 2008; 4(2):68-75.

16. Lamouille S, Xu J and Derynck R. Molecular mechanisms of epithelial-mesenchymal transition. Nat Rev Mol Cell Biol. 2014; 15(3):178-196.

17. Mertz KD, Setlur SR, Dhanasekaran SM, Demichelis F, Perner S, Tomlins S, Tchinda J, Laxman B, Vessella RL, Beroukhim R, Lee C, Chinnaiyan AM and Rubin MA. Molecular characterization of TMPRSS2-ERG gene fusion in the $\mathrm{NCl}-\mathrm{H} 660$ prostate cancer cell line: a new perspective for an old model. Neoplasia. 2007; 9(3):200-206.

18. Yu J, Yu J, Mani RS, Cao Q, Brenner CJ, Cao X, Wang X, Wu L, Li J, Hu M, Gong Y, Cheng H, Laxman B, Vellaichamy A, Shankar S, Li Y, et al. An integrated network of androgen receptor, polycomb, and TMPRSS2-ERG gene fusions in prostate cancer progression. Cancer Cell. 2010; 17(5):443-454. 
19. Sun C, Dobi A, Mohamed A, Li H, Thangapazham RL, Furusato B, Shaheduzzaman S, Tan SH, Vaidyanathan G, Whitman E, Hawksworth DJ, Chen Y, Nau M, Patel V, Vahey M, Gutkind JS, et al. TMPRSS2-ERG fusion, a common genomic alteration in prostate cancer activates C-MYC and abrogates prostate epithelial differentiation. Oncogene. 2008; 27(40):5348-5353.

20. Buttice G, Duterque-Coquillaud M, Basuyaux JP, Carrere S, Kurkinen M and Stehelin D. Erg, an Ets-family member, differentially regulates human collagenase1 (MMP1) and stromelysin1 (MMP3) gene expression by physically interacting with the Fos/Jun complex. Oncogene. 1996; 13(11):2297-2306.

21. Moustakas A and Heldin CH. Non-Smad TGF-beta signals. J Cell Sci. 2005; 118(Pt 16):3573-3584.

22. Zhang YE. Non-Smad pathways in TGF-beta signaling. Cell Res. 2009; 19(1):128-139.

23. Ao M, Williams K, Bhowmick NA and Hayward SW. Transforming growth factor-beta promotes invasion in tumorigenic but not in nontumorigenic human prostatic epithelial cells. Cancer Res. 2006; 66(16):8007-8016.

24. Weidle UH, Schneider B, Georges G and Brinkmann U. Genetically engineered fusion proteins for treatment of cancer. Cancer Genomics Proteomics. 2012; 9(6):357-372.

25. Sanvitale CE, Kerr G, Chaikuad A, Ramel MC, Mohedas AH, Reichert S, Wang Y, Triffitt JT, Cuny GD, Yu PB, Hill CS and Bullock AN. A new class of small molecule inhibitor of BMP signaling. PLoS One. 2013; 8(4):e62721.

26. Miyazono K and Miyazawa K. Id: a target of BMP signaling. Sci STKE. 2002; 2002(151):pe40.

27. Wiercinska E, Wickert L, Denecke B, Said HM, Hamzavi J, Gressner AM, Thorikay M, ten Dijke P, Mertens $\mathrm{PR}$, Breitkopf $\mathrm{K}$ and Dooley S. Id1 is a critical mediator in TGF-beta-induced transdifferentiation of rat hepatic stellate cells. Hepatology. 2006; 43(5):1032-1041.

28. Li Y, Li W, Ying Z, Tian H, Zhu X, Li J and Li M. Metastatic heterogeneity of breast cancer cells is associated with expression of a heterogeneous TGFbeta-activating miR424-503 gene cluster. Cancer Res. 2014; 74(21):6107-6118.

29. Butz H, Racz K, Hunyady L and Patocs A. Crosstalk between TGF-beta signaling and the microRNA machinery. Trends Pharmacol Sci. 2012; 33(7):382-393.

30. Leshem O, Madar S, Kogan-Sakin I, Kamer I, Goldstein I, Brosh R, Cohen Y, Jacob-Hirsch J, Ehrlich M, BenSasson S, Goldfinger N, Loewenthal R, Gazit E, Rotter V and Berger R. TMPRSS2/ERG promotes epithelial to mesenchymal transition through the ZEB1/ZEB2 axis in a prostate cancer model. PLoS One. 2011; 6(7):e21650.

31. Lang SH, Hyde C, Reid IN, Hitchcock IS, Hart CA, Bryden AA, Villette JM, Stower MJ and Maitland NJ. Enhanced expression of vimentin in motile prostate cell lines and in poorly differentiated and metastatic prostate carcinoma. Prostate. 2002; 52(4):253-263.

32. Wei J, Xu G, Wu M, Zhang Y, Li Q, Liu P, Zhu T, Song A, Zhao L, Han Z, Chen G, Wang S, Meng L, Zhou J, Lu $Y$, Wang $S$, et al. Overexpression of vimentin contributes to prostate cancer invasion and metastasis via src regulation. Anticancer Res. 2008; 28(1A):327-334.

33. Becker-Santos DD, Guo Y, Ghaffari M, Vickers ED, Lehman M, Altamirano-Dimas M, Oloumi A, Furukawa J, Sharma M, Wang Y, Dedhar S and Cox ME. Integrin-linked kinase as a target for ERG-mediated invasive properties in prostate cancer models. Carcinogenesis. 2012; 33(12):2558-2567.

34. Zhang Q, Helfand BT, Jang TL, Zhu LJ, Chen L, Yang XJ, Kozlowski J, Smith N, Kundu SD, Yang G, Raji AA, Javonovic B, Pins M, Lindholm P, Guo Y, Catalona WJ, et al. Nuclear factor-kappaB-mediated transforming growth factor-beta-induced expression of vimentin is an independent predictor of biochemical recurrence after radical prostatectomy. Clin Cancer Res. 2009; 15(10):3557-3567.

35. Owens P, Polikowsky H, Pickup MW, Gorska AE, Jovanovic B, Shaw AK, Novitskiy SV, Hong CC and Moses $\mathrm{HL}$. Bone Morphogenetic Proteins stimulate mammary fibroblasts to promote mammary carcinoma cell invasion. PLoS One. 2013; 8(6):e67533.

36. Yang S, Pham LK, Liao CP, Frenkel B, Reddi AH and Roy-Burman P. A novel bone morphogenetic protein signaling in heterotypic cell interactions in prostate cancer. Cancer Res. 2008; 68(1):198-205.

37. Bubendorf L, Schopfer A, Wagner U, Sauter G, Moch H, Willi N, Gasser TC and Mihatsch MJ. Metastatic patterns of prostate cancer: an autopsy study of 1,589 patients. Hum Pathol. 2000; 31(5):578-583. 
38. Wikstrom P, Stattin P, Franck-Lissbrant I, Damber JE and Bergh A. Transforming growth factor beta1 is associated with angiogenesis, metastasis, and poor clinical outcome in prostate cancer. Prostate. 1998; 37(1):19-29.

39. Shariat SF, Shalev M, Menesses-Diaz A, Kim IY, Kattan MW, Wheeler TM and Slawin KM. Preoperative plasma levels of transforming growth factor beta(1) (TGF-beta(1)) strongly predict progression in patients undergoing radical prostatectomy. J Clin Oncol. 2001; 19(11):2856-2864.

40. Haider M, Zhang X, Coleman I, Ericson N, True LD, Lam HM, Brown LG, Ketchanji M, Nghiem B, Lakely B, Coleman R, Montgomery B, Lange PH, Roudier M, Higano CS, Bielas JH, et al. Epithelial mesenchymal-like transition occurs in a subset of cells in castration resistant prostate cancer bone metastases. Clin Exp Metastasis. 2016; 33(3):239-248.

41. Goumans MJ, Valdimarsdottir G, Itoh S, Rosendahl A, Sideras P and ten Dijke P. Balancing the activation state of the endothelium via two distinct TGF-beta type I receptors. EMBO J. 2002; 21(7):1743-1753.

42. David L, Mallet C, Mazerbourg S, Feige JJ and Bailly S. Identification of BMP9 and BMP10 as functional activators of the orphan activin receptor-like kinase 1 (ALK1) in endothelial cells. Blood. 2007; 109(5):1953-1961.

43. Ota T, Fujii M, Sugizaki T, Ishii M, Miyazawa K, Aburatani H and Miyazono K. Targets of transcriptional regulation by two distinct type I receptors for transforming growth factor-beta in human umbilical vein endothelial cells. J Cell Physiol. 2002; 193(3):299-318.

44. Stankic M, Pavlovic S, Chin Y, Brogi E, Padua D, Norton L, Massague J and Benezra R. TGF-beta-Id1 signaling opposes Twist1 and promotes metastatic colonization via a mesenchymal-to-epithelial transition. Cell Rep. 2013; 5(5):1228-1242.

45. Cunha SI, Bocci M, Lovrot J, Eleftheriou N, Roswall P, Cordero E, Lindstrom L, Bartoschek M, Haller BK, Pearsall RS, Mulivor AW, Kumar R, Larsson C, Bergh J and Pietras K. Endothelial ALK1 Is a Therapeutic Target to Block Metastatic Dissemination of Breast Cancer. Cancer Res. 2015; 75(12):2445-2456.

46. Mitchell D, Pobre EG, Mulivor AW, Grinberg AV, Castonguay R, Monnell TE, Solban N, Ucran JA, Pearsall RS, Underwood KW, Seehra J and Kumar R. ALK1-Fc inhibits multiple mediators of angiogenesis and suppresses tumor growth. Mol Cancer Ther. 2010; 9(2):379-388.

47. Van Obberghen-Schilling E, Roche NS, Flanders KC, Sporn MB and Roberts AB. Transforming growth factor beta 1 positively regulates its own expression in normal and transformed cells. J Biol Chem. 1988; 263(16):7741-7746.

48. Zavadil J and Bottinger EP. TGF-beta and epithelial-to-mesenchymal transitions. Oncogene. 2005; 24(37):5764-5774.

49. Gupta S, Iljin K, Sara H, Mpindi JP, Mirtti T, Vainio P, Rantala J, Alanen K, Nees M and Kallioniemi O. FZD4 as a ediator of ERG oncogene-induced WNT signaling and epithelial-to-mesenchymal transition in human prostate cancer cells. Cancer Res. 2010; 70(17):6735-6745.

50. Wu L, Zhao JC, Kim J, Jin HJ, Wang CY and Yu J. ERG is a critical regulator of Wnt/LEF1 signaling in prostate cancer. Cancer Res. 2013; 73(19):6068-6079.

51. Herzig M, Savarese F, Novatchkova M, Semb H and Christofori G. Tumor progression induced by the loss of E-cadherin independent of beta-catenin/Tcf-mediated Wht signaling. Oncogene. 2007; 26(16):22902298.

52. Kavsak P, Rasmussen RK, Causing CG, Bonni S, Zhu H, Thomsen GH and Wrana JL. Smad7 binds to Smurf2 to form an E3 ubiquitin ligase that targets the TGF beta receptor for degradation. Mol Cell. 2000; 6(6):1365-1375.

53. Tang Y, Liu Z, Zhao L, Clemens TL and Cao X. Smad7 stabilizes beta-catenin binding to E-cadherin complex and promotes cell-cell adhesion. J Biol Chem. 2008; 283(35):23956-23963.

54. Zhu H, Li Y, Qu S, Luo H, Zhou Y, Wang Y, Zhao H, You Y, Xiao X and Zuo X. MicroRNA expression abnormalities in limited cutaneous scleroderma and diffuse cutaneous scleroderma. J Clin Immunol. 2012; 32(3):514-522.

55. Llobet-Navas D, Rodriguez-Barrueco R, Castro V, Ugalde AP, Sumazin P, Jacob-Sendler D, Demircan B, Castillo-Martin M, Putcha P, Marshall N, Villagrasa P, Chan J, Sanchez-Garcia F, Pe'er D, Rabadan R, lava- 
rone A, et al. The miR-424(322)/503 cluster orchestrates remodeling of the epithelium in the involuting mammary gland. Genes Dev. 2014; 28(7):765-782.

56. Watahiki A, Wang Y, Morris J, Dennis K, O'Dwyer HM, Gleave M, Gout PW and Wang Y. MicroRNAs associated with metastatic prostate cancer. PLoS One. 2011; 6(9):e24950.

57. Oneyama C, Kito Y, Asai R, Ikeda J, Yoshida T, Okuzaki D, Kokuda R, Kakumoto K, Takayama K, Inoue S, Morii E and Okada M. MiR-424/503-mediated Rictor upregulation promotes tumor progression. PLoS One. 2013; 8(11):e80300.

58. Jiang X, Chen Y, Du E, Yang K, Zhang Z, Qi S and Xu Y. GATA3-driven expression of miR-503 inhibits prostate cancer rogression by repressing ZNF217 expression. Cell Signal. 2016; 28(9):1216-1224.

59. Vecchia L, Olivieri C and Scotti C. Activin Receptor-like kinase 1: a novel anti-angiogenesis target from TGF-beta family. Mini Rev Med Chem. 2013; 13(10):1398-1406.

60. Bendell JC, Gordon MS, Hurwitz HI, Jones SF, Mendelson DS, Blobe GC, Agarwal N, Condon CH, Wilson D, Pearsall AE, Yang Y, McClure T, Attie KM, Sherman ML and Sharma S. Safety, pharmacokinetics, pharmacodynamics, and antitumor activity of dalantercept, an activin receptor-like kinase-1 ligand trap, in patients with advanced cancer. Clin Cancer Res. 2014; 20(2):480-489. 



\section{Chapter 3}

\section{TMPRSS2:ERG overexpression induces}

changes in the epigenetic signature of human prostate cancer cells:

Hypomethylation correlates with

upregulation of FZD4 and HLA-DMB 


\section{ABSTRACT}

In prostate cancer, specific alterations of the DNA methylation profile of distinct molecular subtypes have been reported suggesting DNA methylation as potential biomarker. Distinct methylation patterns have also been observed in TMPRSS2:ERG (T/E) fusionpositive compared to fusion-negative samples. The T/E gene fusion has been associated with epigenetic reprogramming that could be mediated by recurrent overexpression of HDAC1, and cooperativity between ERG and the histone methyltransferase EZH2 leading to target gene silencing.

By using an inducible T/E overexpressing LNCaP cell model, we elucidated a global hypomethylation profile in T/E overexpressing cells that correlated with cell migration and neuron differentiation. Further, hypomethylation of FZD4 and HLA-DMB was identified that correlated with increased expression levels of those genes. These findings were consistent with DNA methylation and gene expression data of the TCGA prostate cancer cohort (PRAD). Our results further corroborated the findings by Börno et al. who reported an increased global methylation in T/E fusion-negative tumors. In conclusion, we show that T/E overexpression affects the epigenetic and transcriptional profile in prostate cancer cells that are correlated with aggressive cell behavior on the global level and suggest that future research could reveal the mechanistic basis of those changes. 


\section{INTRODUCTION}

Prostate cancer (PCa) is characterized by a low somatic mutation frequency $[1,2]$, and copy number variants are recurrently detected [3-5]. However, the identification of a definitive genomic driver event is lacking for many tumors [6]. DNA methylation changes occur at higher rates than copy number changes (10.5\% vs. 2.1\%) [5]. Specific alterations of the DNA methylation profile of distinct molecular subtypes of PCa have been described recently, potentially representing different epigenetic mechanisms with yet unresolved functional consequences proposing DNA methylation as a biomarker in PCa [7]. The DNA methylation profile has also been found to be subject-specific and maintained within metastatic subclones indicating a role as a longitudinal marker $[8,9]$. Promoter-associated hypermethylated $\mathrm{CpG}$ islands were highly enriched for tumor suppressor genes [10] as well as differentiation and developmental processes, and associated with reduced gene expression (e.g. PTEN, TP53, GSTP1), implying that DNA hypermethylation may change the differentiation state and activity of carcinogenic pathways $[8,11]$. Hypermethylation of the pi-class glutathione S-transferase 1 (GSTP1) promoter is among the most common somatic epigenomic changes. It is a well-known DNA methylation marker during the transformation from PIN to adenocarcinoma [1214]. CpG island hypermethylation of a gene panel (GSTP1, APC, RASSF1A, PTGS2, MDR1) could discriminate primary PCa from benign prostate tissue [15]. Hypermethylation of the transcriptional elongation regulator (TCERG1L) in combination with other genomic markers could predict disease relapse in localized PCa [16]. Methylation signature analysis revealed recurrent hypermethylation in castration-resistant prostate cancer (CRPC) samples compared to benign prostate tissue $[5,17]$. DNA methylation levels at CpG islands increased with disease severity [17] and occurred more often at genes with allelic deletion, e.g. RB1 or HSD17B2 [5]. In the same study, it was suggested that heterozygous deletion of CYP17A1 could be compensated by CYP17A1 gene body hypermethylation leading to gene upregulation and sustained androgen synthesis [5]. This implies that epigenetic aberrations could promote androgen signaling in CRPC $[5,18]$. Lin et al. proposed a panel of $13 \mathrm{CpG}$ islands that were increasingly methylated with disease severity and in PCa with NE differentiation [17] encompassing a potential clinical use of those CpG islands to detect advanced PCa. Analysis of the DNA methylation profile segregated NEPC from adenocarcinomas, which was not achieved by standard pathological assessment alone, suggesting that methylation analysis could improve clinical tumor classification [19]. It has further been shown that global hypomethylation leads to genomic instability at later stages of PCa, thereby increasing tumor heterogeneity $[20,21]$.

Only few studies have analysed the methylation profile associated with the T/E gene fusion. Some of these reported distinct methylation patterns in T/E-positive compared to $T / E-n e g a t i v e s ~ s a m p l e s ~[17,22,23]$. Since the $T / E$ gene fusion has been detected in 
PIN lesions, T/E-induced methylation changes can occur early during carcinogenesis before histological manifestation of PCa. Differentially methylated regions have been described to be specifically associated with T/E fusion-positive tumors [22]. Recurrent overexpression of the histone deacetylase 1 (HDAC1) and target gene silencing in T/E overexpressing PCa indicated a role of ERG in epigenetic reprogramming $[24,25]$. ERG has been shown to interact with HDAC1 via the SETDB1 methyl transferase [26, 27]. A cooperativity between ERG and the histone methyltransferase enhancer of zeste homo$\log 2$ (EZH2) was demonstrated to regulate shared target genes [28]. EZH2-mediated lysine methylation of ERG resulted in increased chromatin binding and ERG-induced transcriptional activity associated with a metastatic and dedifferentiation program [29]. Börno et al. observed increased global methylation in T/E fusion-negative tumors [23], in contrast to Kim et al. [22] and Lin et al. [17], who showed lower global methylation in T/E fusion-negative PCa. EZH2 mRNA levels were significantly higher in fusion-negative than in fusion-positive tumors accompanied by hypermethylation of the miR-26a locus providing a mechanism for enhanced EZH2 upregulation in those tumors [23]. We aim to obtain further insights into the T/E-induced epigenetic alterations in prostate cancer cell lines and to determine the molecular mechanism of ERG-mediated epigenetic alterations.

\section{MATERIALS AND METHODS}

\section{Cell lines and culturing}

LNCaP (CRL-1740) cells were purchased from American Type Culture Collection (ATCC, Manassas, VA, USA). Stably transfected acceptor LNCaP cells were maintained in RPMI1640 (Thermo Fisher Scientific, Waltham, MA, USA), supplemented with $10 \%$ of Tet System Approved FBS (tet-FBS, Clontech, Göteborg, Sweden) and $80 \mu \mathrm{g} / \mathrm{mL}$ hygromycin B (Thermo Fisher Scientific). The cells were authenticated using Multiplex Cell Authentication by Multiplexion (Heidelberg, Germany) as described recently [30]. The SNP profile matched known profiles. The purity of the cells was validated using the Multiplex cell Contamination Test by Multiplexion (Heidelberg, Germany) as described recently [31]. Neither Mycoplasma, SMRV nor interspecies contamination was detected.

\section{Generation of LNCaP cell models stably expressing T/E variants}

Establishment of the LNCaP-T/E variant cell model including T/E sequences has been described before [32]. Transgene expression was induced with $50 \mathrm{ng} / \mathrm{mL}$ Dox (SigmaAldrich, Munich, Germany) in RPMI1640 containing 10\% tet-FBS. Medium of the uninduced cells was supplemented with the respective volume of PBS only. After $72 \mathrm{~h}$, cells were harvested and washed once with ice-cold $1 x$ PBS. Cell suspensions were split, centrifuged and the pellet was used for DNA and RNA extraction, respectively. There- 
fore, gene expression levels of differentially methylated genes obtained from EPIC BeadChip analysis were assessed by qPCR in the corresponding RNA samples that were used for methylation profiling.

\section{DNA isolation}

Genomic DNA was isolated from cell lines using the QIAamp DNA Blood Mini Kit (Qiagen, Hilden, Germany) and quality controlled on the 2100 Bioanalyser (Agilent Technologies, Waldbronn, Germany) with DNA 7500 Kit according to the manufacturers' protocols.

\section{Methylation profiling}

The Illumina Infinium MethylationEPIC (850K) array was used to determine the DNA methylation status of 853,307 CpG sites (Illumina, San Diego, USA), according to the manufacturer's instructions at the Genomics and Proteomics Core Facility (GPCF) of the DKFZ applying 1000ng of total DNA with a concentration of $25 \mathrm{ng} / \mu \mathrm{l}$. Raw data (IDATs) were normalized (control normalization) using the Methylation Module of GenomeStudio software (version 2011.1, Illumina) with the HumanMethylationEPIC manifest v1.0. For each CpG locus a methylation $\beta$-value was calculated by dividing the intensity of the methylated allele $(C)$ by the sum of intensity of the methylated $(M)$ and unmethylated $(U)$ alleles $[\beta=M /(M+U)]$. CpG sites showing a $\beta$-value $(\Delta \beta)>|0.2|$ ( $p$-value $<0.05)$ compared to control cells were considered as differentially methylated.

For unsupervised hierarchical clustering, $1 \%$ of the probes with the highest variance across the beta values were selected. Samples were hierarchical clustered with Euclidean distance as the similarity measure using Cluster 3.0 [33] and Treeview software $[34,35]$. The methylation levels were shown in a heat map from methylated and unmethylated status, encoded as 1 and -1 , respectively.

\section{RNA isolation, reverse transcription and quantitative real-time PCR}

From the same samples that were used for methylation analysis, total RNA was isolated using the miRNeasy Mini Kit (Qiagen, Hilden, Germany). Total RNA was reverse transcribed using the RevertAid $H$ Minus First Strand cDNA Synthesis Kit (Thermo Fisher Scientific). Relative mRNA levels were assessed by quantitative RT-PCR on the Lightcycler 480 (Roche Diagnostics, Mannheim, Germany) using Universal Probe Library (UPL) assays and primers listed in Supplementary Table S3.1. Linear expression levels were normalized to GAPDH using the $2^{(-\Delta \Delta \mathrm{Ct})}$ method [36].

\section{Integrative analysis of methylation and gene expression data}

DNA methylation data were integrated with the gene expression profiling data that had been obtained in chapter 2 [32]. Methylation and gene expression data were combined using the Methylation Module of GenomeStudio software (Illumina) with the HumanHT- 
12 manifest v4.0. Methylation $\beta$ and gene expression signal intensity values were sorted using Pearson's correlation coefficient $(r)$ to identify inverse correlated genes $(r=-1)$.

\section{Pathway enrichment analysis}

The Ingenuity Pathway Analysis (IPA) tool was used to identify pathways and biological processes that were over- or underrepresented. IPA uses the Ingenuity knowledge base, a database of protein and gene interactions integrated from published biomedical literature and 3rd party sources. Analysis using IPA (version 26127183) was performed between October 2016 and July 2017. Genes near differentially methylated CpG sites were used for this analysis.

\section{Functional annotations}

Gene expression changes were categorized into functional annotations of molecular and cellular mechanisms. The Ingenuity knowledge base provides a predicted direction of change for the biological function (downstream effect analysis), represented by an activation z-score, where $z>2.0$ or $<-2.0$ is predictive for activation or reduction of the process, respectively. A p-value $<0.05$ indicates a statistically significant association between a set of differentially expressed genes and a given process.

\section{Pathway enrichment analysis}

Ingenuity knowledge base provides an analysis of metabolic and cell signaling pathways that are significantly enriched in the gene expression signature. Pathway significance values were calculated based on Fisher's right tailed exact test and the - $\log (p$-value) by IPA. Pathways meeting the threshold $p$-value $<0.05$ were considered as significant.

Using the 'Compare' tool, IPA identified the intersection and unique gene sets among T/E III and T/E VI versus empty vector datasets. Upstream regulator analysis can identify molecules upstream of the genes in the dataset that potentially explain the observed gene expression changes and molecular functions. It is based on prior knowledge of expected effects between transcriptional regulators and their target genes stored in the Ingenuity knowledge base.

\section{Integration with TCGA prostate cancer patient data}

Prostate cancer patient data from The Cancer Genome Atlas Prostate Cancer (TCGA PRAD) were retrieved using the UCSC Cancer Browser (https://genomecancer.ucsc.edu/). For graphical view of genomic data, gene expression RNAseq ( $\mathrm{n}=$ 550, version: 2016-08-16), exon expression RNAseq ( $n=550$, version: 2016-08-16), copy number ( $n=495$, version: 2016-11-16), and DNA methylation (Methylation450k) ( $n=549$, version: 2016-11-16) data were analysed using the Xena browser. A detailed description of data generation and instructions can be viewed on https://xenabrowser.net. 


\section{Luminex immunoassay for histone modification detection}

The histone extraction kit (Active Motif) was used for acid extraction of histones from cell culture samples. The assay was performed according to the manufacturer's instructions. Cells were treated with Dox to induce ERG overexpression. After $72 \mathrm{~h}$ of induction, cells were harvested using trypsin and washed twice with $1 x$ ice-cold PBS. Ice-cold extraction buffer was added to cells, resuspended and incubated for $2 \mathrm{~h}$ at $4{ }^{\circ} \mathrm{C}$. Cells were centrifuged at 20,000 x g for 10 minutes, the supernatant was transferred to a new prechilled microcentrifuge tube and snap-frozen in a dry-ice/methanol bath. Samples were neutralized by adding neutralization buffer with 0.1M DTT, deacetylase inhibitor, phosphatase inhibitor, protease inhibitor and vortexed. Protein concentrations were determined using Qubit fluorometric quantitation (Thermo Fisher Scientific).

The Histone H3 PTM Multiplex Assay (Active Motif) was used for detection of histone modifications and performed according to the manufacturer's instructions. Five hundred ng of acid histone extracted samples were used. A multiplexed bead master mix was prepared with antibodies against total histone $\mathrm{H3}$, histone $\mathrm{H} 3 \mathrm{~K} 9 \mathrm{ac}$, histone H3K9me2, histone H3K9me3, and histone H3K4me2. Biotinylated histone H3 antibody was diluted 1:250 in Assay Buffer. The fluorescent reporter signals were analysed by a Bio-Plex 200 reader (Bio-Rad).

\section{Statistical testing}

Differences between the induced and uninduced cells were analysed using a paired ttest and between induced cells of T/E III and VI by an unpaired t-test. Statistical significance of t-test depicted as $* p<0.05, * * p<0.01, * * * p<0.001$.

\section{RESULTS}

T/E overexpression induces global epigenetic changes in PCa cell lines

The epigenetic changes induced by $\mathrm{T} / \mathrm{E}$ overexpression compared to uninduced control cells were investigated by methylome analysis on $>850,000 \mathrm{CpG}$ sites. The $1 \%$ most variable differentially methylated CpG sites $(n=8,668)$ were selected for further analysis. Comparison of the DNA methylation level of those CpG sites showed a global hypomethylation profile in T/E expressing cells (Figure 3.1). Of note, stratification by genetic and epigenetic location revealed that hypomethylated $\mathrm{CpGs}$ were enriched in promoter regions (transcription start sites -1500 to $-200 \mathrm{bp}, 5^{\prime}$ UTR), gene bodies, intergenic and open sea regions, but underrepresented in first exons, 3'UTRs and exon/intron boundaries in T/E III (Figure 3.1A and B) as well as T/E VI expressing cells (Figure 3.1C and D). 
A

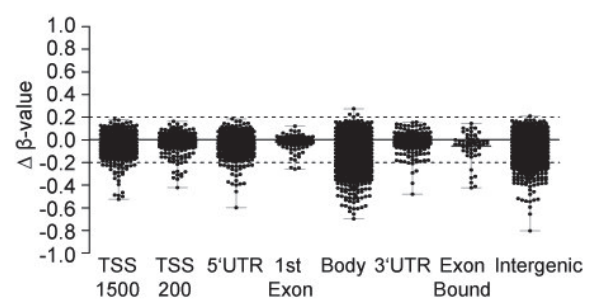

B

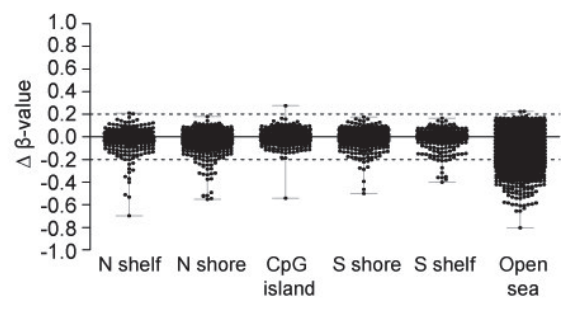

T/E VI cells
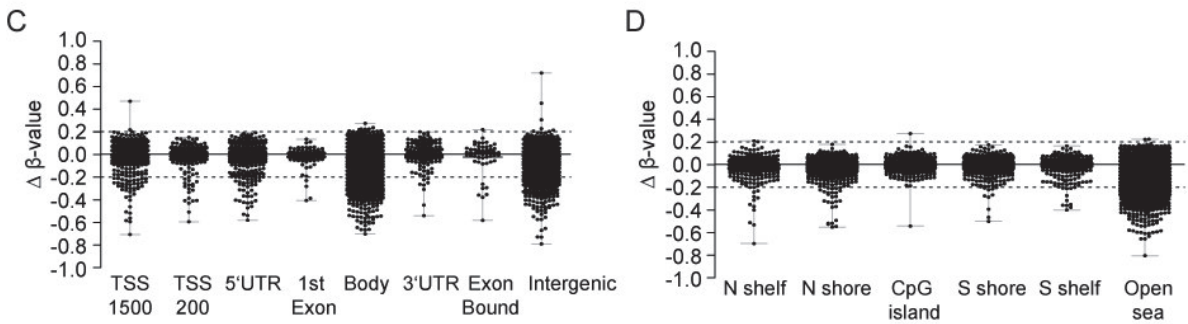

Figure 3.1: Global methylation profile of the top $1 \%$ most variable $\mathrm{CpG}$ sites in T/E expressing cells. Differentially methylated CpG sites in Dox-induced (A, B) LNCaP-T/E III and (C, D) LNCaP-T/E VI cells compared to uninduced control cells. For analysis, the $1 \%$ most variable $\mathrm{CpG}$ sites of a total of $>850,000 \mathrm{CpG}$ sites in the dataset were used. A and $\mathrm{C}$ show the differentially methylated $\mathrm{CpGs}$ assigned to different genetic features based on the annotations of Illumina Infinium Human MethylationEPIC (850K) Beadchip Array. B and D show the CpG methylation status per epigenetic region according to Illumina annotation. A global hypomethylation profile is observed in T/E-overexpressing cells. A large number of differentially methylated regions were observed in intergenic and open sea regions. TSS - transcription start site, UTR - untranslated region, shore - region immediately flanking the $\mathrm{CpG}$ island within $0-2 \mathrm{~kb}$, shelf - regions $2-4 \mathrm{~kb}$ away from the $\mathrm{CpG}$ island, $\mathrm{N}-$ upstream $\left(5^{\prime}\right)$ of $\mathrm{CpG}$ island, $\mathrm{S}=$ downstream $\left(3^{\prime}\right)$ of $\mathrm{CpG}$ island, open sea - isolated CpG sites in the genome with no specific designation to a gene. $\Delta \beta$-value - ratio of methylation intensity at a specific probe and the overall methylation intensity (sum of intensity of the methylated and unmethylated alleles). $A \Delta \beta$-value of $>|0.2|$ is considered as differential methylation.

To identify DNA methylation patterns that are shared between T/E III and T/E VI expressing cells, the overlap of the $1 \%$ CpG sites was calculated. For integrative analysis with expression profiling data, we focused on differentially methylated CpG sites with designation to a specific gene. Those CpG sites involved 3,422 genes in T/E III and 2,637 genes in T/E VI expressing cells, respectively (Figure 3.2). Of these, 1,255 differentially methylated CPG sites associated with coding genes overlapped between T/E III and T/E VI cells (Figure 3.3A). 
A

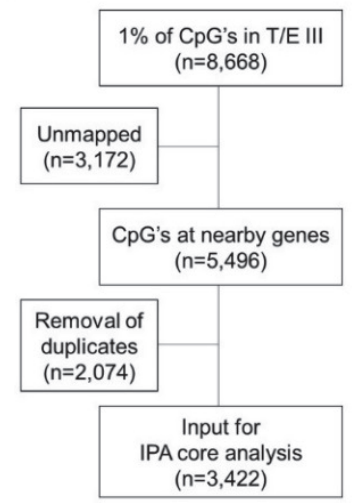

B

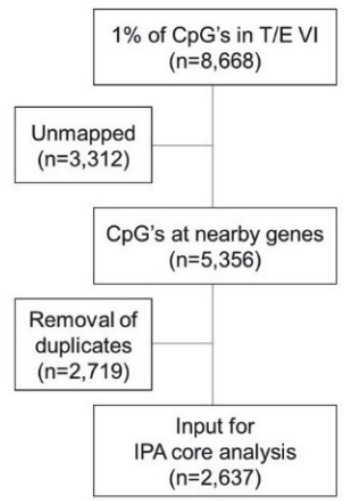

C

Overlap Top $1 \%$ most variable CpG sites $(n=8,668)$

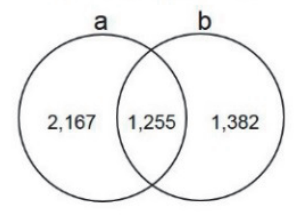

a: Top 1\%-Var in T/E III

b: Top 1\%-Var in T/E VI

Figure 3.2: Strategy for CPG site selection with designation to a gene that were used as input for IPA analysis in (A) T/E III and (B) T/E VI cells. The $1 \%$ most variable CpG sites are used as initial input in IPA. In T/E III cells, 3,172 CpG sites do not map to a gene annotation using Illumina annotation. (C) Identification of differentially methylated CpG sites that are annotated to a gene according to Illumina annotation, and that are common to both T/E expressing cells or specific to TE III or T/E VI cells, respectively.

Unsupervised hierarchical clustering was performed on these differentially methylated CpG sites to identify differences of the DNA methylation profile between T/E expressing and control cells. This cluster analysis showed a separation of T/E III and T/E VI expressing cells from their corresponding uninduced control cells, respectively, indicating that T/E expressing cells have a distinct DNA methylation pattern (Figure 3.3B). A subset of hypomethylated $\mathrm{CpG}$ sites was common to both T/E expressing cells (Figure 3.3B, red box) proposing that this methylation profile could be used as a classifier of T/E-specific methylation. This set of differentially methylated CpG sites $(n=355$; Supplementary Table S3.2) was subsequently applied for pathway analysis using the gene designation as input for the IPA tool to characterize the biological processes and functions of the protein-coding genes, in which the differentially methylated $\mathrm{CpG}$ sites were found ( $\mathrm{Fi}$ gure 3.3C). ERG and the histone deacetylase 2 (HDAC2) were found as upstream regulator indicating activation of the HDAC pathway as consequence of T/E overexpression in LNCaP cells. HDAC1 has been identified as an ERG-interacting protein and its upregulation accompanied by target gene silencing in association with ERG gene expression has previously been reported [24]. The biological processes affected by the T/E-induced methylation profile were related to 'Cytoskeleton organization', 'Cell migration' and 'Neuron differentiation' (Supplementary Table S3.3). The canonical pathways associated with these processes were 'Gastrin signaling' as well as 'cAMP signaling' (Supplementary Table S3.4). 
A

\section{Hypermethylation \\ Hypomethylation}

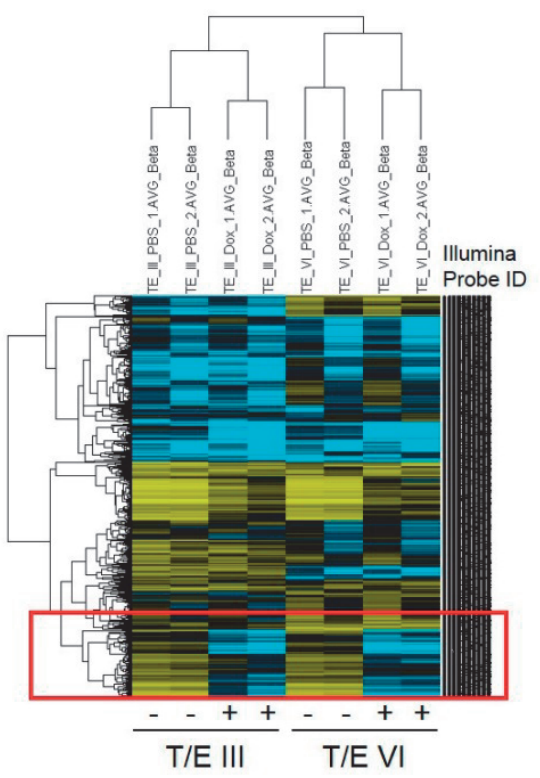

B

\begin{tabular}{lcc}
\hline $\begin{array}{l}\text { Upstream } \\
\text { Regulator }\end{array}$ & p-value & \# Genes \\
\hline VEGF & $8.38 \mathrm{E}-05$ & 20 \\
ERG & $1.92 \mathrm{E}-04$ & 11 \\
TGFB1 & $1.46 \mathrm{E}-03$ & 42 \\
HDAC2 & $5.25 \mathrm{E}-02$ & 5 \\
PI3K complex & $3.18 \mathrm{E}-02$ & 9 \\
\hline
\end{tabular}

Figure 3.3: Global methylation profile in T/E expressing cells. (A) Unsupervised hierarchical clustering of methylation patterns of the top $1 \%$ variable CpG sites in LNCaP-T/E expressing cells. Rows display the methylation levels by continuous $\beta$ values of the top $1 \%$ CpG sites $(n=1,255)$ with the largest intersample methylation variability. Samples are clustered in columns using Euclidean distance as similarity measure. A distinct cluster of hypomethylated CPG sites was observed in T/E expressing cells (red box). Blue - hypomethylation, yellow hypermethylation. (B) An upstream regulator analysis was performed to study potential mechanisms regulating the methylation changes associated with T/E overexpression. This analysis revealed ERG as well as HDAC2 as upstream regulator.

\section{Correlation of methylation status and gene expression}

We next aimed to link the DNA methylation patterns to transcriptional modulation. Differentially methylated $\mathrm{CpG}$ sites with a $\beta$-value of at least 0.2 were correlated to the mRNA expression level of associated genes using the microarray gene expression data that had been used in chapter 2 [32]. Out of these genes that were at least 1.5-fold differentially regulated upon T/E overexpression compared to uninduced control cells were selected ( $n=68$; Supplementary Table S3.2). These genes were compared to data from the TCGA prostate cancer cohort (TCGA PRAD) that had been retrieved from the UCSC Cancer Browser (https://genome-cancer.ucsc.edu/). First, gene expression was integrated with the T/E fusion status (Figure 3.4). Of note, high expression of the WNTreceptor Frizzled-4 (FZD4) and human leukocyte antigen class II histocompatibility antigen, DM beta chain (HLA-DMB), correlated to the T/E fusion in the TCGA PRAD data 
(Figure 3.4A and Figure 3.4B ii and iii). These candidates were therefore analysed in more detail. ERG expression was used as surrogate for the T/E fusion status as visualized in Figure 3.4A. Integration of the DNA methylation level and gene expression from the TCGA PRAD data showed increased expression of FZD4 and HLA-DMB in T/E fusionpositive compared to fusion-negative and benign samples (Figure $3.4 \mathrm{~B}$ ii and iii). This increase was accompanied by a lower DNA methylation level of FZD4 as well as HLA$D M B$ (Figure 3.4B iv and $v$ ). T/E-induced upregulation of FZD4 has been reported to promote Wnt signaling and EMT $[37,38]$. Hypomethylation-induced upregulation of gene expression could be a regulatory mechanism for FZD4 upregulation in T/E expressing cells. Further, ERG-associated upregulation of $H L A-D M B$ is consistent with previous reports $[24,25,39]$. 
A
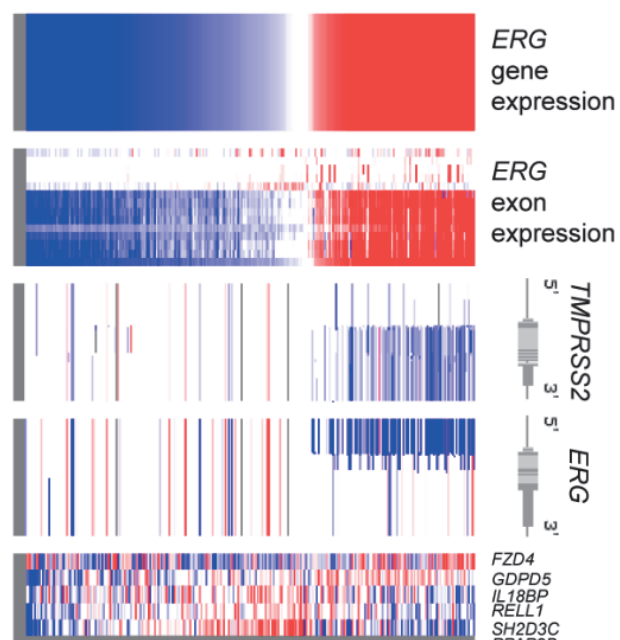

FZD4

GDPD5

REL1

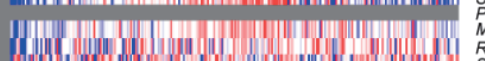

$P P A P 2 B$

RIN2

for SL23A2

Hinn

MSN

TSPAN14

나매

MTV 6

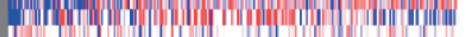

HLA-DMB

COL4A6

PNPLA7

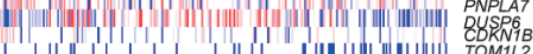

|

แ| PCED1B

MACF1

CD63

I.

TMC1D2B

SORBS

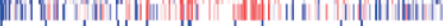

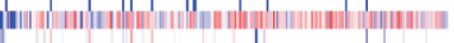

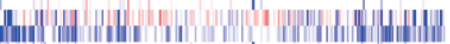

№n

$P R C P$
$T R A-31 P 2$

CRCTN4

${ }_{P H A C T R 2}^{A C T N 4}$

HPSE
FAM160A2

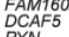

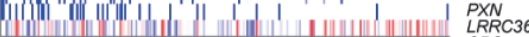

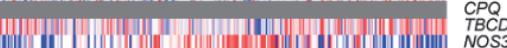

1.

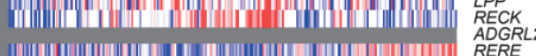

.

$R E R E$
$A P H 1 B$
$F A M 107$

MYM10

H.

$A B P C=3$

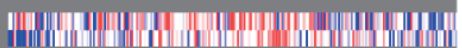

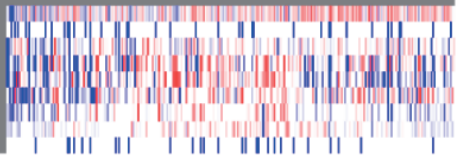

LTBAR

STARD 13
CASC 15

PHC2

NCK2

NCKD 2

$P P E I B P 1$
$B E N D 7$

PDE $P$ PC

SLC35E1

Figure 3.4: RNA transcript and DNA methylation level in TCGA PRAD data. 
B Transcript level

i

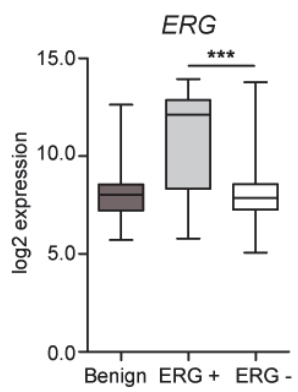

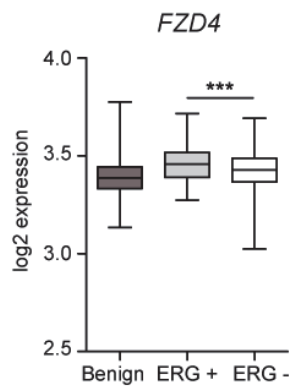

iii

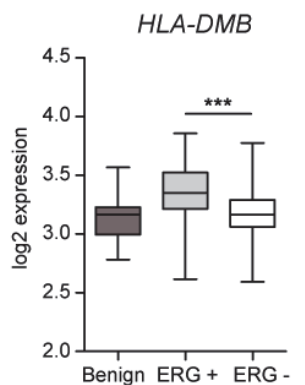

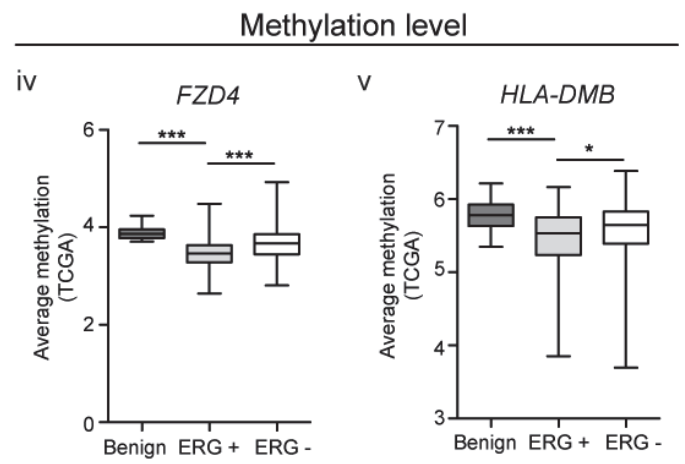

Figure 3.4 continued: (A) Graphical view of the TCGA data using the UCSC Xena browser (http://xena.ucsc.edu). Each row is a sample in the dataset, with different types of data mapped to that sample along the columns. In this view, data is sorted by RNAseq ERG gene expression (left column). Genes that were at least 1.5-fold differentially regulated and differentially methylated upon T/E overexpression in T/E III and VI expressing cells compared to uninduced control cells are depicted $(n=68)$. Samples are mean normalized. Red - high expression, blue - low expression. Sample type: blue - primary tumor, pink - solid tissue normal. (B) Analysis of mRNA expression and DNA methylation according to the T/E fusion status in the TCGA PRAD cohort ( $\mathrm{n}=568$ ). (i) ERG expression. Expression of (ii) FZD4 and (iii) HLA-DMB is significantly higher in T/E fusion-positive (ERG+) compared to fusion-negative (ERG-) and benign samples. DNA methylation of (iv) FZD4 and (v) HLA-DMB is reduced in T/E fusion-positive samples. ERG expression was used as surrogate for the T/E fusion status. ${ }^{*} \mathrm{p}<0.05,{ }^{* * *} \mathrm{p}<0.001$

Hypomethylation of a region of $2 \mathrm{~kb}$ within the transcription start site of FZD4 was found in $\mathrm{T} / \mathrm{E}$ fusion-positive samples compared to fusion-negative and benign samples $(p<0.01$ ) by Börno et al. using MeDIP-Seq analysis [23] (data available under GEO accession number GSE35342.). No differential methylation for HLA-DMB was identified in their dataset. Analysis of the genomic context of the differentially methylated region associated with FZD4 revealed that the CPG site was located within the gene body, a region showing enrichment for the histone $\mathrm{H} 3$ mark $\mathrm{H} 3 \mathrm{~K} 4 \mathrm{Me} 1$, as determined within the ENCODE consortium [40] (Figure 3.5A). For HLA-DMB, the hypomethylated CpG sites was located within $1500 \mathrm{bp}$ upstream of the transcription start site, a region that is 
enriched for the histone H3 marks H3K4Me1 and H3K27ac [40] (Figure 3.5B), suggesting that, apart from differential DNA methylation, alterations in histone modifications might represent an additional level of regulation of gene expression in T/E expressing cells.

A

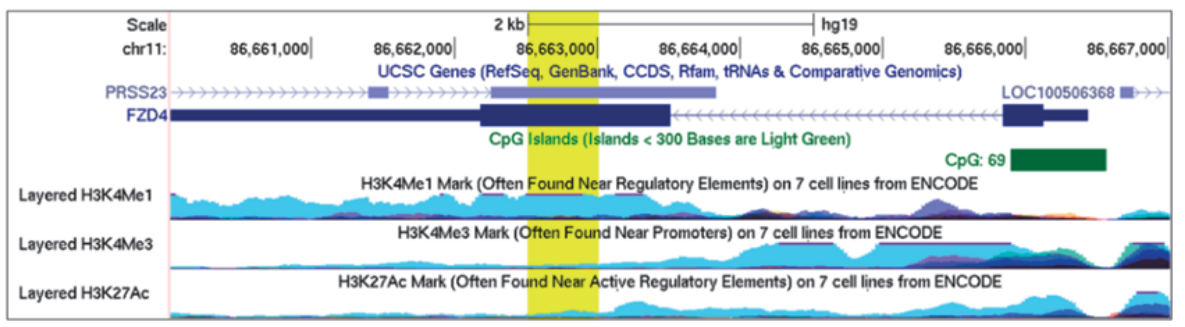

B

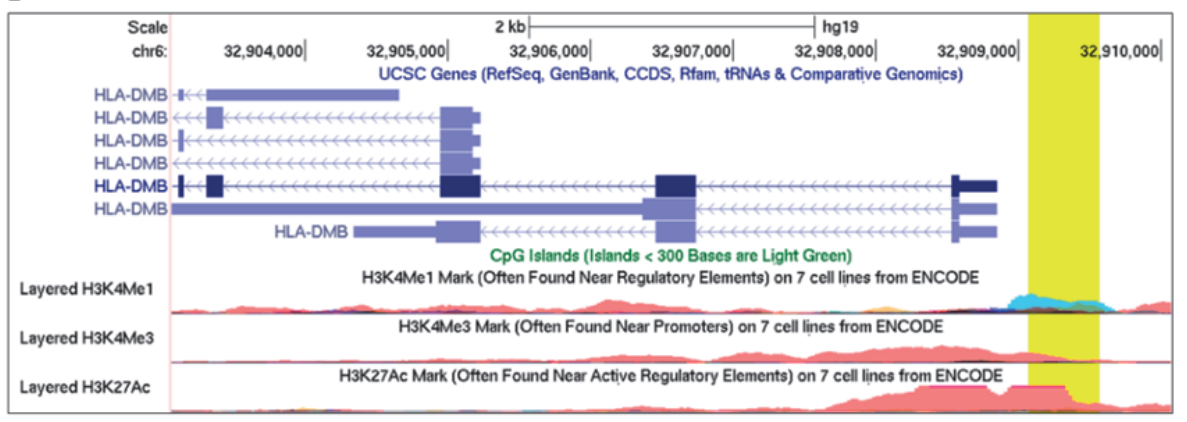

Figure 3.5: Graphical view showing the genomic and epigenetic context of FZD4 and HLA-DMB. (A) FZD4 gene region on chromosome 11 in hg19 assembly derived from the UCSC Genome Browser (http://genome.ucsc.edu/). A CpG island is found upstream of the transcription start site of FZD4 at coordinate chr11:86665902-86666567. The chromosomal coordinate of the CpG site that is hypomethylated upon T/E overexpression is chr11: 86662968 (yellow box in A, depicted as 500 bp bin at chr11:8666251586663014), which is in N-shelf position in relation to the CpG island, and located within a DNase hypersensitivity site at chr11:86662740-86663030. (B) HLA-DMB gene region on chromosome 6 in hg19. The chromosomal coordinate of the $C p G$ site in the HLA-DMB gene that is hypomethylated upon T/E overexpression is chr6: 32909440 (yellow box in B, depicted as 500 bp bin at chr6:32909069-32909568), which is 1500 bp upstream of the TSS (TSS1500) in the regulatory feature at chr6:32908496-32909716 according to Illumina annotation. Half-height boxes - 5'UTR, fullheight boxes - coding regions, thin line with transcription-direction arrows introns. Layered H3K - levels of enrichment of the H3K4Me1, H3K4Me3, and H3K27ac histone mark across the genome as determined by a ChIP-seq assay [40]. The H3K4Me1 mark is associated with enhancers and with DNA regions downstream of transcription starts. The H3K4Me3 histone mark is associated with promoters that are active or poised to be activated. The H3K27ac is thought to enhance transcription possibly by blocking the spread of the repressive histone mark H3K27Me3.

\section{Microarray profiling indicates differentially expressed epigenetic regulators}

To identify the regulatory mechanisms of T/E-induced epigenetic changes in LNCaP-T/E cells, microarray gene expression profiling data were analyzed [32]. Several genes encoding epigenetic regulators were differentially expressed in T/E expressing cells compared to control cells (Figure 3.6A). These included the histone demethylase JMJD1C, 
chromodomain helicase DNA binding proteins (CHDs), CpG-binding proteins, histone demethylases, arginine methyltransferases (PRMTs), and histone methyltransferases (Figure 3.6A). Validation of the transcriptional modulation by qPCR confirmed the increased expression of PRDM1, JMJD1C, CHD9, SIRT2, SETD1B, and CXXC1, and reduced expression of SUV39H1, PRMT1, PRMT5, PRMT6 (Figure 3.6B).

A

\begin{tabular}{|c|c|c|c|}
\hline \multirow[t]{2}{*}{ A } & \multirow[b]{2}{*}{ Gene } & \multicolumn{2}{|c|}{ Fold Change } \\
\hline & & T/E III & T/E VI \\
\hline \multirow{9}{*}{$\begin{array}{c}\text { Chromodomain helicase } \\
\text { DNA binding protein }\end{array}$} & $\overline{A R I D 4 B}$ & NS & 1.84 \\
\hline & $B A Z 1 A$ & 1.71 & 1.79 \\
\hline & $B A Z 2 B$ & 1.81 & 2.40 \\
\hline & BRD2 & NS & 1.56 \\
\hline & BRD9 & 1.50 & 1.68 \\
\hline & CHD1 & NS & 1.80 \\
\hline & CHD4 & NS & 1.65 \\
\hline & CHD7 & 1.75 & 1.65 \\
\hline & CHDg & 1.65 & 3.12 \\
\hline \multirow[t]{8}{*}{ CpG binding protein } & $c \times x C 1$ & NS & 1.52 \\
\hline & HDAC7 & NS & 1.52 \\
\hline & JARID2 & 1.75 & 2.05 \\
\hline & JMND1C & 5.35 & 5.57 \\
\hline & KAT2A & NS & 0.39 \\
\hline & КАТ $2 B$ & 2.19 & 1.96 \\
\hline & KDMRA & 1.78 & NS \\
\hline & $K D M 2 B$ & NS & 3.85 \\
\hline \multirow[t]{9}{*}{ Demethylases } & KDMBA & 1.57 & 2.22 \\
\hline & KDMSA & 1.54 & 2.22 \\
\hline & KDM5B & NS & 1.87 \\
\hline & KDMGA & 1.61 & NS \\
\hline & MSH6 & 0.54 & 0.59 \\
\hline & NCOA1 & 1.61 & NS \\
\hline & NCOA3 & NS & 1.99 \\
\hline & PRDM1 & NS & 5.85 \\
\hline & PRMT1 & NS & 0.49 \\
\hline \multirow{8}{*}{$\begin{array}{c}\text { Arginine } \\
\text { methyltransferase }\end{array}$} & PRMT2 & NS & 1.52 \\
\hline & PRMT3 & NS & 0.44 \\
\hline & PRMT5 & 0.65 & 0.46 \\
\hline & PRMT6 & 0.67 & 0.56 \\
\hline & SETD1B & NS & 1.83 \\
\hline & SETD6 & NS & 0.58 \\
\hline & SIRT1 & NS & 1.90 \\
\hline & SIRT2 & 4.66 & 2.76 \\
\hline \multirow{3}{*}{$\begin{array}{l}\text { H3K9me2/3 methylation, } \\
\text { interaction with DNMT3B }\end{array}$} & SMARCA2 & 1.75 & 2.80 \\
\hline & SUV39H1 & 0.58 & 0.50 \\
\hline & TDRD1 & 1.59 & 2.08 \\
\hline
\end{tabular}

B

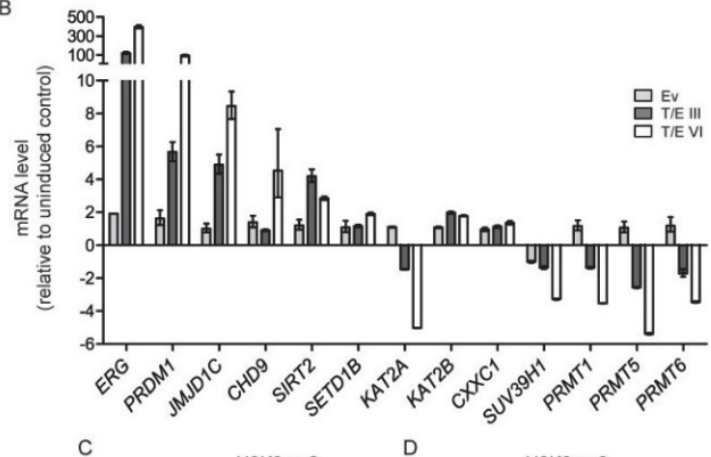

C

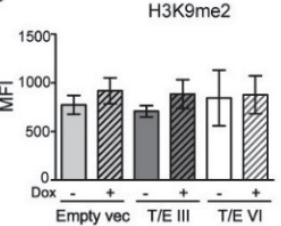

H3K9me3

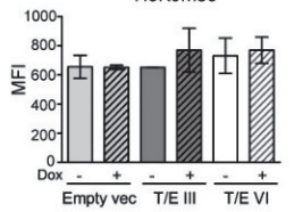

$\mathrm{E}$

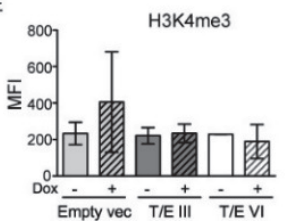

$\mathrm{F}$

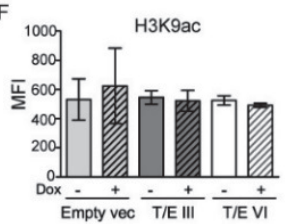

Figure 3.6: Transcriptional modulation of epigenetic regulators and posttranslational histone modifications in LNCaP-T/E cells. (A) Microarray gene expression data indicating differentially expressed epigenetic regulators. (B) qPCR validation of T/E-induced gene expression changes relative to uninduced controls. The mRNA expression profile after $\mathrm{T} / \mathrm{E}$ overexpression is associated with an open chromatin state facilitating gene transcription characterized by increased $\mathrm{H} 3 \mathrm{~K} 9$ acetylation, as well as $\mathrm{H} 3 \mathrm{~K} 9$ and $\mathrm{H} 3 \mathrm{~K} 4$ methylation. For example, JMJD1C, a histone demethylase also known as KDM3C, is involved in maintaining low H3K9me2 levels that are associated with activated target gene expression. JMJD1C has been described as coactivator for several transcription factors including AR $[41,42]$. A general interaction between Jmj-containing KDM proteins and ERG has been reported to lead to activation of the YAP1 proliferation pathway [43]. JMJD1C expression has further been implicated in the reactivation of silenced genes in diverse tissues and cancer [44]. SIRT2, a histone deacetylase, was implicated in tumor progression in hepatocellular cancer by promoting EMT and cell motility [45]. The histone methylation transferase SUV39H1 is required to establish an H3K9me2/3 methylation pattern by interacting with DNMT3B $[46,47]$. Since H3K9 methylation is associated with repressed gene expression, downregulation of SUV39H1 could be associated with low H3K9me2/3 methylation and increased gene transcription that has been associated with cancer progression [48]. Data are shown as $\triangle \mathrm{Cp}$ values relative to GAPDH measured in the same samples, which had been used for the MethylationEPIC Beadchip array. (C-F) Luminex measurements of the histone $\mathrm{H} 3$ modification levels: (C) histone $\mathrm{H} 3$ lysine 9 di-methylation (H3K9me2), (D) histone $\mathrm{H} 3$ lysine 9 tri-methylation (H3K9me3), (E) histone H3 lysine 4 tri-methylation (H3K4me3) and (F) histone H3 lysine 9 acetylation (H3K9ac). MFI - mean fluorescent intensity. Ev - Empty vector; NS - not significant. Red - upregulated; blue - downregulated. 
The expression analysis of genes encoding epigenetic regulators revealed differential regulation of histone modifiers. Histone modifications play an important role in chromatin organization and transcriptional modulation indicating a link between histone modification and differential DNA methylation, which is supported in many recent studies $[49,50]$. This further suggested that dysregulation of histone modifying genes could lead to an altered DNA methylation in T/E expressing cells. The gene expression profile of those histone modifiers indicated a histone modification pattern characterized by increased H3K9 acetylation, as well as increased H3K9 and H3K4 methylation that could reflect the gene expression status. Lysine methylation can be recognized by epigenetic readers that regulate the recruitment of additional enzymatic activities affecting gene transcription [51]. We therefore analysed the global changes in posttranslational histone modification pattern upon T/E overexpression in LNCaP cells using a Luminex histone modification assay (Figure 3.6C-F). However, this analysis did not reveal a significant differential histone modification in T/E expressing cells compared to control cells suggesting that the differentially expressed histone modifying enzymes do not affect the global profile of histone modifications. Alternative techniques such as chromatin immunoprecipitation could provide more insights into the epigenetic changes induced by $T /$ E overexpression.

\section{DISCUSSION}

Clear genomic driver events are lacking for many prostate tumors [6], while DNA methylation changes have been recurrently described [5]. Specific alterations of the DNA methylation profile are known to occur within specific molecular PCa subtypes implying DNA methylation as biomarker in PCa [7]. The functional consequences of those methylation changes remain unclear.

By inducing T/E overexpression in a LNCaP cell model, we found a global hypomethylation profile. However, the majority of these methylation differences showed only a moderate change. Gene ontology analysis revealed that the T/E-induced methylation changes correlated with cell migration and neuron differentiation. Neuronal transformation has been associated with an aggressive clinical phenotype in PCa as reviewed in chapter 1 . Our integrative analysis on epigenetic regulation and gene expression in LNCaP-T/E cells demonstrated that T/E overexpression drives upregulation of FZD4 and $H L A-D M B$ that could be correlated with loss of DNA methylation and histone modification in PCa cells. This data corroborated previous findings of $\mathrm{T} / \mathrm{E}$-induced transcriptional modulation of TDRD1 expression by loss of DNA methylation [52].

Most CpG sites showing a significant differential methylation, were located in gene bodies, which is of interest regarding the proposed role of gene body methylation in transcriptional regulation by impacting the efficiency of transcription elongation, regulation of alternative promoters and RNA splicing or repression of anti-sense transcripts $[53,54]$. Gene body methylation has frequently been associated with increased mRNA 
transcription [55]. DNA methylation was proposed to be mechanistically facilitated by open and actively transcribed chromatin [56]. In our study, gene body hypomethylation correlated with increased mRNA expression, supporting earlier findings that demonstrated low gene body methylation in highly expressed genes potentially due to interference of DNA accessibility to methylating enzymes by the transcriptional machinery [56]. FZD4 mRNA was shown to be upregulated upon T/E overexpression thereby activating $W n t / \beta$-catenin signaling in PCa (chapter 2, [32]). It is not clear from the present analysis whether T/E-induced FZD4 body hypomethylation represents a potential regulatory mechanism of activated gene expression. However, the enriched pattern of histone H3K4me1 modification at the hypomethylated gene body $\mathrm{CpG}$ site, which is often associated with promoters and enhancers, supports a regulatory role of gene body hypomethylation [53]. Another interesting finding is that this hypomethylated CpG site is located within a DNAse hypersensitivity site generally characterized by an open chromatin structure and transcriptional activity [57].

HLA-DMB is a non-classical major histocompatibility complex (MHC) class II molecule acting as a peptide editor for classical MHCII proteins [58]. ERG-associated upregulation of HLA-DMB in PCa cells is consistent with previous reports and was shown as a target of HDAC1-mediated gene regulation [24, 39]. Treatment of VCaP cells with the HDAC inhibitor Trichostatin A (TSA) led to downregulation of HLA-DMB [25]. HLA-DMB expression has previously been correlated with increased cytotoxic T lymphocyte infiltration and improved prognosis in ovarian cancer [59]. The role within the pathogenesis of PCa or as marker of a T/E-induced transcriptional profile remains unknown.

In conclusion, we show that T/E overexpression affects the epigenetic and transcriptional profile in PCa cells that are correlated with aggressive cell behavior on the global level. Future research is necessary to reveal the mechanistic basis of those molecular changes and to analyse the role of differential CpG methylation in regulating transcriptional changes. We used a high-throughput methylation profiling approach to detect global variations in DNA methylation. Bisulfite sequencing is the gold standard for measuring DNA methylation by determining the fraction of bisulfite-converted and unconverted (methylated) cytosines and should be used for subsequent validation of pre-selected genomic regions with single-nucleotide resolution. Further analysis of the epigenomic and transcriptional mechanisms of ERG can be achieved by chromatin immunoprecipitation followed by high-throughput sequencing (ChIP-seq). ChIP-seq analysis using our Dox-inducible LNCaP-T/E cell model would be a valuable contribution to existing data to generate a broader view of the molecular and cellular consequences of T/E overexpression. 


\section{SUPPLEMENTARY INFORMATION}

\section{Content}

1. Supplementary materials

2. Supplementary data

1. Supplementary materials

Supplementary Table S3.1: List of primer sequences and probes used for qPCR

\begin{tabular}{lcll}
\hline Name & \#UPL probe & Sequence forward 5' - $\mathbf{3}^{\prime}$ & Sequence reverse $5^{\prime}-\mathbf{3}^{\prime}$ \\
\hline CHD9 & 75 & tcatcagcatttacatgacagaaa & ccagaaccatcgctcttctt \\
CXXC1 & 13 & ctcagatgactgtggcatgaa & gtgctcttcagcaatgcaag \\
ERG_T/E & 64 & ggttaatgcatgctagaaacaca & agatggttgagcagctttcg \\
FZD4 & 19 & aactttcacaccgctcatcc & tgcacattggcacataaaca \\
GADPH & 60 & agccacatcgctcagacac & gcccaatacgaccaaatcc \\
JMJD1C & 18 & gaagatttgaaacccaatggag & actgaacgaggaatgccagt \\
KAT2A & 25 & tcctcactcacttccccaaa & ttggagagtttgccccatag \\
KAT2B & 83 & ctgcgatctcccaatgatg & ctgtggcacgttgcagtaa \\
PRDM1 & 67 & acgtgtgggtacgaccttg & ctgccaatccctgaaacct \\
PRMT1 & 10 & ccccaaacagctggtcac & ggtcttccaccttgacggta \\
PRMT5 & 6 & gactagtcatcccggagaagc & ggccgattcttagcaggtt \\
PRMT6 & 44 & accgcctgggtatccttc & cccacgtccagtaccgtct \\
SETD1B & ctggcttaacgacacgctct & ccatcgtcccgtttcttct \\
SETDB1 & 22 & aggcacgtggtggaagtc & ccactcacatcttttgtcatcc \\
SIRT2 & 10 & gaaggtgcaggaggctca & caggaagtccatgtctgcttc \\
SUV39H1 & 52 & gtcatggagtacgtgggagag & cctgacggtcgtagatctgg \\
\hline
\end{tabular}

2. Supplementary data

Supplementary Table S3.2: Functional annotation of genes differentially methylated upon $\mathrm{T} / \mathrm{E}$ overexpression

\begin{tabular}{|c|c|c|c|c|c|c|c|c|}
\hline $\begin{array}{c}\text { Gene } \\
\text { Symbol }\end{array}$ & $\begin{array}{c}\text { TE III } \\
\text { FC }\end{array}$ & $\begin{array}{c}\text { TE III } \\
\Delta \beta\end{array}$ & $\begin{array}{c}\text { TE VI } \\
\text { FC }\end{array}$ & $\begin{array}{c}\text { TE VI } \\
\Delta \beta\end{array}$ & $\begin{array}{c}\text { Gene } \\
\text { Region }\end{array}$ & $\begin{array}{c}\text { CpG } \\
\text { Location }\end{array}$ & Chr. & $\begin{array}{c}\text { Illumina } \\
\text { Probe ID }\end{array}$ \\
\hline FZD4 & 22.707 & -0.400 & 49.555 & -0.415 & Body & N_Shelf & 11 & cg06659209 \\
\hline GDPD5 & 22.227 & -0.255 & 12.495 & -0.190 & $5 '$ 'UTR & 0 & 11 & cg22171321 \\
\hline IL18BP & 12.989 & -0.323 & 9.233 & -0.407 & TSS200 & 0 & 11 & cg26149678 \\
\hline RELL1 & 12.107 & -0.341 & 12.068 & -0.488 & Body & 0 & 4 & cg18672030 \\
\hline SH2D3C & 10.850 & -0.347 & 21.081 & -0.595 & TSS200 & 0 & 9 & cg02356631 \\
\hline
\end{tabular}




\section{Supplementary Table S3.2: continued}

\begin{tabular}{|c|c|c|c|c|c|c|c|c|}
\hline$P P A P 2 B$ & 9.174 & -0.166 & 9.486 & -0.256 & Body & 0 & 1 & cg01860101 \\
\hline$M G P$ & 7.846 & -0.336 & 2.549 & -0.334 & TSS200 & 0 & 12 & cg00431549 \\
\hline RIN2 & 7.195 & -0.247 & 8.236 & -0.387 & 1stExon & 0 & 20 & cg06856720 \\
\hline$S L C 23 A 2$ & 6.663 & -0.479 & 15.669 & -0.572 & Body & 0 & 20 & cg22147446 \\
\hline OSBPL10 & 6.524 & -0.632 & 4.495 & -0.598 & Body & 0 & 3 & cg02311396 \\
\hline MSN & 4.847 & -0.147 & 8.723 & -0.255 & Body & 0 & $x$ & cg26588779 \\
\hline SLC44A3 & 4.841 & -0.295 & 6.315 & -0.271 & Body & 0 & 1 & cg01463768 \\
\hline TSPAN14 & 4.571 & -0.216 & 7.382 & -0.187 & Body & 0 & 10 & cg08448786 \\
\hline ETV6 & 4.354 & -0.222 & 7.012 & -0.155 & Body & 0 & 12 & cg06252636 \\
\hline MDS2 & 4.354 & -0.164 & 7.012 & -0.304 & Body & 0 & 1 & cg10372630 \\
\hline PRKCH & 4.008 & -0.255 & 3.175 & -0.250 & Body & 0 & 14 & cg16918236 \\
\hline$H L A-D M B$ & 3.894 & -0.263 & 4.169 & -0.279 & TSS1500 & 0 & 6 & cg10518264 \\
\hline AKAP13 & 3.860 & -0.117 & 3.363 & -0.379 & Body & 0 & 15 & cg05254518 \\
\hline COL4A6 & 3.836 & -0.135 & 2.320 & -0.227 & Body & 0 & $x$ & cg02033305 \\
\hline PNPLA7 & 3.548 & -0.136 & 2.541 & -0.230 & Body & N_Shore & 9 & cg01701837 \\
\hline DUSPG & 3.331 & -0.331 & 4.156 & -0.302 & Body & N_Shore & 12 & cg10077746 \\
\hline CDKN1B & 3.269 & -0.169 & 4.968 & -0.230 & TSS1500 & N_Shore & 12 & cg21142548 \\
\hline TOM1L2 & 3.179 & -0.201 & 1.815 & -0.272 & Body & 0 & 17 & cg08151968 \\
\hline$D D \times 10$ & 3.032 & -0.432 & 4.918 & -0.547 & Body & 0 & 11 & cg13225881 \\
\hline IPCEF1 & 2.990 & -0.336 & 4.930 & -0.299 & ExonBnd & 0 & 6 & cg12263540 \\
\hline PCED1B & 2.958 & -0.229 & 6.040 & -0.143 & 5'UTR & 0 & 12 & cg06869032 \\
\hline MACF1 & 2.947 & -0.216 & 5.745 & -0.199 & Body & 0 & 1 & cg21122391 \\
\hline CD63 & 2.863 & -0.215 & 3.415 & -0.290 & TSS1500 & S_Shore & 12 & cg26418880 \\
\hline$T B C 1 D 2 B$ & 2.665 & -0.274 & 2.251 & -0.202 & Body & 0 & 15 & cg12192261 \\
\hline TMEM217 & 2.623 & -0.465 & 4.237 & -0.563 & TSS1500 & S_Shore & 6 & cg00480799 \\
\hline SORBS1 & 2.580 & -0.386 & 6.418 & -0.424 & 5'UTR & 0 & 10 & cg11041353 \\
\hline$S D P R$ & 2.563 & -0.188 & 6.100 & -0.265 & 5'UTR & 0 & 2 & cg08390172 \\
\hline$B C L 2 L 1$ & 2.542 & -0.202 & 3.626 & -0.195 & Body & 0 & 20 & cg15488794 \\
\hline$P R C P$ & 2.491 & -0.497 & 4.378 & -0.565 & Body & 0 & 11 & cg00808150 \\
\hline CAP2 & 2.376 & -0.350 & 0.996 & -0.263 & Body & 0 & 6 & cg22753611 \\
\hline TRAF3IP2 & 2.347 & -0.257 & 4.178 & -0.269 & Body & 0 & 6 & cg00590039 \\
\hline CRK & 2.302 & -0.438 & 4.621 & -0.419 & Body & 0 & 17 & $\operatorname{cg} 06742476$ \\
\hline ACTN4 & 2.283 & -0.269 & 1.900 & -0.318 & Body & 0 & 19 & cg14891553 \\
\hline
\end{tabular}




\section{Supplementary Table S3.2: continued}

\begin{tabular}{|c|c|c|c|c|c|c|c|c|}
\hline PHACTR2 & 2.272 & -0.133 & 2.707 & -0.232 & Body & 0 & 6 & cg24598922 \\
\hline HPSE & 2.245 & -0.138 & 13.495 & -0.313 & Body & 0 & 4 & cg13186580 \\
\hline FAM160A2 & 2.186 & -0.332 & 2.280 & -0.323 & Body & 0 & 11 & cg13301956 \\
\hline DCAF5 & 2.145 & -0.552 & 2.184 & -0.539 & Body & N_Shore & 14 & cg21250594 \\
\hline$P X N$ & 2.124 & -0.232 & 2.101 & -0.325 & Body & 0 & 12 & cg25220336 \\
\hline FN1 & 2.095 & -0.239 & 1.197 & -0.191 & Body & 0 & 2 & cg14222615 \\
\hline$L R R C 36$ & 2.090 & -0.271 & 2.887 & -0.242 & Body & 0 & 16 & cg09879805 \\
\hline$C P Q$ & 2.042 & -0.444 & 2.660 & -0.360 & Body & 0 & 8 & cg23762726 \\
\hline$T B C D$ & 2.040 & -0.177 & 6.227 & -0.294 & Body & S_Shore & 17 & cg18102305 \\
\hline NOS3 & 2.017 & -0.519 & 2.012 & -0.607 & Body & N_Shore & 7 & cg07643980 \\
\hline$\angle P P$ & 1.968 & -0.373 & 1.787 & -0.317 & 5'UTR & 0 & 3 & cg23070717 \\
\hline RECK & 1.954 & -0.461 & 4.103 & -0.434 & Body & 0 & 9 & cg09959196 \\
\hline ADGRL2 & 1.951 & 0.069 & 4.118 & -0.204 & 5'UTR & 0 & 1 & cg17083209 \\
\hline RERE & 1.927 & -0.240 & 1.894 & -0.273 & Body & 0 & 1 & cg07836226 \\
\hline$S L C 25 A 45$ & 1.922 & -0.545 & 1.304 & -0.574 & 0 & N_Shore & 11 & cg24215776 \\
\hline$A P H 1 B$ & 1.921 & -0.154 & 2.256 & -0.305 & Body & 0 & 15 & cg25074326 \\
\hline FAM107A & 1.916 & -0.300 & 5.671 & -0.352 & TSS1500 & 0 & 3 & $\operatorname{cg} 04232458$ \\
\hline MYO10 & 1.903 & -0.269 & 3.980 & -0.433 & Body & 0 & 5 & cg02288345 \\
\hline$A P P$ & 1.897 & -0.269 & 5.314 & -0.244 & Body & 0 & 21 & cg23877117 \\
\hline SAAL1 & 1.889 & -0.413 & 1.420 & -0.360 & ExonBnd & 0 & 11 & cg14220104 \\
\hline$A B C C 3$ & 1.856 & -0.198 & 11.120 & -0.209 & Body & 0 & 17 & cg06926619 \\
\hline PLSCR3 & 1.841 & -0.120 & 2.062 & -0.330 & Body & N_Shore & 17 & cg21368706 \\
\hline TXNRD2 & 1.825 & -0.423 & 1.119 & -0.451 & Body & 0 & 22 & cg07073234 \\
\hline$L T B 4 R$ & 1.812 & -0.144 & 4.980 & -0.372 & 5'UTR & S_Shore & 14 & cg20542800 \\
\hline SH3YL1 & 1.806 & -0.321 & 0.732 & -0.224 & Body & N_Shore & 2 & cg17500664 \\
\hline STARD13 & 1.784 & -0.198 & 2.388 & -0.267 & Body & 0 & 13 & cg20497682 \\
\hline CASC15 & 1.780 & -0.355 & 2.756 & -0.401 & Body & 0 & 6 & cg03680338 \\
\hline PHC2 & 1.777 & -0.252 & 1.757 & -0.288 & Body & 0 & 1 & cg03944314 \\
\hline$K D M 2 A$ & 1.776 & -0.347 & 1.481 & -0.184 & Body & 0 & 11 & cg16322424 \\
\hline TRIP12 & 1.752 & -0.226 & 1.995 & 0.143 & Body & 0 & 2 & cg11149952 \\
\hline NSMCE2 & 1.751 & -0.585 & 1.448 & -0.475 & Body & 0 & 8 & cg23009206 \\
\hline NCK2 & 1.730 & -0.525 & 1.681 & -0.594 & TSS1500 & N_Shore & 2 & cg26032413 \\
\hline INTS3 & 1.679 & -0.379 & 1.242 & -0.583 & ExonBnd & 0 & 1 & cg18006944 \\
\hline
\end{tabular}




\section{Supplementary Table S3.2: continued}

\begin{tabular}{|c|c|c|c|c|c|c|c|c|}
\hline CHDS & 1.652 & -0.202 & 3.120 & -0.286 & 5'UTR & 0 & 16 & cg25775667 \\
\hline PKM & 1.643 & -0.272 & 1.314 & -0.351 & Body & 0 & 15 & cg09485853 \\
\hline PRKAB1 & 1.585 & -0.579 & 0.896 & -0.437 & Body & 0 & 12 & cg14654609 \\
\hline EML6 & 1.578 & -0.220 & 1.086 & -0.064 & Body & 0 & 2 & cg07450514 \\
\hline PPFIBP1 & 1.565 & -0.241 & 1.703 & -0.266 & 5'UTR & 0 & 12 & cg03114371 \\
\hline BEND7 & 1.561 & -0.163 & 1.509 & -0.281 & TSS1500 & 0 & 10 & cg02648003 \\
\hline$P D E 7 B$ & 1.561 & -0.246 & 1.609 & -0.242 & Body & 0 & 6 & cg11285173 \\
\hline NCOA7 & 1.550 & -0.271 & 2.657 & -0.188 & 5'UTR & 0 & 6 & cg19684445 \\
\hline HSD17B2 & 1.544 & -0.280 & 0.967 & -0.406 & Body & 0 & 16 & cg07307142 \\
\hline IST1 & 1.544 & -0.205 & 1.483 & -0.126 & 3'UTR & 0 & 16 & cg04266019 \\
\hline SLC10A7 & 1.543 & -0.319 & 1.080 & -0.276 & Body & 0 & 4 & cg12484495 \\
\hline SCARB2 & 1.538 & -0.532 & 0.704 & -0.554 & Body & N_Shelf & 4 & cg13870520 \\
\hline ATG7 & 1.527 & -0.335 & 1.178 & -0.402 & Body & 0 & 3 & cg11507857 \\
\hline TSPAN15 & 1.515 & -0.381 & 0.817 & -0.434 & Body & 0 & 10 & cg01632881 \\
\hline SLC35E1 & 1.505 & -0.209 & 2.242 & 0.032 & Body & 0 & 19 & cg26683792 \\
\hline PLEKHM1 & 1.493 & -0.233 & 1.653 & -0.368 & Body & 0 & 17 & cg13030804 \\
\hline SEPTS & 1.492 & -0.656 & 1.007 & -0.662 & Body & 0 & 17 & cg07089333 \\
\hline TNS2 & 1.485 & -0.184 & 1.794 & -0.236 & 5'UTR & S_Shelf & 12 & cg12934686 \\
\hline PPP4R1 & 1.471 & -0.148 & 1.711 & -0.437 & Body & 0 & 18 & cg18483766 \\
\hline CLHC1 & 1.458 & -0.161 & 1.497 & -0.221 & 5'UTR & 0 & 2 & cg22213014 \\
\hline CALD1 & 1.427 & -0.295 & 1.115 & -0.269 & Body & 0 & 7 & cg20055548 \\
\hline NDRG2 & 1.391 & -0.371 & 3.891 & -0.553 & Body & N_Shore & 14 & cg23288563 \\
\hline HDAC7 & 1.389 & -0.224 & 1.518 & -0.231 & Body & 0 & 12 & cg04381888 \\
\hline GPCPD1 & 1.375 & -0.350 & 2.205 & -0.462 & Body & 0 & 20 & cg05287483 \\
\hline STX17 & 1.374 & -0.308 & 1.150 & -0.270 & Body & 0 & 9 & cg03807032 \\
\hline MBNL1 & 1.374 & -0.270 & 1.219 & -0.231 & Body & 0 & 3 & cg12656221 \\
\hline$B R D 2$ & 1.370 & -0.205 & 1.558 & -0.194 & TSS1500 & N_Shore & 6 & cg05111146 \\
\hline MGST3 & 1.366 & -0.168 & 1.135 & -0.252 & 5'UTR & 0 & 1 & cg21165486 \\
\hline MARK2 & 1.347 & -0.249 & 1.118 & -0.332 & TSS1500 & N_Shore & 11 & cg23999391 \\
\hline ERGIC1 & 1.347 & -0.225 & 1.587 & -0.169 & Body & 0 & 5 & cg26899249 \\
\hline FNDC3B & 1.340 & -0.302 & 2.432 & -0.299 & Body & 0 & 3 & cg02889177 \\
\hline NRP1 & 1.323 & -0.494 & 1.965 & -0.508 & Body & 0 & 10 & cg09030553 \\
\hline$D D \times 17$ & 1.320 & -0.280 & 1.365 & -0.249 & Body & 0 & 22 & cg15906007 \\
\hline
\end{tabular}




\section{Supplementary Table S3.2: continued}

\begin{tabular}{|c|c|c|c|c|c|c|c|c|}
\hline VPS26B & 1.315 & -0.275 & 0.973 & -0.264 & 3'UTR & 0 & 11 & cg24000223 \\
\hline CLSTN3 & 1.314 & -0.217 & 1.268 & -0.211 & TSS1500 & 0 & 12 & cg00489652 \\
\hline RAPGEF2 & 1.313 & -0.226 & 1.280 & -0.278 & Body & 0 & 4 & cg16882824 \\
\hline FAM114A1 & 1.307 & -0.222 & 1.306 & -0.473 & 5'UTR & 0 & 4 & cg24576960 \\
\hline ITFG3 & 1.301 & -0.599 & 1.618 & -0.581 & 5'UTR & 0 & 16 & cg09335566 \\
\hline GNL1 & 1.300 & -0.190 & 1.626 & -0.252 & 3'UTR & 0 & 6 & cg01132522 \\
\hline BTNL8 & 1.287 & -0.218 & 1.098 & -0.179 & Body & 0 & 5 & cg17826428 \\
\hline RNF130 & 1.286 & -0.378 & 0.828 & -0.298 & Body & 0 & 5 & cg01402360 \\
\hline MIPOL1 & 1.278 & -0.043 & 1.099 & 0.225 & Body & 0 & 14 & cg27224192 \\
\hline INMT & 1.277 & -0.166 & 6.083 & -0.251 & TSS1500 & 0 & 7 & cg07252961 \\
\hline PCMTD1 & 1.265 & -0.049 & 1.241 & -0.243 & Body & 0 & 8 & cg01730030 \\
\hline MYL12A & 1.256 & -0.492 & 1.039 & -0.707 & TSS1500 & N_Shore & 18 & cg08543623 \\
\hline FGGY & 1.256 & -0.343 & 1.207 & -0.221 & Body & 0 & 1 & cg06329202 \\
\hline MLLT10 & 1.253 & -0.257 & 1.979 & -0.367 & Body & 0 & 10 & cg14673506 \\
\hline PRKCZ & 1.252 & -0.081 & 2.509 & -0.262 & Body & 0 & 1 & $\operatorname{cg} 24475758$ \\
\hline SKI & 1.227 & -0.517 & 1.835 & -0.457 & Body & 0 & 1 & cg11514097 \\
\hline SREK1 & 1.214 & -0.443 & 1.307 & -0.002 & Body & 0 & 5 & cg11497377 \\
\hline EXD2 & 1.208 & -0.481 & 1.193 & -0.541 & 3'UTR & 0 & 14 & cg18836689 \\
\hline$L X N$ & 1.201 & -0.212 & 1.360 & -0.369 & TSS1500 & 0 & 3 & cg17977250 \\
\hline ZNF346 & 1.193 & -0.609 & 1.157 & -0.609 & Body & 0 & 5 & cg22782782 \\
\hline CUBN & 1.187 & -0.132 & 1.556 & -0.230 & Body & 0 & 10 & cg07732336 \\
\hline MINK1 & 1.176 & -0.217 & 1.112 & -0.343 & Body & 0 & 17 & cg01322380 \\
\hline FAM167B & 1.175 & -0.157 & 2.031 & -0.318 & TSS1500 & N_Shore & 1 & cg20555536 \\
\hline SNX27 & 1.174 & -0.362 & 0.999 & -0.333 & Body & 0 & 1 & cg08504644 \\
\hline CREM & 1.170 & -0.149 & 1.247 & -0.296 & Body & 0 & 10 & cg26273724 \\
\hline SGPL1 & 1.167 & -0.465 & 0.719 & -0.395 & Body & 0 & 10 & cg19721326 \\
\hline BMP6 & 1.152 & -0.318 & 1.228 & -0.075 & Body & S_Shelf & 6 & cg23623251 \\
\hline MGRN1 & 1.151 & -0.270 & 0.916 & -0.273 & Body & 0 & 16 & cg03168818 \\
\hline SH3RF3 & 1.149 & -0.196 & 1.291 & -0.221 & Body & 0 & 2 & cg03063658 \\
\hline$E R C 1$ & 1.133 & -0.125 & 1.091 & -0.225 & Body & 0 & 12 & cg03422015 \\
\hline C6orf10 & 1.132 & -0.376 & 1.693 & -0.414 & Body & 0 & 6 & cg14704780 \\
\hline ANKH & 1.131 & -0.229 & 1.223 & -0.330 & Body & 0 & 5 & cg03315407 \\
\hline GHRLOS & 1.130 & -0.233 & 1.129 & -0.289 & Body & 0 & 3 & cg08489410 \\
\hline
\end{tabular}




\section{Supplementary Table S3.2: continued}

\begin{tabular}{|c|c|c|c|c|c|c|c|c|}
\hline$\angle R P 1 B$ & 1.123 & -0.392 & 0.973 & -0.285 & Body & 0 & 2 & cg16711069 \\
\hline$S H B$ & 1.115 & -0.233 & 0.960 & -0.364 & Body & 0 & 9 & cg14195115 \\
\hline KANSL1 & 1.113 & -0.108 & 1.031 & 0.219 & Body & 0 & 17 & cg18699337 \\
\hline PAICS & 1.113 & -0.381 & 1.026 & -0.375 & Body & 0 & 4 & cg18743463 \\
\hline$D C L K 2$ & 1.113 & -0.268 & 1.057 & -0.270 & Body & 0 & 4 & cg18426033 \\
\hline RASAL2 & 1.111 & -0.142 & 1.346 & -0.235 & Body & 0 & 1 & cg15523606 \\
\hline RASGRP3 & 1.111 & -0.092 & 1.137 & -0.290 & TSS200 & 0 & 2 & cg24134261 \\
\hline STX11 & 1.110 & -0.128 & 1.855 & -0.215 & 3'UTR & S_Shelf & 6 & cg22164087 \\
\hline GNAT2 & 1.109 & -0.223 & 1.062 & -0.157 & TSS1500 & 0 & 1 & cg22941294 \\
\hline TRNT1 & 1.108 & -0.360 & 1.176 & -0.297 & Body & S_Shelf & 3 & cg11485152 \\
\hline CLEC4E & 1.106 & 0.029 & 0.998 & -0.230 & Body & 0 & 12 & cg00394101 \\
\hline$A R M C 2$ & 1.104 & -0.217 & 1.186 & -0.334 & Body & 0 & 6 & cg07963885 \\
\hline LIN28B & 1.102 & -0.203 & 1.091 & -0.167 & Body & 0 & 6 & cg23983043 \\
\hline TTC28 & 1.102 & -0.479 & 1.091 & -0.550 & Body & 0 & 22 & cg26480862 \\
\hline PIEZO2 & 1.100 & -0.098 & 0.945 & -0.234 & Body & 0 & 18 & cg11830692 \\
\hline SUSD4 & 1.096 & $-0,031$ & 1.050 & -0.047 & Body & 0 & 1 & cg13791188 \\
\hline$U C K L 1$ & 1.096 & -0.336 & 1.771 & -0.357 & Body & N_Shore & 20 & cg07507493 \\
\hline LATS2 & 1.092 & -0.404 & 0.971 & -0.392 & Body & 0 & 13 & cg04022586 \\
\hline CHRM5 & 1.084 & -0.321 & 1.044 & -0.310 & TSS1500 & 0 & 15 & $\operatorname{cg} 11451033$ \\
\hline REM2 & 1.082 & -0.141 & 1.688 & -0.281 & TSS1500 & 0 & 14 & cg04539476 \\
\hline MITF & 1.082 & -0.368 & 1.011 & -0.233 & Body & 0 & 3 & cg18618113 \\
\hline SDK1 & 1.080 & -0.263 & 1.058 & -0.284 & Body & 0 & 7 & cg08102516 \\
\hline ACSL6 & 1.079 & -0.153 & 1.049 & -0.234 & Body & 0 & 5 & cg14841483 \\
\hline$A B L I M 1$ & 1.078 & -0.390 & 0.997 & -0.409 & 5'UTR & 0 & 10 & cg26051956 \\
\hline C2orf61 & 1.078 & -0.386 & 1.041 & -0.247 & Body & 0 & 2 & cg11709788 \\
\hline ZMIZ1 & 1.077 & -0.244 & 1.224 & -0.427 & Body & 0 & 10 & cg09819520 \\
\hline FMNL3 & 1.077 & -0.295 & 1.412 & -0.352 & Body & 0 & 12 & cg20906710 \\
\hline PRR14L & 1.076 & -0.264 & 1.173 & -0.304 & Body & 0 & 22 & cg02483891 \\
\hline ENDOU & 1.073 & -0.203 & 1.091 & -0.276 & Body & 0 & 12 & cg06475653 \\
\hline SUFU & 1.073 & -0.406 & 1.119 & -0.492 & Body & 0 & 10 & cg24198237 \\
\hline FAM122C & 1.072 & -0.180 & 1.062 & -0.448 & 3'UTR & 0 & $x$ & cg22695906 \\
\hline TULP4 & 1.071 & -0.286 & 0.906 & -0.034 & Body & 0 & 6 & cg24489868 \\
\hline DNM3 & 1.070 & -0.349 & 1.258 & -0.412 & Body & 0 & 1 & cg23577610 \\
\hline
\end{tabular}




\section{Supplementary Table S3.2: continued}

\begin{tabular}{|c|c|c|c|c|c|c|c|c|}
\hline MICAL2 & 1.067 & -0.155 & 0.970 & -0.272 & 5'UTR & 0 & 11 & cg17871234 \\
\hline cxorf36 & 1.066 & -0.158 & 1.371 & -0.387 & TSS200 & 0 & $x$ & cg15029285 \\
\hline FAM120A & 1.066 & -0.302 & 0.887 & -0.371 & Body & 0 & 9 & cg14730017 \\
\hline NRCAM & 1.064 & 0.013 & 1.052 & -0.248 & 5'UTR & 0 & 7 & cg00019997 \\
\hline$M 1 A P$ & 1.064 & -0.224 & 1.021 & -0.285 & Body & 0 & 2 & cg04994425 \\
\hline CNR2 & 1.061 & -0.236 & 1.007 & -0.530 & 5'UTR & 0 & 1 & cg01586797 \\
\hline GRID1 & 1.060 & 0.224 & 1.035 & -0.027 & Body & 0 & 10 & cg03534166 \\
\hline GIMAP8 & 1.060 & -0.151 & 3.935 & -0.408 & 1stExon & 0 & 7 & cg18769241 \\
\hline MIR548N & 1.059 & 0.072 & 1.095 & 0.210 & Body & N_Shelf & 2 & cg19648023 \\
\hline MAP2K6 & 1.056 & -0.284 & 1.090 & -0.413 & Body & 0 & 17 & cg18326562 \\
\hline GLIS3 & 1.054 & -0.347 & 1.059 & -0.378 & Body & 0 & 9 & cg06241070 \\
\hline ASB4 & 1.052 & -0.048 & 1.038 & 0,093 & TSS200 & 0 & 7 & cg14557807 \\
\hline C10orf76 & 1.050 & -0.356 & 1.508 & -0.408 & Body & 0 & 10 & cg10228989 \\
\hline$A R I D 1 B$ & 1.050 & -0.331 & 1.079 & -0.230 & Body & 0 & 6 & cg14692468 \\
\hline FOXN3 & 1.050 & -0.206 & 1.028 & -0.195 & Body & 0 & 14 & cg00616028 \\
\hline NINJ2 & 1.050 & -0.155 & 1.053 & -0.225 & Body & 0 & 12 & cg09409035 \\
\hline IFT140 & 1.047 & -0.200 & 1.062 & -0.355 & Body & 0 & 16 & cg07016549 \\
\hline WIPF1 & 1.047 & -0.190 & 1.042 & -0.318 & 5'UTR & 0 & 2 & cg22047295 \\
\hline FAM 50A & 1.046 & -0.157 & 1.374 & -0.345 & Body & 0 & $x$ & cg07910434 \\
\hline MIRLET7G & 1.046 & -0.183 & 1.042 & -0.254 & TSS200 & 0 & 3 & cg09066298 \\
\hline CSTA & 1.045 & -0.260 & 1.025 & -0.282 & 1stExon & 0 & 3 & cg21932814 \\
\hline TMEM131 & 1.045 & -0.196 & 1.206 & -0.214 & Body & 0 & 2 & cg15177103 \\
\hline RXFP4 & 1.045 & -0.341 & 1.008 & -0.300 & TSS1500 & 0 & 1 & cg21284779 \\
\hline MCC & 1.044 & -0.274 & 1.058 & -0.514 & Body & 0 & 5 & cg02028114 \\
\hline$R B M 18$ & 1.043 & -0.146 & 0.819 & -0.214 & Body & 0 & 9 & cg09128612 \\
\hline SLCOA9 & 1.042 & -0.499 & 1.036 & -0.629 & Body & 0 & 3 & cg27419508 \\
\hline KIAA1522 & 1.042 & -0.210 & 0.528 & -0.149 & Body & S_Shelf & 1 & cg05710142 \\
\hline NEDD4 & 1.041 & -0.377 & 1.049 & -0.244 & Body & 0 & 15 & cg09602650 \\
\hline FAM19A5 & 1.041 & 0.061 & 0.992 & -0.203 & Body & 0 & 22 & cg06409673 \\
\hline CHKA & 1.040 & -0.228 & 1.108 & -0.276 & Body & 0 & 11 & cg24397554 \\
\hline GRK5 & 1.039 & -0.241 & 2.152 & -0.270 & Body & 0 & 10 & cg07835234 \\
\hline SLC5A9 & 1.038 & -0.199 & 1.120 & -0.290 & Body & 0 & 1 & cg14705496 \\
\hline XRN2 & 1.037 & -0.443 & 0.908 & -0.401 & Body & 0 & 20 & cg22265539 \\
\hline
\end{tabular}




\section{Supplementary Table S3.2: continued}

\begin{tabular}{|c|c|c|c|c|c|c|c|c|}
\hline ZNF366 & 1.037 & -0.311 & 1.338 & -0.409 & TSS200 & 0 & 5 & cg04710768 \\
\hline ZFPM2-AS1 & 1.035 & -0.112 & 1.069 & -0.221 & Body & 0 & 6 & cg08140558 \\
\hline GSG1 & 1.034 & -0.108 & 1.084 & -0.226 & Body & N_Shelf & 12 & cg20618695 \\
\hline TRAPPC8 & 1.034 & -0.270 & 1.084 & -0.270 & Body & 0 & 18 & cg04605261 \\
\hline TACR1 & 1.027 & -0.331 & 1.088 & -0.222 & Body & 0 & 2 & cg14632793 \\
\hline TTC7A & 1.022 & -0.211 & 1.026 & -0.413 & Body & 0 & 2 & cg20090162 \\
\hline KCNK12 & 1.017 & -0.112 & 1.036 & -0.221 & Body & N_Shore & 2 & cg17885628 \\
\hline FLJ22447 & 1.015 & -0.331 & 1.067 & -0.324 & 0 & 0 & 14 & cg18728780 \\
\hline SBF2 & 1.015 & -0.386 & 0.986 & -0.299 & Body & 0 & 11 & cg16622342 \\
\hline PKDCC & 1.015 & -0.196 & 0.995 & -0.221 & Body & 0 & 2 & cg12066235 \\
\hline DENND3 & 1.013 & -0.260 & 1.089 & -0.326 & Body & 0 & 8 & cg02574175 \\
\hline $\mathrm{CHD3}$ & 1.011 & -0.152 & 1.030 & -0.354 & ExonBnd & 0 & 17 & cg03096171 \\
\hline C11orf49 & 1.011 & -0.305 & 1.002 & -0.252 & Body & 0 & 11 & cg16379731 \\
\hline NCOR2 & 1.011 & -0.152 & 1.181 & -0.204 & Body & S_Shelf & 12 & cg12349623 \\
\hline AJUBA & 1.009 & -0.239 & 0.994 & -0.240 & Body & N_Shore & 14 & cg08188555 \\
\hline PDS5B & 1.008 & -0.004 & 1.149 & 0.205 & Body & 0 & 13 & cg23199907 \\
\hline ATRX & 1.005 & -0.511 & 1.002 & -0.262 & Body & 0 & $x$ & cg23266487 \\
\hline MYO1C & 1.005 & -0.154 & 2.141 & -0.258 & TSS200 & S_Shore & 17 & cg09269848 \\
\hline BIN1 & 1.004 & -0.178 & 0.995 & -0.242 & Body & S_Shore & 2 & cg17509462 \\
\hline GOT1 & 1.001 & -0.266 & 1.807 & -0.263 & ExonBnd & 0 & 10 & cg13901620 \\
\hline GRK7 & 1.001 & -0.109 & 1.017 & -0.337 & Body & N_Shelf & 3 & cg07768761 \\
\hline COA1 & 1.000 & -0.286 & 1.202 & -0.373 & 0 & 0 & 7 & cg15148064 \\
\hline GATA3 & 1.000 & -0.184 & 1.047 & -0.384 & Body & S_Shore & 10 & cg17489908 \\
\hline C1QL3 & 0.998 & -0.502 & 1.074 & -0.404 & TSS1500 & S_Shore & 10 & cg12875950 \\
\hline SMURF1 & 0.997 & -0.261 & 1.001 & -0.188 & Body & 0 & 7 & cg17232924 \\
\hline RANBP17 & 0.995 & -0.545 & 1.007 & -0.501 & Body & 0 & 5 & cg05617141 \\
\hline EEF1DP3 & 0.995 & -0.159 & 0.920 & -0.202 & Body & N_Shelf & 13 & cg00648883 \\
\hline DYM & 0.995 & -0.598 & 0.744 & -0.664 & Body & 0 & 18 & cg24420086 \\
\hline TMEM204 & 0.995 & -0.369 & 0.994 & -0.389 & Body & N_Shelf & 16 & cg07013955 \\
\hline DNAJC18 & 0.991 & -0.161 & 0.957 & -0.267 & Body & 0 & 5 & cg09622871 \\
\hline PKD1L1 & 0.990 & -0.102 & 1.270 & -0.212 & TSS1500 & 0 & 7 & cg15302078 \\
\hline CNNM4 & 0.989 & -0.246 & 0.952 & -0.140 & Body & 0 & 2 & cg17415382 \\
\hline $\mathrm{MSH} 2$ & 0.988 & -0.230 & 0.969 & 0.183 & Body & 0 & 2 & cg14051210 \\
\hline
\end{tabular}




\section{Supplementary Table S3.2: continued}

\begin{tabular}{|c|c|c|c|c|c|c|c|c|}
\hline NEK4 & 0.987 & -0.171 & 0.947 & -0.312 & Body & 0 & 3 & cg12911970 \\
\hline RIOK2 & 0.981 & -0.002 & 0.735 & 0.209 & Body & 0 & 5 & cg09922808 \\
\hline ARHGEF28 & 0.980 & -0.361 & 1.148 & -0.586 & Body & 0 & 5 & cg18159467 \\
\hline LGALS4 & 0.978 & -0.330 & 1.009 & -0.360 & Body & 0 & 19 & cg27061207 \\
\hline CACNA2D3 & 0.978 & -0.395 & 0.971 & -0.369 & Body & 0 & 3 & cg00846417 \\
\hline GCNT2 & 0.978 & -0.488 & 1.060 & -0.584 & TSS1500 & 0 & 6 & cg14112601 \\
\hline FBX031 & 0.975 & -0.151 & 1.101 & -0.357 & Body & 0 & 16 & cg21533743 \\
\hline CSRNP3 & 0.975 & -0.306 & 1.882 & -0.138 & 5'UTR & 0 & 2 & cg12084046 \\
\hline THSD7A & 0.970 & -0.253 & 0.917 & 0.043 & Body & 0 & 7 & cg04688366 \\
\hline SCUBE1 & 0.967 & -0.096 & 0.991 & -0.233 & Body & 0 & 22 & cg03879473 \\
\hline CLCN4 & 0.967 & -0.171 & 0.958 & -0.213 & 5'UTR & 0 & $x$ & cg02383649 \\
\hline SLC16A1 & 0.967 & -0.151 & 0.943 & -0.221 & Body & 0 & 1 & cg07572909 \\
\hline$S L C 2 A 13$ & 0.966 & -0.286 & 0.998 & -0.234 & Body & 0 & 12 & cg18568497 \\
\hline PTPRE & 0.962 & -0.232 & 1.156 & -0.459 & 5'UTR & 0 & 10 & cg08048809 \\
\hline SLC39A11 & 0.959 & -0.236 & 0.812 & -0.339 & Body & 0 & 17 & $\operatorname{cg} 17303039$ \\
\hline C3orf52 & 0.959 & -0.275 & 1.003 & -0.288 & Body & S_Shelf & 3 & cg16217908 \\
\hline SMC4 & 0.959 & -0.410 & 1.072 & -0.283 & Body & 0 & 3 & cg15729450 \\
\hline$C D C P 2$ & 0.958 & -0.303 & 1.180 & -0.316 & TSS200 & 0 & 1 & $\operatorname{cg} 01367140$ \\
\hline WDR82 & 0.957 & -0.186 & 0.910 & -0.284 & Body & 0 & 3 & cg25236791 \\
\hline CELSR1 & 0.957 & -0.376 & 0.949 & -0.278 & Body & N_Shore & 22 & $\operatorname{cg} 04332442$ \\
\hline C6orf136 & 0.956 & -0.211 & 0.800 & -0.178 & 3'UTR & 0 & 6 & cg02434880 \\
\hline EXOC5 & 0.956 & -0.697 & 0.945 & -0.703 & Body & N_Shelf & 14 & $\operatorname{cg} 25653900$ \\
\hline RBM47 & 0.955 & -0.191 & 0.771 & -0.252 & TSS1500 & 0 & 4 & cg09249657 \\
\hline GPR45 & 0.954 & -0.230 & 0.937 & -0.287 & TSS1500 & N_Shore & 2 & $\operatorname{cg} 11223196$ \\
\hline TPD52 & 0.948 & -0.241 & 0.861 & -0.381 & Body & 0 & 8 & cg09597589 \\
\hline ACKR2 & 0.947 & -0.146 & 1.080 & -0.369 & 5'UTR & 0 & 3 & $\operatorname{cg} 13702846$ \\
\hline CCL17 & 0.944 & -0.134 & 0.970 & -0.253 & 5'UTR & 0 & 16 & cg02573340 \\
\hline TAOK3 & 0.944 & -0.232 & 0.987 & -0.220 & 5'UTR & 0 & 12 & $\operatorname{cg} 01341698$ \\
\hline CLRN3 & 0.942 & -0.142 & 0.954 & -0.249 & Body & 0 & 10 & $\operatorname{cg} 07269647$ \\
\hline$A R I D 1 A$ & 0.940 & -0.423 & 0.959 & -0.291 & Body & 0 & 1 & cg09849688 \\
\hline PGAP2 & 0.938 & -0.171 & 0.714 & -0.429 & 5'UTR & 0 & 11 & cg11559794 \\
\hline PIP4K2A & 0.936 & -0.434 & 1.709 & -0.550 & Body & 0 & 10 & cg09273683 \\
\hline PITPNC1 & 0.935 & -0.440 & 1.047 & -0.436 & Body & 0 & 17 & cg08708167 \\
\hline
\end{tabular}




\section{Supplementary Table S3.2: continued}

\begin{tabular}{|c|c|c|c|c|c|c|c|c|}
\hline$S L C 1 A 1$ & 0.928 & -0.309 & 0.842 & -0.277 & Body & 0 & 9 & cg14366878 \\
\hline EPB41L1 & 0.925 & -0.261 & 0.986 & -0.188 & 5'UTR & 0 & 20 & cg20296980 \\
\hline CMTM7 & 0.922 & -0.249 & 1.685 & -0.318 & TSS1500 & N_Shore & 3 & cg10101634 \\
\hline NPEPL1 & 0.913 & -0.282 & 0.800 & -0.303 & TSS200 & N_Shelf & 20 & cg00771376 \\
\hline YLPM1 & 0.908 & -0.348 & 0.936 & -0.411 & Body & 0 & 14 & cg02536712 \\
\hline TANGO6 & 0.906 & -0.238 & 0.922 & -0.365 & Body & 0 & 16 & cg22375758 \\
\hline DOCKO & 0.903 & -0.308 & 0.851 & -0.249 & Body & 0 & 13 & cg13570883 \\
\hline SPTLC2 & 0.901 & -0.494 & 0.905 & -0.539 & Body & 0 & 14 & cg05690233 \\
\hline KIAA0391 & 0.900 & -0.273 & 0.788 & -0.387 & Body & 0 & 14 & cg18680181 \\
\hline MAP2K4 & 0.895 & -0.352 & 0.869 & -0.184 & Body & 0 & 17 & cg12046729 \\
\hline$M O B 1 B$ & 0.892 & -0.249 & 0.865 & -0.277 & Body & 0 & 4 & cg04576707 \\
\hline PTPRG & 0.884 & -0.351 & 1.458 & -0.290 & Body & 0 & 3 & cg01071477 \\
\hline PBX4 & 0.879 & -0.308 & 1.040 & -0.291 & Body & 0 & 19 & cg01153902 \\
\hline RALGDS & 0.874 & -0.161 & 0.990 & -0.308 & Body & N_Shore & 9 & cg07521475 \\
\hline FAM104B & 0.857 & -0.177 & 0.891 & -0.309 & Body & 0 & $x$ & cg17243829 \\
\hline TRAPPC6A & 0.846 & -0.304 & 0.882 & -0.122 & Body & 0 & 19 & cg26097728 \\
\hline RALGPS1 & 0.845 & -0.091 & 1.172 & -0.238 & Body & 0 & 9 & cg09874683 \\
\hline$A D G R G 1$ & 0.841 & -0.227 & 0.314 & -0.424 & 5'UTR & 0 & 16 & cg26955845 \\
\hline $\mathrm{KCNH} 4$ & 0.841 & -0.190 & 1.052 & -0.338 & Body & 0 & 17 & cg06685556 \\
\hline CA12 & 0.839 & -0.313 & 0.776 & -0.234 & Body & N_Shelf & 15 & cg08947167 \\
\hline POC1B & 0.839 & -0.254 & 1.018 & -0.477 & Body & 0 & 12 & cg13598864 \\
\hline DIAPH3 & 0.836 & 0.170 & 0.813 & -0.229 & Body & 0 & 13 & cg24289237 \\
\hline$A P 2 B 1$ & 0.820 & -0.320 & 0.776 & -0.304 & Body & 0 & 17 & cg04170952 \\
\hline$T B L 1 X$ & 0.813 & -0.186 & 0.966 & -0.278 & Body & 0 & $x$ & cg13853116 \\
\hline C5orf63 & 0.809 & -0.225 & 0.815 & -0.540 & 5'UTR & N_Shore & 5 & cg00207226 \\
\hline DCPS & 0.803 & -0.283 & 0.572 & -0.303 & Body & 0 & 11 & cg05522498 \\
\hline DPP4 & 0.802 & -0.513 & 3.137 & -0.645 & Body & N_Shelf & 2 & cg12649175 \\
\hline CRELD2 & 0.794 & -0.203 & 0.675 & -0.215 & Body & S_Shore & 22 & cg20610988 \\
\hline POLR3A & 0.770 & -0.515 & 0.688 & -0.544 & Body & 0 & 10 & cg02586876 \\
\hline LARS2 & 0.745 & -0.379 & 0.641 & -0.311 & Body & 0 & 3 & cg05380759 \\
\hline IARS2 & 0.733 & -0.501 & 0.512 & -0.595 & Body & 0 & 1 & cg11170368 \\
\hline ARID5B & 0.722 & -0.453 & 0.544 & -0.317 & Body & 0 & 10 & cg13541977 \\
\hline RINL & 0.704 & -0.458 & 0.637 & -0.232 & 5'UTR & 0 & 19 & cg09565670 \\
\hline
\end{tabular}




\section{Supplementary Table S3.2: continued}

\begin{tabular}{|c|c|c|c|c|c|c|c|c|}
\hline SUCLG2 & 0.695 & -0.194 & 0.521 & -0.287 & Body & 0 & 3 & cg09067993 \\
\hline GMDS & 0.689 & -0.327 & 0.547 & -0.359 & Body & 0 & 6 & cg11058558 \\
\hline MRPL33 & 0.680 & -0.377 & 0.359 & -0.597 & Body & S_Shelf & 2 & cg15947193 \\
\hline OVOL2 & 0.676 & -0.129 & 0.549 & -0.234 & Body & N_Shore & 20 & cg05728394 \\
\hline TACC1 & 0.665 & -0.361 & 0.530 & -0.272 & 5'UTR & 0 & 8 & cg18316192 \\
\hline RNLS & 0.634 & -0.584 & 0.601 & -0.667 & Body & 0 & 10 & cg09721144 \\
\hline C12orf10 & 0.619 & -0.286 & 0.519 & -0.518 & TSS1500 & N_Shore & 12 & cg08525575 \\
\hline PCK2 & 0.611 & -0.283 & 0.662 & -0.463 & TSS1500 & N_Shore & 14 & cg10264529 \\
\hline SEC62 & 0.598 & -0.360 & 0.619 & -0.480 & Body & 0 & 3 & cg04602039 \\
\hline GFM1 & 0.598 & -0.424 & 0.575 & -0.293 & ExonBnd & 0 & 3 & cg22141067 \\
\hline SLC7A5 & 0.592 & 0.274 & 0.948 & -0.004 & Body & Island & 16 & cg08617020 \\
\hline$A C L Y$ & 0.581 & -0.201 & 0.654 & -0.159 & Body & N_Shelf & 17 & cg02486737 \\
\hline FAM198B & 0.578 & -0.138 & 0.769 & -0.349 & Body & 0 & 4 & cg01589294 \\
\hline ILIRAPLI & 0.555 & -0.064 & 0.626 & 0.210 & Body & 0 & $X$ & cg17531668 \\
\hline DHRS7 & 0.549 & -0.329 & 0.488 & -0.252 & Body & 0 & 14 & cg15520210 \\
\hline RAP1GAP & 0.548 & -0.242 & 0.422 & -0.241 & Body & 0 & 1 & cg06165723 \\
\hline SLC35F2 & 0.543 & -0.427 & 0.992 & -0.324 & Body & 0 & 11 & cg16408039 \\
\hline CDK19 & 0.382 & -0.351 & 0.330 & -0.251 & Body & 0 & 6 & cg01725626 \\
\hline HSD17B12 & 0.358 & 0.013 & 0.477 & -0.206 & TSS1500 & N_Shore & 11 & cg06112137 \\
\hline ECT2 & 0.354 & -0.543 & 0.299 & 0.719 & 0 & Island & 3 & cg12393503 \\
\hline$S L C 7 A 1$ & 0.323 & -0.391 & 0.313 & -0.403 & 5'UTR & 0 & 13 & cg11069855 \\
\hline STK39 & 0.274 & -0.597 & 0.193 & -0.605 & Body & 0 & 2 & cg10123669 \\
\hline $\mathrm{RHOU}$ & 0.161 & -0.155 & 0.337 & -0.250 & Body & S_Shelf & 1 & cg10922143 \\
\hline$B B O \times 1-A S 1$ & \#NV & -0.432 & \#NV & -0.449 & Body & 0 & 11 & cg19130723 \\
\hline DGUOK-AS1 & $\# N V$ & -0.608 & $\# N V$ & -0.556 & Body & 0 & 2 & cg02418306 \\
\hline DLGAP1-AS2 & $\# N V$ & -0.279 & \#NV & -0.280 & TSS200 & 0 & 18 & cg05757358 \\
\hline FAM53B-AS1 & \#NV & -0.422 & \#NV & -0.431 & TSS200 & 0 & 10 & cg11937172 \\
\hline GLIS2-AS1 & \#NV & -0.394 & $\# N V$ & -0.268 & TSS1500 & S_Shore & 16 & cg26196104 \\
\hline ITPKB-IT1 & $\# N V$ & -0.383 & \#NV & -0.455 & Body & 0 & 1 & cg24113686 \\
\hline КССАT211 & \#NV & -0.460 & \#NV & -0.502 & Body & 0 & 3 & cg08046836 \\
\hline KIAA1211L & \#NV & -0.292 & \#NV & -0.354 & 3'UTR & 0 & 2 & cg24047187 \\
\hline KIAA2012 & $\# N V$ & -0.325 & $\# N V$ & -0.379 & ExonBnd & 0 & 2 & cg06203744 \\
\hline LINC00271 & \#NV & -0.217 & \#NV & -0.212 & Body & 0 & 6 & cg05739816 \\
\hline
\end{tabular}




\section{Supplementary Table S3.2: continued}

\begin{tabular}{|c|c|c|c|c|c|c|c|c|}
\hline LINC00313 & \#NV & -0.229 & \#NV & -0.250 & TSS1500 & 0 & 21 & cg21655830 \\
\hline LINC00487 & \#NV & -0.206 & \#NV & -0.252 & 0 & 0 & 2 & cg02738156 \\
\hline LINC00589 & \#NV & -0.328 & \#NV & -0.316 & Body & 0 & 8 & cg17315703 \\
\hline LINC00920 & \#NV & -0.207 & \#NV & -0.198 & 0 & S_Shore & 16 & cg27326306 \\
\hline LINC01119 & \#NV & -0.212 & \#NV & -0.443 & Body & 0 & 2 & cg22661501 \\
\hline LINC01237 & \#NV & -0.183 & \#NV & -0.281 & Body & 0 & 2 & cg07262940 \\
\hline LNX1-AS2 & \#NV & -0.285 & \#NV & -0.224 & TSS1500 & 0 & 4 & cg00729984 \\
\hline LOC100506368 & \#NV & -0.214 & \#NV & -0.304 & Body & 0 & 11 & cg12452371 \\
\hline LOC101929450 & \#NV & -0.218 & \#NV & -0.177 & Body & 0 & 8 & cg23363841 \\
\hline LOC101929596 & \#NV & -0.322 & \#NV & -0.519 & Body & 0 & 2 & cg23813542 \\
\hline LOC102724050 & \#NV & -0.352 & \#NV & -0.318 & Body & 0 & 12 & cg25516577 \\
\hline LOC102724312 & \#NV & -0.250 & \#NV & -0.382 & Body & N_Shore & 1 & cg07898743 \\
\hline LOC286059 & \#NV & -0.202 & \#NV & -0.338 & Body & 0 & 8 & cg15666431 \\
\hline LOC643542 & \#NV & -0.278 & \#NV & -0.111 & Body & 0 & 18 & cg12294310 \\
\hline LOC729867 & \#NV & -0.400 & \#NV & -0.338 & 5 'UTR & S_Shelf & 1 & cg13109911 \\
\hline MIR4290 & \#NV & -0.363 & \#NV & -0.221 & TSS1500 & 0 & 9 & cg09253224 \\
\hline MIR5009 & \#NV & -0.236 & \#NV & -0.261 & Body & 0 & 21 & cg12975010 \\
\hline MIR99AHG & \#NV & -0.217 & \#NV & -0.118 & Body & 0 & 21 & cg02711653 \\
\hline ZFPM2-AS1 & \#NV & -0.270 & \#NV & 0.039 & Body & 0 & 8 & cg05718647 \\
\hline
\end{tabular}


Supplementary Table S3.3: Functional annotation of genes differentially methylated upon T/E overexpression

\begin{tabular}{|c|c|c|c|c|}
\hline Functional annotation & Genes & p-value & z-score* & \# Genes' \\
\hline $\begin{array}{l}\text { Organization of } \\
\text { cytoskeleton }\end{array}$ & $\begin{array}{l}\text { FN1, SEPT9, MARK2, WIPF1, MSN, NRP1, } \\
\text { MYO10, CRK, NRCAM, NCK2 }\end{array}$ & 7.27E-07 & 3.667 & 29 \\
\hline & ATG7, BCL2L1, GATA3, APP, CHRM5, & & & \\
\hline Cellular homeostasis & $\begin{array}{l}\text { CDKN1B, PRKCH, STK39, MIRLET7G, } \\
\text { SLC16A1 }\end{array}$ & $3.63 \mathrm{E}-03$ & 4.012 & 25 \\
\hline Cell migration & $\begin{array}{l}\text { FN1, APP, CCL17, PXN, NOS3, NRP1, } \\
\text { LTB4R, BMP6, CDKN1B, GATA3 }\end{array}$ & 9.06E-06 & 3.609 & 45 \\
\hline Neuron differentiation & $\begin{array}{l}\text { APP, BCL2L1, IL1RAPL1, GDPD5, MIR- } \\
\text { LET7G, ECT2, CHKA, FN1, BMP6 }\end{array}$ & $9.22 \mathrm{E}-03$ & 2.549 & 9 \\
\hline
\end{tabular}

Top 10 differentially expressed genes in our dataset that were annotated to a function. A gene was selected when its annotation to the indicated function was based on at least two findings in the Ingenuity knowledge base. *Activation z-score is a measure of predicted change (increase or decrease) of the process. †Total number of genes supporting a specific functional annotation.

Supplementary Table S3.4: Canonical pathway analysis of genes differentially methylated upon T/E overexpression

\begin{tabular}{lccc}
\hline Ingenuity Canonical Pathways & p-value & z-score* & \# Genes \\
\hline Gastrin signaling & $7.89 \mathrm{E}-04$ & 2.646 & $7(101)$ \\
Rho GTPase signaling & $1.29 \mathrm{E}-03$ & 1.667 & $11(248)$ \\
Moleculer Mechanisms of Cancer & $1.61 \mathrm{E}-03$ & $\mathrm{NaN}$ & $14(376)$ \\
cAMP signaling & $6.40 \mathrm{E}-03$ & 0.707 & $9(223)$ \\
Ephrin signaling & $1.56 \mathrm{E}-02$ & 2.646 & $7(174)$ \\
\hline
\end{tabular}

Significantly enriched canonical pathways across the dataset of commonly methylated genes between T/E III and $\mathrm{VI}$ are shown. *Activation z-score is a measure of predicted change (activated or reduced) of the process. $\mathrm{NaN}$ - not a number. +Number of genes in the dataset, which are represented in the pathway. Numbers in brackets depict the total number of genes in the pathway in the reference gene set. 


\section{REFERENCES}

1. Kumar A, White TA, MacKenzie AP, Clegg N, Lee C, Dumpit RF, Coleman I, Ng SB, Salipante SJ, Rieder MJ, Nickerson DA, Corey E, Lange PH, Morrissey C, Vessella RL, Nelson PS, et al. Exome sequencing identifies a spectrum of mutation frequencies in advanced and lethal prostate cancers. Proc Natl Acad Sci U S A. 2011; 108(41):17087-17092.

2. Taylor BS, Schultz N, Hieronymus H, Gopalan A, Xiao Y, Carver BS, Arora VK, Kaushik P, Cerami E, Reva B, Antipin Y, Mitsiades N, Landers T, Dolgalev I, Major JE, Wilson M, et al. Integrative genomic profiling of human prostate cancer. Cancer Cell. 2010; 18(1):11-22.

3. Ross-Adams H, Lamb AD, Dunning MJ, Halim S, Lindberg J, Massie CM, Egevad LA, Russell R, RamosMontoya A, Vowler SL, Sharma NL, Kay J, Whitaker H, Clark J, Hurst R, Gnanapragasam VJ, et al. Integration of copy number and transcriptomics provides risk stratification in prostate cancer: A discovery and validation cohort study. EBioMedicine. 2015; 2(9):1133-1144.

4. Tomlins SA, Rhodes DR, Perner S, Dhanasekaran SM, Mehra R, Sun XW, Varambally S, Cao X, Tchinda J, Kuefer R, Lee C, Montie JE, Shah RB, Pienta KJ, Rubin MA and Chinnaiyan AM. Recurrent fusion of TMPRSS2 and ETS transcription factor genes in prostate cancer. Science. 2005; 310(5748):644-648.

5. Friedlander TW, Roy R, Tomlins SA, Ngo VT, Kobayashi Y, Azameera A, Rubin MA, Pienta KJ, Chinnaiyan A, Ittmann MM, Ryan CJ and Paris PL. Common structural and epigenetic changes in the genome of castration-resistant prostate cancer. Cancer Res. 2012; 72(3):616-625.

6. Barbieri CE, Baca SC, Lawrence MS, Demichelis F, Blattner M, Theurillat JP, White TA, Stojanov P, Van Allen E, Stransky N, Nickerson E, Chae SS, Boysen G, Auclair D, Onofrio RC, Park K, et al. Exome sequencing identifies recurrent SPOP, FOXA1 and MED12 mutations in prostate cancer. Nat Genet. 2012; 44(6):685-689.

7. Cancer Genome Atlas Research N. The Molecular Taxonomy of Primary Prostate Cancer. Cell. 2015; 163(4):1011-1025.

8. Aryee MJ, Liu W, Engelmann JC, Nuhn P, Gurel M, Haffner MC, Esopi D, Irizarry RA, Getzenberg RH, Nelson WG, Luo J, Xu J, Isaacs WB, Bova GS and Yegnasubramanian S. DNA methylation alterations exhibit intraindividual stability and interindividual heterogeneity in prostate cancer metastases. Sci Transl Med. 2013; 5(169):169ra110.

9. Mundbjerg K, Chopra S, Alemozaffar M, Duymich C, Lakshminarasimhan R, Nichols PW, Aron M, Siegmund KD, Ukimura O, Aron M, Stern M, Gill P, Carpten JD, Orntoft TF, Sorensen KD, Weisenberger DJ, et al. Identifying aggressive prostate cancer foci using a DNA methylation classifier. Genome Biol. 2017; 18(1):3.

10. Park JY, Zheng W, Kim D, Cheng JQ, Kumar N, Ahmad N and Pow-Sang J. Candidate tumor suppressor gene SLC5A8 is frequently down-regulated by promoter hypermethylation in prostate tumor. Cancer Detect Prev. 2007; 31(5):359-365.

11. Brocks D, Assenov Y, Minner S, Bogatyrova O, Simon R, Koop C, Oakes C, Zucknick M, Lipka DB, Weischenfeldt J, Feuerbach L, Cowper-Sal Lari R, Lupien M, Brors B, Korbel J, Schlomm T, et al. Intratumor DNA methylation heterogeneity reflects clonal evolution in aggressive prostate cancer. Cell Rep. 2014; 8(3):798-806.

12. Lee WH, Isaacs WB, Bova GS and Nelson WG. CG island methylation changes near the GSTP1 gene in prostatic carcinoma cells detected using the polymerase chain reaction: a new prostate cancer biomarker. Cancer Epidemiol Biomarkers Prev. 1997; 6(6):443-450.

13. Zelic R, Fiano V, Zugna D, Grasso C, Delsedime L, Daniele L, Galliano D, Pettersson A, Gillio-Tos A, Merletti F and Richiardi L. Global Hypomethylation (LINE-1) and Gene-Specific Hypermethylation (GSTP1) on Initial Negative Prostate Biopsy as Markers of Prostate Cancer on a Rebiopsy. Clin Cancer Res. 2016; 22(4):984-992.

14. Lee WH, Morton RA, Epstein JI, Brooks JD, Campbell PA, Bova GS, Hsieh WS, Isaacs WB and Nelson WG. Cytidine methylation of regulatory sequences near the pi-class glutathione S-transferase gene accompanies human prostatic carcinogenesis. Proc Natl Acad Sci U S A. 1994; 91(24):11733-11737. 
15. Yegnasubramanian S, Kowalski J, Gonzalgo ML, Zahurak M, Piantadosi S, Walsh PC, Bova GS, De Marzo AM, Isaacs WB and Nelson WG. Hypermethylation of CpG islands in primary and metastatic human prostate cancer. Cancer Res. 2004; 64(6):1975-1986.

16. Fraser M, Sabelnykova VY, Yamaguchi TN, Heisler LE, Livingstone J, Huang V, Shiah YJ, Yousif F, Lin X, Masella AP, Fox NS, Xie M, Prokopec SD, Berlin A, Lalonde E, Ahmed M, et al. Genomic hallmarks of localized, non-indolent prostate cancer. Nature. 2017; 541(7637):359-364.

17. Lin PC, Giannopoulou EG, Park K, Mosquera JM, Sboner A, Tewari AK, Garraway LA, Beltran H, Rubin MA and Elemento O. Epigenomic alterations in localized and advanced prostate cancer. Neoplasia. 2013; 15(4):373-383.

18. Angulo JC, Andres G, Ashour N, Sanchez-Chapado M, Lopez JI and Ropero S. Development of Castration Resistant Prostate Cancer can be Predicted by a DNA Hypermethylation Profile. J Urol. 2016; 195(3):619626.

19. Beltran H, Prandi D, Mosquera JM, Benelli M, Puca L, Cyrta J, Marotz C, Giannopoulou E, Chakravarthi BV, Varambally S, Tomlins SA, Nanus DM, Tagawa ST, Van Allen EM, Elemento O, Sboner A, et al. Divergent clonal evolution of castration-resistant neuroendocrine prostate cancer. Nat Med. 2016; 22(3):298305.

20. Yegnasubramanian S, Haffner MC, Zhang Y, Gurel B, Cornish TC, Wu Z, Irizarry RA, Morgan J, Hicks J, DeWeese TL, Isaacs WB, Bova GS, De Marzo AM and Nelson WG. DNA hypomethylation arises later in prostate cancer progression than CPG island hypermethylation and contributes to metastatic tumor heterogeneity. Cancer Res. 2008; 68(21):8954-8967.

21. Schulz WA, Elo JP, Florl AR, Pennanen S, Santourlidis S, Engers R, Buchardt M, Seifert HH and Visakorpi T. Genomewide DNA hypomethylation is associated with alterations on chromosome 8 in prostate carcinoma. Genes Chromosomes Cancer. 2002; 35(1):58-65.

22. Kim JH, Dhanasekaran SM, Prensner JR, Cao X, Robinson D, Kalyana-Sundaram S, Huang C, Shankar S, Jing X, lyer M, Hu M, Sam L, Grasso C, Maher CA, Palanisamy N, Mehra R, et al. Deep sequencing reveals distinct patterns of DNA methylation in prostate cancer. Genome Res. 2011; 21(7):1028-1041.

23. Borno ST, Fischer A, Kerick M, Falth M, Laible M, Brase JC, Kuner R, Dahl A, Grimm C, Sayanjali B, Isau M, Rohr C, Wunderlich A, Timmermann B, Claus R, Plass C, et al. Genome-wide DNA methylation events in TMPRSS2-ERG fusion-negative prostate cancers implicate an EZH2-dependent mechanism with miR-26a hypermethylation. Cancer Discov. 2012; 2(11):1024-1035.

24. Iljin K, Wolf M, Edgren H, Gupta S, Kilpinen S, Skotheim RI, Peltola M, Smit F, Verhaegh G, Schalken J, Nees $\mathrm{M}$ and Kallioniemi O. TMPRSS2 fusions with oncogenic ETS factors in prostate cancer involve unbalanced genomic rearrangements and are associated with HDAC1 and epigenetic reprogramming. Cancer Res. 2006; 66(21):10242-10246.

25. Bjorkman M, Iljin K, Halonen P, Sara H, Kaivanto E, Nees M and Kallioniemi OP. Defining the molecular action of HDAC inhibitors and synergism with androgen deprivation in ERG-positive prostate cancer. Int J Cancer. 2008; 123(12):2774-2781.

26. Yang L, Xia L, Wu DY, Wang H, Chansky HA, Schubach WH, Hickstein DD and Zhang Y. Molecular cloning of ESET, a novel histone $\mathrm{H3}$-specific methyltransferase that interacts with ERG transcription factor. Oncogene. 2002; 21(1):148-152.

27. Yang L, Mei Q, Zielinska-Kwiatkowska A, Matsui Y, Blackburn ML, Benedetti D, Krumm AA, Taborsky GJ, Jr. and Chansky HA. An ERG (ets-related gene)-associated histone methyltransferase interacts with histone deacetylases $1 / 2$ and transcription co-repressors mSin3A/B. Biochem J. 2003; 369(Pt 3):651-657.

28. Yu J, Yu J, Mani RS, Cao Q, Brenner CJ, Cao X, Wang X, Wu L, Li J, Hu M, Gong Y, Cheng H, Laxman B, Vellaichamy A, Shankar S, Li Y, et al. An integrated network of androgen receptor, polycomb, and TMPRSS2-ERG gene fusions in prostate cancer progression. Cancer Cell. 2010; 17(5):443-454.

29. M. Zoma LC, D. Shinde, A. Mitra, D. Albino, S. Rossi, G. Civenni, M. Losa, G. Thalmann, G. Chiorino, C.V. Catapano, G.M. Carbone. (2017). A novel epigenetic crosstalk between ERG and EZH2 leads to prostate cancer progression. 32nd Annual EAU Congress. (London, United Kingdom.

30. Castro F, Dirks WG, Fahnrich S, Hotz-Wagenblatt A, Pawlita M and Schmitt M. High-throughput SNPbased authentication of human cell lines. Int J Cancer. 2013; 132(2):308-314. 
31. Schmitt M and Pawlita M. High-throughput detection and multiplex identification of cell contaminations. Nucleic Acids Res. 2009; 37(18):e119.

32. Ratz L, Laible M, Kacprzyk LA, Wittig-Blaich SM, Tolstov $Y$, Duensing S, Altevogt $P$, Klauck SM and Sultmann H. TMPRSS2:ERG gene fusion variants induce TGF-beta signaling and epithelial to mesenchymal transition in human prostate cancer cells. Oncotarget. 2017; 8(15):25115-25130.

33. de Hoon MJ, Imoto S, Nolan J and Miyano S. Open source clustering software. Bioinformatics. 2004; 20(9):1453-1454.

34. Saldanha AJ. Java Treeview--extensible visualization of microarray data. Bioinformatics. 2004; 20(17):3246-3248.

35. Eisen MB, Spellman PT, Brown PO and Botstein D. Cluster analysis and display of genome-wide expression patterns. Proc Natl Acad Sci U S A. 1998; 95(25):14863-14868.

36. Pfaffl MW. A new mathematical model for relative quantification in real-time RT-PCR. Nucleic Acids Res. 2001; 29(9):e45

37. Gupta S, Iljin K, Sara H, Mpindi JP, Mirtti T, Vainio P, Rantala J, Alanen K, Nees M and Kallioniemi O. FZD4 as a mediator of ERG oncogene-induced WNT signaling and epithelial-to-mesenchymal transition in human prostate cancer cells. Cancer Res. 2010; 70(17):6735-6745.

38. Wu L, Zhao JC, Kim J, Jin HJ, Wang CY and Yu J. ERG is a critical regulator of Wnt/LEF1 signaling in prostate cancer. Cancer Res. 2013; 73(19):6068-6079.

39. Paulo P, Ribeiro FR, Santos J, Mesquita D, Almeida M, Barros-Silva JD, Itkonen H, Henrique R, Jeronimo C, Sveen A, Mills IG, Skotheim RI, Lothe RA and Teixeira MR. Molecular subtyping of primary prostate cancer reveals specific and shared target genes of different ETS rearrangements. Neoplasia. 2012; 14(7):600-611.

40. Consortium EP. An integrated encyclopedia of DNA elements in the human genome. Nature. 2012; 489(7414):57-74.

41. Kim SM, Kim JY, Choe NW, Cho IH, Kim JR, Kim DW, Seol JE, Lee SE, Kook H, Nam KI, Kook H, Bhak YY and Seo SB. Regulation of mouse steroidogenesis by WHISTLE and JMJD1C through histone methylation balance. Nucleic Acids Res. 2010; 38(19):6389-6403.

42. Wolf SS, Patchev VK and Obendorf M. A novel variant of the putative demethylase gene, s-JMJD1C, is a coactivator of the AR. Arch Biochem Biophys. 2007; 460(1):56-66.

43. Kim TD, Shin S and Janknecht R. ETS transcription factor ERG cooperates with histone demethylase KDM4A. Oncol Rep. 2016; 35(6):3679-3688.

44. Katoh $\mathrm{M}$ and Katoh M. Comparative integromics on JMJD1C gene encoding histone demethylase: conserved POU5F1 binding site elucidating mechanism of JMJD1C expression in undifferentiated ES cells and diffuse-type gastric cancer. Int J Oncol. 2007; 31(1):219-223.

45. Chen J, Chan AW, To KF, Chen W, Zhang Z, Ren J, Song C, Cheung YS, Lai PB, Cheng SH, Ng MH, Huang A and Ko BC. SIRT2 overexpression in hepatocellular carcinoma mediates epithelial to mesenchymal transition by protein kinase B/glycogen synthase kinase-3beta/beta-catenin signaling. Hepatology. 2013; 57(6):2287-2298.

46. Lehnertz B, Ueda Y, Derijck AA, Braunschweig U, Perez-Burgos L, Kubicek S, Chen T, Li E, Jenuwein T and Peters $\mathrm{AH}$. Suv39h-mediated histone H3 lysine 9 methylation directs DNA methylation to major satellite repeats at pericentric heterochromatin. Curr Biol. 2003; 13(14):1192-1200.

47. Snowden AW, Gregory PD, Case CC and Pabo CO. Gene-specific targeting of H3K9 methylation is sufficient for initiating repression in vivo. Curr Biol. 2002; 12(24):2159-2166.

48. Braig M, Lee S, Loddenkemper C, Rudolph C, Peters AH, Schlegelberger B, Stein H, Dorken B, Jenuwein T and Schmitt CA. Oncogene-induced senescence as an initial barrier in lymphoma development. Nature. 2005; 436(7051):660-665.

49. Cedar $\mathrm{H}$ and Bergman $\mathrm{Y}$. Linking DNA methylation and histone modification: patterns and paradigms. Nat Rev Genet. 2009; 10(5):295-304.

50. Rose NR and Klose RJ. Understanding the relationship between DNA methylation and histone lysine methylation. Biochim Biophys Acta. 2014; 1839(12):1362-1372. 


\section{CHAPTER 3}

51. Hojfeldt JW, Agger K and Helin K. Histone lysine demethylases as targets for anticancer therapy. Nat Rev Drug Discov. 2013; 12(12):917-930.

52. Kacprzyk LA, Laible M, Andrasiuk T, Brase JC, Borno ST, Falth M, Kuner R, Lehrach H, Schweiger MR and Sultmann H. ERG induces epigenetic activation of Tudor domain-containing protein 1 (TDRD1) in ERG rearrangement-positive prostate cancer. PLoS One. 2013; 8(3):e59976.

53. Mendizabal I, Zeng J, Keller TE and Yi SV. Body-hypomethylated human genes harbor extensive intragenic transcriptional activity and are prone to cancer-associated dysregulation. Nucleic Acids Res. 2017; 45(8):4390-4400.

54. Lou S, Lee HM, Qin H, Li JW, Gao Z, Liu X, Chan LL, KI Lam V, So WY, Wang Y, Lok S, Wang J, Ma RC, Tsui SK, Chan JC, Chan TF, et al. Whole-genome bisulfite sequencing of multiple individuals reveals complementary roles of promoter and gene body methylation in transcriptional regulation. Genome Biol. 2014; 15(7):408.

55. Yang X, Han H, De Carvalho DD, Lay FD, Jones PA and Liang G. Gene body methylation can alter gene expression and is a therapeutic target in cancer. Cancer Cell. 2014; 26(4):577-590.

56. Jjingo D, Conley AB, Yi SV, Lunyak VV and Jordan IK. On the presence and role of human gene-body DNA methylation. Oncotarget. 2012; 3(4):462-474.

57. Thurman RE, Rynes E, Humbert R, Vierstra J, Maurano MT, Haugen E, Sheffield NC, Stergachis AB, Wang H, Vernot B, Garg K, John S, Sandstrom R, Bates D, Boatman L, Canfield TK, et al. The accessible chromatin landscape of the human genome. Nature. 2012; 489(7414):75-82.

58. Shiina T, Hosomichi K, Inoko H and Kulski JK. The HLA genomic loci map: expression, interaction, diversity and disease. J Hum Genet. 2009; 54(1):15-39.

59. Callahan MJ, Nagymanyoki Z, Bonome T, Johnson ME, Litkouhi B, Sullivan EH, Hirsch MS, Matulonis UA, Liu J, Birrer MJ, Berkowitz RS and Mok SC. Increased HLA-DMB expression in the tumor epithelium is associated with increased CTL infiltration and improved prognosis in advanced-stage serous ovarian cancer. Clin Cancer Res. 2008; 14(23):7667-7673. 


\section{Chapter 4}

\section{INSM1 induces a neuroendocrine phenotype in prostate cancer cells}

Leonie Ratz, Peter Altevogt, Sabine M Klauck, Holger Sültmann

In preparation 


\section{ABSTRACT}

Risk stratification and discrimination of indolent versus clinically significant potentially lethal prostate cancer (PCa) is challenged by its heterogeneous appearance. Neuroendocrine differentiation of ADT-treated PCa is considered a highly aggressive variant of the disease. Due to a lack of rebiopsy specimens and underestimation of this subtype, the molecular characteristics of neuroendocrine prostate cancer are poorly understood. A systematic selection of PCa-relevant candidate genes from expression profiling and RNA-sequencing data of PCa patient tumor samples revealed the neuronal transcription factor INSM1 as a prominent regulator of a neuroendocrine network. Functional characterization of the role of INSM1 in the PCa cell lines VCaP, NCI-H660, PC-3, and LNCaP showed regulation of NE marker expression (ASCL1, CHGA, CHGB, SYP, TUBB3) and increased oncogenic properties of the cells, such as migration and invasion, by INSM1. A strong correlation between INSM1 expression and the transcription factor ERG was observed in clinical data and PCa cells. ERG overexpression was accompanied by high expression of NE markers (TUBB3, SCG3, ASCL1). INSM1 overexpression led to reduced expression of the RE-1 silencing transcription factor (REST). REST was shown to mediate repression of neuronal genes (e.g. SYP, CHGB) as well as MYCN, NCAM, and L1CAM in PCa cells. This finding is consistent with earlier reports in different tumors. We showed that REST was also involved in the regulation of INSM1 expression. Comparative microarray expression profiling analysis upon siRNA-mediated knockdown of INSM1, REST, and LICAM identified the extracellular glycoprotein reelin (RELN), which is involved in neuronal migration, as a factor that could confer aggressive properties in PCa cells by activation of oncogenic signaling pathways. In conclusion, we identified INSM1 as a promising determinant of a neuroendocrine transcriptional network in PCa cells. Since INSM1 expression is usually restricted to neuronal and endocrine tissue, reactivation of INSM1 in PCa could be of major interest for future studies and drug development. We provide a rationale for future examination of INSM1 as marker in histological diagnosis of PCa and to address its role as specific therapeutic target for neuroendocrine prostate cancer. 


\section{INTRODUCTION}

Prostate cancer (PCa) is a disease with complex histopathological and molecular features and divergent clinical outcome. Tumor heterogeneity and genomic complexity of PCa pose challenges of the determination of aggressive lethal disease, which is not recognized by histological grading alone, and for the optimal therapy decision. The identification of genes playing a critical role in the progression of PCa could provide markers of aggressive disease, improve existing diagnostic tests and risk stratification, and reveal novel drug targets.

Neuroendocrine prostate cancer (NEPC) is a highly aggressive manifestation of advanced PCa, as reviewed earlier in chapter 1 . NEPC is predominantly detected in previously treated adenocarcinomas and may be linked to androgen-deprivation therapy (ADT) resistance. NEPC is considered as an adaptive clinical phenotype established under the treatment stress of prolonged ADT. This is corroborated by the detection of differential gene expression and copy number alterations between adenocarcinoma cells and NEPC [1-6]. Reduced expression of the androgen receptor (AR) is a hallmark of NEPC [7, 8]. As a consequence, the AR-regulated genes PSA, TMPRSS2, and NKX3.1 are recurrently downregulated in NEPC [2, 7-9]. Histopathologically, NEPC is distinguished from prostatic adenocarcinoma by unique ultrastructural characteristics, such as neurosecretory granules, and immunohistochemical staining for various neuroendocrine elements and polypeptide hormones (e.g. synaptophysin (SYP), chromogranins A and B (CHGA, CHGB), neuron-specific enolase (NSE/ENO2), or neuronal cell adhesion molecule (NCAM1/CD56)) [10-12].

It was initially assumed that NEPC developed from outgrowth of normal prostatic NE cells, promoted by the selective pressure of androgen-independent growth [13]. Current evidence indicates that NEPC originates from prostate adenocarcinoma cells supported by concordant molecular alterations, involving TMPRSS2:ERG (T/E) gene fusion and TP53 mutations [14-16]. This concept suggests that prostate adenocarcinoma cells transdifferentiate into cells with NE characteristics, underpinned by the detection of epithelial markers in NEPC cells such as expression of CK8, CK18, and AMACR $[5,17,18]$, as wells as allelotyping studies showing a genetic link between PCa cells and NE differentiated tumor cells [14]. NEPC is currently diagnosed by means of clinical characteristics and is increasingly documented during the clinical course of PCa which is of significance regarding the advent of novel highly potent AR-targeted therapies. Since sampling of PCa metastases is rare in routine practice, the molecular mechanisms determining neuroendocrine transformation are poorly explored [7, 19]. 


\section{MATERIAL AND METHODS}

\section{Strategy for target gene selection}

A systematic selection of PCa-relevant genes of PCa patient tumor samples was performed using data from the expression profiling NGFN IG Prostate Cancer project (IGP) [20] and RNA-sequencing data from the International Cancer Genome Consortium-Early Onset Prostate Cancer project (ICGC-EOPC) [21]. A candidate gene approach was used to prioritize relevant genes. Genes showing a fold change of $>|1.5|$, an FPKM (fragments per kilobase of exon per million fragments mapped) $>1$, and a count (number of reads aligned to each transcript) $>100$ were selected for further analysis. Those candidates were further prioritized according to the 'guilt-by-association' concept, which identifies most promising candidates based on their similarity to genes already known to be linked to a biological process of interest, such as PTEN-PI3K/AKT and AR signaling including co-factors regulating AR activity $[22,23]$. Next, by using disease-specific web tools for cancer transcriptomic data analysis (Oncomine, TCGA), genes were correlated to mutational and functional information, such as ERG overexpression. The online software tool Ingenuity Pathway Analysis (IPA) was used to predict cancer-relevant gene function, and to identify interaction networks and pathway involvement, thereby linking the selected candidates to PCa-relevant biological processes. Subsequently, the biological relevance of our candidate genes was experimentally validated using cell culture models.

\section{Cell lines and culturing}

RWPE-1, LNCaP, VCaP, DU-145, PC-3 and NCl-H660 cells were purchased from American Type Culture Collection (ATCC, Manassas, VA, USA) (Supplementary Table S4.1). LNCaP and DU-145 cells were cultured in RPMI1640 supplemented with 10\% FBS. VCaP cells were maintained in DMEM medium supplemented with 10\% FBS. PC-3 cells were cultured in $\mathrm{F} 12-\mathrm{K}$ medium supplemented with $10 \% \mathrm{FBS}$. $\mathrm{NCl}-\mathrm{H} 660$ cells were maintained in HITES medium supplemented with $5 \%$ fetal bovine serum according to the provider's instructions. RWPE-1 cells were cultured in Keratinocyte Serum Free Medium (K-SFM, Invitrogen 17005) supplemented with bovine pituitary extract (BPE) and epidermal growth factor (EGF). All cell lines were authenticated using Multiplex Cell Authentication by Multiplexion (Heidelberg, Germany) as described recently [24]. The SNP profiles matched known profiles or were unique. The purity of cell lines was validated using the Multiplex cell Contamination Test by Multiplexion (Heidelberg, Germany) as described recently [25]. No Mycoplasma, SMRV or interspecies contamination was detected.

LNCaP cells stably expressing T/E variants (LNCaP-T/E) were described earlier [26] (see chapter 2). Transgene expression was induced with $50 \mathrm{ng} / \mathrm{mL}$ Dox (Sigma-Aldrich, Munich, Germany) in RPMI1640 containing 10\% tet-FBS. Medium of the uninduced cells was supplemented with the respective volume of PBS only. 
RNA isolation, reverse transcription and quantitative real-time $P C R$

Total RNA was isolated from cell lines using the miRNeasy Mini Kit (Qiagen, Hilden, Germany) and quality controlled on the 2100 Bioanalyser (Agilent Technologies, Waldbronn, Germany) with RNA 6000 Nano Kit according to manufacturer's protocols. Total RNA was reverse transcribed using the RevertAid H Minus First Strand cDNA Synthesis Kit (Thermo Fisher Scientific). HotStarTaqDNA polymerase (Qiagen) was used for RT-PCR with 50ng of cDNA template. Relative mRNA levels were assessed by quantitative RTPCR on the Lightcycler 480 (Roche Diagnostics, Mannheim, Germany) using Universal Probe Library (UPL) assays and primers listed in Supplementary Table S4.2. Linear expression levels were normalized to GAPDH using the $2^{(-\Delta \Delta C t)}$ method [27].

\section{Microarray gene expression profiling}

RNA was isolated with the RNase-Free DNase Set (Qiagen) according to the manufacturer's protocol. After quality control, 500ng of total RNA with a concentration of $50 \mathrm{ng} / \mu \mathrm{l}$ were submitted to the DKFZ Genomics and Proteomics Core Facility (GPCF) for Illumina Whole-Genome Expression Beadchip Analysis (Human HT-12 Chip). The raw data were quantile-normalized using the Bioconductor package preprocessCore in R. Genes showing expression fold change $>|1.3|$ ( $p$-value $<0.05$ ) were considered as differentially expressed and were analysed with Ingenuity Pathway Analysis (IPA) (see below). Genes involved in relevant biological processes obtained from microarray analysis were validated by qPCR in the same samples that were used for microarray profiling.

\section{SiRNA-mediated gene knock-down}

Cells were transfected with siRNA (Qiagen, Supplementary Table S4.3) using Lipofectamine RNAiMAX (Thermo Fisher Scientific) and OptiMEM ${ }^{\circledR}$ I (Thermo Fisher Scientific) according to the manufacturer's protocol. VCaP and $\mathrm{NCl}-\mathrm{H} 660$ cells were transfected with 50nM siRNA against INSM1 or ERG (Qiagen), LNCaP cells were treated with 20nM siRNA against REST (Qiagen), and PC-3 cells were transfected with 10nM siRNA against $\angle 1 C A M$ and RELN, respectively. Cells transfected with nonsilencing AllStars Negative Control siRNA (Qiagen) were used as controls. All cells were incubated for $72 \mathrm{~h}$ in $5 \%$ $\mathrm{CO} 2$ at $37^{\circ} \mathrm{C}$ and processed for further analysis.

\section{Chemical transformation of bacteria}

Chemically competent TOP10 E. coli cells (Invitrogen) were transformed with recombinant plasmids (Supplementary Table S4.4) using the heat shock method. Fifty $\mu \mathrm{L}$ of competent cells were thawed on ice. Two $\mu$ l of plasmid DNA was added to $10 \mu$ l of competent cells and incubated on ice for $30 \mathrm{~min}$. Then the cells were subjected to a heat shock at $42^{\circ} \mathrm{C}$ for $30 \mathrm{sec}$ in a water bath and directly placed on ice for 2 min thereafter. $200 \mu \mathrm{L}$ of pre-warmed SOC medium (Invitrogen) was added to the bacteria for recovery from the heat shock. The bacteria were then incubated for $1 \mathrm{~h}$ at $37^{\circ} \mathrm{C}$ horizontally sha- 
king at $220 \mathrm{rpm} .100 \mu \mathrm{L}$ of the bacteria solution was plated on LB agar plates containing the appropriate antibiotic and incubated over night at $37^{\circ} \mathrm{C}$.

\section{Colony PCR}

Colony PCR was used to screen for successfully recombined plasmids from bacterial transformation reactions. Single bacterial colonies were picked up from the agar plates with a sterile pipet tip and transferred to PCR tubes containing $25 \mu \mathrm{l}$ of PCR master mix while cooled on ice. DreamTaq DNA polymerase (Thermo Scientific) was used for colony PCR (1.25 U/reaction). The following reagents are contained in the PCR master mix: $2 x$ DreamTaq Green PCR Master Mix $(12.5 \mu \mathrm{L})$ containing $0.4 \mathrm{mM}$ dNTPs, $20 \mu \mathrm{M}$ primer mix $(0.75 \mu \mathrm{L})$, and water $(\mathrm{ad} 25 \mu \mathrm{L})$. The following temperature cycling was performed in a thermal cycler: initial denaturation $\left(1 \mathrm{~min}\right.$ at $\left.95^{\circ} \mathrm{C}\right)$, denaturation $\left(30 \mathrm{sec}\right.$ at $\left.95^{\circ} \mathrm{C}\right)$, annealing ( $30 \mathrm{sec}$ at $50^{\circ} \mathrm{C}$ ), extension $\left(1 \mathrm{~min} / \mathrm{kb}\right.$ expected PCR product size at $72^{\circ} \mathrm{C}$ ). Steps from denaturation to extension were repeated 35 times followed by a final extension step for $10 \mathrm{~min}$ at $72^{\circ} \mathrm{C}$ and cooling to $10^{\circ} \mathrm{C}$. PCR products were analysed by agarose gel electrophoresis.

\section{Cryopreservation of bacterial stocks}

Glycerol stocks for long term storage of the bacteria clones and re-inoculation of growth medium were prepared from over-night cultures. Bacteria culture $(800 \mu l)$ was mixed with $200 \mu \mathrm{l}$ of $87 \%$ sterile glycerol, transferred to a $1.8 \mathrm{~mL}$ CryoTube (Nunc) and frozen at $-80^{\circ} \mathrm{C}$.

\section{Sanger sequencing}

Sanger sequencing was used to verify sequences of cloned DNA fragments. DNA and primers were submitted to GATC Biotech (Konstanz, Germany) where the sequencing reactions were performed.

\section{Agarose gel electrophoresis}

DNA fragments or PCR products were separated by agarose gel electrophoresis. Agarose was added to 1 XTAE buffer to the desired concentration ( $2 \%$ for standard use) and boiled until the agarose was completely dissolved. Liquid agarose was cooled down to $\sim 50^{\circ} \mathrm{C}$ before casting the gels. Gels were run in $1 \times T A E$ buffer containing $0.5 \mathrm{mg} / \mathrm{L}$ ethidium bromide solution at $80 \mathrm{~V}$ until the loading dye had migrated for the desired distance. Bands were visualized using a UV transilluminator.

\section{Plasmid DNA preparation}

For plasmid preparation, LB medium containing the correct antibiotic was inoculated from a single bacterial colony and incubated over night at $37^{\circ} \mathrm{C}$ while horizontally shaking at $220 \mathrm{rpm}$. For cloning, plasmids were prepared with the Plasmid Mini Kit (Qia- 
gen). The Plasmid Midi Kit (Qiagen) were used to prepare plasmid DNA for transfection of cell lines. All kits were used according to the manufacturer's instructions.

\section{Plasmid transfection}

DNA transfection of cell lines was performed using the jetPEI DNA transfection reagent (VWR International). Cells (LNCaP and PC-3 at $1.5 \times 10^{5}$ cells, VCaP at $3 \times 10^{5}$ cells) were seeded $24-48 \mathrm{~h}$ in 6-well plates prior to transfection. One $\mu \mathrm{g}$ of DNA was diluted in $100 \mu \mathrm{l}$ of $150 \mathrm{mM} \mathrm{NaCl}$. Four $\mu \mathrm{l}$ jetPEI transfection reagent (VWR International) was diluted in $100 \mu \mathrm{l}$ of $150 \mathrm{mM} \mathrm{NaCl}$. The jetPEI solution was added to the DNA solution, vortexed and incubated for $30 \mathrm{~min}$ at RT. Meanwhile, the culture medium of the cells was aspirated and refreshed by $1800 \mu \mathrm{l}$ of growth medium. $200 \mu \mathrm{l}$ of the jetPEI/DNA mixture was added drop-wise onto the culture medium in each well, homogenized by gently swirling the plate and incubated at $37^{\circ} \mathrm{C}$ for $72 \mathrm{~h}$.

\section{Cell proliferation assay}

Cells were transfected with siRNA or overexpression plasmid for $48 \mathrm{~h}$ and subsequently seeded into 96-well plates at 5000 cells/well in $90 \mu \mathrm{l}$ 10\% FBS-containing medium in triplicate and again incubated for $24 \mathrm{~h}$. Ten $\mu \mathrm{l}$ of the colorimetric WST-1 reagent (Roche Diagnostics) was added to the medium and incubated at $37^{\circ} \mathrm{C}$. Absorbance was measured $2 \mathrm{~h}$ after addition of WST-1 reagent using a Tecan Infinite ${ }^{\circledR}$ M200 microplate reader (Tecan Group Ltd., Männedorf, Switzerland).

\section{Colony formation assay}

Cells were transfected with siRNA or overexpression plasmid for $48 \mathrm{~h}$ and subsequently seeded into 6-well plates at 700 cells/well in $2000 \mu \mathrm{l} 10 \%$ FBS-containing medium in duplicate and incubated for 20 days in $5 \% \mathrm{CO} 2$ at $37^{\circ} \mathrm{C}$. Colonies of $>50$ cells were fixed with $100 \%$ methanol on ice and stained with $0.1 \%$ Crystal Violet (Sigma- Aldrich). Colonies were counted using the Clono-Counter software [28].

\section{Migration and invasion assays}

In vitro cell migration assays were performed in duplicate using 24-well transwell chambers with $8 \mu \mathrm{m}$ pore size (Merck Millipore). Cells were transfected with siRNA or overexpression plasmid for $48 \mathrm{~h}$ and subsequently seeded at $5 \times 10^{5}$ cells $/ \mathrm{mL}$ into the upper chamber in $200 \mu \mathrm{l}$ serum-free medium. Seven hundred $\mu \mathrm{l}$ of medium supplemented with $10 \%$ FBS as chemoattractant was filled into the bottom well. After $48 \mathrm{~h}$ of cultivation in $5 \% \mathrm{CO} 2$ at $37^{\circ} \mathrm{C}$, migrated cells attached to the lower surface of the insert were fixed with $100 \%$ methanol on ice and stained with $0.1 \%$ crystal violet (Sigma- Aldrich). Migrated cells were counted in four random fields under a light microscope (10x magnification). 
Invasion assays were performed analogously after coating the transwell chambers with $100 \mu$ l Matrigel (BD Biosciences, Heidelberg, Germany) per filter.

\section{Cell lysis and Western blot analysis}

Whole-cell lysates were prepared in RIPA lysis buffer $(50 \mathrm{mM}$ Tris-HCl pH 8.0, $150 \mathrm{mM}$ $\mathrm{NaCl}, 1 \% \mathrm{NP}-40,0.5 \%$ sodium deoxycholate, $0.1 \% \mathrm{SDS}$ ), supplemented with $1 \times \mathrm{cOm}$ plete Mini Protease Inhibitor Cocktail (Roche Diagnostics) and 1x PhosSTOP Phosphatase Inhibitor Cocktail (Roche Diagnostics). Lysates were boiled 5 min at $95^{\circ} \mathrm{C}$ with $4 \mathrm{x}$ reducing Roti-Load protein loading buffer (Roth, Karlsruhe, Germany). Samples were separated on a mini polyacrylamide gel (Bio-Rad, Munich, Germany) and transferred to PVDF membranes using the Trans-Blot Turbo semi-dry blotting system (Bio-Rad) at 1.3A, 25V for 7-10 min. After blocking with 5\% BSA in Tween-20/PBS, membranes were probed with primary antibodies prepared in blocking solution overnight at $4^{\circ} \mathrm{C}$ on a roller, followed by incubation with horseradish peroxidase-conjugated secondary antibody in blocking solution for $1 \mathrm{~h}$ at room temperature and ECL detection (Thermo Fisher Scientific) by the ChemiDoc XRS+ system (Bio-Rad). Western blotting was performed using primary antibodies against INSM1 (Sigma-Aldrich, Munich, Germany), REST (EMD Millipore, Darmstadt, Germany), L1CAM (clone L1-11A, by Peter Altevogt), and GAPDH (Cell Signaling Technology, Danvers, MA, USA) at 1:1000 dilution. Secondary antibodies used were anti-rabbit-HRP (at 1:25000 dilution; Dianova, Hamburg, Germany) and antimouse-HRP (at 1:10000 dilution; Cell Signaling). Quantitative analysis of protein expression relative to GAPDH was done using Image Lab software (Bio-Rad).

\section{Ingenuity Pathway Analysis}

Functional annotation and pathway enrichment of differentially regulated genes were identified using Ingenuity Pathway Analysis (IPA) software (Qiagen). IPA uses the Ingenuity knowledge base, a database of protein and gene interactions integrated from published biomedical literature and third party sources. Analysis using IPA was performed between September 2015 and February 2016 (Ingenuity version 26127183).

\section{Functional annotations}

Gene expression changes were categorized into functional annotations of molecular and cellular mechanisms. The Ingenuity knowledge base provides a predicted direction of change for the biological function (downstream effect analysis), represented by an activation z-score, where $z>2.0$ or $<-2.0$ is predictive for activation or reduction of the process, respectively. A p-value $<0.05$ indicates a statistically significant association between a set of differentially expressed genes and a given process. 
Pathway enrichment analysis

Ingenuity knowledge base provides an analysis of metabolic and cell signaling pathways that are significantly enriched in the gene expression signature. Pathway significance values were calculated based on Fisher's right tailed exact test and the - $\log (p$-value) by IPA. Pathways meeting the threshold $p$-value $<0.05$ were considered as significant.

\section{Statistical testing}

Expression differences between the induced and uninduced cells were analysed using a paired t-test and between induced cells of T/E III and VI by an unpaired t-test. Statistical significance of t-test depicted as $* p<0.05, * * p<0.01, * * * p<0.001$.

\section{RESULTS}

INSM1 is highly expressed in ERG fusion-positive PCa samples and cell lines

A systematic candidate gene selection was performed to prioritize PCa-relevant genes using data from the expression profiling NGFN IG Prostate Cancer project (IGP) [20] and RNA-sequencing data from the International Cancer Genome Consortium-Early Onset Prostate Cancer project (ICGC-EOPC) [21]. The gene insulinoma-associated-1 (INSM1) was strongly upregulated in tumor samples (21-fold, count: 1259, FPKM: 1.537) compared to normal tissue of the ICGC-EOPCA RNA-seq data set. INSM1 plays a role in pancreatic and neuronal development and is usually expressed during the embryonic development of NE tissue $[29,30]$. In adult tissue, INSM1 expression levels are low or absent. In NE tumors of different origin, INSM1 shows aberrant high expression [31]. Differential gene expression analysis for $E R G$ fusion-positive versus $E R G$ fusion-negative tumor samples using the ICGC RNA-seq data (unpublished) further revealed increased expression of INSM1 (1.4-log fold, p-value<0.005) in ERG fusion-positive samples (Figure 4.1A). The association of INSM1 with ERG was evaluated using the TCGA PRAD RNA-seq (IlluminaHiSeq) $(\mathrm{n}=550)$ dataset confirming an increased expression of INSM1 in ERG fusion-positive tumor samples ( $p$-value<0.0001; Figure 4.1B). Together, these data indicated that the expression of INSM1 was upregulated in PCa tumor samples and correlated with the T/E fusion status. 
A

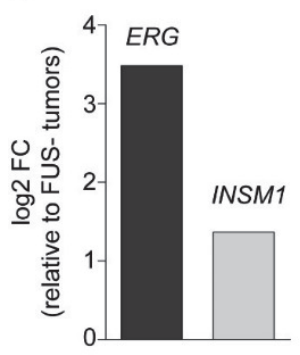

B

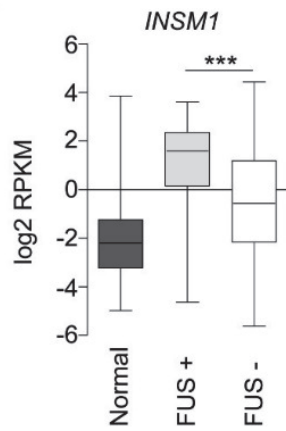

Figure 4.1: Gene expression levels of INSM1 in prostate tissue. (A) Differential gene expression of INSM1 in PCa tumor samples using ICGC RNA-seq data $(n=90)$. Expression values are shown as $\log 2 F C$ in $T / E$ fusion-positive samples relative to fusion-negative samples. (B) INSM1 expression using the TCGA PRAD RNA-seq (IlluminaHiSeq) ( $\mathrm{n}=550)$ dataset. Values are given as log2 RPKM. FUS - TMPRSS2:ERG fusion.

To assess the expression pattern of INSM1 in PCa cells, qPCR analysis was performed across cell lines representing different characteristics of PCa. INSM1 mRNA levels were high in VCaP ( 30,000-fold) and NCl-H660 ( 97,000-fold) cells, both positive for the T/E gene fusion [32], compared to the non-neoplastic human epithelial prostate cells RWPE1 [33] (Figure 4.2A), indicating that the expression of INSM1 also correlated with the presence of the T/E gene fusion in PCa cell lines. The high expression of INSM1 in the $\mathrm{NE}-$ like $\mathrm{NCl}-\mathrm{H} 660$ cell line, which was originally derived from a prostatic small cell carcinoma, suggested that INSM1 is associated with the neuroendocrine phenotype [32]. The classical fusion-negative cell lines LNCaP, DU-145, and PC-3 cells, showed low or absent INSM1 expression (Figure 4.2A).

A

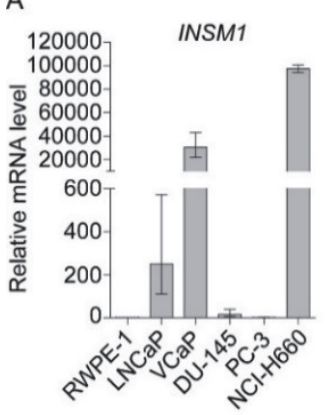

B

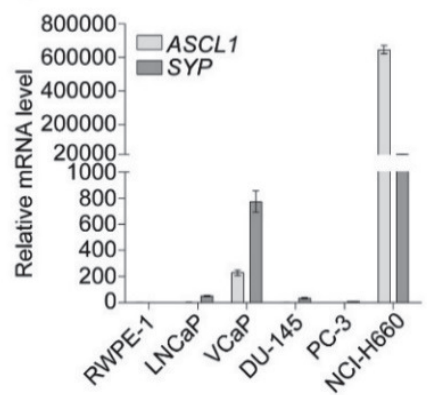

C

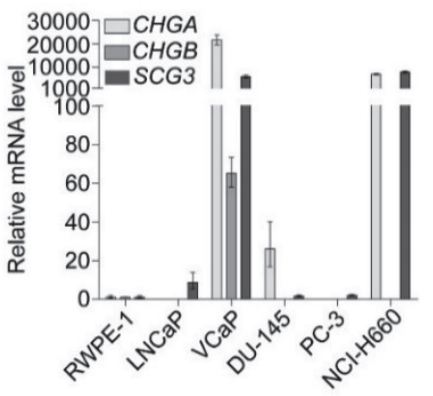

Figure 4.2: T/E-positive PCa cell lines express INSM1 and NE markers. (A) qPCR analysis across different PCa cell lines shows upregulation of INSM1 mRNA in the T/E-positive cells VCaP and NCI-H660 compared to RWPE-1 cells. (B-C) mRNA expression of the NE markers (B) SYP, ASCL1, and (C) CHGA, CHGB, and SCG3 is high in VCaP and $\mathrm{NCI}-\mathrm{H} 660$ cells. $\triangle \mathrm{Cp}$ values from three independent experiments are shown relative to GAPDH. 
INSM1 induces a NE molecular signature in PCa cells

The linkage of INSM1 to neuronal processes stimulated us to analyse its function in the development of NEPC. First, basic expression levels of the pro-neural transcription factor achaete-scute homolog 1 (ASCL1), the membrane glycoprotein synaptophysin (SYP), chromogranin A and $\mathrm{B}$ (CHGA, CHGB), and secretogranin 3 (SCG3), markers of neuroendocrine neoplasms [34], could be detected in VCaP and $\mathrm{NCl}-\mathrm{H} 660$ cells, but not in LNCaP, DU-145, PC-3, and RWPE-1 cells (Figure 4.2B and C). The high expression of NE markers in $\mathrm{NCl}-\mathrm{H} 660$ cells is in accordance with the neuroendocrine origin of this cell line [32]. Further, expression levels of NE markers in VCaP and NCl-H660 cells correlated with the high expression of INSM1 in these cells.

The role of INSM1 in controlling neuroendocrine differentiation (NED) in PCa cells was analysed using siRNA-mediated knockdown and plasmid overexpression. Knockdown of INSM1 in VCaP cells resulted in 50\% reduced expression of CHGA and revealed increased mRNA expression (1.5-fold) of the RE-1 silencing transcription factor (REST/NRSF), a transcriptional repressor of neuronal genes [35] (Figure 4.3A), indicating that INSM1 functions as negative regulator of REST in NED. Knockdown of INSM1 in NCl-H660 cells reduced the expression of CHGA (60-75\% reduction) and SYP (60\% reduction) (Figure 4.3B). Upon INSM1 overexpression in LNCaP cells, the NE markers SYP and ASCL1 were increased (3.5-fold and 7-fold, respectively) (Figure 4.3C). Western blot analysis showed that overexpression of INSM1 reduced REST protein levels in LNCaP cells (Figure 4.3D). Likewise, INSM1 overexpression in PC-3 cells induced upregulation of SYP (3-fold, Figure 4.3E), the neuron-associated tubulin beta 3 (TUBB3) [36] (1.3-fold) (Figure 4.3F) and L1CAM mRNA (4-fold, Figure 4.3F) as well as L1CAM protein (Figure 4.3G-H). The neuronal L1 cell adhesion molecule (L1CAM), a member of the neuronal immunoglobulin (Ig) super-family is involved in neurite outgrowth and migration [37]. It has been associated with poor prognosis and tumor progression [38, 39]. Taken together, these results indicate that INSM1 induces NE marker expression, which are not normally expressed in PCa cells and present INSM1 as negative regulator of REST expression. However, evidence for a direct regulation of REST by INSM1 needs further experimental validation.

To identify the transcriptional modulation and regulatory function induced by INSM1, Illumina microarray expression profiling after siRNA-knockdown was performed. Microarray services were provided by the Genomics and Proteomics Core Facility at the DKFZ. Normalized data were analysed for differential expression. Genes showing $>|1.3|$ fold change compared to control were considered as significantly differentially regulated and used for further analysis using the Ingenuity Pathway analysis (IPA) tool (Supplementary Table S4.5). Comparison of differential mRNA expression between the INSM1 knockdown expression signature obtained by microarray profiling in VCaP cells 
(Supplementary Table S4.5) and RNA-seq data in NEPC [2] revealed consistent differential expression, including the genes STEAP1, ALDH1A3, HEPACAM2, and E2F2. For example, ALDH1A3, an AR-regulated gene [40-42], and STEAP1, suggested as a marker of prostate adenocarcinoma $[43,44]$, were higher expressed in prostate adenocarcinoma samples compared to NEPC tissue [2] and were upregulated upon INSM1 knockdown.

Gene ontology terms were determined to reveal the functional context upon INSM1 knockdown. 'Neuritogenesis' was among the most significant biological processes (Supplementary Table S4.6A), which was consistent with the involvement of INSM1 and its regulated genes in neuronal functions. Pathway analysis (Supplementary Table S4.6B) revealed the 'Protein Ubiquitination Pathway', suggesting a role in protein processing and degradation that could be involved in a cellular phenotype change. Further, 'Gap Junction Signaling', 'EIF2 Signaling', and 'Melatonin Signaling' were identified, implying the involvement of INSM1 in intercellular communication and CAMP signaling that could be associated with neuronal signaling mechanisms [45-47]. 
A

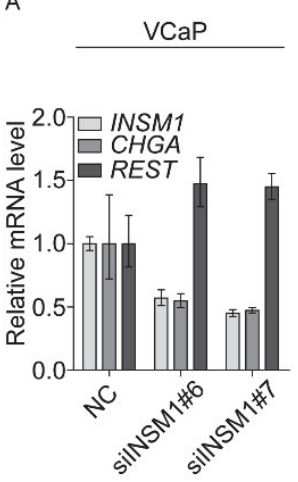

B

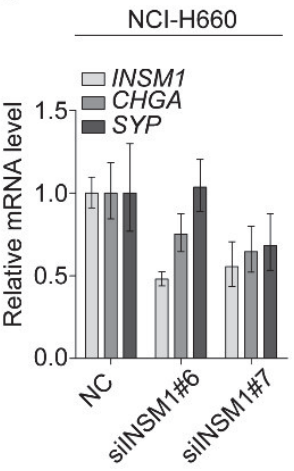

C

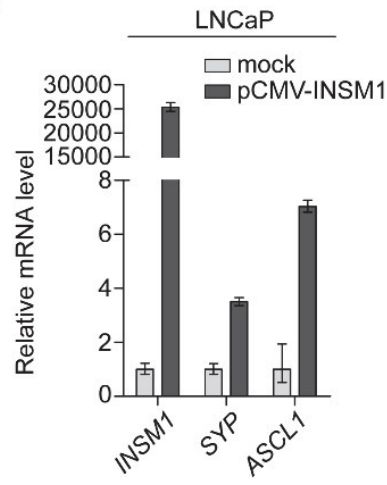

$\mathrm{F}$

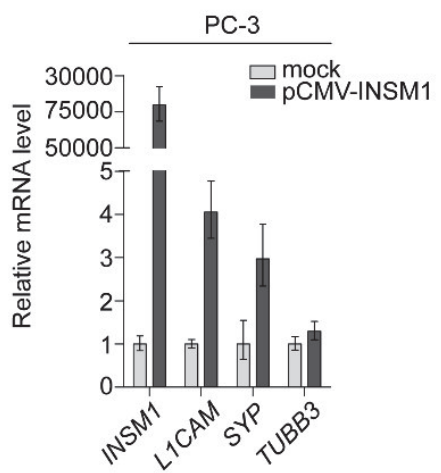

D

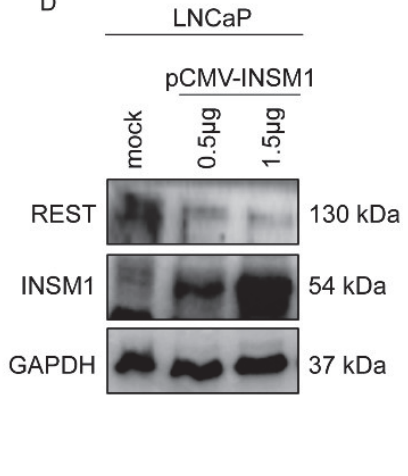

$E$

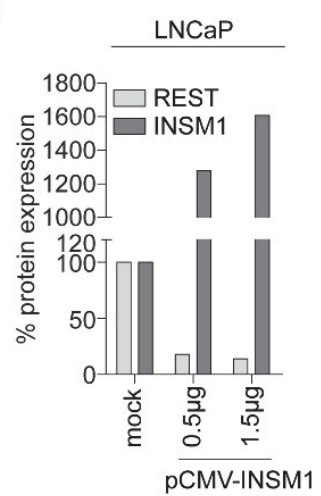

$\mathrm{H}$

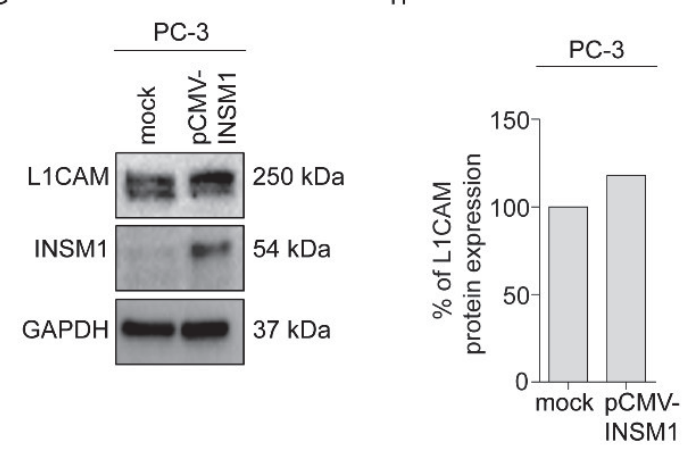

Figure 4.3: INSM1 is involved in the expression of a NE transcriptional network. SiRNA-mediated knockdown of INSM1 in (A) VCaP and (B) NCl-H660 cells using 50nM siRNA shows downregulation of NE markers. REST is upregulated in VCaP cells. (C-E) INSM1 overexpression in LNCaP cells shows upregulation of SYP and ASCL1, and reduced expression of REST protein. (E) Densitometric analysis of Western blot bands shown in (D). (F-H) INSM1 overexpression in PC-3 cells induced upregulation of L1CAM mRNA and protein, and increased SYP and TUBB3 mRNA levels. (H) Densitometric analysis of L1CAM Western blot bands shown in (G). NC - non-target control. 


\section{INSM1 plays a role in migration and invasion in prostate cancer cells}

Overexpression of INSM1 was performed to determine its role on cellular functions. In PC-3 cells, overexpression of INSM1 increased cell viability (Figure 4.4A). INSM1overexpressing PC-3 cells further showed significantly faster migration and invasion after $24 \mathrm{~h}$ of observation (Figure 4.4B). Assessment of viability in LNCaP cells revealed a slight reduction (Figure 4.4C) and reduced clonogenic potential as demonstrated by decreased colony formation upon INSM1 overexpression (Figure 4.4D). INSM1 overexpression further led to a strong enhancement of the migratory potential (Figure 4.4E) of LNCaP cells. Together, these data provide evidence that INSM1 is involved in the regulation of an oncogenic cellular phenotype, but with distinct outcomes depending on the individual genetic tumor background. The observed discrepancy in viability outcome is most likely due to the distinct genetic backgrounds of the cell lines, but also reflects the diverse reports regarding the dynamics of NEPC cells, which will be discussed in more detail later.

A

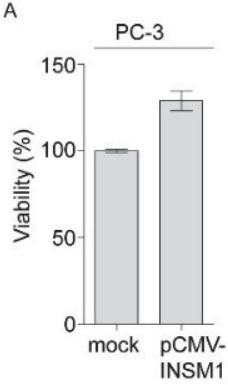

C

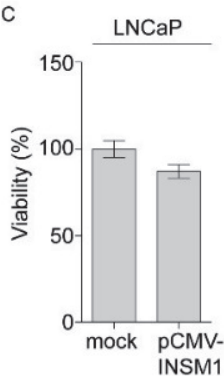

B

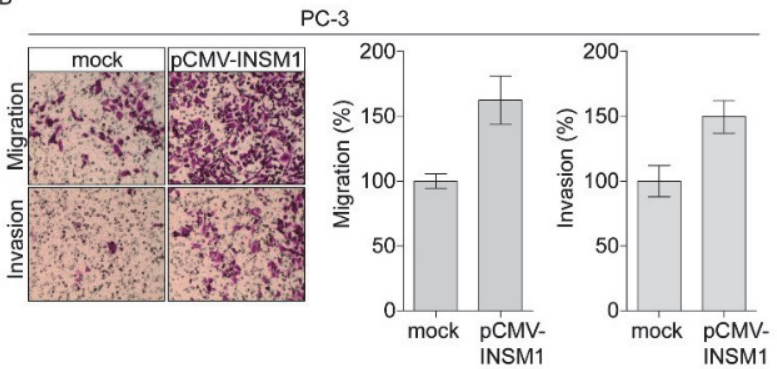

D

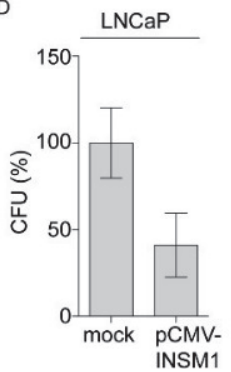

E

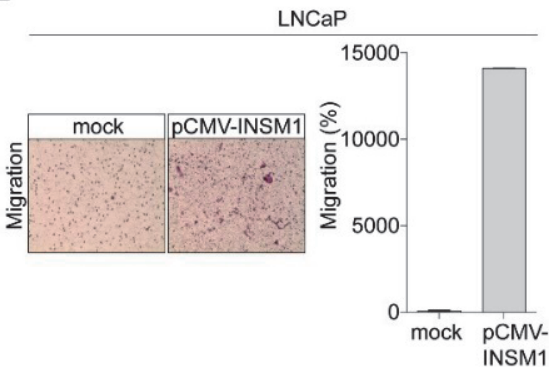

Figure 4.4: Functional characterization of INSM1 by its overexpression in PC-3 and LNCaP cells. (A) Increased viability was determined by using the WST-1 assay in PC-3 cells. (B) In the transwell migration and invasion assay PC-3 cells show significantly faster migration and invasion after $24 \mathrm{~h}$ of observation. (C) Slightly reduced viability of LNCaP cells using the WST-1 assay is noted. (D) Colony formation in LNCaP cells reveals reduced clonogenic potential in LNCaP cells. CFU: colony forming units. (E) INSM1 overexpression leads to strong enhancement of the migratory potential in LNCaP cells. 
ERG promotes a NE-like gene expression signature

Since a correlation between the expression of INSMI and ERG was observed in PCa samples and the T/E-positive cell lines VCaP and $\mathrm{NCl}-\mathrm{H} 660$, we evaluated this link in more detail by knocking down and overexpressing ERG in different cell models. SiRNAmediated ERG knockdown in VCaP (Figure 4.5A) and NCl-H660 (Figure 4.5B) cells led to reduced expression of INSM1 and was accompanied by reduced mRNA levels of the neuroblastoma Myc oncogene (MYCN), which has previously been characterized as a driver of NEPC $[48,49]$. In contrast, REST expression in VCaP cells was increased after siRNA knockdown of ERG (Figure 4.5A). MYCN was also reduced upon ERG knockdown in $\mathrm{NCl}-\mathrm{H} 660$ cells, accompanied by reduced CHGA and SYP expression (Figure 4.5B). However, we did not observe a reduction in REST mRNA upon ERG knockdown in NClH660 cells (data not shown).

The correlation between INSMI and ERG overexpression was further examined using the previously described LNCaP-T/E expressing cell model [26]. This revealed increased INSM1 mRNA levels in T/E expressing cells, respectively, compared to uninduced cells (Figure 4.5C) corroborating ERG-dependent regulation of INSM1 expression. In this cell model, induction of T/E expression further revealed increased levels of $\angle 1 C A M, A S C L 1$, TUBB3, and SCG3 (Figure 4.5C). In summary, our data provide a profound rationale for the role of INSM1 and ERG in the development of a NE signature. 
A

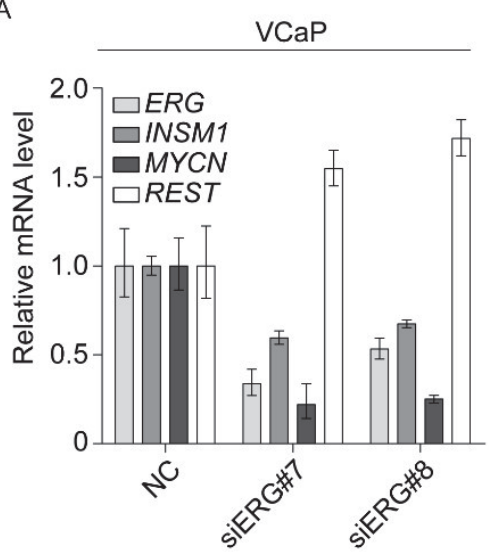

B

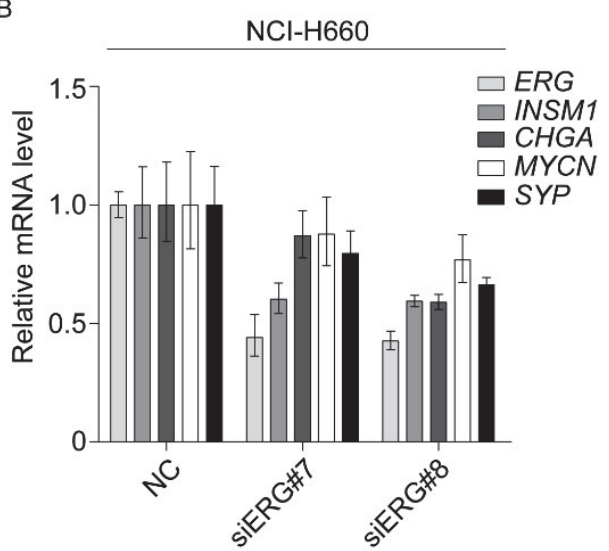

C

LNCaP\#126
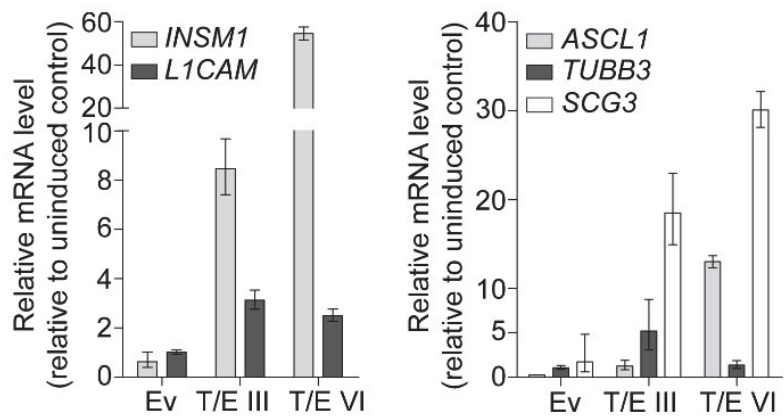

Figure 4.5: ERG regulates INSM1 and NE markers. (A-B) qPCR analysis upon siRNA-mediated ERG knockdown using 50nM siRNA in (A) VCaP cells and (B) NCl-H660 cells. (C) qPCR analysis of NE markers in ERGoverexpressing LNCaP cells (parental clone \#126). NC: non-target control; Ev - empty vector. T/E III and T/E VI - TMPRSS2:ERG gene fusion variants III and VI, respectively.

The neuronal gene silencer REST represses NE markers in PCa cells

REST is known to mediate the restriction of neuronal gene expression in neuronal progenitors and non-neuronal tissue [50,51]. REST expression decreases with terminal differentiation into mature neurons and has been shown to be lost in NEPC $[2,35]$. Assessment of REST mRNA expression levels in PCa cells using qPCR revealed reduced levels in VCaP and NCl-H660 cells, as well as in PC-3 cells compared to RWPE-1 cells (Figure 4.6A). REST levels were highest in LNCaP and DU-145 cells (Figure 4.6A). Correlation analysis using the ExonArray IGP [20] dataset showed an inverse correlation between REST and INSM1 expression (Figure 4.6B). This analysis further identified an inverse correlation of REST with the expression of CHGA, SYP, and L1CAM (Figure 4.6B). 


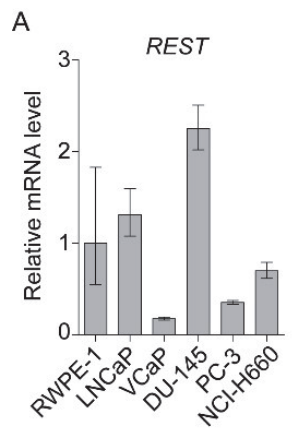

B

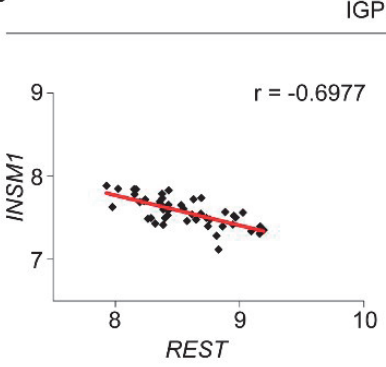

GP data
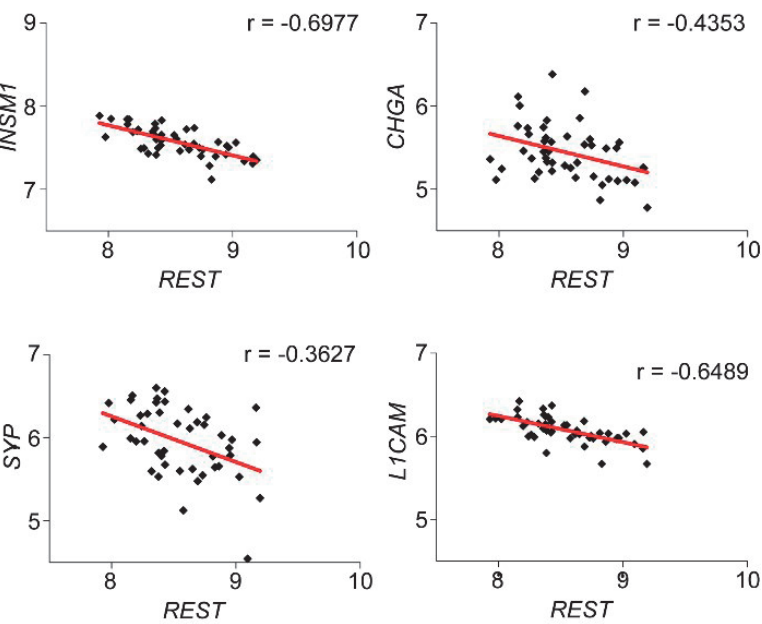

Figure 4.6: REST expression in PCa cells. (A) LNCaP and DU-145 cells show increased REST mRNA levels, while REST expression is low in VCaP, NCl-H660 and PC-3 cells compared to RWPE-1 cells. (B) Correlation of gene expression in the ExonArray IGP dataset, showing negative correlation between REST and INSM1, CHGA, SYP, and LICAM, respectively. IGP data - ExonArray expression profiling from the NGFN IG Prostate Cancer (IGP) project.

Microarray gene expression profiling was performed upon siRNA-mediated REST knockdown in LNCaP cells. Genes showing $>|1.5|$ fold change compared to control were considered as significantly differentially regulated and used for further analysis using the Ingenuity Pathway analysis (IPA) tool (Supplementary Table S4.7). Gene ontology analysis revealed activation of genes involved in biological mechanisms that are associated with neuronal function, such as 'Neurite growth', 'Neuronal migration' and 'Molecule transport' (Supplementary Table S4.8A) supporting the repressive role of REST on these processes. Interestingly, 'Glioma signaling' and 'Reelin signaling in neurons' were among the top regulated canonical pathways upon REST knockdown (Supplementary Table S4.8B). The transcriptional profile induced by REST knockdown thus indicated that LNCaP cells acquire a gene expression signature and cellular processes that are characteristic for neuronal and NE tumor cells, when the repressive effect of REST is lost. Comparison of differential mRNA expression between REST knockdown in LNCaP cells (Supplementary Tables S4.7) and RNA-seq data in NEPC [2] revealed opposed differential expression, including the genes BEX1, VGF, SYP, DDC, CHGA, $C H G B, O N E C U T 2, A D C Y 1$, that have been associated with NE transdifferentiation. The effect of REST on INSM1 expression and the NE signature was analysed in more detail using overexpression and knockdown of REST. In VCaP cells, REST overexpression reduced INSM1 and LICAM expression levels, as well as expression of SYP, CHGB, MYCN and 
NCAM (Figure 4.7A). When knocking down REST using siRNAs, the levels of CHGA, and SYP, as well as of L1CAM increased in PC-3 and LNCaP cells (Figures 4.7B and C), which was consistent with previous findings [51]. REST knockdown further stimulated L1CAM protein expression in PC-3 and DU-145 cells, which corroborated the REST-mediated repression of neuronal genes in PCa cells (Figure 4.7D and E). Cell migration and invasion were reduced upon REST overexpression in VCaP cells (Figure 4.8A), whereas in LNCaP cells, REST knockdown led to enhanced cell migration (Figure 4.8B) indicating that loss of REST facilitates an aggressive phenotype in PCa cells.

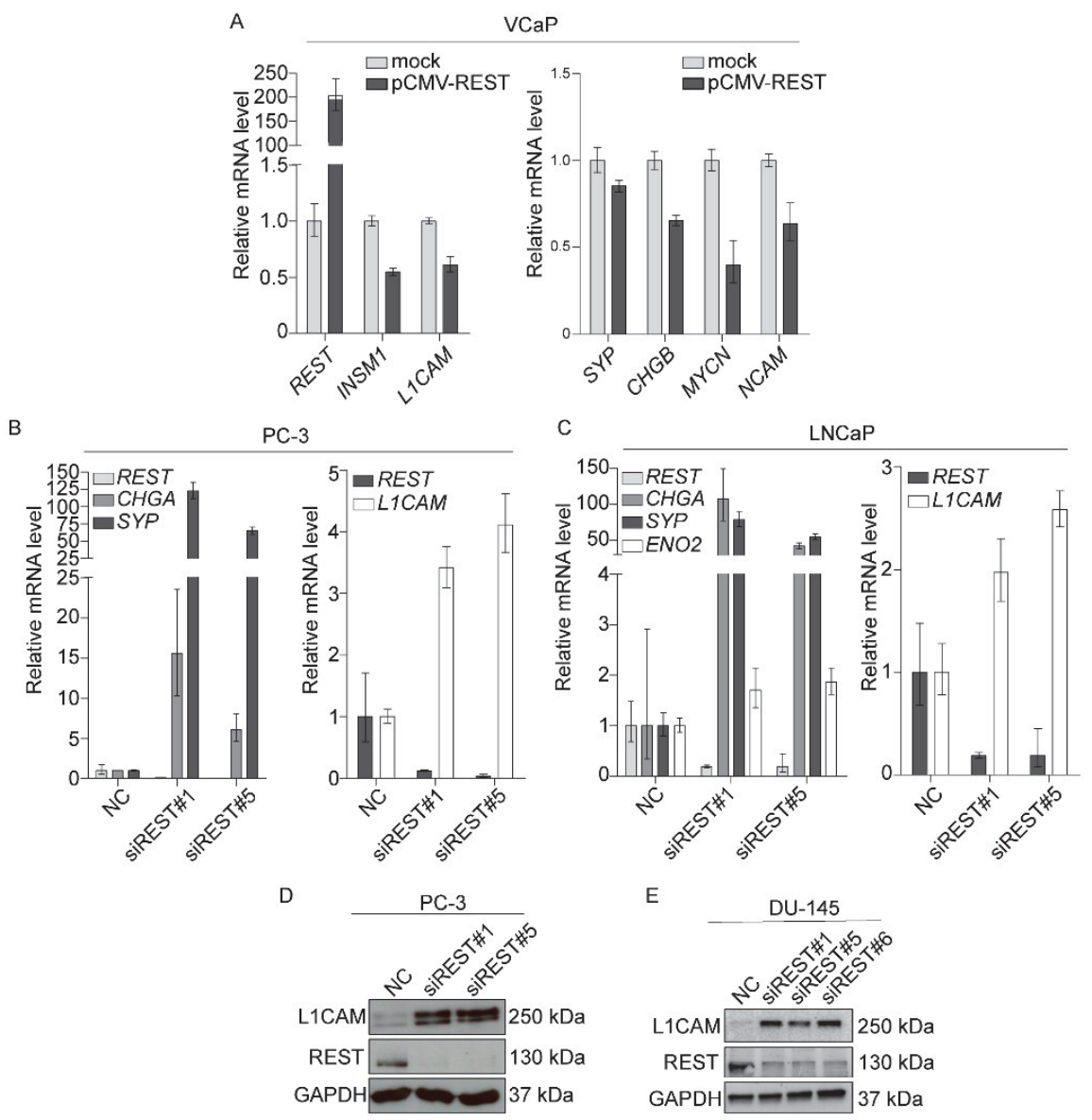

Figure 4.7: REST regulates NE markers in PCa cells. Upon REST overexpression VCaP cells show reduced levels of (A) INSM1 and LICAM as well as the neuronal genes SYP, CHGB, MYCN, and NCAM. (B-C) REST knockdown in (B) PC-3 and (C) LNCaP cells leads to increased NE-marker expression, determined by qPCR. Protein and mRNA levels of the neuronal cell adhesion molecule L1CAM were increased upon REST knockdown in (B, D) PC-3, (C) LNCaP, and (E) DU-145 cells. NC - non-target control. 
A

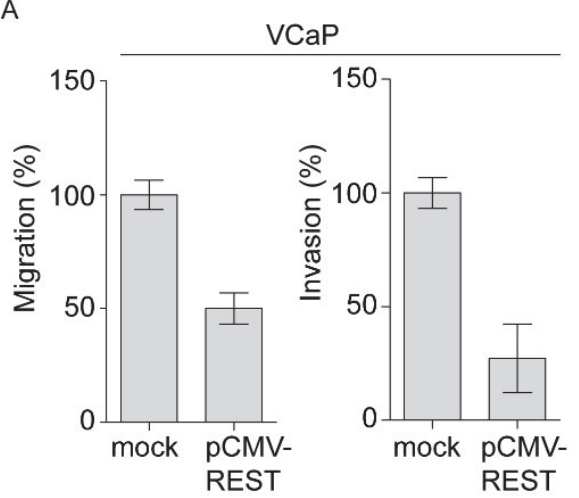

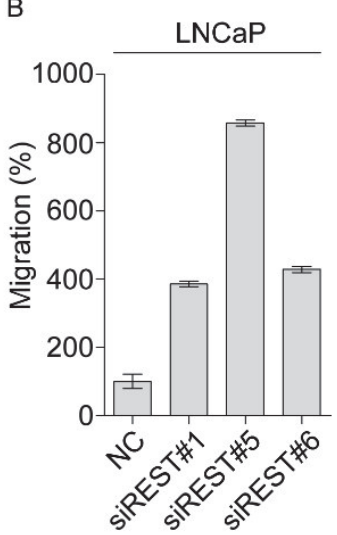

Figure 4.8: Functional consequences of REST overexpression or knockdown. (A) REST overexpression in VCaP cells led to significantly reduced migration and invasion of the cells compared to mock control. (B) SiRNAmediated knockdown of REST in LNCaP cells (20nM of siRNA) induced significantly faster migration of the cells compared to NC-treated control cells. NC - non-target control.

\section{L1CAM is a marker of NE differentiation in PCa cells}

The neuronal cell adhesion molecule LICAM is an established target of REST [52] and plays an important role in the developing nervous system and neuronal migration. In several human tumors, its expression was correlated to poor clinical outcome and therapy resistance $[38,39,53]$. Recently, L1CAM was implicated in metastasis formation in PCa [54]. We showed that L1CAM was regulated by INSM1 together with NE markers (Figure 4.3F). Among the analysed PCa cell lines, the L1CAM mRNA level was highest in the neuroendocrine $\mathrm{NCl}-\mathrm{H} 660$ cells (Figure 4.9A). In human PCa samples of the ExonArray IGP cohort, LICAM was negatively correlated to AR expression (Figure 4.9B), which is consistent with earlier reports [55]. In contrast, L1CAM further showed positive correlation with CHGA and SYP (Figure 4.9B) suggesting that it is upregulated when PCa cells lose their epithelial properties. 


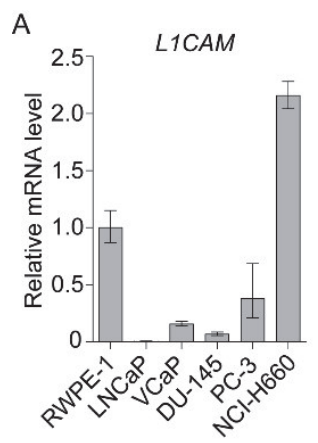

B IGP data
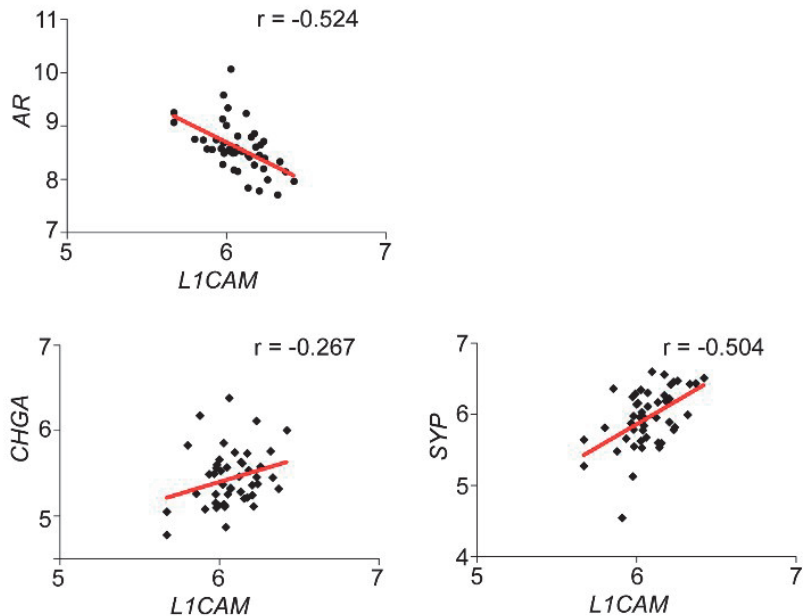

Figure 4.9: L1CAM expression in PCa cells and PCa tumor samples. (A) NCl-H660 cells show increased L1CAM mRNA levels compared to RWPE-1 cells. (B) Correlation of gene expression in the IGP dataset, showing negative correlation between LICAM and AR, but positive correlation of LICAM with CHGA, and SYP, respectively.

Reelin is a central signaling hub in neuroendocrine differentiation in PCa cell lines

To this point, we identified INSM1 as a gene involved in NE differentiation in prostate cancer cells, and REST as a negative regulator of this process. To obtain insights into the downstream mechanisms that guide PCa cells into NED, we performed a comparative analysis of the INSM1 and the REST knockdown signatures using our expression profiling data. We also performed gene expression profiling upon L1CAM knockdown in PC-3 cells (Supplementary Table S4.9) to further elucidate the cellular mechanisms involved in L1CAM-associated migration and metastasis formation in PCa (Supplementary Table S4.10A and B). Of note, the extracellular glycoprotein Reelin (RELN) emerged as a common signaling pathway downstream of INSM1, LICAM and REST (Figure 4.10B). Reelin controls essential steps of neuronal migration and positioning during nervous system development and synaptic plasticity $[56,57]$. On the surface of neurons, Reelin binds to its receptors (VLDLR, APOER2, and $\alpha 3 \beta 1$ integrin) relaying signaling intracellularly via the DAB1 adaptor protein (Figure 4.11C). DAB1 is a tyrosine-phosphorylated protein promoting interaction with the nonreceptor tyrosine kinases Src, Fyn, Abl, and connecting Reelin to molecular mechanisms of migration such as PI3K/AKT signaling [58]. DAB1 also recruits Crk adaptor proteins (CRK, CRKL) to activate integrin $\alpha 5 \beta 1$ signaling [59].

A literature-based survey of gene expression that defines Reelin signaling identified an altered gene expression profile of major Reelin signaling components [60]. Upon REST 
knockdown in LNCaP cells, upregulation of the signaling components CDK5R1, MAPK8IP2, MAPT, MAP1B, PIK3CB, and PIK3R1 was detected. Reelin and its downstream signaling molecules (MAP2K4, PAFAH1B3) were reduced upon INSM1 knockdown in VCaP cells as well as upon L1CAM knockdown in PC-3 cells. However, $A P O E$, which antagonizes Reelin signaling through the APOER2 receptor [61], was upregulated upon LICAM knockdown, indicating reduced activity of Reelin signaling when L1CAM levels are reduced.

A NE marker expression

\begin{tabular}{lccc} 
& \multicolumn{3}{c}{ Fold Change } \\
\cline { 2 - 4 } $\begin{array}{l}\text { Gene } \\
\text { Symbol }\end{array}$ & siREST & silNSM1 & siL1CAM \\
\hline TUBB3 & 2.60 & 0.88 & 0.57 \\
SYP & 4.80 & NS & NS \\
STX1A & 1.90 & 1.12 & NS \\
KCNQ2 & 1.60 & NS & NS \\
CHGB & 1.60 & NS & NS \\
CHGA & 1.35 & 0.95 & NS \\
SCG3 & 8.70 & 0.96 & NS \\
SYT4 & 1.80 & 0.84 & NS \\
SYT7 & 1.70 & NS & NS \\
STMN3 & 11.00 & NS & NS \\
BEX1 & 11.20 & NS & 0.55 \\
CELSR3 & 5.40 & NS & NS \\
VGF & 5.30 & 1.28 & 1.69 \\
MDK & NS & NS & 0.39 \\
CD24 & 1.12 & NS & 0.58 \\
ENO2 & 1.13 & NS & 2.98 \\
\hline
\end{tabular}

B Reelin signaling

\begin{tabular}{lccc} 
& \multicolumn{3}{c}{ Fold Change } \\
\cline { 2 - 4 } $\begin{array}{l}\text { Gene } \\
\text { Symbol }\end{array}$ & siREST & silNSM1 & siL1CAM \\
\hline RELN & 1.38 & 0.73 & 0.64 \\
CDK5 & 1.13 & NS & NS \\
CDK5R1 & 1.76 & 0.88 & NS \\
CRK & 0.70 & 1.19 & 0.62 \\
CRKL & NS & 0.85 & NS \\
BDNF & NS & 0.81 & 0.54 \\
APOE & NS & NS & 2.63 \\
NDEL1 & 0.71 & NS & NS \\
LYN & 0.73 & 1.16 & NS \\
MAPK8IP2 & 2.28 & NS & NS \\
MAPT & 1.43 & NS & NS \\
PAFAH1B3 & 1.30 & 0.73 & NS \\
PIK3CB & 1.45 & 1.15 & NS \\
PIK3R1 & 1.47 & NS & NS \\
MAP1B & 1.80 & NS & NS \\
VLDLR & 1.16 & 0.88 & 3.27 \\
\hline MAP2K4 & NS & 0.76 & NS \\
\hline & & & \\
\hline
\end{tabular}

Figure 4.10: Transcriptional modulation of a neuroendocrine network in PCa cells. (A-B) Microarray gene expression after knockdown of REST, INSM1, and LICAM indicating (A) NE marker expression and (B) deregulated Reelin signaling. Red - upregulated; Blue - downregulated; NS - not significant.

Genes involved in Reelin signaling obtained from the microarray analysis were validated by qPCR in the same samples that had been used for microarray analysis (Figure 4.11). As expected, INSM1 knockdown was accompanied by a $50 \%$ reduction of Reelin mRNA level (Figure 4.11A). To validate the role of INSM1, its overexpression in PC-3 and LNCaP cells led to increased Reelin expression ( 2-fold) (Figure 4.11B). We subsequently analysed the transcriptional changes of signaling molecules downstream of Reelin (Figure 4.11C). INSM1 overexpression had a stimulating effect on the mRNA expression of Reelin-associated signaling molecules (Figure 11.D). Validation of Reelin mRNA levels in REST knockdown samples revealed up to 6-fold elevated expression (Figure 4.11E) and Reelin mRNA responded to forced REST expression by a 3-fold decrease in the expression level (Figure 4.11F). Expression of Reelin and its signaling components also responded to L1CAM knockdown (Figure 4.11G and $\mathrm{H}$ ) corresponding to siRNA-mediated Reelin knockdown (Figure 4.11I). 
A

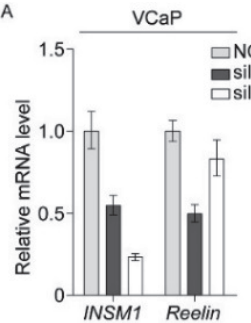

C

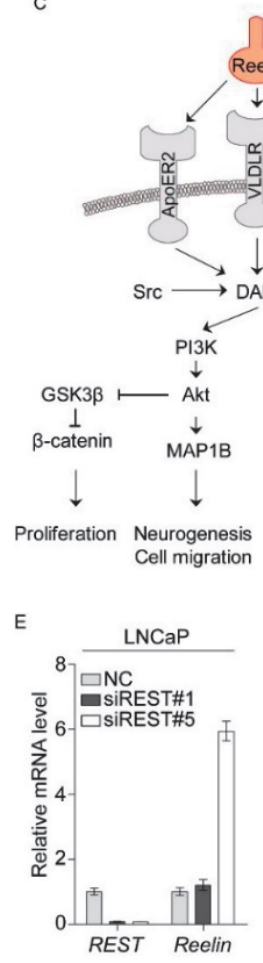

B

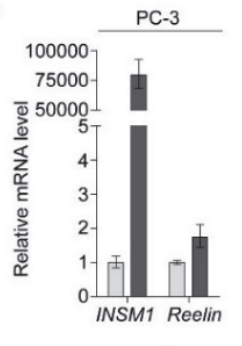

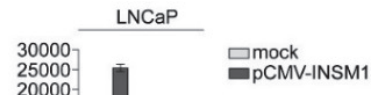

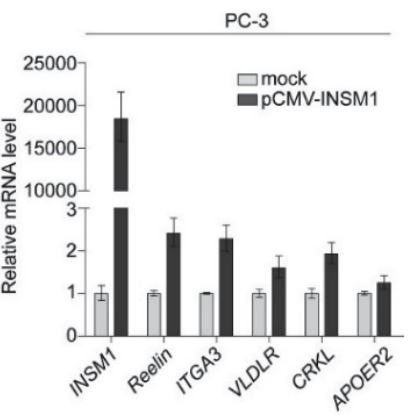

H
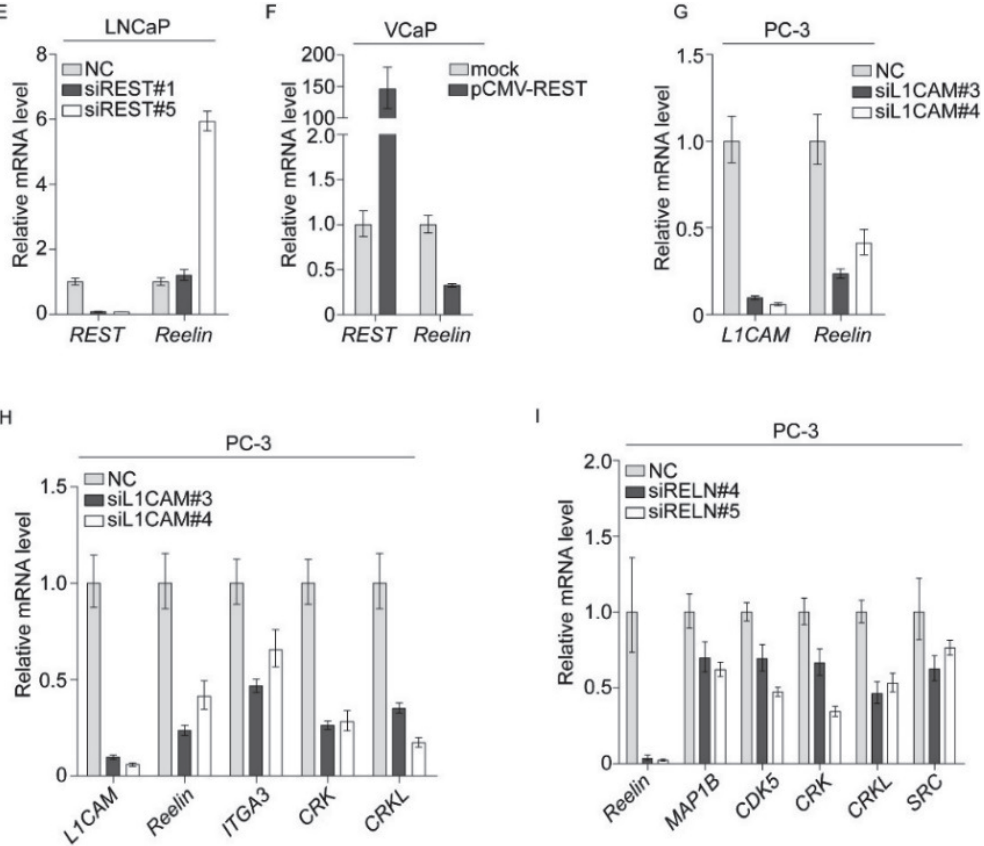

Figure 4.11: Reelin guidance is a common signaling pathway in PCa cells that acquired a NE profile. 
Figure 4.11: continued

(A) SiRNA-mediated INSM1 knockdown leads to reduced Reelin levels in VCaP cells. (B) Reelin increases upon INSM1 overexpression in PC-3 and LNCaP cells. (C) Schematic model of Reelin and downstream signaling mechanisms. (D) Expression levels of the Reelin signaling components ITGA3, VLDLR, CRKL, and APOER2 are increased by INSM1 overexpression in PC-3 cells. (E) Upon REST knockdown, Reelin is increased in LNCaP cells. (F) Overexpression of REST represses Reelin mRNA levels in VCaP cells. (G) SiRNA-mediated L1CAM knockdown reveals a reducing effect on Reelin expression and $(\mathrm{H})$ downstream signaling molecules (ITGA3, CRK, CRKL) in PC-3 cells. (I) Using siRNA-knockdown of Reelin, downstream molecules (MAP1B, CDK5, CRK, CRKL, $S R C$ ) are also reduced, indicating their regulation by Reelin expression. NC - non-target control.

\section{DISCUSSION}

Neuroendocrine differentiation in the context of metastatic PCa is of clinical concern due to its unresponsiveness to hormone therapy, aggressive clinical course and poor prognosis [7]. Defining the molecular characteristics of NEPC is necessary to understand the mechanisms of therapy-resistance and disease progression of aggressive PCa. By using a candidate gene approach, we identified INSMI as regulator of a NE transcriptional program that stimulates PCa cells to express NE markers. The transcription factor INSM1 (IA-1), originally cloned from a human insulinoma subtraction library [31], is involved in pancreatic and neuronal development controlling the early stages of NE differentiation. The INSM1 promoter confers tissue-restricted expression pattern throughout the nervous system during normal embryonic development with an expression peak during the onset of neurogenesis [29, 30]. In adult tissue, INSM1 expression levels are normally low or absent, but are maintained in the lateral ventricle wall, a site of adult neurogenesis [62]. However, INSM1 has been found to be aberrantly expressed in NE tumors of different origin including insulinoma, pituitary tumor, pheochromocytoma, medullary thyroid carcinoma, medulloblastoma, neuroblastoma, retinoblastoma, and small cell lung carcinoma [31]. It has recently been shown that INSM1 is a sensitive marker of human gastrointestinal NED and small cell lung cancer [63-65]. In PCa, adenocarcinomas with a NED component exhibited high expression of INSM1, while tumors without NED were negative for INSM1 [63].

Our results demonstrate that INSM1 regulates expression of CHGA, ASCL1, and SYP in PCa cell lines, NE markers that were recently detected as differentially expressed in NEPC compared to prostatic adenocarcinomas [9]. Increased CHGA expression has been associated with progression to CRPC and negatively correlated to overall survival [66]. High ASCL1 mRNA expression was present in tissue specimens of patients that had been treated with ADT and showed NED features [67]. Recently, INSM1-induced expression of ASCL1, CHGA, NCAM1, SYP, and BRN2 was demonstrated in PCa and lung adenocarcinoma cells. A ChIP-assay revealed ASCL1 promoter binding by INSM1 suggesting INSM1 as direct regulator of a NE program in lung cancer $[68,69]$. INSM1 recruits cyclin D1 and histone deacetylase 3 (HDAC3) leading to altered histone H3/4 acetylation and reduced promoter activity of target genes [70]. Further, concordant mechanisms in the 
endocrine differentiation of $\beta$-cells and NED in PCa have been suggested [71-73]. INSM1 was shown to co-occupy regulatory sequences that maintain the gene expression program in endocrine $\beta$-cells together with the bHLH protein NEUROD1 and FoxA2. INSM1 binds the HES1 promoter in neuroendocrine lung cells thereby repressing Notch signaling, which is required for adequate development of neuroendocrine cells in the lung, and has been implicated in small cell lung cancer $[74,75]$. RNA-seq data of NEPC revealed differential expression of neuroendocrine-associated genes compared to PCa that were also differentially regulated upon INSM1 knockdown in VCaP cells [9]. Intriguingly, INSM1 expression was shown to be induced by N-myc in neuroblastoma cells resulting in increased $\mathrm{N}$-myc stabilization and tumor aggressiveness. This effect was mediated by extra-nuclear activity of INSM1 that stimulated PI3K/AKT signaling, leading to reduced GSK3 $\beta$ kinase activity and failure to phosphorylate and subsequently degrade NMYC [76]. In neuroblastoma, medulloblastoma and small cell lung cancer, INSM1 expression was suggested as a downstream target of sonic hedgehog signaling activity [76-79].

The cell type of origin of NEPC is controversially discussed. However mounting evidence points towards a lineage crisis or transdifferentiation mechanism from initial AR-positive adeno-PCa in favor of AR-independent survival $[5,80]$. The T/E gene fusion is detected in primary adenocarcinoma as well as in NEPC suggesting a common origin of these disease manifestations [15]. In our study, different cell models were used to analyse the role of ERG in NEPC. In VCaP and NCI-H660 cells, we demonstrated ERG-dependent regulation of INSM1 expression upon siRNA-mediated ERG knockdown. Using transgene T/E expressing LNCaP clones, we showed that T/E gene fusion variants induce molecular changes and cellular phenotypes related to a NE phenotype, suggesting that the detection of $\mathrm{T} / \mathrm{E}$ rearrangements could implicate a causal mechanism for the development of NEPC, although controversial data exist $[9,81]$.

In the transformation process towards a NEPC phenotype, two consecutive stages are assumed: First, NED as an adaptive response to survive androgen deprivation, and second, the induction of cell proliferation [82]. Upon INSM1 overexpression, we observed increased migration but different effects on the proliferation of PC-3 and LNCaP cells, suggesting that additional factors are involved in the regulation of proliferation during NED. This is also reflected by contradicting reports concerning the proliferative activity of NE cells: In the pancreatic cancer cell Panc-1, cell cycle arrest was observed upon INSM1 overexpression, mediated by competitive binding of INSM1 to Cyclin D1, thereby interrupting cyclin D1 binding to CDK4 rendering Rb in a hypophosphorylated state and failure of cell cycle progression. INSM1-mediated cell cycle arrest was suggested to facilitate entry into a NE differentiation route $[83,84]$. NE cancer cells have been considered as non-proliferative, postmitotic cells located adjacent to proliferative Bcl-2positive cells $[13,85]$. NED areas exhibited the highest proliferation index across tumor tissue and the extent of NED correlated with a higher proliferation index of the whole tumor $[86,87]$. It was further shown that NE cancer cells secrete growth stimulating peptides (e.g. bombesin) inducing increased proliferation of adjacent PCa cells [86, 8893]. However, in small cell PCa cells, upregulation of mitotic genes (UBE2C, AURKA) and 
the proliferation-associated polo-like kinase 1 (PLK1) co-expressed with NE markers was identified [86] [94, 95]. It therefore remains a matter of discussion and further research to elucidate the dynamics of NE tumor cells in PCa. Interestingly, UBE2C was shown to be under positive regulation of the $A R$ splice variant $A R-V 7$ in $\mathrm{PCa}$ that promoted proliferation of VCaP cells and has emerged as clinically relevant resistance mechanism under enzalutamide treatment $[96,97]$. The fact that resistance subtypes to enzalutamide has also been proposed as precursor for NEPC differentiation (as described in chapter 1) further highlights the complexity of resistance mechanisms leading to MCRPC [98].

Our results suggest that upon INSM1 overexpression PCa cells adapt a neuronal expression programme accompanied by NE marker upregulation, enhanced cell migration and invasion. Our concept implicates that compromised REST activity facilitates the conversion into NED demonstrated by reduced REST expression upon INSM1 overexpression (Figure 4.12). Putative INSM1 binding sites were identified in the REST promoter region using the JASPAR database [72]. REST regulates neuronal gene transcription in stem cells and non-neuronal tissue through recognition of neuron restrictive silencing elements (NRSE/RE-1 binding sites) and subsequent recruitment of histone modifiers and chromatin-binding proteins (referred to as REST cofactors), thereby blocking target gene expression [50, 51, 99]. REST has been described as regulator of NED in PCa [100]. Upon REST knockdown in LNCaP cells, GO terms indicated enrichment in neuronal functions. Differential gene expression of associated genes underlying NED processes (STMN3, VGF, BSN, ONECUT2, AURKA, LMNB1) in our dataset was consistent with RNAseq data from NEPC tissue [9]. Of note, REST was reported to repress a genetic program required for pancreatic $\beta$-cells development, corroborating our proposed model of opposing functions of INSM1 and REST in NED [101, 102]. Since REST overexpression resulted in reduced INSM1 expression, a reciprocal regulatory mechanism is suggested, but it remains open for further research whether this is a direct consequence.

In small cell lung cancer cell lines, redued REST transcript levels resulted in increased expression of L1CAM and NCAM [103]. L1CAM has been identified as a neuronal cell adhesion molecule that plays an important role in the nervous system development by regulating neuronal migration and adhesion, and guidance of neurite outgrowth [104]. It has been correlated to a poor prognosis in many human tumors, in which it promoted cell motility, invasion, metastasis formation and chemoresistance [38, 39]. Recently, L1CAM was shown to promote PCa metastases and was expressed by androgen receptor-negative PCa cell lines [54]. However, its precise role in PCa is poorly investigated, inciting our study to analyse the involvement of LICAM within the regulatory circuit of INSM1 and REST as potential marker of NEPC. We showed positive regulation of LICAM by INSM1 along with NE markers, but negative regulation by REST. RE-1 binding sites within the promoter of $L 1 C A M$ are recognized by REST conferring restriction of L1CAM expression to neuronal tissue and inhibiting its expression in non-neuronal tissue [52]. The regulatory mechanisms between INSM1 and LICAM have not been described before and needs to be further evaluated in future studies. 


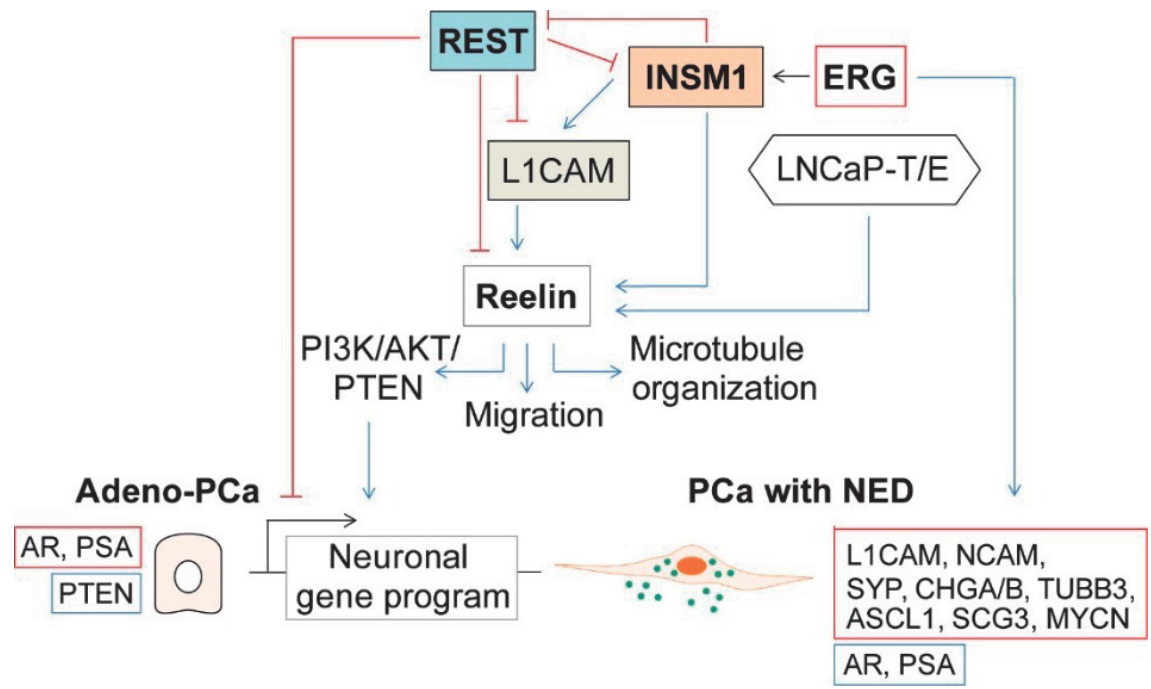

Figure 4.12: Schematic model of the INSM1-REST-L1CAM network. A network involving the neuronal transcription factor INSM1, neuronal cell adhesion molecule L1CAM, and the negative regulator of neuronal gene transcription REST playing a role in NE differentiation in PCa was identified. Blue arrows indicate activating, red arrows indicate inhibitory (indirect) interaction.

It is interesting to note that the extracellular glycoprotein and neuronal guidance molecule Reelin emerged as a central molecule in the regulatory network involving INSM1, L1CAM and REST. Reelin, commonly secreted by Cajal-Retzius cells in the developing nervous system, is increased in small cell lung cancer, retinoblastoma, esophageal cancer and multiple myeloma [105-108]. In PCa, a correlation between Reelin expression and Gleason score has been described [109]. However, the molecular mechanisms of Reelin signaling in the aggressiveness of $\mathrm{PCa}$ is yet unknown. Downstream signaling events of Reelin involve recruitment of CRK and CRKL [110], and Src family tyrosine kinases, mediating subsequent activation of the PI3K/AKT pathway and inhibition of GSK3 3 [11, 112]. Recently, the Src, STAT3 and AKT pathways, hyperactivated in NEPC, were shown to be stimulated by Reelin signaling in multiple myeloma corroborating the importance of Reelin signaling in NEPC $[108,113]$. Notably, Reelin induced upregulation of HIF1 $\alpha$ in multiple myeloma, which has also been implicated in NEPC $[108,114]$. Upregulation of Reelin signaling components (MAP1B, MAPK8IP1, NDEL1) in NEPC tissue has been identified by RNA-seq [9]. Positive regulation of Reelin and downstream signaling components by INSM1 could implicate utilization of Reelin signaling in NEPC suggesting Reelin pathway activation as marker of NEPC. Our results further show that $R E S T$ restricts the expression of Reelin and downstream molecules suggesting that loss of REST facilitates Reelin signaling in NEPC. These findings encourage future studies to investigate the value of Reelin as biomarker in NEPC and target for therapies. 
The connection between L1CAM and Reelin signaling has not been described earlier. Both signals have been reported to use integrins as adaptor molecules that can synergize with diverse cell surface receptor systems for signaling modulation. Reelin/ $\alpha 3 \beta 1-$ integrin interactions could contribute to appropriate neuronal positioning [115]. In neuroblastoma cells, L1CAM binding to $\beta 1$-integrins promotes cell migration and neurite outgrowth through the signaling intermediates c-Src and PI3K [116].

In conclusion, we identified INSM1 as a promising factor of a neuroendocrine transcriptional network in PCa cells (Figure 4.12). Since INSM1 is not expressed in adult nonneuronal tissues and considering its established role in neuronal and endocrine tissues, reactivation of INSM1 in PCa could be of major interest for future studies and drug development. We provide a rationale for future examination of INSM1 as a marker in histological diagnosis of PCa and to address its role as specific therapeutic target for NEPC. 


\section{SUPPLEMENTARY INFORMATION}

\section{Supplementary materials}

2. Supplementary data

1. Supplementary materials

Supplementary Table S4.1: Cell lines

\begin{tabular}{llll}
\hline Cell lines & Supplier & Catalog Number & Origin \\
\hline DU145 & ATCC & HTB-81 & prostate carcinoma, brain metastasis \\
LNCaP (clone FGC) & ATCC & CRL-1740 & prostate carcinoma, lymph node metastasis \\
NCl-H660 & ATCC & CRL-5813 & $\begin{array}{l}\text { prostate small cell carcinoma, lymph node } \\
\text { metastasis }\end{array}$ \\
PC-3 & ATCC & CRL-1435 & prostate adenocarcinoma, bone metastasis \\
RWPE1 & ATCC & CRL-11609 & normal prostatic epithelium immortalized \\
& & with \\
VCaP & ATCC & CRL-2876 & a single copy of HPV-18 \\
\hline
\end{tabular}

Supplementary Table S4.2: List of primer sequences and probes used for qPCR

\begin{tabular}{|c|c|c|c|}
\hline Name & \#UPL probe & Sequence forward $5^{\prime}-3^{\prime}$ & Sequence reverse $5^{\prime}-3^{\prime}$ \\
\hline APOER2 & 27 & ctcccgaagaaccctctttc & gcttaatgccactcgcttg \\
\hline ASCL1 & 38 & cgacttcaccaactggttctg & atgcaggttgtgcgatca \\
\hline CDK5 & 3 & cgatgaccagttgaagaggat & tctggcagcttggtcataga \\
\hline CHGA & 17 & caaaccgcagaccagagg & tccagctctgcttcaatgg \\
\hline$C H G B$ & 75 & agccgccatcttcctttc & Cactggcatggaattgacag \\
\hline CRK & 16 & ccagtcccttacgtcgagaa & tttaccagctcaccgacctc \\
\hline CRKL & 77 & tggagttttacaagatccactacct & attggtgggcttggatacc \\
\hline ENO2 & 27 & actttgtcagggactatcctgtg & tccctacattggctgtgaact \\
\hline$E R G_{-} T / E$ & 64 & ggttaatgcatgctagaaacaca & agatggttgagcagctttcg \\
\hline GAPDH & 60 & agccacatcgctcagacac & gcccaatacgaccaaatcc \\
\hline INSM1 & 54 & cgctgtgttcatggtctagaaa & catagagagcagagattggtaggc \\
\hline ITGA3 & 13 & gaggacatgtggcttggagt & gtagcggtgggcacagac \\
\hline L1CAM & 18 & caaatggctgtgaagaccaa & cacaaagccgatgaaccag \\
\hline$M A P 1 B$ & 43 & gacgctttgttggaaggaaa & ctgagtcatgagttgggatcag \\
\hline NCAM & 20 & ttaccgcggcaagaacat & ccacctgcagagaaactgc \\
\hline NTS & 35 & tgctactcctggctttcagc & gcatattggtcaagaaatctgct \\
\hline$R E L N$ & 24 & tgagagccagcctacagga & tcgttccacattctgtaccaa \\
\hline REST & 2 & tggaaaatgcaactatttttcaga & gaacttgagtaaggacaaagttcaca \\
\hline SCG3 & 79 & aagcttgaaggattccacaaaa & ctgatggcttccaaataggc \\
\hline
\end{tabular}


INSM 1 IN NEUROENDOCRINE PROSTATE CANCER

Supplementary Table S4.2: continued

\begin{tabular}{llll}
\hline SRC & 61 & ccatgttcactccggtttac & ttcaaatcctggctctgtctc \\
SYP & 83 & acatggacgtggtgaatcag & cattgcagcaccttcacaa \\
TUBB3 & 12 & gcctgacaatttcatctttggt & gcaggcagtcgcagtttt \\
VLDLR & 80 & ggagaagatgaagaaaactgtgg & catcctggccattgcatac \\
\hline
\end{tabular}

Supplementary Table S4.3: List of siRNAs

\begin{tabular}{lll}
\hline Name & Catalog number & Supplier \\
\hline Allstar Negative Control & SI03650318 & Qiagen \\
SiERG\#7 & SI03064726 & Qiagen \\
SiERG\#8 & SI03089443 & Qiagen \\
SilNSM1\#6 & SI03204901 & Qiagen \\
SilNSM1\#7 & SI04179392 & Qiagen \\
SiRELN\#4 & SI00071806 & Qiagen \\
SiRELN\#5 & SI03051818 & Qiagen \\
SiREST\#1 & SI00701407 & Qiagen \\
SiREST\#5 & SI04153765 & Qiagen \\
SiREST\#6 & SI04179434 & Qiagen \\
SiL1CAM\#3 & SI00009289 & Qiagen \\
SiL1CAM\#4 & SI00009296 & Qiagen \\
SiL1CAM\#6 & SI04179434 & Qiagen \\
\hline
\end{tabular}

Supplementary Table S4.4: Plasmid vectors

\begin{tabular}{lll}
\hline Vector & Catalog number & Source \\
\hline pCMV6-AC with ACVRL1 cDNA (NM_000020) & SC321860 & Origene \\
pCMV6-XL5 with INSM1 cDNA (NM_002196 & SC303146-OR & Origene \\
pCMV6-XL4 with L1CAM cDNA (NM_000425.2) & SC109376-OR & Origene \\
pCMV6-XL5 with REST cDNA (NM_005612) & SC318496-OR & Origene \\
TCF REPORTER PLASMID KIT & 17-285 & Merck \\
$\quad$ TOPflash TCF Reporter Plasmid (NM_000545.4) & & \\
FOPflash TCF Reporter Plasmid Negative Control & &
\end{tabular}




\section{Supplementary data}

\section{Supplementary Table S4.5: Genes with FC $>|1.3|$ upon INSM1 knockdown in VCaP cells}

\begin{tabular}{|c|c|c|}
\hline Gene ID & $\begin{array}{c}\text { Fold } \\
\text { change }\end{array}$ & p-value \\
\hline$D D C$ & 1.8969 & $5.187 \mathrm{E}-14$ \\
\hline PPPDE1 & 1.8492 & $6.154 \mathrm{E}-18$ \\
\hline CCNC & 1.7735 & $1.653 \mathrm{E}-15$ \\
\hline STEAP 1 & 1.6628 & $6.374 \mathrm{E}-08$ \\
\hline REG4 & 1.6189 & $2.272 \mathrm{E}-14$ \\
\hline$M A P 2 K 2$ & 1.6176 & 4.508E-06 \\
\hline$A L D H 1 A 3$ & 1.5743 & $1.012 \mathrm{E}-13$ \\
\hline TMTC1 & 1.5575 & 7.183E-14 \\
\hline RPL6 & 1.5332 & $1.599 \mathrm{E}-13$ \\
\hline NPDC1 & 1.5128 & $6.208 \mathrm{E}-10$ \\
\hline BTBD1 & 1.5098 & $2.128 \mathrm{E}-10$ \\
\hline PMEPA1 & 1.5064 & 5.315E-09 \\
\hline MAL2 & 1.4960 & $2.603 \mathrm{E}-17$ \\
\hline NOV & 1.4951 & $4.324 \mathrm{E}-16$ \\
\hline HOXA10 & 1.4893 & $5.903 \mathrm{E}-13$ \\
\hline FASTK & 1.4844 & $1.691 \mathrm{E}-08$ \\
\hline TROVE2 & 1.4839 & 2.997E-11 \\
\hline$O C R L$ & 1.4752 & $2.955 \mathrm{E}-10$ \\
\hline AKIRIN1 & 1.4748 & $5.555 \mathrm{E}-13$ \\
\hline RPL29 & 1.4746 & $1.024 \mathrm{E}-12$ \\
\hline$R P L 7 L 1$ & 1.4743 & $1.692 \mathrm{E}-08$ \\
\hline UCHL1 & 1.4639 & $1.234 \mathrm{E}-11$ \\
\hline TSC22D1 & 1.4614 & $2.794 \mathrm{E}-13$ \\
\hline CLEC2D & 1.4513 & $4.220 \mathrm{E}-08$ \\
\hline MCCC2 & 1.4487 & $1.903 \mathrm{E}-06$ \\
\hline HIST1H2AC & 1.4424 & $3.772 \mathrm{E}-10$ \\
\hline AP1S1 & 1.4403 & $7.640 \mathrm{E}-10$ \\
\hline STUB1 & 1.4371 & $2.688 \mathrm{E}-07$ \\
\hline THOC3 & 1.4367 & 3.050E-09 \\
\hline$G N A Q$ & 1.4337 & $3.466 \mathrm{E}-08$ \\
\hline DYRK $1 A$ & 1.4336 & $1.288 \mathrm{E}-07$ \\
\hline
\end{tabular}

\begin{tabular}{|c|c|c|}
\hline$R A B 28$ & 1.4329 & $8.095 \mathrm{E}-10$ \\
\hline$N A A A$ & 1.4320 & $3.740 \mathrm{E}-08$ \\
\hline PECl & 1.4291 & 4.239E-09 \\
\hline PFN1 & 1.4288 & $2.046 \mathrm{E}-07$ \\
\hline TSPAN3 & 1.4257 & 4.563E-08 \\
\hline$R A B 4 A$ & 1.4243 & $8.670 \mathrm{E}-11$ \\
\hline FLJ21511 & 1.4243 & $1.437 \mathrm{E}-07$ \\
\hline CROT & 1.4209 & $3.262 \mathrm{E}-10$ \\
\hline LYGE & 1.4208 & $1.471 \mathrm{E}-08$ \\
\hline TOP1MT & 1.4206 & $5.883 \mathrm{E}-08$ \\
\hline HNRPK & 1.4191 & $9.068 \mathrm{E}-08$ \\
\hline CDC42EP3 & 1.4179 & $1.452 \mathrm{E}-08$ \\
\hline STAG3L1 & 1.4169 & $2.326 \mathrm{E}-08$ \\
\hline$A M D 1$ & 1.4125 & $1.176 \mathrm{E}-07$ \\
\hline$R Y K$ & 1.4122 & $2.250 \mathrm{E}-09$ \\
\hline CD151 & 1.4114 & $3.986 \mathrm{E}-09$ \\
\hline PLEK2 & 1.4107 & $1.050 \mathrm{E}-08$ \\
\hline RPL29 & 1.4100 & $1.576 \mathrm{E}-10$ \\
\hline$N A A A$ & 1.4080 & $2.232 \mathrm{E}-12$ \\
\hline C17orf95 & 1.4078 & $3.894 \mathrm{E}-09$ \\
\hline STEAP1 & 1.4059 & $1.445 \mathrm{E}-12$ \\
\hline MGC35361 & 1.4034 & $3.977 \mathrm{E}-10$ \\
\hline ACTB & 1.4022 & $1.038 \mathrm{E}-09$ \\
\hline$E I F 4 G 2$ & 1.3987 & $9.545 \mathrm{E}-11$ \\
\hline DPAGT1 & 1.3913 & $1.780 \mathrm{E}-07$ \\
\hline$U B B$ & 1.3895 & $3.810 \mathrm{E}-06$ \\
\hline STXBP1 & 1.3880 & $1.019 \mathrm{E}-07$ \\
\hline C4orf18 & 1.3845 & $1.789 \mathrm{E}-08$ \\
\hline$M 6 P R$ & 1.3842 & $1.315 \mathrm{E}-10$ \\
\hline C20orf177 & 1.3835 & $1.706 \mathrm{E}-10$ \\
\hline$A P 1 S 1$ & 1.3829 & $3.840 \mathrm{E}-06$ \\
\hline CAMK $2 B$ & 1.3824 & $4.830 \mathrm{E}-08$ \\
\hline MED27 & 1.3814 & $1.240 \mathrm{E}-09$ \\
\hline
\end{tabular}

\begin{tabular}{|c|c|c|}
\hline PPM1A & 1.3810 & $3.490 \mathrm{E}-08$ \\
\hline SNCA & 1.3802 & $4.920 \mathrm{E}-14$ \\
\hline MORF4L2 & 1.3793 & 8.836E-09 \\
\hline ACTG1 & 1.3785 & 4.300E-07 \\
\hline$N A A A$ & 1.3766 & $2.425 \mathrm{E}-13$ \\
\hline C1orf109 & 1.3761 & $1.734 \mathrm{E}-10$ \\
\hline$S L C 31 A 1$ & 1.3759 & $6.766 \mathrm{E}-06$ \\
\hline$D D \times 47$ & 1.3753 & $1.810 \mathrm{E}-07$ \\
\hline RPS26 & 1.3750 & $9.204 \mathrm{E}-07$ \\
\hline PRDX2 & 1.3743 & $1.304 \mathrm{E}-08$ \\
\hline PIAS1 & 1.3742 & $2.788 \mathrm{E}-07$ \\
\hline STEAP1 & 1.3737 & $6.582 \mathrm{E}-11$ \\
\hline TSPO & 1.3727 & $1.645 \mathrm{E}-10$ \\
\hline C12orf11 & 1.3727 & $5.844 \mathrm{E}-08$ \\
\hline SIPA1 & 1.3716 & $2.530 \mathrm{E}-07$ \\
\hline CASC4 & 1.3713 & $3.494 \mathrm{E}-08$ \\
\hline MGAT2 & 1.3708 & $2.332 \mathrm{E}-06$ \\
\hline PRDX3 & 1.3695 & $3.038 \mathrm{E}-09$ \\
\hline KRT19 & 1.3693 & $1.035 \mathrm{E}-08$ \\
\hline UBE1 & 1.3681 & $9.135 \mathrm{E}-07$ \\
\hline C21orf59 & 1.3668 & $3.736 \mathrm{E}-06$ \\
\hline$A B H D 11$ & 1.3658 & $2.043 \mathrm{E}-08$ \\
\hline INPP5A & 1.3655 & $3.420 \mathrm{E}-10$ \\
\hline PCBD1 & 1.3644 & $3.552 \mathrm{E}-07$ \\
\hline LYRM2 & 1.3635 & $7.227 \mathrm{E}-10$ \\
\hline NAMPT & 1.3616 & 9.487E-08 \\
\hline PSMC1 & 1.3597 & $3.406 \mathrm{E}-12$ \\
\hline ROPN1B & 1.3592 & $3.810 \mathrm{E}-09$ \\
\hline GUF1 & 1.3587 & $6.853 \mathrm{E}-08$ \\
\hline TADA3 & 1.3579 & $1.259 \mathrm{E}-07$ \\
\hline SC4MOL & 1.3572 & $2.261 \mathrm{E}-06$ \\
\hline$A D D 3$ & 1.3541 & 1.399E-09 \\
\hline PSPH & 1.3525 & 1.677E-07 \\
\hline
\end{tabular}


INSM1 IN NEUROENDOCRINE PROSTATE CANCER

Supplementary Table S4.5: continued

\begin{tabular}{|c|c|c|}
\hline$R R M 2 B$ & 1.3525 & 3.514E-08 \\
\hline TRAPPC6B & 1.3512 & $6.985 \mathrm{E}-10$ \\
\hline$Y W H A E$ & 1.3492 & $6.769 \mathrm{E}-07$ \\
\hline RPS24 & 1.3485 & 4.122E-11 \\
\hline FAM135A & 1.3481 & $1.271 \mathrm{E}-06$ \\
\hline CAPNS1 & 1.3480 & $1.056 \mathrm{E}-08$ \\
\hline FAM127C & 1.3479 & $2.283 \mathrm{E}-10$ \\
\hline AFF4 & 1.3456 & $8.351 \mathrm{E}-09$ \\
\hline$A R P C 1 B$ & 1.3444 & $2.287 \mathrm{E}-08$ \\
\hline MFF & 1.3440 & $9.348 \mathrm{E}-08$ \\
\hline FZD4 & 1.3436 & $3.921 \mathrm{E}-06$ \\
\hline DNAJB6 & 1.3434 & 5.556E-09 \\
\hline CKMT1B & 1.3428 & 4.774E-11 \\
\hline FAM135A & 1.3424 & 2.492E-09 \\
\hline C1orf63 & 1.3421 & $5.862 \mathrm{E}-07$ \\
\hline TMPO & 1.3402 & $1.909 \mathrm{E}-08$ \\
\hline PCSK1N & 1.3401 & $5.943 \mathrm{E}-07$ \\
\hline DHCR24 & 1.3396 & $6.400 \mathrm{E}-09$ \\
\hline PIPSL & 1.3395 & 1.135E-09 \\
\hline CCT7 & 1.3392 & $3.972 \mathrm{E}-08$ \\
\hline PSMC4 & 1.3390 & $3.765 \mathrm{E}-08$ \\
\hline CKMT1A & 1.3389 & $1.429 \mathrm{E}-09$ \\
\hline NBPF10 & 1.3385 & $6.916 \mathrm{E}-09$ \\
\hline RPL8 & 1.3384 & 5.305E-07 \\
\hline C20orf191 & 1.3381 & $2.739 \mathrm{E}-06$ \\
\hline GALK2 & 1.3370 & 4.113E-07 \\
\hline PRDX2 & 1.3356 & 6.199E-07 \\
\hline$T B L 1 X R 1$ & 1.3345 & $1.018 \mathrm{E}-06$ \\
\hline$H P N$ & 1.3334 & $6.930 \mathrm{E}-07$ \\
\hline LAMP2 & 1.3330 & $9.877 \mathrm{E}-08$ \\
\hline NBPF11 & 1.3330 & $1.578 \mathrm{E}-09$ \\
\hline СТВP1 & 1.3327 & $1.460 \mathrm{E}-05$ \\
\hline$I K B I P$ & 1.3318 & $3.248 \mathrm{E}-07$ \\
\hline CICE & 1.3315 & 8.650E-09 \\
\hline TUBG1 & 1.3311 & $1.381 \mathrm{E}-05$ \\
\hline NAB2 & 1.3305 & 3.923E-07 \\
\hline
\end{tabular}

\begin{tabular}{|c|c|c|}
\hline ATP6VOC & 1.3298 & 8.743E-08 \\
\hline HSPBP 1 & 1.3290 & $1.297 \mathrm{E}-06$ \\
\hline XPOT & 1.3284 & $2.374 \mathrm{E}-06$ \\
\hline POLR1D & 1.3282 & $1.896 \mathrm{E}-06$ \\
\hline MAPKAP1 & 1.3272 & $4.298 \mathrm{E}-08$ \\
\hline RFC3 & 1.3265 & $9.516 \mathrm{E}-07$ \\
\hline PRKAR1B & 1.3264 & $1.957 \mathrm{E}-07$ \\
\hline KCTD3 & 1.3260 & $3.541 \mathrm{E}-06$ \\
\hline THAP1 & 1.3254 & $6.845 \mathrm{E}-06$ \\
\hline SSR2 & 1.3249 & 4.797E-07 \\
\hline NDRG3 & 1.3248 & $1.331 \mathrm{E}-03$ \\
\hline MRPL18 & 1.3240 & $1.489 \mathrm{E}-09$ \\
\hline$R A B 3 B$ & 1.3238 & $1.710 \mathrm{E}-07$ \\
\hline OPA3 & 1.3233 & $3.096 \mathrm{E}-05$ \\
\hline MST4 & 1.3231 & 4.466E-09 \\
\hline DYRK1A & 1.3231 & $4.366 \mathrm{E}-06$ \\
\hline UBE2E1 & 1.3230 & $1.842 \mathrm{E}-07$ \\
\hline$D P P 7$ & 1.3227 & $3.443 \mathrm{E}-06$ \\
\hline PRMT1 & 1.3218 & 7.197E-07 \\
\hline RBBP5 & 1.3185 & $1.883 \mathrm{E}-05$ \\
\hline AASDHPPT & 1.3179 & $9.916 \mathrm{E}-06$ \\
\hline UBE2G2 & 1.3173 & 6.799E-11 \\
\hline C5orf44 & 1.3163 & $1.124 \mathrm{E}-06$ \\
\hline RPL32 & 1.3153 & $2.637 \mathrm{E}-06$ \\
\hline BLOC1S1 & 1.3150 & $4.056 \mathrm{E}-03$ \\
\hline$M A Z$ & 1.3149 & $2.889 \mathrm{E}-08$ \\
\hline TMEM $38 B$ & 1.3146 & $1.272 \mathrm{E}-05$ \\
\hline KRT18 & 1.3135 & $1.493 \mathrm{E}-07$ \\
\hline RFC2 & 1.3128 & $1.056 \mathrm{E}-05$ \\
\hline C1orf59 & 1.3128 & $1.344 \mathrm{E}-06$ \\
\hline$S L C 25 A 1$ & 1.3122 & $1.405 \mathrm{E}-07$ \\
\hline IRS2 & 1.3115 & $7.618 \mathrm{E}-07$ \\
\hline C11orf48 & 1.3109 & $1.739 \mathrm{E}-13$ \\
\hline LSM12 & 1.3103 & 5.807E-05 \\
\hline$H P N$ & 1.3102 & $8.572 \mathrm{E}-06$ \\
\hline HMBS & 1.3100 & 2.684E-06 \\
\hline
\end{tabular}

\begin{tabular}{|c|c|c|}
\hline PGAM4 & 1.3094 & $1.310 \mathrm{E}-06$ \\
\hline LIMS1 & 1.3090 & $3.324 \mathrm{E}-05$ \\
\hline$S B D S P$ & 1.3086 & $1.456 \mathrm{E}-07$ \\
\hline TCEA1 & 1.3081 & 3.847E-04 \\
\hline TAF9L & 1.3077 & $6.788 \mathrm{E}-07$ \\
\hline TJP1 & 1.3071 & $3.500 \mathrm{E}-05$ \\
\hline NT5C3 & 1.3070 & 7.491E-06 \\
\hline C12orf5 & 1.3069 & 6.120E-05 \\
\hline C10orf32 & 1.3065 & 4.165E-06 \\
\hline SLC39A3 & 1.3064 & 4.327E-05 \\
\hline PBRM1 & 1.3051 & $3.130 \mathrm{E}-05$ \\
\hline OCRL & 1.3047 & $3.561 \mathrm{E}-12$ \\
\hline TPM1 & 1.3042 & $1.220 \mathrm{E}-04$ \\
\hline TRIM37 & 1.3038 & $2.571 \mathrm{E}-06$ \\
\hline PIR & 1.3030 & 5.255E-06 \\
\hline NEDD8 & 1.3029 & 1.055E-05 \\
\hline STARD10 & 1.3028 & $3.892 \mathrm{E}-06$ \\
\hline GAR1 & 1.3026 & 2.909E-06 \\
\hline PFKFB2 & 1.3025 & $4.056 \mathrm{E}-04$ \\
\hline QKI & 1.3021 & $1.261 \mathrm{E}-02$ \\
\hline SNORD31 & 1.3014 & $2.044 \mathrm{E}-06$ \\
\hline ASS1 & 1.3001 & 5.375E-06 \\
\hline ZDHHCS & 0.7698 & $1.258 \mathrm{E}-04$ \\
\hline SNORA64 & 0.7697 & $2.623 \mathrm{E}-10$ \\
\hline RAPGEF1 & 0.7693 & $9.952 \mathrm{E}-08$ \\
\hline SLC3OA4 & 0.7691 & 4.205E-05 \\
\hline KIAA1875 & 0.7689 & 3.103E-03 \\
\hline ZNF544 & 0.7689 & $3.181 \mathrm{E}-08$ \\
\hline MGC15634 & 0.7689 & $1.390 \mathrm{E}-02$ \\
\hline HEPACAM 2 & 0.7682 & 5.236E-09 \\
\hline DPY19L4 & 0.7679 & $2.406 \mathrm{E}-07$ \\
\hline IQGAP2 & 0.7677 & $1.436 \mathrm{E}-04$ \\
\hline PPP1R14A & 0.7672 & $9.162 \mathrm{E}-05$ \\
\hline C15orf42 & 0.7670 & $2.798 \mathrm{E}-08$ \\
\hline ZNF157 & 0.7666 & $2.760 \mathrm{E}-03$ \\
\hline SERPING1 & 0.7665 & 7.713E-04 \\
\hline
\end{tabular}


CHAPTER 4

\section{Supplementary Table S4.5: continued}

\begin{tabular}{|c|c|c|}
\hline TMEM141 & 0.7663 & $3.171 \mathrm{E}-08$ \\
\hline FOLR1 & 0.7656 & $1.592 \mathrm{E}-03$ \\
\hline ISG2O & 0.7653 & $1.284 \mathrm{E}-09$ \\
\hline ANKRD22 & 0.7651 & $5.802 \mathrm{E}-04$ \\
\hline METTLTA & 0.7647 & $1.221 \mathrm{E}-06$ \\
\hline ZNF586 & 0.7646 & 5.447E-06 \\
\hline$S L C 12 A 2$ & 0.7645 & 8.631E-04 \\
\hline$C X X C 1$ & 0.7643 & 1.170E-05 \\
\hline DUS2L & 0.7640 & 7.654E-08 \\
\hline$J A G 1$ & 0.7640 & $1.367 \mathrm{E}-08$ \\
\hline DSTN & 0.7635 & $8.463 \mathrm{E}-06$ \\
\hline MYO10 & 0.7634 & $3.613 \mathrm{E}-05$ \\
\hline KIAA1731 & 0.7630 & $2.351 \mathrm{E}-05$ \\
\hline IP6K1 & 0.7629 & $3.669 \mathrm{E}-06$ \\
\hline$A P O B E C 3 D$ & 0.7623 & $6.540 \mathrm{E}-05$ \\
\hline ZNF583 & 0.7620 & $1.136 \mathrm{E}-08$ \\
\hline GRPEL2 & 0.7617 & $9.283 \mathrm{E}-08$ \\
\hline DCUN1D4 & 0.7614 & $1.240 \mathrm{E}-04$ \\
\hline$H 2 B F W T$ & 0.7605 & $8.353 \mathrm{E}-04$ \\
\hline SLC26A11 & 0.7600 & $5.404 \mathrm{E}-08$ \\
\hline KIAA0090 & 0.7598 & $5.352 \mathrm{E}-07$ \\
\hline PCDHB9 & 0.7596 & 3.547E-05 \\
\hline HIPK2 & 0.7596 & $3.912 \mathrm{E}-07$ \\
\hline CAPRIN1 & 0.7595 & $1.025 \mathrm{E}-07$ \\
\hline$E I F 2 C 2$ & 0.7594 & $1.443 \mathrm{E}-06$ \\
\hline HNMT & 0.7594 & 4.347E-07 \\
\hline SIL1 & 0.7592 & 2.179E-09 \\
\hline MAP2K4 & 0.7586 & $2.604 \mathrm{E}-07$ \\
\hline$R A P 2 C$ & 0.7581 & 5.506E-07 \\
\hline TFPI & 0.7578 & $1.015 \mathrm{E}-04$ \\
\hline USP48 & 0.7575 & $1.045 \mathrm{E}-06$ \\
\hline$S L C 25 A 22$ & 0.7573 & $4.876 \mathrm{E}-10$ \\
\hline PCGF6 & 0.7573 & 4.043E-05 \\
\hline$C D C 25 A$ & 0.7571 & $2.556 \mathrm{E}-11$ \\
\hline C10orf57 & 0.7564 & $3.312 \mathrm{E}-06$ \\
\hline
\end{tabular}

\begin{tabular}{|c|c|c|}
\hline IRAK2 & 0.7561 & 7.381E-08 \\
\hline DNAJBP & 0.7560 & $3.049 \mathrm{E}-04$ \\
\hline RBM12 & 0.7559 & $1.428 \mathrm{E}-07$ \\
\hline ZNF302 & 0.7544 & $1.263 \mathrm{E}-06$ \\
\hline CYP1B1 & 0.7536 & $1.918 \mathrm{E}-05$ \\
\hline PKD2 & 0.7533 & $1.580 \mathrm{E}-06$ \\
\hline NCAPG & 0.7533 & $6.417 \mathrm{E}-09$ \\
\hline HSPA5 & 0.7532 & $1.733 \mathrm{E}-09$ \\
\hline$S P C 24$ & 0.7530 & $8.045 \mathrm{E}-06$ \\
\hline ACOT7 & 0.7524 & $5.448 \mathrm{E}-10$ \\
\hline MAP $3 K 2$ & 0.7523 & $2.439 \mathrm{E}-05$ \\
\hline RPS27L & 0.7518 & $1.595 \mathrm{E}-04$ \\
\hline PELI2 & 0.7514 & 5.621E-09 \\
\hline RAPGEF2 & 0.7504 & 7.505E-06 \\
\hline POLR3B & 0.7503 & $3.084 \mathrm{E}-09$ \\
\hline UBE3A & 0.7502 & $3.901 \mathrm{E}-08$ \\
\hline C2orf 42 & 0.7501 & $8.173 \mathrm{E}-06$ \\
\hline PCM1 & 0.7499 & $1.077 \mathrm{E}-06$ \\
\hline SERF2 & 0.7496 & $4.985 \mathrm{E}-10$ \\
\hline SEC63 & 0.7493 & $7.851 \mathrm{E}-05$ \\
\hline$C B F B$ & 0.7485 & $9.301 \mathrm{E}-08$ \\
\hline TP53INP1 & 0.7484 & $1.618 \mathrm{E}-08$ \\
\hline MARCKS & 0.7477 & $3.191 \mathrm{E}-14$ \\
\hline NR1H3 & 0.7475 & $4.555 \mathrm{E}-07$ \\
\hline S100A11 & 0.7470 & $9.099 \mathrm{E}-10$ \\
\hline DSCC1 & 0.7466 & $2.327 \mathrm{E}-05$ \\
\hline RBMS1 & 0.7465 & $6.551 \mathrm{E}-11$ \\
\hline DSEL & 0.7454 & $3.787 \mathrm{E}-06$ \\
\hline$A T P B D 1 B$ & 0.7451 & $2.150 \mathrm{E}-07$ \\
\hline MCM10 & 0.7450 & 7.767E-08 \\
\hline PTAR1 & 0.7450 & $1.222 \mathrm{E}-07$ \\
\hline LYPLA2 & 0.7431 & $8.215 \mathrm{E}-05$ \\
\hline$N F X 1$ & 0.7430 & 8.495E-06 \\
\hline$D C P 2$ & 0.7428 & $3.584 \mathrm{E}-08$ \\
\hline HIST1H2BH & 0.7427 & $8.451 \mathrm{E}-07$ \\
\hline
\end{tabular}

\begin{tabular}{|c|c|c|}
\hline RPLG & 0.7425 & $3.604 \mathrm{E}-06$ \\
\hline$E 2 F 2$ & 0.7425 & $1.595 \mathrm{E}-05$ \\
\hline$A R L 5 B$ & 0.7410 & $1.888 \mathrm{E}-05$ \\
\hline$K L H D C 2$ & 0.7405 & $5.256 \mathrm{E}-08$ \\
\hline POLR1E & 0.7392 & $1.577 \mathrm{E}-08$ \\
\hline SPC25 & 0.7390 & $1.009 \mathrm{E}-07$ \\
\hline SESN3 & 0.7373 & $2.460 \mathrm{E}-08$ \\
\hline HIC2 & 0.7365 & $3.626 \mathrm{E}-11$ \\
\hline ZFYVE21 & 0.7362 & 4.163E-07 \\
\hline SNORA22 & 0.7358 & $1.341 \mathrm{E}-09$ \\
\hline SNORA23 & 0.7356 & $8.451 \mathrm{E}-12$ \\
\hline PAFAH1B3 & 0.7341 & $6.688 \mathrm{E}-10$ \\
\hline IFT122 & 0.7338 & 2.557E-06 \\
\hline TPRG1L & 0.7337 & $3.432 \mathrm{E}-10$ \\
\hline DENND4C & 0.7329 & $1.614 \mathrm{E}-09$ \\
\hline FAM111A & 0.7327 & $1.091 \mathrm{E}-13$ \\
\hline$A S B 1$ & 0.7326 & $2.272 \mathrm{E}-08$ \\
\hline$H M G B 1$ & 0.7317 & $9.999 \mathrm{E}-08$ \\
\hline$C D C 23$ & 0.7316 & $9.146 \mathrm{E}-10$ \\
\hline C5orf28 & 0.7297 & $3.166 \mathrm{E}-02$ \\
\hline$M O B K L 2 A$ & 0.7294 & $1.852 \mathrm{E}-06$ \\
\hline RELN & 0.7293 & 5.965E-10 \\
\hline$P O L Q$ & 0.7280 & $1.345 \mathrm{E}-05$ \\
\hline FAM160B1 & 0.7279 & 6.709E-07 \\
\hline CHRFAM7A & 0.7276 & $1.322 \mathrm{E}-03$ \\
\hline MIR1264 & 0.7271 & 8.485E-03 \\
\hline TSEN15 & 0.7261 & 2.035E-07 \\
\hline DICER1 & 0.7256 & 4.968E-06 \\
\hline PAPSS1 & 0.7254 & 5.135E-06 \\
\hline TSPAN8 & 0.7254 & $1.659 \mathrm{E}-13$ \\
\hline POU $2 F 1$ & 0.7254 & $2.052 \mathrm{E}-07$ \\
\hline MNS1 & 0.7191 & 1.485E-09 \\
\hline PRKD1 & 0.7184 & 4.109E-06 \\
\hline$\angle P P$ & 0.7179 & $5.473 \mathrm{E}-10$ \\
\hline FRG1 & 0.7168 & $1.921 \mathrm{E}-08$ \\
\hline
\end{tabular}




\section{Supplementary Table S4.5: continued}

\begin{tabular}{|c|c|c|}
\hline TFAP2C & 0.7167 & $5.729 \mathrm{E}-10$ \\
\hline RBL2 & 0.7135 & $1.644 \mathrm{E}-10$ \\
\hline SHISA2 & 0.7087 & $2.480 \mathrm{E}-07$ \\
\hline CDT1 & 0.7073 & $5.248 \mathrm{E}-10$ \\
\hline BOLA2 & 0.7068 & $1.058 \mathrm{E}-05$ \\
\hline FDPS & 0.7063 & $3.654 \mathrm{E}-07$ \\
\hline PPIL3 & 0.7060 & $5.135 \mathrm{E}-12$ \\
\hline SCARNA22 & 0.7052 & $1.337 \mathrm{E}-05$ \\
\hline SLC41A3 & 0.7042 & $3.846 \mathrm{E}-10$ \\
\hline ULK1 & 0.7029 & $5.903 \mathrm{E}-17$ \\
\hline RAB11FIP5 & 0.7005 & $3.047 \mathrm{E}-13$ \\
\hline C1Orf218 & 0.6994 & $6.919 \mathrm{E}-07$ \\
\hline ATG5 & 0.6992 & $7.897 \mathrm{E}-09$ \\
\hline KATNAL1 & 0.6985 & $3.059 \mathrm{E}-07$ \\
\hline TELO2 & 0.6979 & $3.293 \mathrm{E}-02$ \\
\hline
\end{tabular}

\begin{tabular}{|c|c|c|}
\hline ULK1 & 0.6958 & $4.020 \mathrm{E}-18$ \\
\hline PKIA & 0.6957 & $1.073 \mathrm{E}-13$ \\
\hline C9orf5 & 0.6943 & $3.081 \mathrm{E}-11$ \\
\hline CAMSAP1 & 0.6916 & $6.955 \mathrm{E}-12$ \\
\hline DCBLD2 & 0.6889 & $2.496 \mathrm{E}-10$ \\
\hline TMEM54 & 0.6843 & $4.084 \mathrm{E}-13$ \\
\hline LAMP2 & 0.6803 & $8.163 \mathrm{E}-08$ \\
\hline SNORA38B & 0.6799 & $1.136 \mathrm{E}-12$ \\
\hline CST2 & 0.6757 & $1.346 \mathrm{E}-05$ \\
\hline SUGT1 & 0.6723 & $3.590 \mathrm{E}-08$ \\
\hline TM4SF1 & 0.6692 & $1.698 \mathrm{E}-07$ \\
\hline LYSMD2 & 0.6625 & $4.964 \mathrm{E}-11$ \\
\hline SCARNA11 & 0.6574 & $1.598 \mathrm{E}-14$ \\
\hline P15RS & 0.6573 & $1.197 \mathrm{E}-12$ \\
\hline WWP1 & 0.6569 & $1.952 \mathrm{E}-10$ \\
\hline
\end{tabular}

\begin{tabular}{|c|c|c|}
\hline FSTL1 & 0.6469 & $9.232 \mathrm{E}-12$ \\
\hline TNFRSF19 & 0.6421 & $8.346 \mathrm{E}-13$ \\
\hline HIST2H2AA3 & 0.6378 & $2.465 \mathrm{E}-05$ \\
\hline IFI6 & 0.6368 & $6.239 \mathrm{E}-05$ \\
\hline SLC44A2 & 0.6311 & $4.312 \mathrm{E}-15$ \\
\hline SNORA63 & 0.6188 & $1.381 \mathrm{E}-21$ \\
\hline SSBP4 & 0.6101 & $4.348 \mathrm{E}-14$ \\
\hline ATPAF1 & 0.5942 & $1.425 \mathrm{E}-20$ \\
\hline BAMBI & 0.5907 & $1.513 \mathrm{E}-16$ \\
\hline DEPDC1B & 0.5264 & $2.469 \mathrm{E}-11$ \\
\hline INSM1 & 0.3894 & $7.752 \mathrm{E}-38$ \\
\hline
\end{tabular}


Supplementary Table S4.6A: Functional annotation of genes differentially regulated upon INSM1 knockdown in VCaP cells

\begin{tabular}{|c|c|c|c|c|}
\hline Functional annotation & Genes & $p$-value & z-score* & \# Genes† \\
\hline Cell death & $\begin{array}{l}\text { STUB1, GNAQ, STXBP1, SNCA, PRDX2, } \\
\text { NAMPT, CAPNS1, KRT18, JAG1, HIPK2 }\end{array}$ & 2.91E-06 & -0.60 & 94 \\
\hline Neuritogenesis & $\begin{array}{l}\text { PFN1, RYK, SNCA, CAPNS1, RAPGEF2, } \\
\text { UBE3A, RELN, DICER1, ULK1, CAMSAP1 }\end{array}$ & $1.32 \mathrm{E}-03$ & 1.049 & 20 \\
\hline Metabolism of DNA & $\begin{array}{l}\text { SNCA, ISG20, PCM1, E2F2, HMGB1, CDT1, } \\
\text { PFN1, CDC25A, S100A11 }\end{array}$ & $1.53 \mathrm{E}-04$ & 0.259 & 18 \\
\hline $\begin{array}{l}\text { Proliferation of tumor } \\
\text { cell lines }\end{array}$ & $\begin{array}{l}\text { PMEPA1, NOV, UCHL1, HNRPK, CD151, } \\
\text { PRDX2, KRT19, TADA3, HSPA5, RBL2, }\end{array}$ & $1.74 \mathrm{E}-02$ & -0.189 & 38 \\
\hline $\begin{array}{l}\text { Formation of cellular } \\
\text { inclusion bodies }\end{array}$ & $\begin{array}{l}\text { ATG5, DNAJB6, KRT18, PSMC4, SNCA, } \\
\text { STUB1, UBE3A, UCHL1 }\end{array}$ & $2.48 \mathrm{E}-05$ & 0.28 & 8 \\
\hline
\end{tabular}

Top 10 differentially expressed genes in our dataset that were annotated to a function. A gene was selected when its annotation to the indicated function was based on at least two findings in the Ingenuity knowledge base. *Activation z-score is a measure of predicted change (increase or decrease) of the process. †Total number of genes supporting a specific functional annotation.

Supplementary Table S4.6B: Canonical pathway analysis of genes differentially regulated upon INSM1 knockdown in VCaP cells

\begin{tabular}{lccc}
\hline Ingenuity Canonical Pathways & p-value & z-score* & \# Genes† \\
\hline EIF2 Signaling & $7.90 \mathrm{E}-07$ & 2.33 & $15(221)$ \\
Protein Ubiquitination Pathway & $7.43 \mathrm{E}-06$ & $\mathrm{NaN}$ & $15(265)$ \\
Gap Junction Signaling & $3.88 \mathrm{E}-05$ & $\mathrm{NaN}$ & $11(171)$ \\
Melatonin Signaling & $5.91 \mathrm{E}-04$ & 1.63 & $6(72)$ \\
Integrin Signaling & $3.46 \mathrm{E}-04$ & 3.16 & $11(219)$ \\
\hline
\end{tabular}

Significantly enriched canonical pathways across the dataset of commonly regulated genes between T/E III and $\mathrm{VI}$ are shown. *Activation z-score is a measure of predicted change (activated or reduced) of the process. $\mathrm{NaN}$ - not a number. +Number of genes in the dataset, which are represented in the pathway. Numbers in brackets depict the total number of genes in the pathway in the reference gene set. 
INSM1 IN NEUROENDOCRINE PROSTATE CANCER

Supplementary Table S4.7: Genes with FC $>|1.5|$ upon REST knockdown in LNCaP cells

\begin{tabular}{|c|c|c|}
\hline Gene ID & $\begin{array}{c}\text { Fold } \\
\text { change }\end{array}$ & $p$-value \\
\hline BEX1 & 11.269 & $2.760 \mathrm{E}-36$ \\
\hline STMN3 & 10.979 & $4.284 \mathrm{E}-40$ \\
\hline SCG3 & 10.136 & $3.621 \mathrm{E}-33$ \\
\hline TMEM145 & 5.434 & 8.235E-39 \\
\hline CELSR3 & 5.404 & $7.054 \mathrm{E}-49$ \\
\hline$V G F$ & 5.279 & $1.911 \mathrm{E}-45$ \\
\hline$S Y P$ & 4.762 & $2.193 E-49$ \\
\hline$C P L X 1$ & 3.573 & $1.605 E-30$ \\
\hline$B S N$ & 2.859 & $5.147 \mathrm{E}-37$ \\
\hline DPYSL4 & 2.701 & $6.654 \mathrm{E}-36$ \\
\hline TUBB3 & 2.645 & $2.400 \mathrm{E}-29$ \\
\hline MANEAL & 2.467 & $2.476 \mathrm{E}-22$ \\
\hline MIR1282 & 2.448 & 5.355E-01 \\
\hline DISP2 & 2.417 & $4.768 \mathrm{E}-31$ \\
\hline KIAA1324 & 2.340 & $5.396 \mathrm{E}-34$ \\
\hline$A S P H D 1$ & 2.331 & $3.928 \mathrm{E}-36$ \\
\hline CAMKV & 2.294 & $6.221 \mathrm{E}-35$ \\
\hline MAPK8IP2 & 2.290 & $2.149 \mathrm{E}-30$ \\
\hline CECR6 & 2.130 & $9.683 \mathrm{E}-24$ \\
\hline KCNMA1 & 2.101 & $1.272 \mathrm{E}-29$ \\
\hline$D D C$ & 2.091 & $1.478 \mathrm{E}-40$ \\
\hline STX1A & 1.980 & $9.228 \mathrm{E}-19$ \\
\hline RELL2 & 1.952 & $2.218 \mathrm{E}-35$ \\
\hline BEX2 & 1.947 & $2.274 \mathrm{E}-27$ \\
\hline GDAP1 & 1.929 & $2.978 \mathrm{E}-16$ \\
\hline TMEM180 & 1.911 & $2.764 \mathrm{E}-23$ \\
\hline KREMEN2 & 1.905 & $9.072 E-26$ \\
\hline CKMT1B & 1.884 & $2.510 \mathrm{E}-27$ \\
\hline FAM134B & 1.883 & $1.193 \mathrm{E}-20$ \\
\hline$O G D H L$ & 1.879 & $1.948 \mathrm{E}-16$ \\
\hline CKMT1A & 1.864 & $6.557 \mathrm{E}-24$ \\
\hline C7orf63 & 1.841 & $1.446 \mathrm{E}-19$ \\
\hline
\end{tabular}

\begin{tabular}{|c|c|c|}
\hline UGT2B28 & 1.829 & $1.433 \mathrm{E}-13$ \\
\hline$B C H E$ & 1.822 & $3.356 \mathrm{E}-32$ \\
\hline$H B Q 1$ & 1.816 & $6.402 E-29$ \\
\hline SYT4 & 1.799 & $2.880 \mathrm{E}-28$ \\
\hline GRB10 & 1.786 & $1.351 \mathrm{E}-26$ \\
\hline$S L C 4 A 4$ & 1.775 & $1.070 \mathrm{E}-26$ \\
\hline CDK5R1 & 1.763 & $1.282 \mathrm{E}-12$ \\
\hline$M A P 1 B$ & 1.757 & $8.981 E-26$ \\
\hline TMEM198 & 1.753 & $3.102 E-22$ \\
\hline HEPACAM & 1.753 & $3.351 \mathrm{E}-18$ \\
\hline UGT2B11 & 1.752 & 3.597E-12 \\
\hline SYT7 & 1.733 & $1.013 \mathrm{E}-24$ \\
\hline SEZ6L2 & 1.723 & $1.977 \mathrm{E}-18$ \\
\hline$A B C B 11$ & 1.720 & $3.030 \mathrm{E}-19$ \\
\hline C19orf4 & 1.715 & 5.297E-06 \\
\hline PAQR4 & 1.710 & $2.249 \mathrm{E}-23$ \\
\hline$A P L P 1$ & 1.710 & $2.572 \mathrm{E}-24$ \\
\hline NFASC & 1.697 & $1.718 \mathrm{E}-21$ \\
\hline HIST1H2BK & 1.685 & $6.687 \mathrm{E}-20$ \\
\hline MAST4 & 1.681 & $1.910 \mathrm{E}-28$ \\
\hline CAMK2N2 & 1.651 & $9.938 \mathrm{E}-18$ \\
\hline WASF3 & 1.646 & $1.849 \mathrm{E}-16$ \\
\hline$A C P P$ & 1.640 & $9.448 \mathrm{E}-19$ \\
\hline MFSD6 & 1.635 & $9.146 \mathrm{E}-16$ \\
\hline EPPB9 & 1.635 & $8.849 \mathrm{E}-20$ \\
\hline OCRL & 1.634 & $7.084 \mathrm{E}-22$ \\
\hline GNG4 & 1.630 & $1.260 \mathrm{E}-17$ \\
\hline CHPF & 1.626 & 4.097E-17 \\
\hline HIST1H2BD & 1.621 & $2.669 \mathrm{E}-17$ \\
\hline MYT1 & 1.609 & $2.137 \mathrm{E}-16$ \\
\hline NMNAT2 & 1.605 & $3.805 \mathrm{E}-13$ \\
\hline TMEFF2 & 1.600 & $5.001 E-32$ \\
\hline$S B K 1$ & 1.599 & $3.548 \mathrm{E}-31$ \\
\hline$V W F$ & 1.598 & 6.187E-12 \\
\hline
\end{tabular}

\begin{tabular}{|c|c|c|}
\hline TELO2 & 1.594 & 4.016E-02 \\
\hline CBLN2 & 1.593 & $6.550 \mathrm{E}-11$ \\
\hline PPM1E & 1.583 & $2.447 \mathrm{E}-10$ \\
\hline BCYRN1 & 1.583 & $4.678 \mathrm{E}-16$ \\
\hline RTN1 & 1.581 & $7.167 \mathrm{E}-18$ \\
\hline SPIRE2 & 1.580 & $7.911 \mathrm{E}-23$ \\
\hline$A N G$ & 1.579 & 4.697E-23 \\
\hline C5orf53 & 1.579 & $3.418 \mathrm{E}-17$ \\
\hline$D S C 2$ & 1.574 & $6.376 \mathrm{E}-13$ \\
\hline$A B H D 2$ & 1.572 & $6.321 \mathrm{E}-15$ \\
\hline VSTM2L & 1.567 & $9.164 \mathrm{E}-21$ \\
\hline ATP6VOA1 & 1.563 & $1.201 \mathrm{E}-26$ \\
\hline$C H G B$ & 1.561 & $4.940 \mathrm{E}-17$ \\
\hline LRP11 & 1.561 & $4.349 \mathrm{E}-14$ \\
\hline CHPT1 & 1.560 & $9.778 \mathrm{E}-21$ \\
\hline PBX3 & 1.559 & $1.997 \mathrm{E}-16$ \\
\hline SLC10A7 & 1.559 & $1.334 \mathrm{E}-19$ \\
\hline ONECUT2 & 1.554 & $4.232 \mathrm{E}-16$ \\
\hline TMEM43 & 1.552 & $9.942 \mathrm{E}-20$ \\
\hline KCNQ2 & 1.550 & $1.370 \mathrm{E}-09$ \\
\hline S100P & 1.546 & $7.245 E-14$ \\
\hline CFDP1 & 1.546 & $3.179 E-20$ \\
\hline$R A P 1 G A P$ & 1.544 & $3.934 \mathrm{E}-21$ \\
\hline B9D1 & 1.544 & $2.097 \mathrm{E}-18$ \\
\hline SLC22A17 & 1.544 & $8.463 \mathrm{E}-27$ \\
\hline SRGAP3 & 1.543 & $3.841 \mathrm{E}-20$ \\
\hline PKNOX2 & 1.542 & $7.930 E-14$ \\
\hline SCAMP5 & 1.541 & $2.429 \mathrm{E}-16$ \\
\hline B3GNT1 & 1.537 & $2.069 \mathrm{E}-10$ \\
\hline MYNN & 1.536 & $1.916 \mathrm{E}-17$ \\
\hline LUZP2 & 1.536 & $3.191 \mathrm{E}-10$ \\
\hline PLAGL2 & 1.536 & $5.661 \mathrm{E}-16$ \\
\hline FERMT2 & 1.529 & $3.200 \mathrm{E}-12$ \\
\hline$S L C 22 A 3$ & 1.525 & $3.162 \mathrm{E}-16$ \\
\hline
\end{tabular}


CHAPTER 4

Supplementary Table S4.7: continued

\begin{tabular}{|c|c|c|}
\hline MCCC2 & 1.522 & $6.871 \mathrm{E}-09$ \\
\hline PLA2G2A & 1.522 & $1.590 \mathrm{E}-11$ \\
\hline BRWD1 & 1.520 & $3.313 \mathrm{E}-13$ \\
\hline TSC22D3 & 1.519 & $2.052 \mathrm{E}-15$ \\
\hline ABCG1 & 1.517 & $2.146 \mathrm{E}-18$ \\
\hline KIAA1618 & 1.513 & $3.056 \mathrm{E}-16$ \\
\hline CRIP2 & 1.511 & $9.875 \mathrm{E}-16$ \\
\hline HIST1H2BC & 1.507 & $4.059 \mathrm{E}-10$ \\
\hline MBOAT7 & 1.506 & $5.394 \mathrm{E}-10$ \\
\hline HIST1H2AC & 1.505 & $5.090 \mathrm{E}-14$ \\
\hline FBXO2 & 1.504 & $7.607 \mathrm{E}-11$ \\
\hline HIST1H2BJ & 1.502 & $7.418 \mathrm{E}-09$ \\
\hline RILPL2 & 1.501 & $3.082 \mathrm{E}-11$ \\
\hline CROT & 1.501 & $1.211 \mathrm{E}-12$ \\
\hline COQ4 & 1.500 & $3.571 \mathrm{E}-03$ \\
\hline
\end{tabular}

\begin{tabular}{|c|c|c|}
\hline ARPP19 & 0.664 & $2.437 \mathrm{E}-15$ \\
\hline MTHFD2 & 0.662 & $2.639 \mathrm{E}-15$ \\
\hline PDHX & 0.662 & $9.988 \mathrm{E}-14$ \\
\hline EML4 & 0.657 & $3.500 \mathrm{E}-18$ \\
\hline PQLC1 & 0.653 & $6.306 \mathrm{E}-20$ \\
\hline SESN3 & 0.651 & $1.192 \mathrm{E}-10$ \\
\hline KIF2OA & 0.650 & $3.460 \mathrm{E}-16$ \\
\hline FOXK1 & 0.649 & $1.641 \mathrm{E}-10$ \\
\hline VPS26A & 0.644 & $2.807 \mathrm{E}-21$ \\
\hline ODAM & 0.643 & $1.435 \mathrm{E}-16$ \\
\hline COMMD8 & 0.643 & $2.257 \mathrm{E}-12$ \\
\hline PRPF4 & 0.639 & $8.476 \mathrm{E}-21$ \\
\hline LIPA & 0.635 & $9.630 \mathrm{E}-16$ \\
\hline CLIC4 & 0.624 & $2.361 \mathrm{E}-11$ \\
\hline SCOC & 0.624 & $2.116 \mathrm{E}-17$ \\
\hline
\end{tabular}

\begin{tabular}{|c|c|c|}
\hline PIB5PA & 0.619 & $4.410 \mathrm{E}-24$ \\
\hline THOC7 & 0.608 & $5.935 \mathrm{E}-16$ \\
\hline RELL1 & 0.601 & $1.355 \mathrm{E}-12$ \\
\hline SPRYD5 & 0.592 & $3.034 \mathrm{E}-27$ \\
\hline YRDC & 0.587 & $4.106 \mathrm{E}-26$ \\
\hline BAMBI & 0.587 & $1.777 \mathrm{E}-17$ \\
\hline TRIM48 & 0.570 & $1.976 \mathrm{E}-24$ \\
\hline C18Orf56 & 0.568 & $1.310 \mathrm{E}-26$ \\
\hline HMGB2 & 0.551 & $1.089 \mathrm{E}-17$ \\
\hline COMMD6 & 0.546 & $3.079 \mathrm{E}-30$ \\
\hline HGD & 0.542 & $8.798 \mathrm{E}-17$ \\
\hline C9Orf123 & 0.528 & $3.024 \mathrm{E}-27$ \\
\hline NT5DC3 & 0.522 & $5.835 \mathrm{E}-29$ \\
\hline HSPE1 & 0.505 & $6.318 \mathrm{E}-04$ \\
\hline
\end{tabular}


INSM 1 IN NEUROENDOCRINE PROSTATE CANCER

Supplementary Table S4.8A: Functional annotation of genes differentially regulated upon REST knockdown in LNCaP cells

\begin{tabular}{|c|c|c|c|c|}
\hline Functional annotation & Genes & $p$-value & z-score* & \# Genes† \\
\hline $\begin{array}{l}\text { Formation of cellular } \\
\text { protrusions }\end{array}$ & $\begin{array}{l}\text { MAPT, MAP1B, RELN, CRK, VGF, BSN, } \\
\text { CELSR3, ONECUT2, MAPK8IP2, CDK5R1 }\end{array}$ & 5.97E-05 & 2.297 & 21 \\
\hline Growth of neurites & $\begin{array}{l}\text { VGF, HBA2, GPRIN1, SLC12A2, EXOC5, } \\
\text { CDK5R1, CDC2, MAP1B, DCX, RAP1GAP }\end{array}$ & $2.62 \mathrm{E}-03$ & 2.318 & 20 \\
\hline Migration of neurons & $\begin{array}{l}\text { CELSR3, MAP1B, CDK5R1, DCX, SLC12A2, } \\
\text { LAMA1, AURKA, LMNB1, CNTNAP2, } \\
\text { SEMA6A }\end{array}$ & $2.77 \mathrm{E}-03$ & 1.255 & 12 \\
\hline Microtubule dynamics & $\begin{array}{l}\text { MAPT, MAP1B, MAPRE1, RELN, PALM, } \\
\text { PACSIN1, NCAM2, LYN, BBS4, STMN3 }\end{array}$ & $9.65 \mathrm{E}-06$ & 2.475 & 30 \\
\hline Transport of molecule & $\begin{array}{l}\text { LYN, CROT, ABCG1, TTR, SLC6A9, } \\
\text { ATP13A2, CNKSR3, SLC7A2, SLC16A10, } \\
\text { SLC46A1 }\end{array}$ & $5.11 \mathrm{E}-03$ & 3.757 & 20 \\
\hline
\end{tabular}

Top 10 differentially expressed genes in our dataset that were annotated to a function. A gene was selected when its annotation to the indicated function was based on at least two findings in the Ingenuity knowledge base. *Activation z-score is a measure of predicted change (increase or decrease) of the process. †Total number of genes supporting a specific functional annotation.

Supplementary Table S4.8B: Canonical pathway analysis of genes differentially regulated upon REST knockdown in LNCaP cells

\begin{tabular}{lccc}
\hline Ingenuity Canonical Pathways & p-value & z-score* & \# Genes† \\
\hline CDK5 Signaling & $5.12 \mathrm{E}-03$ & 1.63 & $6(99)$ \\
Reelin Signaling in Neurons & $1.07 \mathrm{E}-03$ & 0 & $8(92)$ \\
Neuregulin Signaling & $1.34 \mathrm{E}-02$ & 1.34 & $5(88)$ \\
Glioma Signaling & $1.30 \mathrm{E}-02$ & 1.34 & $7(112)$ \\
cAMP-mediated Signaling & $1.21 \mathrm{E}-02$ & -0.63 & $11(223)$ \\
\hline
\end{tabular}

Significantly enriched canonical pathways across the dataset of commonly regulated genes between T/E III and $\mathrm{VI}$ are shown. *Activation z-score is a measure of predicted change (activated or reduced) of the process. +Number of genes in the dataset, which are represented in the pathway. Numbers in brackets depict the total number of genes in the pathway in the reference gene set. 
CHAPTER 4

Supplementary Table S4.9: Genes with FC >|1.5| upon L1CAM knockdown in PC-3 cells

\begin{tabular}{|c|c|c|}
\hline $\begin{array}{c}\text { Gene } \\
\text { ID }\end{array}$ & $\begin{array}{c}\text { Fold } \\
\text { change }\end{array}$ & $\begin{array}{c}p- \\
\text { value }\end{array}$ \\
\hline ANGPTL4 & 17,907 & $1,324 \mathrm{E}-53$ \\
\hline S100P & 10,371 & $9,887 \mathrm{E}-54$ \\
\hline GDF15 & 9,283 & $1,394 \mathrm{E}-41$ \\
\hline MUCSAC & 9,017 & $1,403 E-33$ \\
\hline RASD1 & 8,354 & $4,638 \mathrm{E}-51$ \\
\hline$R B P 4$ & 6,570 & $2,339 \mathrm{E}-28$ \\
\hline TFF3 & 6,503 & $1,084 \mathrm{E}-46$ \\
\hline SUSD2 & 6,247 & $1,628 \mathrm{E}-30$ \\
\hline COLZAI & 6,117 & $1,898 \mathrm{E}-35$ \\
\hline FABP4 & 6,081 & $8,445 E-36$ \\
\hline IGFBP5 & 5,992 & $2,533 \mathrm{E}-35$ \\
\hline SYT11 & 5,750 & $1,457 \mathrm{E}-22$ \\
\hline C15orf 48 & 5,743 & $5,416 \mathrm{E}-29$ \\
\hline IGFBP3 & 5,376 & $2,710 \mathrm{E}-28$ \\
\hline ITGAI & 5,364 & $6,535 E-39$ \\
\hline KIF5C & 4,759 & $6,272 \mathrm{E}-33$ \\
\hline LFNG & 4,355 & $3,286 \mathrm{E}-36$ \\
\hline KRT4 & 4,306 & $2,882 \mathrm{E}-38$ \\
\hline SLC22A18 & 4,051 & $1,661 \mathrm{E}-45$ \\
\hline CDKN1C & 4,047 & $1,990 \mathrm{E}-37$ \\
\hline ERO1L & 4,040 & $6,760 E-37$ \\
\hline MAL & 4,038 & $2,815 \mathrm{E}-30$ \\
\hline C6orf 85 & 4,001 & $1,415 \mathrm{E}-36$ \\
\hline TNFRSF6B & 3,933 & $2,879 \mathrm{E}-38$ \\
\hline TMPRSS2 & 3,932 & $1,124 \mathrm{E}-28$ \\
\hline SERPINE2 & 3,896 & $2,279 \mathrm{E}-32$ \\
\hline MSLN & 3,732 & $8,626 \mathrm{E}-29$ \\
\hline MGC16121 & 3,694 & $4,845 \mathrm{E}-34$ \\
\hline COL5A1 & 3,679 & $5,785 \mathrm{E}-32$ \\
\hline TFF1 & 3,653 & $9,670 E-23$ \\
\hline NTSE & 3,645 & $4,501 E-30$ \\
\hline HOXA11AS & 3,610 & $2,149 \mathrm{E}-31$ \\
\hline
\end{tabular}

\begin{tabular}{|c|c|c|}
\hline$A D M$ & 3,587 & $1,242 \mathrm{E}-38$ \\
\hline SEMA3B & 3,536 & $7,330 \mathrm{E}-26$ \\
\hline MEGF6 & 3,506 & $1,099 \mathrm{E}-31$ \\
\hline FERMT2 & 3,424 & $3,759 \mathrm{E}-26$ \\
\hline OLFML3 & 3,389 & $5,148 \mathrm{E}-23$ \\
\hline$W \mid P / 1$ & 3,359 & $2,857 \mathrm{E}-40$ \\
\hline HIST2HZAC & 3,347 & $1,419 \mathrm{E}-51$ \\
\hline$C F D$ & 3,337 & $1,485 \mathrm{E}-43$ \\
\hline RGS11 & 3,336 & $4,639 \mathrm{E}-29$ \\
\hline$G P X 2$ & 3,331 & $2,926 \mathrm{E}-29$ \\
\hline HIST2HZAAB & 3,328 & $9,359 \mathrm{E}-31$ \\
\hline FSTL1 & 3,317 & $1,869 \mathrm{E}-49$ \\
\hline HIST2H2AA4 & 3,311 & $1,941 \mathrm{E}-31$ \\
\hline MUC16 & 3,285 & $1,347 \mathrm{E}-26$ \\
\hline FERIL4 & 3,281 & $1,419 \mathrm{E}-20$ \\
\hline VLDLR & 3,270 & $6,030 \mathrm{E}-22$ \\
\hline$\pi$ TT19 & 3,267 & $9,883 E-34$ \\
\hline $\mathrm{RDH} 1 \mathrm{O}$ & 3,260 & $1,283 \mathrm{E}-33$ \\
\hline TMEM 45B & 3,250 & $1,637 \mathrm{E}-34$ \\
\hline WNK4 & 3,232 & $4,500 E-47$ \\
\hline PGM2L1 & 3,198 & $1,466 \mathrm{E}-34$ \\
\hline ASS1 & 3,197 & $2,034 \mathrm{E}-38$ \\
\hline KIAA1199 & 3,183 & $4,318 \mathrm{E}-49$ \\
\hline LGALS3 & 3,172 & $4,221 \mathrm{E}-28$ \\
\hline FBN2 & 3,160 & $4,898 \mathrm{E}-38$ \\
\hline MMP23B & 3,136 & $2,090 \mathrm{E}-36$ \\
\hline BAGALT4 & 3,111 & $7,724 \mathrm{E}-31$ \\
\hline ERMP1 & 3,105 & $1,396 \mathrm{E}-24$ \\
\hline$M B$ & 3,045 & $1,525 \mathrm{E}-43$ \\
\hline NIPA1 & 3,032 & $6,112 \mathrm{E}-26$ \\
\hline INHBB & 3,013 & $3,566 \mathrm{E}-30$ \\
\hline ITGB4 & 3,012 & $2,657 \mathrm{E}-29$ \\
\hline C21orf58 & 3,000 & $8,874 \mathrm{E}-27$ \\
\hline CYR61 & 2,990 & $1,184 \mathrm{E}-29$ \\
\hline
\end{tabular}

\begin{tabular}{|c|c|c|}
\hline ENO2 & 2,979 & $3,323 E-31$ \\
\hline DDIT4 & 2,952 & $5,617 \mathrm{E}-31$ \\
\hline HTRA1 & 2,949 & $5,161 \mathrm{E}-35$ \\
\hline SPTLC3 & 2,945 & $5,805 E-34$ \\
\hline ITGB2 & 2,927 & $7,214 \mathrm{E}-45$ \\
\hline GLS & 2,918 & $1,112 \mathrm{E}-26$ \\
\hline GASG & 2,893 & $2,762 E-31$ \\
\hline SELM & 2,881 & $9,053 \mathrm{E}-40$ \\
\hline IGSF3 & 2,863 & $1,725 \mathrm{E}-20$ \\
\hline SPDEF & 2,853 & $4,483 E-48$ \\
\hline CRIP1 & 2,847 & $4,702 \mathrm{E}-28$ \\
\hline INSIG1 & 2,846 & $6,858 \mathrm{E}-33$ \\
\hline SERPIND1 & 2,842 & $2,127 \mathrm{E}-28$ \\
\hline C10orf41 & 2,831 & $2,762 E-27$ \\
\hline$C P Z$ & 2,831 & $1,066 \mathrm{E}-30$ \\
\hline ADSSLI & 2,802 & $4,733 E-38$ \\
\hline KLK5 & 2,787 & $2,003 \mathrm{E}-34$ \\
\hline UPK2 & 2,784 & $6,642 \mathrm{E}-32$ \\
\hline ZNF467 & 2,783 & $1,245 E-46$ \\
\hline HISTIH4H & 2,779 & $4,569 \mathrm{E}-34$ \\
\hline$S D C B P 2$ & 2,774 & $5,973 E-45$ \\
\hline SMARCD3 & 2,767 & $6,353 \mathrm{E}-31$ \\
\hline ALPP & 2,766 & $5,772 E-41$ \\
\hline HOXA1O & 2,762 & $2,575 E-30$ \\
\hline MMP23A & 2,758 & $7,102 \mathrm{E}-36$ \\
\hline TGFBR3 & 2,751 & $4,268 \mathrm{E}-31$ \\
\hline TNPO1 & 2,746 & $3,148 \mathrm{E}-20$ \\
\hline EPAS1 & 2,744 & $5,861 E-28$ \\
\hline ILIR2 & 2,726 & $1,027 \mathrm{E}-25$ \\
\hline P4HA2 & 2,722 & $1,259 \mathrm{E}-26$ \\
\hline MATN2 & 2,720 & $5,998 \mathrm{E}-30$ \\
\hline$A B C C 3$ & 2,708 & $1,840 \mathrm{E}-37$ \\
\hline PLAT & 2,706 & $7,735 E-38$ \\
\hline NOXA1 & 2,693 & $2,330 \mathrm{E}-18$ \\
\hline
\end{tabular}

\begin{tabular}{|c|c|c|}
\hline FTHL11 & 2,685 & $1,497 \mathrm{E}-20$ \\
\hline TMCO3 & 2,680 & $2,298 \mathrm{E}-43$ \\
\hline COL7AI & 2,677 & $1,920 \mathrm{E}-20$ \\
\hline DRAM1 & 2,674 & $1,009 \mathrm{E}-27$ \\
\hline ACHE & 2,660 & $5,253 \mathrm{E}-30$ \\
\hline$F G B$ & 2,649 & $1,832 \mathrm{E}-32$ \\
\hline TUBB2B & 2,639 & $3,774 \mathrm{E}-70$ \\
\hline SLCAA7 & 2,636 & $8,496 \mathrm{E}-28$ \\
\hline TNNC1 & 2,635 & $2,843 \mathrm{E}-25$ \\
\hline KIFC2 & 2,634 & $2,499 \mathrm{E}-15$ \\
\hline NDRG4 & 2,633 & $1,151 \mathrm{E}-29$ \\
\hline$A P O E$ & 2,630 & $2,690 \mathrm{E}-27$ \\
\hline PLOD2 & 2,627 & $5,755 \mathrm{E}-27$ \\
\hline KLKG & 2,626 & $3,912 \mathrm{E}-33$ \\
\hline PIM1 & 2,626 & $1,225 \mathrm{E}-32$ \\
\hline CNTNAP1 & 2,623 & $3,097 \mathrm{E}-36$ \\
\hline RBM24 & 2,622 & $4,253 \mathrm{E}-24$ \\
\hline CPT1C & 2,612 & $1,326 \mathrm{E}-37$ \\
\hline$J A G 2$ & 2,611 & $2,002 \mathrm{E}-21$ \\
\hline$A B C B 6$ & 2,610 & $8,170 \mathrm{E}-37$ \\
\hline GPRC5A & 2,600 & $1,722 \mathrm{E}-31$ \\
\hline NOTCH3 & 2,599 & $1,629 \mathrm{E}-35$ \\
\hline IL6 & 2,594 & $5,071 \mathrm{E}-34$ \\
\hline SELENBP1 & 2,593 & $1,013 \mathrm{E}-19$ \\
\hline$B G N$ & 2,591 & $8,050 \mathrm{E}-35$ \\
\hline CCL26 & 2,590 & $1,754 \mathrm{E}-27$ \\
\hline NGF & 2,588 & $4,803 E-32$ \\
\hline HISTIH1C & 2,587 & $5,852 \mathrm{E}-24$ \\
\hline EFEMP2 & 2,571 & $4,396 \mathrm{E}-27$ \\
\hline MICALI & 2,568 & $3,376 \mathrm{E}-24$ \\
\hline SCARAS & 2,562 & $4,188 \mathrm{E}-40$ \\
\hline TAGLN3 & 2,561 & $2,851 \mathrm{E}-35$ \\
\hline TLEG & 2,552 & $4,008 \mathrm{E}-26$ \\
\hline DSC2 & 2,549 & $1,162 \mathrm{E}-36$ \\
\hline
\end{tabular}


Supplementary Table S4.9: continued

\begin{tabular}{|c|c|c|}
\hline GPR177 & 2,547 & $2,715 \mathrm{E}-23$ \\
\hline LIMCH1 & 2,540 & $1,967 \mathrm{E}-24$ \\
\hline$\angle A M C 2$ & 2,539 & $6,283 \mathrm{E}-22$ \\
\hline FAM188A & 2,533 & $2,523 \mathrm{E}-37$ \\
\hline LAMC1 & 2,529 & $1,566 \mathrm{E}-32$ \\
\hline SLC22A23 & 2,528 & $3,286 \mathrm{E}-25$ \\
\hline ADAMTS1 & 2,524 & $2,784 \mathrm{E}-29$ \\
\hline FLJ20920 & 2,518 & $3,120 \mathrm{E}-36$ \\
\hline DUSP1 & 2,515 & $4,950 \mathrm{E}-28$ \\
\hline SLC29A4 & 2,505 & $1,762 \mathrm{E}-37$ \\
\hline C20orf 46 & 2,502 & $9,788 \mathrm{E}-29$ \\
\hline HOXAS & 2,494 & $7,039 \mathrm{E}-33$ \\
\hline GDPD3 & 2,493 & $6,541 \mathrm{E}-30$ \\
\hline HOXA13 & 2,484 & $5,562 \mathrm{E}-32$ \\
\hline 148 & 2,473 & $6,684 \mathrm{E}-15$ \\
\hline HMGCS1 & 2,473 & $1,765 \mathrm{E}-32$ \\
\hline LEPREL1 & 2,467 & $4,690 \mathrm{E}-27$ \\
\hline ENC1 & 2,464 & $4,589 \mathrm{E}-27$ \\
\hline APPLL2 & 2,461 & $1,465 \mathrm{E}-24$ \\
\hline GBX2 & 2,459 & $5,852 \mathrm{E}-36$ \\
\hline FSD1 & 2,455 & $3,681 \mathrm{E}-31$ \\
\hline EPB41L4B & 2,451 & $1,811 \mathrm{E}-20$ \\
\hline ATRN & 2,450 & $3,816 \mathrm{E}-23$ \\
\hline CDH15 & 2,447 & $5,560 \mathrm{E}-47$ \\
\hline ZDHHC11 & 2,444 & $1,268 \mathrm{E}-36$ \\
\hline OSR1 & 2,438 & $9,639 \mathrm{E}-37$ \\
\hline C1S & 2,426 & $1,701 \mathrm{E}-18$ \\
\hline MT2A & 2,423 & $6,067 \mathrm{E}-30$ \\
\hline PRRT3 & 2,420 & $4,206 \mathrm{E}-25$ \\
\hline TSPAN8 & 2,420 & $4,234 \mathrm{E}-32$ \\
\hline LAMB2 & 2,414 & $6,501 E-34$ \\
\hline RABAC1 & 2,413 & $2,242 \mathrm{E}-34$ \\
\hline RHPN1 & 2,410 & $3,058 \mathrm{E}-28$ \\
\hline
\end{tabular}

\begin{tabular}{|c|c|c|}
\hline PDGFRL & 2,409 & $6,024 \mathrm{E}-23$ \\
\hline PNPLA7 & 2,408 & $3,590 \mathrm{E}-19$ \\
\hline CTGF & 2,408 & $3,183 \mathrm{E}-27$ \\
\hline $\mathrm{FBXO2}$ & 2,406 & $1,053 \mathrm{E}-30$ \\
\hline HIST2H2BE & 2,398 & $3,667 \mathrm{E}-29$ \\
\hline H2AFJ & 2,395 & $6,769 \mathrm{E}-26$ \\
\hline CSPG5 & 2,394 & $5,638 \mathrm{E}-18$ \\
\hline GABBR2 & 2,393 & $6,775 \mathrm{E}-32$ \\
\hline NOV & 2,390 & $6,465 \mathrm{E}-27$ \\
\hline$H P G D$ & 2,389 & $5,509 \mathrm{E}-32$ \\
\hline IGFBPG & 2,389 & $1,480 \mathrm{E}-36$ \\
\hline PTPRM & 2,384 & $1,671 \mathrm{E}-32$ \\
\hline CST1 & 2,379 & $3,809 \mathrm{E}-41$ \\
\hline HHIP & 2,378 & $3,017 \mathrm{E}-29$ \\
\hline LHFPL2 & 2,377 & $9,296 \mathrm{E}-27$ \\
\hline AIG1 & 2,376 & $3,262 \mathrm{E}-38$ \\
\hline KIAA1881 & 2,376 & $6,174 \mathrm{E}-30$ \\
\hline KRT7 & 2,373 & $2,571 \mathrm{E}-47$ \\
\hline TBX3 & 2,369 & $2,318 \mathrm{E}-21$ \\
\hline LAMA3 & 2,367 & $1,451 \mathrm{E}-24$ \\
\hline BRSK1 & 2,362 & $1,833 \mathrm{E}-39$ \\
\hline NDRG 1 & 2,359 & $1,131 \mathrm{E}-26$ \\
\hline OSTalpha & 2,357 & $7,523 \mathrm{E}-26$ \\
\hline GATA2 & 2,353 & $3,545 \mathrm{E}-29$ \\
\hline CFDP1 & 2,342 & $9,511 \mathrm{E}-39$ \\
\hline RAB15 & 2,338 & $7,077 \mathrm{E}-33$ \\
\hline RNF165 & 2,337 & $3,378 \mathrm{E}-27$ \\
\hline ZNF682 & 2,335 & $1,434 \mathrm{E}-23$ \\
\hline SLC44A4 & 2,333 & $8,753 \mathrm{E}-24$ \\
\hline FTHL2 & 2,327 & $3,100 \mathrm{E}-25$ \\
\hline DLK2 & 2,322 & $1,142 \mathrm{E}-45$ \\
\hline NLRP3 & 2,321 & $1,731 \mathrm{E}-20$ \\
\hline REG4 & 2,321 & $1,586 \mathrm{E}-21$ \\
\hline
\end{tabular}

\begin{tabular}{|c|c|c|}
\hline MT1A & 2,318 & $1,703 \mathrm{E}-30$ \\
\hline DENND3 & 2,315 & $1,587 \mathrm{E}-26$ \\
\hline SLC22A17 & 2,309 & $8,107 E-37$ \\
\hline$D C P 2$ & 2,307 & $1,082 E-27$ \\
\hline WNT7B & 2,307 & $8,606 \mathrm{E}-23$ \\
\hline ASAP3 & 2,305 & $4,903 \mathrm{E}-22$ \\
\hline CCNA1 & 2,302 & $1,567 \mathrm{E}-27$ \\
\hline MUM1 & 2,297 & $8,598 \mathrm{E}-33$ \\
\hline TCEA3 & 2,295 & $9,859 \mathrm{E}-44$ \\
\hline ALDOC & 2,294 & $1,872 \mathrm{E}-33$ \\
\hline ACSF2 & 2,293 & $4,073 E-27$ \\
\hline LAMBB & 2,290 & $2,383 \mathrm{E}-22$ \\
\hline $\mathrm{CDH} 2$ & 2,289 & $3,726 \mathrm{E}-32$ \\
\hline INPPLI & 2,289 & $5,334 \mathrm{E}-29$ \\
\hline ANG & 2,288 & $2,527 \mathrm{E}-30$ \\
\hline C10orf116 & 2,280 & $7,680 E-36$ \\
\hline$C K B$ & 2,273 & $3,513 \mathrm{E}-40$ \\
\hline GABARAPL1 & 2,273 & $2,504 \mathrm{E}-27$ \\
\hline THBS1 & 2,272 & $2,893 \mathrm{E}-18$ \\
\hline SESN1 & 2,269 & $1,217 \mathrm{E}-23$ \\
\hline BRWD1 & 2,269 & $5,227 \mathrm{E}-29$ \\
\hline PHLDA3 & 2,268 & $1,397 \mathrm{E}-30$ \\
\hline GDPDS & 2,267 & $1,475 E-40$ \\
\hline CHN2 & 2,265 & $8,473 E-34$ \\
\hline$P I R$ & 2,260 & $1,564 \mathrm{E}-41$ \\
\hline RNF24 & 2,260 & $2,232 \mathrm{E}-27$ \\
\hline CTSB & 2,259 & $4,742 \mathrm{E}-34$ \\
\hline CAPN12 & 2,255 & $1,019 \mathrm{E}-29$ \\
\hline C20orf56 & 2,254 & $3,693 E-31$ \\
\hline$F \sqcup 33996$ & 2,252 & $2,003 E-32$ \\
\hline KRT8 & 2,247 & $1,447 \mathrm{E}-26$ \\
\hline$\stackrel{L R C H 4}{ }$ & 2,247 & $2,524 \mathrm{E}-30$ \\
\hline MiR1282 & 2,246 & $9,691 \mathrm{E}-02$ \\
\hline
\end{tabular}

\begin{tabular}{|c|c|c|}
\hline PLXNA3 & 2,241 & $1,228 \mathrm{E}-31$ \\
\hline$\angle P P G$ & 2,239 & $1,125 \mathrm{E}-23$ \\
\hline ZFHX3 & 2,236 & $2,325 \mathrm{E}-23$ \\
\hline SLPI & 2,226 & $4,458 \mathrm{E}-34$ \\
\hline$A P L P 2$ & 2,219 & $6,268 \mathrm{E}-24$ \\
\hline$T S C 22 D 3$ & 2,217 & $9,326 \mathrm{E}-33$ \\
\hline DENNDSB & 2,217 & $2,055 \mathrm{E}-29$ \\
\hline FAT1 & 2,213 & $1,239 \mathrm{E}-25$ \\
\hline C10orf140 & 2,211 & $4,480 \mathrm{E}-32$ \\
\hline$\angle Y P D 3$ & 2,208 & $4,549 \mathrm{E}-35$ \\
\hline DHX4O & 2,207 & $8,834 \mathrm{E}-24$ \\
\hline$B A M B I$ & 2,207 & $2,490 \mathrm{E}-35$ \\
\hline EPS\&L1 & 2,207 & $3,177 \mathrm{E}-20$ \\
\hline LGMN & 2,203 & $2,190 \mathrm{E}-32$ \\
\hline TRIMG & 2,198 & $1,957 \mathrm{E}-25$ \\
\hline SLC4A11 & 2,194 & $1,421 \mathrm{E}-26$ \\
\hline C7orf41 & 2,194 & $5,641 \mathrm{E}-20$ \\
\hline $1 T G A 5$ & 2,191 & $5,022 \mathrm{E}-27$ \\
\hline PDGFB & 2,190 & $1,306 \mathrm{E}-25$ \\
\hline KRT15 & 2,190 & $5,094 \mathrm{E}-24$ \\
\hline PLCH2 & 2,188 & $7,851 \mathrm{E}-30$ \\
\hline SVIL & 2,188 & $1,254 \mathrm{E}-24$ \\
\hline PCSK1N & 2,188 & $8,508 \mathrm{E}-29$ \\
\hline$R G L 1$ & 2,187 & $5,570 \mathrm{E}-27$ \\
\hline AHNAK2 & 2,184 & $2,040 \mathrm{E}-21$ \\
\hline CACNA1H & 2,181 & $3,605 \mathrm{E}-33$ \\
\hline$F \sqcup 36131$ & 2,180 & $1,135 \mathrm{E}-31$ \\
\hline MST1 & 2,176 & $5,973 \mathrm{E}-17$ \\
\hline ANKZF1 & 2,173 & $2,056 \mathrm{E}-24$ \\
\hline DOCKG & 2,172 & $1,160 \mathrm{E}-32$ \\
\hline SCPEP1 & 2,172 & $9,609 \mathrm{E}-36$ \\
\hline FTHL3 & 2,170 & $2,875 \mathrm{E}-35$ \\
\hline SCSDL & 2,169 & $2,520 \mathrm{E}-35$ \\
\hline
\end{tabular}


CHAPTER 4

Supplementary Table S4.9: continued

\begin{tabular}{|c|c|c|}
\hline SCNN1D & 2,167 & $5,568 \mathrm{E}-23$ \\
\hline PLXNB2 & 2,165 & $2,288 \mathrm{E}-35$ \\
\hline LRPB & 2,161 & $2,000 \mathrm{E}-26$ \\
\hline VEGFA & 2,160 & $4,000 \mathrm{E}-14$ \\
\hline DPYSLL & 2,159 & $5,383 \mathrm{E}-25$ \\
\hline CCBE1 & 2,157 & $1,831 \mathrm{E}-27$ \\
\hline BNIP3 & 2,156 & $7,725 \mathrm{E}-34$ \\
\hline$E \mid D 2 B$ & 2,153 & $7,789 \mathrm{E}-30$ \\
\hline TP53/NP1 & 2,149 & $8,626 \mathrm{E}-18$ \\
\hline PANX2 & 2,147 & $4,187 \mathrm{E}-43$ \\
\hline C5orf39 & 2,144 & $3,689 \mathrm{E}-21$ \\
\hline C8orf45 & 2,141 & $5,039 \mathrm{E}-19$ \\
\hline HAGHL & 2,140 & $1,413 \mathrm{E}-22$ \\
\hline ROR1 & 2,140 & $1,407 \mathrm{E}-24$ \\
\hline AGRN & 2,135 & $1,073 \mathrm{E}-33$ \\
\hline APLP1 & 2,132 & $5,724 \mathrm{E}-23$ \\
\hline PMSZLL & 2,129 & $1,977 \mathrm{E}-17$ \\
\hline MYOF & 2,128 & $5,120 \mathrm{E}-26$ \\
\hline KIAA1324 & 2,127 & $1,174 \mathrm{E}-21$ \\
\hline$S R G N$ & 2,122 & $6,607 \mathrm{E}-29$ \\
\hline KIF1B & 2,122 & $8,006 \mathrm{E}-24$ \\
\hline NOX5 & 2,120 & $2,626 \mathrm{E}-31$ \\
\hline NTN4 & 2,118 & $3,279 \mathrm{E}-16$ \\
\hline$G P C 2$ & 2,118 & $2,200 \mathrm{E}-18$ \\
\hline ATP\&B2 & 2,116 & $2,243 \mathrm{E}-33$ \\
\hline PLA2G4B & 2,115 & $4,450 \mathrm{E}-23$ \\
\hline ITM2C & 2,115 & $2,929 \mathrm{E}-34$ \\
\hline CGNL1 & 2,114 & $6,300 E-27$ \\
\hline GLCE & 2,113 & $2,901 \mathrm{E}-25$ \\
\hline FER1L3 & 2,109 & $1,918 \mathrm{E}-27$ \\
\hline CATSPER2 & 2,109 & $9,299 \mathrm{E}-25$ \\
\hline TSC22D1 & 2,109 & $1,224 \mathrm{E}-26$ \\
\hline 5003 & 2,107 & $1,611 \mathrm{E}-30$ \\
\hline
\end{tabular}

\begin{tabular}{|c|c|c|}
\hline TMTC1 & 2,106 & $1,733 \mathrm{E}-23$ \\
\hline MIA3 & 2,103 & $5,163 \mathrm{E}-21$ \\
\hline ARIDSB & 2,102 & $5,963 \mathrm{E}-22$ \\
\hline SPIRE2 & 2,102 & $9,762 \mathrm{E}-29$ \\
\hline FBXO32 & 2,096 & $9,664 \mathrm{E}-25$ \\
\hline$C D 63$ & 2,096 & $1,224 \mathrm{E}-19$ \\
\hline PLTP & 2,095 & $6,698 \mathrm{E}-32$ \\
\hline CYP1B1 & 2,092 & $5,465 \mathrm{E}-23$ \\
\hline Gos2 & 2,090 & $3,597 \mathrm{E}-23$ \\
\hline FAM175A & 2,084 & $6,971 \mathrm{E}-24$ \\
\hline RNASET2 & 2,084 & $1,369 \mathrm{E}-38$ \\
\hline TGFB3 & 2,083 & $1,581 \mathrm{E}-28$ \\
\hline TNFSF 4 & 2,082 & $6,625 \mathrm{E}-33$ \\
\hline SC4MOL & 2,081 & $1,334 \mathrm{E}-22$ \\
\hline HK2 & 2,080 & $2,681 \mathrm{E}-19$ \\
\hline GPR64 & 2,080 & $5,947 \mathrm{E}-17$ \\
\hline ATP2C2 & 2,078 & $2,070 \mathrm{E}-15$ \\
\hline HIST1H2BC & 2,077 & $3,656 \mathrm{E}-20$ \\
\hline WNT4 & 2,076 & $1,354 \mathrm{E}-29$ \\
\hline MAP3K12 & 2,072 & $1,688 \mathrm{E}-23$ \\
\hline FAM73A & 2,072 & $6,148 \mathrm{E}-19$ \\
\hline OSBPL1O & 2,069 & $8,725 \mathrm{E}-33$ \\
\hline CCNYLI & 2,066 & $1,398 \mathrm{E}-22$ \\
\hline FLNC & 2,062 & $2,139 \mathrm{E}-34$ \\
\hline EFNA1 & 2,061 & $1,656 \mathrm{E}-29$ \\
\hline FTHL16 & 2,057 & $2,102 \mathrm{E}-25$ \\
\hline CYFIP2 & 2,057 & $1,254 \mathrm{E}-24$ \\
\hline UNKL & 2,056 & $1,116 \mathrm{E}-25$ \\
\hline FRMD 6 & 2,054 & $1,144 \mathrm{E}-23$ \\
\hline WSB1 & 2,054 & $1,689 \mathrm{E}-20$ \\
\hline MAN2B2 & 2,053 & $2,998 \mathrm{E}-28$ \\
\hline TGFB2 & 2,052 & $5,045 \mathrm{E}-17$ \\
\hline UBL3 & 2,048 & $7,796 \mathrm{E}-21$ \\
\hline
\end{tabular}

\begin{tabular}{|c|c|c|}
\hline TUBG2 & 2,046 & $1,065 \mathrm{E}-32$ \\
\hline NCCRP1 & 2,045 & $3,779 \mathrm{E}-31$ \\
\hline ITPRI & 2,044 & $2,108 \mathrm{E}-22$ \\
\hline $50 \times 8$ & 2,042 & $4,519 \mathrm{E}-20$ \\
\hline TNFAIP2 & 2,041 & $3,231 \mathrm{E}-22$ \\
\hline FAM $43 A$ & 2,041 & $3,067 \mathrm{E}-32$ \\
\hline CDKN1B & 2,040 & $8,797 \mathrm{E}-32$ \\
\hline TXNRD1 & 2,040 & $1,337 \mathrm{E}-31$ \\
\hline TSPAN3 & 2,039 & $3,107 \mathrm{E}-29$ \\
\hline HIATL2 & 2,039 & $1,393 \mathrm{E}-27$ \\
\hline SPTBN1 & 2,037 & $1,068 \mathrm{E}-20$ \\
\hline$S L C 16 A 2$ & 2,037 & $2,751 \mathrm{E}-26$ \\
\hline MTMR11 & 2,034 & $6,629 \mathrm{E}-19$ \\
\hline BCYRN1 & 2,034 & $1,790 \mathrm{E}-20$ \\
\hline SLIT2 & 2,032 & $9,764 \mathrm{E}-34$ \\
\hline HIST1H2BG & 2,032 & $2,926 \mathrm{E}-27$ \\
\hline$\pi C 3$ & 2,031 & $1,321 \mathrm{E}-21$ \\
\hline RHOQ & 2,030 & $1,963 \mathrm{E}-23$ \\
\hline PRSS35 & 2,030 & $1,585 \mathrm{E}-20$ \\
\hline C10orf10 & 2,028 & $7,705 \mathrm{E}-29$ \\
\hline C11orf70 & 2,027 & $2,629 \mathrm{E}-27$ \\
\hline ITGB5 & 2,026 & $1,334 \mathrm{E}-38$ \\
\hline$A B C C 5$ & 2,024 & $8,469 \mathrm{E}-27$ \\
\hline$\angle M C D 1$ & 2,024 & $9,898 \mathrm{E}-30$ \\
\hline$R A B 40 B$ & 2,024 & $4,642 \mathrm{E}-29$ \\
\hline GDI1 & 2,023 & $1,024 \mathrm{E}-36$ \\
\hline PLEKHH3 & 2,023 & $6,039 \mathrm{E}-33$ \\
\hline C4orf 34 & 2,022 & $7,482 \mathrm{E}-25$ \\
\hline RND3 & 2,020 & $2,129 \mathrm{E}-28$ \\
\hline LPIN1 & 2,016 & $2,391 \mathrm{E}-28$ \\
\hline SORLI & 2,016 & $7,002 \mathrm{E}-21$ \\
\hline HLA-F & 2,015 & $7,413 \mathrm{E}-29$ \\
\hline FBLN1 & 2,015 & $6,369 \mathrm{E}-25$ \\
\hline
\end{tabular}

\begin{tabular}{|c|c|c|}
\hline RNASE4 & 2,014 & $1,476 \mathrm{E}-22$ \\
\hline PDZK1 & 2,013 & $1,367 \mathrm{E}-21$ \\
\hline$\angle T B P 2$ & 2,011 & $1,485 \mathrm{E}-22$ \\
\hline TMEM64 & 2,011 & $1,437 \mathrm{E}-24$ \\
\hline FSTL3 & 2,011 & $2,042 \mathrm{E}-25$ \\
\hline TIMP2 & 2,008 & $9,732 \mathrm{E}-31$ \\
\hline ARHGAP28 & 2,007 & $2,700 \mathrm{E}-19$ \\
\hline$C D C 14 B$ & 2,006 & $3,790 \mathrm{E}-24$ \\
\hline GPT2 & 2,006 & $1,037 \mathrm{E}-24$ \\
\hline STGGAL1 & 2,002 & $1,123 \mathrm{E}-19$ \\
\hline UNC93B1 & 2,002 & $7,810 \mathrm{E}-28$ \\
\hline KIAA1751 & 2,002 & $2,228 \mathrm{E}-24$ \\
\hline SYT7 & 1,996 & $5,250 \mathrm{E}-33$ \\
\hline PTX3 & 1,995 & $6,591 \mathrm{E}-20$ \\
\hline ARFGAP3 & 1,992 & $1,971 \mathrm{E}-23$ \\
\hline$C 2 C D 2$ & 1,991 & $9,560 \mathrm{E}-32$ \\
\hline CAP2 & 1,990 & $2,360 \mathrm{E}-15$ \\
\hline DYSF & 1,990 & $3,571 \mathrm{E}-24$ \\
\hline SLC9A1 & 1,989 & $6,433 \mathrm{E}-28$ \\
\hline KIAA0513 & 1,989 & $9,054 \mathrm{E}-20$ \\
\hline P2RY2 & 1,989 & $1,768 \mathrm{E}-29$ \\
\hline CLIC3 & 1,988 & $1,414 \mathrm{E}-25$ \\
\hline SPAG4 & 1,987 & $1,939 \mathrm{E}-26$ \\
\hline$P P L$ & 1,984 & $3,007 \mathrm{E}-19$ \\
\hline SEMA3E & 1,984 & $2,855 \mathrm{E}-26$ \\
\hline NME3 & 1,983 & $6,188 \mathrm{E}-31$ \\
\hline HOMER3 & 1,983 & $3,474 \mathrm{E}-15$ \\
\hline$A C A A 1$ & 1,981 & $6,930 \mathrm{E}-27$ \\
\hline Clorf116 & 1,979 & $4,351 \mathrm{E}-23$ \\
\hline STC1 & 1,979 & $2,582 \mathrm{E}-25$ \\
\hline TFF2 & 1,976 & $5,457 \mathrm{E}-14$ \\
\hline HBEGF & 1,974 & $1,589 \mathrm{E}-29$ \\
\hline NELF & 1,974 & $9,971 \mathrm{E}-31$ \\
\hline
\end{tabular}


Supplementary Table S4.9: continued

\begin{tabular}{|c|c|c|}
\hline CHRNAS & 1,974 & $2,113 \mathrm{E}-27$ \\
\hline TBXAS1 & 1,973 & $9,804 \mathrm{E}-24$ \\
\hline SLC38A1O & 1,972 & $2,752 \mathrm{E}-28$ \\
\hline$T D P 1$ & 1,971 & $6,633 \mathrm{E}-20$ \\
\hline WDR54 & 1,969 & $9,599 \mathrm{E}-38$ \\
\hline PXDN & 1,968 & $1,890 \mathrm{E}-18$ \\
\hline CAMK $2 N 1$ & 1,968 & $3,960 \mathrm{E}-31$ \\
\hline ITGA3 & 1,967 & $4,276 \mathrm{E}-27$ \\
\hline LIF & 1,965 & $2,667 \mathrm{E}-23$ \\
\hline EVPL & 1,965 & $3,851 \mathrm{E}-26$ \\
\hline UBFD1 & 1,964 & $5,365 \mathrm{E}-24$ \\
\hline PTPRF & 1,963 & $4,520 \mathrm{E}-26$ \\
\hline COL16A1 & 1,961 & $5,602 \mathrm{E}-19$ \\
\hline HLA-B & 1,961 & $1,016 \mathrm{E}-22$ \\
\hline GPRC5C & 1,960 & $1,102 \mathrm{E}-32$ \\
\hline FAM26A & 1,956 & $1,215 \mathrm{E}-23$ \\
\hline OBFC2A & 1,955 & $7,894 \mathrm{E}-24$ \\
\hline BIN1 & 1,953 & $1,653 \mathrm{E}-26$ \\
\hline MCOLN1 & 1,953 & $1,000 \mathrm{E}-26$ \\
\hline C1orf106 & 1,952 & $2,253 \mathrm{E}-29$ \\
\hline B4GALNT1 & 1,951 & $3,143 \mathrm{E}-26$ \\
\hline CHSY3 & 1,948 & $2,600 \mathrm{E}-21$ \\
\hline SLC27A3 & 1,943 & $4,853 \mathrm{E}-33$ \\
\hline HIST2H $4 A$ & 1,942 & $5,133 \mathrm{E}-20$ \\
\hline DOCK11 & 1,940 & $1,940 \mathrm{E}-13$ \\
\hline HLA-H & 1,940 & $8,545 \mathrm{E}-26$ \\
\hline PPPDE1 & 1,939 & $5,070 \mathrm{E}-23$ \\
\hline HLA-E & 1,938 & $7,273 \mathrm{E}-30$ \\
\hline SLCZAB & 1,937 & $3,209 \mathrm{E}-24$ \\
\hline GADD $45 B$ & 1,937 & $3,650 E-30$ \\
\hline TTLL3 & 1,936 & $4,297 \mathrm{E}-18$ \\
\hline ILIRLI & 1,933 & $1,191 \mathrm{E}-17$ \\
\hline MARCH4 & 1,932 & $6,151 \mathrm{E}-27$ \\
\hline
\end{tabular}

\begin{tabular}{|c|c|c|}
\hline ZNF669 & 1,932 & $6,560 \mathrm{E}-27$ \\
\hline RAB24 & 1,930 & $1,706 \mathrm{E}-16$ \\
\hline UST & 1,930 & $1,849 \mathrm{E}-20$ \\
\hline ATHL1 & 1,929 & $8,866 \mathrm{E}-25$ \\
\hline CITED2 & 1,929 & $9,576 \mathrm{E}-23$ \\
\hline GGA2 & 1,922 & $1,009 \mathrm{E}-30$ \\
\hline CHPF2 & 1,922 & $8,976 \mathrm{E}-23$ \\
\hline ATP2B4 & 1,922 & $1,676 \mathrm{E}-36$ \\
\hline MFSDG & 1,920 & $7,036 \mathrm{E}-18$ \\
\hline YIPF1 & 1,918 & $1,948 \mathrm{E}-19$ \\
\hline TPM2 & 1,918 & $3,236 \mathrm{E}-24$ \\
\hline EPHXI & 1,917 & $6,812 \mathrm{E}-24$ \\
\hline CLDND1 & 1,915 & $6,047 \mathrm{E}-22$ \\
\hline$\angle I P A$ & 1,913 & $8,708 \mathrm{E}-38$ \\
\hline FAM $46 C$ & 1,912 & $5,403 E-21$ \\
\hline GAA & 1,912 & $5,147 \mathrm{E}-26$ \\
\hline MAP1B & 1,911 & $8,963 \mathrm{E}-21$ \\
\hline RHBDF1 & 1,909 & $7,498 \mathrm{E}-28$ \\
\hline ZNF14 & 1,908 & $2,484 \mathrm{E}-29$ \\
\hline EDN1 & 1,906 & $1,284 \mathrm{E}-24$ \\
\hline LAMAS & 1,906 & $1,328 \mathrm{E}-14$ \\
\hline CERK & 1,906 & $1,117 \mathrm{E}-25$ \\
\hline COL1A1 & 1,905 & $8,772 \mathrm{E}-24$ \\
\hline GAPDH & 1,905 & $9,381 \mathrm{E}-33$ \\
\hline PNMA2 & 1,904 & $2,069 \mathrm{E}-18$ \\
\hline LAMB1 & 1,903 & $8,323 E-16$ \\
\hline PTHLH & 1,903 & $3,738 \mathrm{E}-16$ \\
\hline C14orf 149 & 1,902 & $6,336 \mathrm{E}-28$ \\
\hline$D G K Q$ & 1,901 & $1,476 \mathrm{E}-27$ \\
\hline EHBP1L1 & 1,899 & $1,342 \mathrm{E}-21$ \\
\hline RCOR2 & 1,898 & $9,490 \mathrm{E}-21$ \\
\hline C17orf58 & 1,897 & $2,832 \mathrm{E}-25$ \\
\hline CTH & 1,897 & $4,923 \mathrm{E}-16$ \\
\hline
\end{tabular}

\begin{tabular}{|c|c|c|}
\hline GAPDHLG & 1,896 & $4,570 \mathrm{E}-22$ \\
\hline SH3GL3 & 1,896 & $1,850 \mathrm{E}-26$ \\
\hline SRPX2 & 1,895 & $1,601 \mathrm{E}-19$ \\
\hline COROZAA & 1,894 & $2,515 \mathrm{E}-21$ \\
\hline C16orf7 & 1,893 & $3,409 \mathrm{E}-29$ \\
\hline RHBDLL & 1,892 & $5,808 \mathrm{E}-24$ \\
\hline$C B S$ & 1,891 & $2,939 \mathrm{E}-32$ \\
\hline FAM116B & 1,891 & $1,084 \mathrm{E}-25$ \\
\hline FAM83H & 1,890 & $2,390 \mathrm{E}-30$ \\
\hline NFIB & 1,890 & $1,209 \mathrm{E}-28$ \\
\hline FTH1 & 1,890 & $3,268 \mathrm{E}-20$ \\
\hline STAG3L2 & 1,888 & $6,351 \mathrm{E}-17$ \\
\hline ADAM 8 & 1,888 & $1,294 \mathrm{E}-30$ \\
\hline PTGER1 & 1,888 & $2,137 \mathrm{E}-22$ \\
\hline SATB2 & 1,886 & $1,872 \mathrm{E}-24$ \\
\hline $\begin{array}{c}R P 5- \\
1022 P 6.2\end{array}$ & 1,886 & $3,619 \mathrm{E}-25$ \\
\hline SPRY4 & 1,886 & $1,310 \mathrm{E}-31$ \\
\hline QRFPR & 1,885 & $1,671 \mathrm{E}-23$ \\
\hline OPLAH & 1,885 & $1,386 \mathrm{E}-23$ \\
\hline ARL16 & 1,884 & $2,468 \mathrm{E}-19$ \\
\hline C20orf111 & 1,884 & $2,405 \mathrm{E}-19$ \\
\hline IL23A & 1,881 & $9,668 \mathrm{E}-20$ \\
\hline CD276 & 1,879 & $3,390 \mathrm{E}-19$ \\
\hline PAM & 1,879 & $3,163 \mathrm{E}-26$ \\
\hline C14orf78 & 1,879 & $6,356 \mathrm{E}-21$ \\
\hline PLCD4 & 1,878 & $2,130 \mathrm{E}-35$ \\
\hline PYGB & 1,877 & $2,464 \mathrm{E}-31$ \\
\hline SEMASA & 1,875 & $2,560 \mathrm{E}-26$ \\
\hline TCIRG1 & 1,874 & $3,467 \mathrm{E}-23$ \\
\hline TGM1 & 1,874 & $4,056 \mathrm{E}-15$ \\
\hline ALCAM & 1,873 & $2,289 \mathrm{E}-19$ \\
\hline ARID3A & 1,873 & 3,159E-16 \\
\hline$A B C A 7$ & 1,872 & $1,094 \mathrm{E}-25$ \\
\hline
\end{tabular}

\begin{tabular}{|c|c|c|}
\hline CORO1B & 1,872 & $6,076 \mathrm{E}-33$ \\
\hline$C S A D$ & 1,872 & $7,874 \mathrm{E}-20$ \\
\hline$P G C P$ & 1,872 & $3,110 \mathrm{E}-19$ \\
\hline STAG3L1 & 1,871 & $7,509 \mathrm{E}-19$ \\
\hline OLFML2A & 1,869 & $1,281 \mathrm{E}-24$ \\
\hline AKIRIN1 & 1,869 & $5,586 \mathrm{E}-28$ \\
\hline NR2F1 & 1,869 & $7,293 \mathrm{E}-32$ \\
\hline FL14213 & 1,869 & $7,346 \mathrm{E}-20$ \\
\hline PDLIM7 & 1,868 & $7,745 \mathrm{E}-34$ \\
\hline ELF3 & 1,867 & $1,342 \mathrm{E}-29$ \\
\hline SLC12A2 & 1,866 & $5,652 \mathrm{E}-15$ \\
\hline MGC42105 & 1,865 & $3,905 E-18$ \\
\hline RAXL1 & 1,865 & $1,156 \mathrm{E}-16$ \\
\hline ILIORB & 1,865 & $2,404 \mathrm{E}-35$ \\
\hline$D D \times 41$ & 1,862 & $3,230 \mathrm{E}-23$ \\
\hline SERINC3 & 1,859 & $4,804 \mathrm{E}-24$ \\
\hline PLXNB1 & 1,859 & $9,615 E-21$ \\
\hline GSN & 1,859 & $1,203 \mathrm{E}-18$ \\
\hline $\begin{array}{c}\text { CDKN2AIPN } \\
L\end{array}$ & 1,857 & $6,953 \mathrm{E}-30$ \\
\hline$F \sqcup 40722$ & 1,857 & $2,473 \mathrm{E}-23$ \\
\hline MAN1B1 & 1,856 & $1,639 \mathrm{E}-25$ \\
\hline MiR1978 & 1,856 & $1,381 \mathrm{E}-37$ \\
\hline$S D C 2$ & 1,856 & $1,492 \mathrm{E}-14$ \\
\hline CALHM3 & 1,855 & $3,763 \mathrm{E}-25$ \\
\hline MTE & 1,853 & $1,323 \mathrm{E}-22$ \\
\hline MYL5 & 1,853 & $3,591 \mathrm{E}-14$ \\
\hline MOCS1 & 1,852 & $8,345 \mathrm{E}-22$ \\
\hline TNK2 & 1,851 & $1,065 \mathrm{E}-20$ \\
\hline$F Z D 4$ & 1,851 & $3,077 \mathrm{E}-38$ \\
\hline$I T G B 1$ & 1,847 & $1,233 \mathrm{E}-17$ \\
\hline TFAP2C & 1,846 & $6,451 \mathrm{E}-27$ \\
\hline HBP1 & 1,845 & $1,307 \mathrm{E}-26$ \\
\hline$C X X C 5$ & 1,843 & $2,548 \mathrm{E}-14$ \\
\hline
\end{tabular}


CHAPTER 4

Supplementary Table S4.9: continued

\begin{tabular}{|c|c|c|}
\hline CROT & 1,842 & $2,486 \mathrm{E}-22$ \\
\hline DRAP1 & 1,841 & $7,498 \mathrm{E}-37$ \\
\hline NMNAT2 & 1,836 & $6,649 \mathrm{E}-19$ \\
\hline SLC44A3 & 1,836 & $2,884 \mathrm{E}-23$ \\
\hline AHNAK & 1,835 & $1,864 \mathrm{E}-13$ \\
\hline EPDR1 & 1,835 & $2,987 \mathrm{E}-21$ \\
\hline CHST15 & 1,834 & $6,063 \mathrm{E}-20$ \\
\hline FLJ37644 & 1,833 & $2,497 \mathrm{E}-20$ \\
\hline$M V D$ & 1,831 & $1,814 \mathrm{E}-20$ \\
\hline SEZ6L2 & 1,831 & $5,197 \mathrm{E}-23$ \\
\hline $\mathrm{CDH} 1$ & 1,831 & $2,104 \mathrm{E}-24$ \\
\hline GRIPAP1 & 1,830 & $5,440 \mathrm{E}-19$ \\
\hline SLC16A3 & 1,829 & $1,239 \mathrm{E}-44$ \\
\hline GLB1 & 1,828 & $1,322 \mathrm{E}-21$ \\
\hline OXTR & 1,828 & $1,026 \mathrm{E}-19$ \\
\hline KREMEN2 & 1,827 & $1,270 \mathrm{E}-14$ \\
\hline CRIM1 & 1,824 & $2,777 \mathrm{E}-16$ \\
\hline METRNL & 1,824 & $8,752 \mathrm{E}-18$ \\
\hline$B I D$ & 1,823 & $2,540 E-25$ \\
\hline CA9 & 1,820 & $7,172 E-25$ \\
\hline STOM & 1,820 & $3,591 E-21$ \\
\hline TBX2 & 1,820 & $1,099 E-29$ \\
\hline DTWD2 & 1,820 & $1,467 E-23$ \\
\hline N4BP $L 2$ & 1,819 & $5,223 E-28$ \\
\hline$C G N$ & 1,819 & $1,019 E-18$ \\
\hline TMC4 & 1,819 & $2,988 E-20$ \\
\hline PODXL. & 1,819 & $2,535 \mathrm{E}-25$ \\
\hline TIMP1 & 1,819 & $2,706 E-21$ \\
\hline CCDC151 & 1,818 & $1,388 E-24$ \\
\hline CAMK1D & 1,816 & $2,869 E-19$ \\
\hline HIST1H $2 B E$ & 1,816 & $2,857 E-14$ \\
\hline PLAUR & 1,815 & $7,774 \mathrm{E}-33$ \\
\hline HEGI & 1,815 & $8,703 E-21$ \\
\hline
\end{tabular}

\begin{tabular}{|c|c|c|}
\hline BAT5 & 1,815 & $2,719 E-26$ \\
\hline ASGR1 & 1,814 & $6,884 E-32$ \\
\hline C5orf53 & 1,814 & $4,554 E-22$ \\
\hline ST3GAL4 & 1,814 & $3,097 E-20$ \\
\hline LEP & 1,814 & $8,779 E-18$ \\
\hline KIAAO922 & 1,814 & $1,023 E-20$ \\
\hline TGIF1 & 1,813 & $4,846 \mathrm{E}-25$ \\
\hline TJP3 & 1,810 & $1,502 \mathrm{E}-17$ \\
\hline ARHGEF1O & 1,810 & $1,161 \mathrm{E}-17$ \\
\hline GRB2 & 1,809 & $1,239 \mathrm{E}-11$ \\
\hline LOXL4 & 1,809 & $1,061 \mathrm{E}-22$ \\
\hline HSPA5 & 1,808 & $2,252 \mathrm{E}-31$ \\
\hline CSF2RA & 1,808 & $1,296 \mathrm{E}-17$ \\
\hline KIAA1147 & 1,807 & $1,521 \mathrm{E}-23$ \\
\hline GALNTL4 & 1,806 & $3,794 \mathrm{E}-19$ \\
\hline sox15 & 1,806 & $9,165 \mathrm{E}-24$ \\
\hline$F I S 1$ & 1,804 & $5,896 \mathrm{E}-23$ \\
\hline SQSTM1 & 1,804 & $1,931 \mathrm{E}-31$ \\
\hline HISTIH4E & 1,803 & $1,818 \mathrm{E}-14$ \\
\hline KLHL17 & 1,803 & $5,398 \mathrm{E}-13$ \\
\hline CD164 & 1,802 & $7,200 E-17$ \\
\hline AFAPILI & 1,802 & $7,149 \mathrm{E}-18$ \\
\hline LAMP2 & 1,800 & $2,080 \mathrm{E}-16$ \\
\hline HCG2P7 & 1,800 & $3,747 \mathrm{E}-30$ \\
\hline$F L N B$ & 1,799 & $3,764 \mathrm{E}-26$ \\
\hline PTGER2 & 1,797 & $3,480 \mathrm{E}-21$ \\
\hline$A P H 1 B$ & 1,795 & $5,481 \mathrm{E}-26$ \\
\hline ANKRD37 & 1,793 & $3,239 \mathrm{E}-31$ \\
\hline$C C D C 125$ & 1,792 & $1,143 \mathrm{E}-23$ \\
\hline NPAL3 & 1,792 & $6,393 \mathrm{E}-28$ \\
\hline$F \sqcup 353390$ & 1,790 & $1,143 \mathrm{E}-27$ \\
\hline HHIPLL & 1,789 & $7,882 \mathrm{E}-18$ \\
\hline FAM39DP & 1,788 & $5,126 \mathrm{E}-18$ \\
\hline
\end{tabular}

\begin{tabular}{|c|c|c|}
\hline MGC102966 & 1,788 & $2,185 \mathrm{E}-25$ \\
\hline FAM62B & 1,787 & $2,641 \mathrm{E}-27$ \\
\hline FHLI & 1,787 & $2,134 \mathrm{E}-28$ \\
\hline RELL2 & 1,787 & $3,710 \mathrm{E}-24$ \\
\hline C3orf57 & 1,786 & $1,213 \mathrm{E}-15$ \\
\hline PHKG2 & 1,785 & $7,065 \mathrm{E}-25$ \\
\hline NEDD4 & 1,784 & $3,373 \mathrm{E}-22$ \\
\hline$P C$ & 1,784 & $1,791 \mathrm{E}-18$ \\
\hline$A C S L 3$ & 1,784 & $2,289 \mathrm{E}-33$ \\
\hline TMPRSS3 & 1,783 & $3,558 \mathrm{E}-23$ \\
\hline KRT86 & 1,783 & $4,086 \mathrm{E}-26$ \\
\hline TMEM17 & 1,783 & $6,896 \mathrm{E}-19$ \\
\hline$R A B G B$ & 1,783 & $1,554 \mathrm{E}-25$ \\
\hline NMD3 & 1,782 & $1,264 \mathrm{E}-16$ \\
\hline KLF13 & 1,782 & $5,416 \mathrm{E}-22$ \\
\hline C19orf 4 & 1,782 & $7,347 \mathrm{E}-11$ \\
\hline TNNT1 & 1,781 & $3,078 \mathrm{E}-23$ \\
\hline ZNF702P & 1,781 & $3,775 \mathrm{E}-23$ \\
\hline$\angle L 1 B$ & 1,780 & $6,233 E-31$ \\
\hline ZNF394 & 1,780 & $1,347 \mathrm{E}-24$ \\
\hline EPHBG & 1,780 & $5,771 \mathrm{E}-23$ \\
\hline$V P S 4 B$ & 1,780 & $2,359 \mathrm{E}-16$ \\
\hline ELAVL1 & 1,779 & $3,370 \mathrm{E}-24$ \\
\hline DUSP16 & 1,779 & $5,259 \mathrm{E}-25$ \\
\hline IL17RD & 1,779 & $1,801 \mathrm{E}-26$ \\
\hline SDF4 & 1,777 & $1,705 \mathrm{E}-32$ \\
\hline MAPKSIP3 & 1,776 & $2,035 \mathrm{E}-21$ \\
\hline SPINT1 & 1,776 & $1,239 \mathrm{E}-19$ \\
\hline C3orf34 & 1,775 & $1,835 \mathrm{E}-19$ \\
\hline$A C L Y$ & 1,774 & $1,316 \mathrm{E}-23$ \\
\hline TPBG & 1,774 & $5,189 \mathrm{E}-21$ \\
\hline$A R$ & 1,774 & $1,133 \mathrm{E}-22$ \\
\hline SLC35F3 & 1,774 & $1,286 \mathrm{E}-14$ \\
\hline
\end{tabular}

\begin{tabular}{|c|c|c|}
\hline TALDO1 & 1,774 & $1,447 \mathrm{E}-23$ \\
\hline PHF21A & 1,774 & $4,498 \mathrm{E}-24$ \\
\hline WNT7A & 1,773 & $1,059 \mathrm{E}-23$ \\
\hline NLRPB & 1,773 & $1,337 \mathrm{E}-29$ \\
\hline GOLGABB & 1,773 & $5,712 \mathrm{E}-20$ \\
\hline PIP5К $2 B$ & 1,772 & $3,518 \mathrm{E}-16$ \\
\hline BMSIPS & 1,772 & $2,029 \mathrm{E}-26$ \\
\hline$M V P$ & 1,770 & $2,016 \mathrm{E}-22$ \\
\hline FUCA1 & 1,769 & $1,565 \mathrm{E}-26$ \\
\hline$D M C 1$ & 1,768 & $8,912 \mathrm{E}-29$ \\
\hline $\operatorname{sox} 18$ & 1,768 & $9,587 \mathrm{E}-28$ \\
\hline SMOX & 1,766 & $4,950 \mathrm{E}-21$ \\
\hline$P P P 2 R 2 C$ & 1,766 & $4,771 \mathrm{E}-28$ \\
\hline SLC2A1O & 1,765 & $1,157 \mathrm{E}-20$ \\
\hline C10orf54 & 1,765 & $1,673 \mathrm{E}-18$ \\
\hline UAP1L1 & 1,764 & $2,585 \mathrm{E}-19$ \\
\hline MAPG & 1,764 & $2,589 \mathrm{E}-18$ \\
\hline SEL1L3 & 1,764 & $2,268 \mathrm{E}-23$ \\
\hline C140rf85 & 1,764 & $4,658 \mathrm{E}-27$ \\
\hline PLEK2 & 1,763 & $2,603 \mathrm{E}-17$ \\
\hline SERPINB 7 & 1,762 & $1,059 \mathrm{E}-30$ \\
\hline P4HAI & 1,762 & $2,140 \mathrm{E}-31$ \\
\hline$F L V C R 2$ & 1,761 & $2,657 \mathrm{E}-25$ \\
\hline RPSGKA2 & 1,761 & $6,653 \mathrm{E}-30$ \\
\hline OSBP2 & 1,760 & $1,438 \mathrm{E}-20$ \\
\hline SYT17 & 1,760 & $7,479 \mathrm{E}-23$ \\
\hline SH3D19 & 1,759 & $1,186 \mathrm{E}-16$ \\
\hline DPY19L1 & 1,759 & $6,575 \mathrm{E}-24$ \\
\hline MAN2B1 & 1,759 & $1,188 \mathrm{E}-17$ \\
\hline CATSPER 1 & 1,758 & $4,045 \mathrm{E}-22$ \\
\hline METRN & 1,757 & $9,596 \mathrm{E}-19$ \\
\hline ALDH $3 A 1$ & 1,756 & $1,343 \mathrm{E}-22$ \\
\hline IGFBP4 & 1,756 & $2,938 \mathrm{E}-29$ \\
\hline
\end{tabular}


Supplementary Table S4.9: continued

\begin{tabular}{|c|c|c|}
\hline DFNB59 & 1,756 & $1,691 \mathrm{E}-18$ \\
\hline S100A13 & 1,755 & $2,948 \mathrm{E}-29$ \\
\hline RNF144B & 1,755 & $3,772 \mathrm{E}-22$ \\
\hline ZMAT3 & 1,754 & $2,249 \mathrm{E}-23$ \\
\hline$\angle R R C 37 B 2$ & 1,754 & $2,964 \mathrm{E}-18$ \\
\hline DDX51 & 1,754 & $1,130 \mathrm{E}-26$ \\
\hline PILRB & 1,753 & $9,252 \mathrm{E}-25$ \\
\hline OSBPL1A & 1,752 & $3,927 \mathrm{E}-22$ \\
\hline ODZ4 & 1,751 & $1,723 \mathrm{E}-19$ \\
\hline LSS & 1,750 & $8,308 \mathrm{E}-29$ \\
\hline HSPC268 & 1,750 & $4,896 \mathrm{E}-23$ \\
\hline HTATIP2 & 1,749 & $4,139 \mathrm{E}-25$ \\
\hline C11orf63 & 1,748 & $4,010 \mathrm{E}-19$ \\
\hline TMEM2 & 1,747 & $1,461 \mathrm{E}-17$ \\
\hline ATF3 & 1,747 & $9,748 \mathrm{E}-21$ \\
\hline CHSY1 & 1,745 & $1,867 \mathrm{E}-23$ \\
\hline SSH3 & 1,745 & $7,682 \mathrm{E}-17$ \\
\hline PTPLAD2 & 1,744 & $8,542 \mathrm{E}-23$ \\
\hline RBMG & 1,741 & $1,020 \mathrm{E}-11$ \\
\hline FKBP1A & 1,741 & $1,390 \mathrm{E}-15$ \\
\hline CTSLI & 1,740 & $6,866 \mathrm{E}-17$ \\
\hline FERMT1 & 1,740 & $3,247 \mathrm{E}-25$ \\
\hline SAMD14 & 1,739 & $5,326 \mathrm{E}-25$ \\
\hline SLCGAG & 1,736 & $2,556 \mathrm{E}-13$ \\
\hline SH3PXD $2 A$ & 1,736 & $3,523 \mathrm{E}-24$ \\
\hline SMCR5 & 1,736 & $4,512 \mathrm{E}-21$ \\
\hline MCART1 & 1,736 & $1,400 \mathrm{E}-20$ \\
\hline$\angle R A P$ & 1,736 & $8,794 \mathrm{E}-24$ \\
\hline$H S D 17 B 7$ & 1,735 & $7,345 \mathrm{E}-22$ \\
\hline C5orf 41 & 1,735 & $5,478 \mathrm{E}-17$ \\
\hline GALIG & 1,734 & $5,635 \mathrm{E}-14$ \\
\hline ZNF486 & 1,734 & $6,964 \mathrm{E}-15$ \\
\hline PTGR2 & 1,733 & $1,324 \mathrm{E}-15$ \\
\hline
\end{tabular}

\begin{tabular}{|c|c|c|}
\hline NET1 & 1,732 & $3,708 \mathrm{E}-20$ \\
\hline$S N X 8$ & 1,731 & $1,729 \mathrm{E}-17$ \\
\hline OSBPL2 & 1,731 & $3,373 \mathrm{E}-29$ \\
\hline TMEM49 & 1,731 & $2,973 \mathrm{E}-26$ \\
\hline ANXA2P1 & 1,731 & $4,160 \mathrm{E}-16$ \\
\hline NEBL & 1,731 & $1,822 \mathrm{E}-25$ \\
\hline SERPINA3 & 1,730 & $5,618 \mathrm{E}-21$ \\
\hline AGR2 & 1,729 & $1,769 \mathrm{E}-20$ \\
\hline ZFAND2A & 1,729 & $1,008 \mathrm{E}-26$ \\
\hline TFAP2A & 1,729 & $1,169 \mathrm{E}-29$ \\
\hline HIST1H $2 B D$ & 1,728 & $4,394 \mathrm{E}-20$ \\
\hline ITFG1 & 1,728 & $2,905 \mathrm{E}-23$ \\
\hline ITPKA & 1,727 & $3,779 \mathrm{E}-32$ \\
\hline JMJD1A & 1,727 & $5,424 \mathrm{E}-16$ \\
\hline$N 4 B P 2$ & 1,727 & $1,428 \mathrm{E}-14$ \\
\hline C16orf74 & 1,725 & $3,982 \mathrm{E}-12$ \\
\hline$\angle D H D$ & 1,725 & $9,449 \mathrm{E}-16$ \\
\hline$\angle R P 1$ & 1,725 & $6,244 \mathrm{E}-16$ \\
\hline BNIP3L & 1,724 & $1,149 \mathrm{E}-17$ \\
\hline ARMC7 & 1,724 & $9,653 \mathrm{E}-28$ \\
\hline COL18A1 & 1,724 & $1,978 \mathrm{E}-19$ \\
\hline SERPINB1 & 1,724 & $5,895 \mathrm{E}-15$ \\
\hline SMADG & 1,724 & $9,687 \mathrm{E}-30$ \\
\hline$F \cup 44124$ & 1,724 & $7,309 \mathrm{E}-24$ \\
\hline $\mathrm{CSF} 2$ & 1,724 & $5,184 \mathrm{E}-20$ \\
\hline FAM119A & 1,723 & $2,628 \mathrm{E}-21$ \\
\hline UBR4 & 1,723 & $6,391 \mathrm{E}-23$ \\
\hline FYN & 1,722 & $1,591 \mathrm{E}-12$ \\
\hline TNRC6A & 1,722 & $3,985 \mathrm{E}-15$ \\
\hline RNF149 & 1,722 & $4,238 \mathrm{E}-23$ \\
\hline UPK $1 A$ & 1,721 & $3,661 \mathrm{E}-20$ \\
\hline LDHA & 1,721 & $4,944 \mathrm{E}-19$ \\
\hline SIPA1L2 & 1,720 & $1,152 \mathrm{E}-24$ \\
\hline
\end{tabular}

\begin{tabular}{|c|c|c|}
\hline C20orf 177 & 1,719 & $6,202 \mathrm{E}-18$ \\
\hline DEM1 & 1,719 & $3,035 \mathrm{E}-24$ \\
\hline PPA2 & 1,718 & $8,452 \mathrm{E}-27$ \\
\hline PNCK & 1,717 & $9,116 \mathrm{E}-21$ \\
\hline ERBB 2 & 1,717 & $2,916 \mathrm{E}-23$ \\
\hline BLVRB & 1,715 & $2,127 \mathrm{E}-30$ \\
\hline PADI3 & 1,714 & $6,010 \mathrm{E}-22$ \\
\hline AMHR2 & 1,714 & $3,088 \mathrm{E}-19$ \\
\hline GNG5 & 1,713 & $9,051 \mathrm{E}-23$ \\
\hline AXIN2 & 1,713 & $2,892 \mathrm{E}-23$ \\
\hline CTPS2 & 1,712 & $7,029 \mathrm{E}-29$ \\
\hline RUNDC3A & 1,712 & $8,628 \mathrm{E}-23$ \\
\hline ESM1 & 1,711 & $3,548 \mathrm{E}-13$ \\
\hline RHOU & 1,711 & $2,152 \mathrm{E}-16$ \\
\hline MBD4 & 1,711 & $1,925 \mathrm{E}-19$ \\
\hline HMHAI & 1,711 & $3,667 \mathrm{E}-19$ \\
\hline FAM173A & 1,711 & $5,238 \mathrm{E}-26$ \\
\hline C2orf69 & 1,711 & $5,734 \mathrm{E}-21$ \\
\hline C14orf 173 & 1,710 & $2,757 \mathrm{E}-30$ \\
\hline UCA1 & 1,710 & $5,514 \mathrm{E}-20$ \\
\hline ZC $3 \mathrm{H} 12 \mathrm{~A}$ & 1,710 & $7,391 \mathrm{E}-13$ \\
\hline PHTF1 & 1,709 & $1,235 \mathrm{E}-16$ \\
\hline YRDC & 1,708 & $2,324 \mathrm{E}-22$ \\
\hline HSEST2 & 1,708 & $1,260 \mathrm{E}-20$ \\
\hline KIAA0363 & 1,708 & $6,056 \mathrm{E}-18$ \\
\hline C15orf52 & 1,708 & $2,574 \mathrm{E}-20$ \\
\hline SFTAIP & 1,708 & $2,763 \mathrm{E}-16$ \\
\hline ERBB3 & 1,707 & $3,446 \mathrm{E}-19$ \\
\hline$S L C 4 A 3$ & 1,707 & $1,121 \mathrm{E}-19$ \\
\hline CYCSL1 & 1,707 & $6,203 \mathrm{E}-15$ \\
\hline$A B C C 4$ & 1,706 & $4,345 \mathrm{E}-23$ \\
\hline HEATR1 & 1,706 & $4,312 \mathrm{E}-22$ \\
\hline$F \mid B C D 1$ & 1,705 & $4,507 \mathrm{E}-15$ \\
\hline
\end{tabular}

\begin{tabular}{|c|c|c|}
\hline POFUT1 & 1,705 & $2,899 \mathrm{E}-25$ \\
\hline THBS3 & 1,705 & $2,486 \mathrm{E}-21$ \\
\hline NAGK & 1,704 & $7,499 \mathrm{E}-33$ \\
\hline PON2 & 1,704 & $6,479 \mathrm{E}-24$ \\
\hline PKD2 & 1,704 & $9,538 \mathrm{E}-24$ \\
\hline ETS2 & 1,704 & $3,498 \mathrm{E}-23$ \\
\hline TMEM106A & 1,704 & $7,812 \mathrm{E}-22$ \\
\hline SGSM2 & 1,703 & $1,613 \mathrm{E}-17$ \\
\hline ZSWIMG & 1,702 & $3,073 \mathrm{E}-15$ \\
\hline PRODH & 1,702 & $1,980 \mathrm{E}-15$ \\
\hline$\angle M O D 3$ & 1,702 & $1,070 \mathrm{E}-18$ \\
\hline STUB1 & 1,700 & $1,618 \mathrm{E}-15$ \\
\hline $\operatorname{CDg}$ & 1,700 & $1,014 \mathrm{E}-20$ \\
\hline WDR22 & 1,700 & $1,931 \mathrm{E}-18$ \\
\hline FAM63A & 1,700 & $3,191 \mathrm{E}-21$ \\
\hline SLC2OA1 & 1,698 & $4,462 \mathrm{E}-29$ \\
\hline HLA-A & 1,698 & $1,009 \mathrm{E}-19$ \\
\hline VGF & 1,697 & $3,675 \mathrm{E}-18$ \\
\hline SLC2A12 & 1,697 & $2,509 \mathrm{E}-16$ \\
\hline GALNT1 & 1,697 & $3,573 \mathrm{E}-16$ \\
\hline TUBBA & 1,697 & $8,311 \mathrm{E}-21$ \\
\hline ZNF738 & 1,697 & $2,351 \mathrm{E}-18$ \\
\hline ANTXR2 & 1,696 & $3,012 \mathrm{E}-24$ \\
\hline СMTM8 & 1,696 & $2,706 \mathrm{E}-21$ \\
\hline GCNT2 & 1,696 & $1,659 \mathrm{E}-22$ \\
\hline FXYD3 & 1,696 & $4,464 \mathrm{E}-24$ \\
\hline PNPT1 & 1,696 & $7,109 \mathrm{E}-24$ \\
\hline STARD13 & 1,695 & $4,299 \mathrm{E}-13$ \\
\hline C1orf115 & 1,695 & $2,803 \mathrm{E}-14$ \\
\hline CDKSRAP3 & 1,695 & $3,938 \mathrm{E}-26$ \\
\hline DPPG & 1,695 & $3,333 \mathrm{E}-16$ \\
\hline CAMSAPILI & 1,694 & $2,061 \mathrm{E}-19$ \\
\hline UCKL1 & 1,694 & $6,871 \mathrm{E}-20$ \\
\hline
\end{tabular}


CHAPTER 4

Supplementary Table S4.9: continued

\begin{tabular}{|c|c|c|}
\hline ELOVL4 & 1,693 & $2,349 \mathrm{E}-13$ \\
\hline RASSF7 & 1,693 & $1,553 \mathrm{E}-21$ \\
\hline SEPT5 & 1,692 & $2,022 \mathrm{E}-20$ \\
\hline CCDC146 & 1,692 & $8,296 \mathrm{E}-16$ \\
\hline BLZF1 & 1,691 & $1,483 \mathrm{E}-15$ \\
\hline$J A G 1$ & 1,691 & $1,456 \mathrm{E}-15$ \\
\hline SECISBP 2 & 1,691 & $1,531 \mathrm{E}-23$ \\
\hline ADARB1 & 1,690 & $5,996 \mathrm{E}-25$ \\
\hline C14orf 153 & 1,689 & $4,357 \mathrm{E}-18$ \\
\hline$A D C K 5$ & 1,689 & $1,189 \mathrm{E}-26$ \\
\hline UBE2L6 & 1,688 & $8,489 \mathrm{E}-30$ \\
\hline ILI3RA1 & 1,688 & $3,064 \mathrm{E}-30$ \\
\hline AGAPB & 1,688 & $1,675 \mathrm{E}-18$ \\
\hline PAOX & 1,687 & $6,047 \mathrm{E}-22$ \\
\hline$E I F 4 G 3$ & 1,687 & $2,420 \mathrm{E}-14$ \\
\hline CAPN5 & 1,687 & $1,056 \mathrm{E}-21$ \\
\hline$T N N / 3$ & 1,687 & $2,673 \mathrm{E}-23$ \\
\hline GOLM1 & 1,687 & $2,582 \mathrm{E}-14$ \\
\hline SLC26A11 & 1,685 & $1,190 \mathrm{E}-22$ \\
\hline ATP1B1 & 1,684 & $6,865 \mathrm{E}-17$ \\
\hline ZNF483 & 1,683 & $6,550 \mathrm{E}-15$ \\
\hline KISSIR & 1,683 & $1,286 \mathrm{E}-18$ \\
\hline $\cos 2$ & 1,683 & $7,069 \mathrm{E}-29$ \\
\hline MAGED2 & 1,682 & $7,978 \mathrm{E}-18$ \\
\hline NRBP 2 & 1,680 & $3,226 \mathrm{E}-23$ \\
\hline GRN & 1,680 & $9,216 \mathrm{E}-23$ \\
\hline$X R C C 2$ & 1,680 & $3,324 \mathrm{E}-14$ \\
\hline ATPGVOB & 1,680 & $5,388 \mathrm{E}-12$ \\
\hline HES2 & 1,678 & $6,132 E-21$ \\
\hline HYOU1 & 1,676 & $3,034 \mathrm{E}-17$ \\
\hline MYADM & 1,676 & $1,864 \mathrm{E}-17$ \\
\hline RRBP1 & 1,676 & $3,245 \mathrm{E}-16$ \\
\hline DUSP19 & 1,673 & $1,544 \mathrm{E}-24$ \\
\hline$C C N G 2$ & 1,672 & $7,359 \mathrm{E}-17$ \\
\hline
\end{tabular}

\begin{tabular}{|c|c|c|}
\hline ZNF462 & 1,672 & $1,705 \mathrm{E}-20$ \\
\hline PITPNM 1 & 1,671 & $1,370 \mathrm{E}-23$ \\
\hline NXF1 & 1,671 & $7,410 \mathrm{E}-23$ \\
\hline BUGALNT4 & 1,671 & $1,926 \mathrm{E}-16$ \\
\hline MT1G & 1,671 & $4,214 \mathrm{E}-13$ \\
\hline PAPSS1 & 1,670 & $2,179 \mathrm{E}-15$ \\
\hline CEBPB & 1,670 & $2,301 \mathrm{E}-31$ \\
\hline CADM4 & 1,670 & $1,480 \mathrm{E}-23$ \\
\hline CKMTIA & 1,670 & $5,364 E-21$ \\
\hline$M C C C 1$ & 1,670 & $5,409 \mathrm{E}-19$ \\
\hline WDR68 & 1,670 & $6,509 \mathrm{E}-22$ \\
\hline KLHL3 & 1,669 & $5,298 \mathrm{E}-20$ \\
\hline YPELLS & 1,668 & $3,055 \mathrm{E}-19$ \\
\hline RGS 10 & 1,668 & $2,477 \mathrm{E}-23$ \\
\hline PLDN & 1,667 & $1,325 \mathrm{E}-18$ \\
\hline FAM $20 C$ & 1,667 & $2,350 E-14$ \\
\hline ERRF/1 & 1,666 & $6,873 \mathrm{E}-22$ \\
\hline DAPP1 & 1,663 & $3,067 \mathrm{E}-20$ \\
\hline LMTK3 & 1,663 & $2,148 \mathrm{E}-24$ \\
\hline FCAR & 1,662 & $9,019 \mathrm{E}-22$ \\
\hline SCNN1G & 1,661 & $1,285 \mathrm{E}-11$ \\
\hline C19orf10 & 1,661 & $3,803 \mathrm{E}-13$ \\
\hline CD9gL2 & 1,660 & $3,600 \mathrm{E}-26$ \\
\hline PNPLA2 & 1,660 & $3,364 \mathrm{E}-23$ \\
\hline DUXAP3 & 1,659 & $2,248 \mathrm{E}-18$ \\
\hline ARHGAP23 & 1,658 & $3,282 \mathrm{E}-18$ \\
\hline MPPE 1 & 1,658 & $2,231 \mathrm{E}-11$ \\
\hline KCNMB2 & 1,657 & $3,420 \mathrm{E}-16$ \\
\hline SYTLL & 1,657 & $2,295 \mathrm{E}-17$ \\
\hline $1 G D C C 4$ & 1,657 & $1,130 \mathrm{E}-20$ \\
\hline MFSD11 & 1,655 & $2,313 \mathrm{E}-19$ \\
\hline ZNFG9 & 1,655 & $4,357 \mathrm{E}-21$ \\
\hline PRKAA1 & 1,655 & $8,182 \mathrm{E}-18$ \\
\hline PTGFRN & 1,654 & $1,027 \mathrm{E}-16$ \\
\hline
\end{tabular}

\begin{tabular}{|c|c|c|}
\hline HLA-C & 1,654 & $1,347 \mathrm{E}-13$ \\
\hline EPBA1L1 & 1,653 & $8,094 \mathrm{E}-15$ \\
\hline$F J X 1$ & 1,653 & $1,622 \mathrm{E}-21$ \\
\hline RAB26 & 1,653 & $3,274 \mathrm{E}-24$ \\
\hline PURB & 1,653 & $2,701 \mathrm{E}-21$ \\
\hline HLA-DRA & 1,652 & $7,135 \mathrm{E}-21$ \\
\hline$S L C 1 A 3$ & 1,652 & $4,162 \mathrm{E}-22$ \\
\hline AACS & 1,652 & $8,911 \mathrm{E}-17$ \\
\hline CRCP & 1,652 & $5,523 \mathrm{E}-09$ \\
\hline CLK2 & 1,651 & $3,679 \mathrm{E}-19$ \\
\hline ADAM17 & 1,651 & $1,764 \mathrm{E}-21$ \\
\hline PIP4K2A & 1,651 & $3,945 \mathrm{E}-18$ \\
\hline ANXA11 & 1,651 & $5,189 \mathrm{E}-16$ \\
\hline KAT2B & 1,651 & $4,935 \mathrm{E}-15$ \\
\hline ICAI & 1,650 & $2,558 \mathrm{E}-11$ \\
\hline$F \sqcup 20489$ & 1,650 & $5,201 E-22$ \\
\hline$S H 3 G L 2$ & 1,649 & $6,725 \mathrm{E}-18$ \\
\hline ENDOD 1 & 1,648 & $1,061 \mathrm{E}-13$ \\
\hline SLC2AG & 1,647 & $1,119 \mathrm{E}-28$ \\
\hline PLLP & 1,647 & $9,889 \mathrm{E}-15$ \\
\hline VIPR1 & 1,646 & $2,848 \mathrm{E}-16$ \\
\hline PDGFA & 1,646 & $8,547 \mathrm{E}-18$ \\
\hline PPFIA4 & 1,645 & $9,935 \mathrm{E}-16$ \\
\hline RNU1G2 & 1,644 & $7,417 \mathrm{E}-28$ \\
\hline C14orf37 & 1,644 & $3,124 \mathrm{E}-16$ \\
\hline INF2 & 1,644 & $2,051 \mathrm{E}-23$ \\
\hline NES & 1,644 & $1,585 \mathrm{E}-17$ \\
\hline TUSC3 & 1,643 & $1,683 \mathrm{E}-20$ \\
\hline CYP26B1 & 1,643 & $6,666 \mathrm{E}-13$ \\
\hline P2RYS & 1,642 & $1,060 \mathrm{E}-17$ \\
\hline C1orf24 & 1,642 & $4,862 \mathrm{E}-17$ \\
\hline CDKL3 & 1,642 & $6,921 \mathrm{E}-22$ \\
\hline SULTIAI & 1,641 & $9,479 \mathrm{E}-19$ \\
\hline$T B C B$ & 1,641 & $5,514 \mathrm{E}-18$ \\
\hline
\end{tabular}

\begin{tabular}{|c|c|c|}
\hline ARTN & 1,641 & $6,410 \mathrm{E}-19$ \\
\hline LAMA4 & 1,641 & $3,300 \mathrm{E}-17$ \\
\hline CEACAM 6 & 1,640 & $5,663 \mathrm{E}-14$ \\
\hline KIAAO913 & 1,640 & $9,921 \mathrm{E}-24$ \\
\hline RNF215 & 1,640 & $4,736 \mathrm{E}-15$ \\
\hline MIB2 & 1,640 & $1,929 \mathrm{E}-19$ \\
\hline RALGDS & 1,639 & $2,058 \mathrm{E}-25$ \\
\hline FKBP14 & 1,639 & $2,369 \mathrm{E}-19$ \\
\hline ZNF185 & 1,639 & $5,803 \mathrm{E}-21$ \\
\hline KCNKG & 1,639 & $9,465 \mathrm{E}-20$ \\
\hline ITGAV & 1,639 & $2,542 \mathrm{E}-18$ \\
\hline$B C O R$ & 1,639 & $2,256 \mathrm{E}-15$ \\
\hline OCRL & 1,638 & $1,327 \mathrm{E}-27$ \\
\hline DYNC1H1 & 1,638 & $6,126 \mathrm{E}-22$ \\
\hline$S G K 1$ & 1,638 & $3,248 \mathrm{E}-18$ \\
\hline CKMT1B & 1,638 & $3,057 \mathrm{E}-20$ \\
\hline$F L 25363$ & 1,638 & $5,831 \mathrm{E}-15$ \\
\hline VPS28 & 1,636 & $2,538 \mathrm{E}-28$ \\
\hline SLC15A4 & 1,636 & $1,076 \mathrm{E}-16$ \\
\hline SULF2 & 1,636 & $3,096 \mathrm{E}-17$ \\
\hline MAP4K2 & 1,636 & $2,603 \mathrm{E}-26$ \\
\hline SEC14L1 & 1,636 & $2,409 \mathrm{E}-18$ \\
\hline TMEM163 & 1,635 & $1,193 \mathrm{E}-16$ \\
\hline PPM1H & 1,634 & $9,857 \mathrm{E}-18$ \\
\hline ATP6AP1 & 1,634 & $1,869 \mathrm{E}-27$ \\
\hline PCYT2 & 1,634 & $4,545 \mathrm{E}-19$ \\
\hline SLC38A2 & 1,634 & $1,071 \mathrm{E}-19$ \\
\hline C5orf13 & 1,633 & $3,164 \mathrm{E}-15$ \\
\hline TRIM13 & 1,633 & $5,877 \mathrm{E}-19$ \\
\hline PTPN13 & 1,632 & $4,854 \mathrm{E}-18$ \\
\hline MCM8 & 1,632 & $9,935 \mathrm{E}-19$ \\
\hline SRGAP3 & 1,632 & $1,413 \mathrm{E}-18$ \\
\hline SLC2AI & 1,632 & $5,506 \mathrm{E}-16$ \\
\hline$S E C 61 A 2$ & 1,632 & $1,058 \mathrm{E}-23$ \\
\hline
\end{tabular}


Supplementary Table S4.9: continued

\begin{tabular}{|c|c|c|}
\hline SLC25A29 & 1,631 & $1,171 \mathrm{E}-14$ \\
\hline ZNF652 & 1,631 & $4,487 \mathrm{E}-20$ \\
\hline STXBP2 & 1,631 & $1,925 \mathrm{E}-18$ \\
\hline $\begin{array}{c}\text { STEGALNAC } \\
2\end{array}$ & 1,631 & $4,545 \mathrm{E}-13$ \\
\hline GRAMD1B & 1,629 & $2,528 \mathrm{E}-21$ \\
\hline NIN & 1,628 & $1,165 \mathrm{E}-21$ \\
\hline PRO1853 & 1,628 & $5,287 \mathrm{E}-12$ \\
\hline$C D 24$ & 1,628 & $1,516 \mathrm{E}-24$ \\
\hline CREB1 & 1,628 & $9,789 \mathrm{E}-20$ \\
\hline HNRNPU & 1,627 & $7,692 \mathrm{E}-12$ \\
\hline$\angle C O R$ & 1,627 & $1,277 \mathrm{E}-23$ \\
\hline TMEM156 & 1,627 & $7,265 \mathrm{E}-27$ \\
\hline FL46309 & 1,626 & $1,096 \mathrm{E}-17$ \\
\hline NFE2L1 & 1,626 & $2,999 \mathrm{E}-23$ \\
\hline CA12 & 1,625 & $8,889 \mathrm{E}-19$ \\
\hline TSPANS & 1,624 & $2,609 \mathrm{E}-18$ \\
\hline DACT3 & 1,624 & $1,510 \mathrm{E}-20$ \\
\hline FLЗ38717 & 1,624 & $4,113 \mathrm{E}-18$ \\
\hline DMKN & 1,624 & $1,477 \mathrm{E}-21$ \\
\hline RGS2 & 1,623 & $2,243 \mathrm{E}-16$ \\
\hline SPTLC1 & 1,623 & $2,592 \mathrm{E}-19$ \\
\hline GPR56 & 1,623 & $3,761 \mathrm{E}-22$ \\
\hline LCN2 & 1,621 & $1,461 \mathrm{E}-15$ \\
\hline C16orf13 & 1,621 & $2,384 \mathrm{E}-32$ \\
\hline MYH9 & 1,621 & $7,819 \mathrm{E}-20$ \\
\hline SIGIRR & 1,620 & $7,590 \mathrm{E}-19$ \\
\hline NTSC2 & 1,619 & $1,809 \mathrm{E}-23$ \\
\hline HLTF & 1,618 & $2,265 \mathrm{E}-12$ \\
\hline ABTB1 & 1,617 & $3,938 \mathrm{E}-18$ \\
\hline FAM193B & 1,617 & $6,729 \mathrm{E}-20$ \\
\hline TRIM3 & 1,615 & $6,447 \mathrm{E}-18$ \\
\hline ARFGEF1 & 1,614 & $1,040 \mathrm{E}-16$ \\
\hline CLDN1 & 1,614 & $2,164 \mathrm{E}-12$ \\
\hline
\end{tabular}

\begin{tabular}{|c|c|c|}
\hline CLCN6 & 1,614 & $1,963 \mathrm{E}-14$ \\
\hline HLCS & 1,614 & $3,840 \mathrm{E}-16$ \\
\hline UBE2O & 1,612 & $7,459 \mathrm{E}-16$ \\
\hline BCAP31 & 1,612 & $3,974 \mathrm{E}-20$ \\
\hline PMP22 & 1,612 & $1,910 \mathrm{E}-21$ \\
\hline ZNF160 & 1,612 & $1,778 \mathrm{E}-17$ \\
\hline PRKAB2 & 1,611 & $7,954 \mathrm{E}-14$ \\
\hline C19orf12 & 1,611 & $6,968 \mathrm{E}-18$ \\
\hline PFKP & 1,610 & $2,307 E-30$ \\
\hline RIMKLA & 1,610 & $2,223 \mathrm{E}-21$ \\
\hline KLHDCBB & 1,610 & $1,734 \mathrm{E}-23$ \\
\hline DGATI & 1,609 & $7,577 \mathrm{E}-21$ \\
\hline PRR4 & 1,609 & $6,389 \mathrm{E}-20$ \\
\hline HOMER2 & 1,609 & $5,335 E-17$ \\
\hline$A P P$ & 1,609 & $6,847 \mathrm{E}-20$ \\
\hline ANKRD13D & 1,608 & $1,930 \mathrm{E}-14$ \\
\hline RHPN2 & 1,608 & $2,727 \mathrm{E}-11$ \\
\hline$O D C 1$ & 1,607 & $5,087 \mathrm{E}-20$ \\
\hline ZNF786 & 1,607 & $4,319 \mathrm{E}-18$ \\
\hline FAMG9B & 1,606 & $2,074 \mathrm{E}-26$ \\
\hline FTHL12 & 1,606 & $8,755 \mathrm{E}-26$ \\
\hline TNFRSF1A & 1,606 & $4,847 \mathrm{E}-21$ \\
\hline$A C P 2$ & 1,606 & $5,471 \mathrm{E}-13$ \\
\hline DSTYK & 1,605 & $1,525 \mathrm{E}-16$ \\
\hline BMP1 & 1,605 & $3,680 \mathrm{E}-12$ \\
\hline MYST4 & 1,605 & $1,330 \mathrm{E}-16$ \\
\hline RASSF5 & 1,605 & $1,445 \mathrm{E}-25$ \\
\hline$L R / G 1$ & 1,603 & $4,950 \mathrm{E}-15$ \\
\hline NUDT16L1 & 1,602 & $2,105 E-15$ \\
\hline EFCABAAA & 1,602 & $1,188 \mathrm{E}-11$ \\
\hline SHROOM4 & 1,602 & $1,176 \mathrm{E}-22$ \\
\hline NICN1 & 1,601 & $6,179 \mathrm{E}-20$ \\
\hline ABHD12 & 1,601 & $1,032 \mathrm{E}-20$ \\
\hline
\end{tabular}

\begin{tabular}{|c|c|c|}
\hline ZNF223 & 1,601 & $5,360 \mathrm{E}-22$ \\
\hline GMPR & 1,601 & $7,081 \mathrm{E}-11$ \\
\hline$A D / 1$ & 1,599 & $2,679 \mathrm{E}-16$ \\
\hline$T B C 1 D 9 B$ & 1,599 & $6,787 \mathrm{E}-19$ \\
\hline TLE2 & 1,599 & $7,944 \mathrm{E}-25$ \\
\hline PTBP2 & 1,599 & $3,418 \mathrm{E}-17$ \\
\hline QSOXX & 1,598 & $3,013 \mathrm{E}-16$ \\
\hline PPP1R10 & 1,598 & $5,121 \mathrm{E}-11$ \\
\hline PSMD1 & 1,598 & $1,471 \mathrm{E}-22$ \\
\hline CAMK $2 B$ & 1,597 & $2,212 \mathrm{E}-17$ \\
\hline GPX4 & 1,597 & $7,872 \mathrm{E}-24$ \\
\hline ROBLD3 & 1,597 & $1,971 \mathrm{E}-20$ \\
\hline RRAS & 1,596 & $2,807 \mathrm{E}-20$ \\
\hline CALM1 & 1,596 & $8,561 \mathrm{E}-26$ \\
\hline EDEM1 & 1,596 & $1,826 \mathrm{E}-17$ \\
\hline ZNF91 & 1,595 & $6,040 \mathrm{E}-10$ \\
\hline FOXO3 & 1,595 & $3,910 \mathrm{E}-24$ \\
\hline PRKCD & 1,595 & $3,579 \mathrm{E}-23$ \\
\hline HRK & 1,594 & $1,586 \mathrm{E}-18$ \\
\hline C6orf 170 & 1,593 & $3,018 \mathrm{E}-17$ \\
\hline$R A B 3 B$ & 1,593 & $2,746 \mathrm{E}-18$ \\
\hline$A D C Y G$ & 1,593 & $2,700 \mathrm{E}-10$ \\
\hline ATPSA & 1,592 & $2,808 \mathrm{E}-23$ \\
\hline MBOAT2 & 1,592 & $5,246 E-14$ \\
\hline COTL1 & 1,592 & $1,146 \mathrm{E}-05$ \\
\hline SFXNS & 1,592 & $5,564 \mathrm{E}-20$ \\
\hline HINT3 & 1,591 & $3,453 \mathrm{E}-09$ \\
\hline RAPGEFLI & 1,590 & $5,137 \mathrm{E}-17$ \\
\hline PYCRL & 1,590 & $1,178 \mathrm{E}-14$ \\
\hline CACNBB & 1,590 & $1,270 \mathrm{E}-19$ \\
\hline DDRI & 1,590 & $2,935 \mathrm{E}-21$ \\
\hline MAPT & 1,590 & $1,520 \mathrm{E}-16$ \\
\hline LRRFIP1 & 1,589 & $6,989 \mathrm{E}-11$ \\
\hline
\end{tabular}

\begin{tabular}{|c|c|c|}
\hline C3orf58 & 1,589 & $2,014 \mathrm{E}-20$ \\
\hline FBXO15 & 1,589 & $1,202 \mathrm{E}-17$ \\
\hline ZNF577 & 1,588 & $4,527 \mathrm{E}-20$ \\
\hline SSU72 & 1,588 & $2,342 \mathrm{E}-18$ \\
\hline MOXD1 & 1,588 & $9,560 \mathrm{E}-18$ \\
\hline COLGA3 & 1,588 & $1,189 \mathrm{E}-17$ \\
\hline WFDC3 & 1,587 & $1,986 \mathrm{E}-14$ \\
\hline ERGIC3 & 1,587 & $4,111 \mathrm{E}-25$ \\
\hline d/341010.1 & 1,586 & $2,997 \mathrm{E}-11$ \\
\hline STAG3L3 & 1,586 & $1,684 \mathrm{E}-19$ \\
\hline HMGA2 & 1,586 & $1,960 \mathrm{E}-17$ \\
\hline ZNF365 & 1,586 & $8,567 \mathrm{E}-29$ \\
\hline BIRC3 & 1,586 & $1,960 \mathrm{E}-22$ \\
\hline STXE & 1,585 & $8,250 \mathrm{E}-15$ \\
\hline MED24 & 1,585 & $1,483 \mathrm{E}-23$ \\
\hline USMGS & 1,585 & $7,996 \mathrm{E}-21$ \\
\hline ACADB & 1,585 & $1,947 \mathrm{E}-09$ \\
\hline KCNK1 & 1,583 & $2,640 \mathrm{E}-14$ \\
\hline ARL $4 A$ & 1,583 & $9,295 \mathrm{E}-22$ \\
\hline RACB & 1,583 & $5,106 E-19$ \\
\hline HCST & 1,583 & $7,938 \mathrm{E}-14$ \\
\hline C1orf51 & 1,583 & $3,049 \mathrm{E}-17$ \\
\hline TGM2 & 1,583 & $5,039 \mathrm{E}-15$ \\
\hline ANOG & 1,583 & $8,941 \mathrm{E}-12$ \\
\hline CPA4 & 1,582 & $2,683 \mathrm{E}-15$ \\
\hline TMEM63B & 1,582 & $3,112 \mathrm{E}-17$ \\
\hline HK1 & 1,582 & $1,082 \mathrm{E}-19$ \\
\hline CEP27 & 1,582 & $2,744 \mathrm{E}-16$ \\
\hline CCDC136 & 1,582 & $5,145 \mathrm{E}-16$ \\
\hline MAGT1 & 1,582 & $2,338 \mathrm{E}-17$ \\
\hline$A S B 1$ & 1,581 & $1,167 \mathrm{E}-17$ \\
\hline MAPBPIP & 1,581 & $3,426 \mathrm{E}-28$ \\
\hline$B C K D H A$ & 1,581 & $4,430 \mathrm{E}-23$ \\
\hline
\end{tabular}


CHAPTER 4

Supplementary Table S4.9: continued

\begin{tabular}{|c|c|c|}
\hline IFFO2 & 1,580 & $2,053 \mathrm{E}-14$ \\
\hline TNRC6B & 1,580 & $6,776 \mathrm{E}-15$ \\
\hline ZMYM3 & 1,580 & $5,488 \mathrm{E}-16$ \\
\hline HSD11B1L & 1,580 & $1,882 \mathrm{E}-14$ \\
\hline SAT1 & 1,580 & $3,523 \mathrm{E}-16$ \\
\hline CXorf38 & 1,580 & $2,815 \mathrm{E}-15$ \\
\hline CRY2 & 1,580 & $1,208 \mathrm{E}-17$ \\
\hline STK38 & 1,579 & $1,564 \mathrm{E}-22$ \\
\hline FAM120B & 1,579 & $4,129 \mathrm{E}-24$ \\
\hline PPP2RSB & 1,578 & $2,760 \mathrm{E}-21$ \\
\hline GUCA1B & 1,578 & $2,941 \mathrm{E}-23$ \\
\hline MGLL & 1,578 & $3,587 \mathrm{E}-18$ \\
\hline$E P O R$ & 1,577 & $6,959 \mathrm{E}-16$ \\
\hline C19orf6 & 1,577 & $1,855 \mathrm{E}-11$ \\
\hline TANC1 & 1,577 & $1,580 \mathrm{E}-15$ \\
\hline ULBP1 & 1,577 & $6,639 \mathrm{E}-18$ \\
\hline SCYLI & 1,576 & $1,142 \mathrm{E}-25$ \\
\hline FZD2 & 1,576 & $9,209 \mathrm{E}-30$ \\
\hline GCLM & 1,575 & $2,042 \mathrm{E}-15$ \\
\hline C2orf82 & 1,575 & $1,431 \mathrm{E}-15$ \\
\hline NEDD4L & 1,575 & $1,604 \mathrm{E}-20$ \\
\hline CAPS & 1,574 & $1,417 \mathrm{E}-20$ \\
\hline PAGI & 1,574 & $1,662 \mathrm{E}-15$ \\
\hline$B C L 6$ & 1,574 & $1,070 \mathrm{E}-19$ \\
\hline SLC9AG & 1,574 & $2,063 \mathrm{E}-18$ \\
\hline C7orf68 & 1,573 & $2,120 \mathrm{E}-14$ \\
\hline C10orf33 & 1,572 & $1,244 \mathrm{E}-18$ \\
\hline TSPYL2 & 1,572 & $1,129 \mathrm{E}-10$ \\
\hline BMI1 & 1,572 & $2,397 \mathrm{E}-17$ \\
\hline SLC22A4 & 1,571 & $1,220 \mathrm{E}-14$ \\
\hline RPSGKA1 & 1,570 & $2,631 \mathrm{E}-17$ \\
\hline POLD4 & 1,570 & $7,977 \mathrm{E}-16$ \\
\hline FAM4OB & 1,570 & $3,490 \mathrm{E}-14$ \\
\hline
\end{tabular}

\begin{tabular}{|c|c|c|}
\hline ARRDCZ & 1,570 & $8,122 \mathrm{E}-24$ \\
\hline PLXNB3 & 1,569 & $6,299 \mathrm{E}-15$ \\
\hline PCOLCE2 & 1,568 & $6,669 \mathrm{E}-17$ \\
\hline KIAA1875 & 1,568 & $4,284 \mathrm{E}-12$ \\
\hline$E \mid F 5 A 2$ & 1,568 & $1,693 \mathrm{E}-22$ \\
\hline PHKA2 & 1,568 & $1,550 \mathrm{E}-19$ \\
\hline USP 49 & 1,567 & $6,282 \mathrm{E}-17$ \\
\hline GJB2 & 1,567 & $2,993 \mathrm{E}-18$ \\
\hline$R A C 2$ & 1,567 & $5,258 \mathrm{E}-22$ \\
\hline$U G D H$ & 1,567 & $2,833 \mathrm{E}-17$ \\
\hline SDHALP1 & 1,567 & $1,005 E-14$ \\
\hline GRINA & 1,566 & $1,870 \mathrm{E}-19$ \\
\hline HSPAIA & 1,565 & $3,485 \mathrm{E}-16$ \\
\hline SH3TC1 & 1,565 & $1,744 \mathrm{E}-16$ \\
\hline$V C P$ & 1,564 & $1,057 \mathrm{E}-25$ \\
\hline TOB1 & 1,564 & $1,484 \mathrm{E}-14$ \\
\hline FCGRT & 1,564 & $5,963 \mathrm{E}-21$ \\
\hline$A N X A 2 P 3$ & 1,564 & $1,551 \mathrm{E}-10$ \\
\hline SNTB1 & 1,563 & $2,810 \mathrm{E}-19$ \\
\hline LIMS2 & 1,563 & $1,075 E-24$ \\
\hline ULK1 & 1,563 & $2,623 \mathrm{E}-18$ \\
\hline$C C N D B P 1$ & 1,563 & $5,400 \mathrm{E}-23$ \\
\hline PROS1 & 1,563 & $1,001 \mathrm{E}-15$ \\
\hline VGLL1 & 1,563 & $1,374 \mathrm{E}-17$ \\
\hline$F \bigsqcup 20021$ & 1,563 & $9,735 \mathrm{E}-16$ \\
\hline DENNDIA & 1,562 & $3,145 \mathrm{E}-19$ \\
\hline EFNB1 & 1,562 & $2,122 \mathrm{E}-18$ \\
\hline NUMA1 & 1,562 & $6,670 \mathrm{E}-14$ \\
\hline FGFR4 & 1,562 & $6,955 \mathrm{E}-20$ \\
\hline MAPGDI & 1,562 & $1,776 \mathrm{E}-16$ \\
\hline MZF1 & 1,562 & $9,120 \mathrm{E}-21$ \\
\hline DYRK2 & 1,561 & $8,825 \mathrm{E}-19$ \\
\hline KLHLL28 & 1,561 & $5,517 \mathrm{E}-12$ \\
\hline
\end{tabular}

\begin{tabular}{|c|c|c|}
\hline ВТВDЗ & 1,561 & $1,611 \mathrm{E}-13$ \\
\hline SAPS2 & 1,561 & $3,676 \mathrm{E}-19$ \\
\hline ZNF211 & 1,560 & $1,201 \mathrm{E}-15$ \\
\hline NAPB & 1,559 & $2,805 \mathrm{E}-18$ \\
\hline STAMBP & 1,559 & $9,919 \mathrm{E}-13$ \\
\hline RBM 33 & 1,559 & $4,066 \mathrm{E}-14$ \\
\hline FHODI & 1,556 & $2,554 \mathrm{E}-20$ \\
\hline TSPAN31 & 1,556 & $4,330 \mathrm{E}-17$ \\
\hline$O C I A D 1$ & 1,556 & $5,118 \mathrm{E}-25$ \\
\hline TMEM120A & 1,555 & $7,823 \mathrm{E}-19$ \\
\hline GATS & 1,554 & $4,170 \mathrm{E}-15$ \\
\hline KIAA1598 & 1,554 & $2,726 \mathrm{E}-18$ \\
\hline TMCG & 1,553 & $1,946 \mathrm{E}-18$ \\
\hline KCNMA1 & 1,553 & $1,354 \mathrm{E}-22$ \\
\hline HES1 & 1,553 & $3,583 \mathrm{E}-18$ \\
\hline AKR1C3 & 1,552 & $2,070 \mathrm{E}-19$ \\
\hline PGK1 & 1,552 & $8,745 \mathrm{E}-24$ \\
\hline RHBDD2 & 1,552 & $2,447 E-17$ \\
\hline PPIC & 1,552 & $1,924 \mathrm{E}-24$ \\
\hline PMS2L3 & 1,551 & $4,849 \mathrm{E}-18$ \\
\hline LLRBA & 1,551 & $1,375 \mathrm{E}-23$ \\
\hline ICAM5 & 1,551 & $9,005 \mathrm{E}-16$ \\
\hline SS18LI & 1,551 & $2,206 \mathrm{E}-25$ \\
\hline DFNAS & 1,551 & $5,192 \mathrm{E}-12$ \\
\hline SCHIP1 & 1,550 & $6,371 \mathrm{E}-12$ \\
\hline RNU1-5 & 1,549 & $1,558 \mathrm{E}-17$ \\
\hline$C D A$ & 1,549 & $6,256 \mathrm{E}-17$ \\
\hline SAMD $4 A$ & 1,548 & $8,742 \mathrm{E}-18$ \\
\hline VPS41 & 1,548 & $1,319 \mathrm{E}-14$ \\
\hline PRR15L & 1,548 & $1,183 \mathrm{E}-19$ \\
\hline NNMT & 1,548 & $2,365 \mathrm{E}-17$ \\
\hline C22orf36 & 1,547 & $2,231 \mathrm{E}-18$ \\
\hline PCNX & 1,546 & $1,128 \mathrm{E}-18$ \\
\hline
\end{tabular}

\begin{tabular}{|c|c|c|}
\hline TDRD1 & 1,546 & $6,045 \mathrm{E}-20$ \\
\hline SNAPC1 & 1,546 & $5,741 \mathrm{E}-17$ \\
\hline ELOVL1 & 1,546 & $5,855 \mathrm{E}-15$ \\
\hline C17orf28 & 1,546 & $9,301 \mathrm{E}-19$ \\
\hline KRT19 & 1,546 & $1,338 \mathrm{E}-22$ \\
\hline CRTAP & 1,545 & $6,031 \mathrm{E}-16$ \\
\hline TRPM4 & 1,544 & $1,661 \mathrm{E}-21$ \\
\hline SLCAA5 & 1,544 & $2,632 \mathrm{E}-13$ \\
\hline $\begin{array}{c}\text { NCRNAOOO16 } \\
1\end{array}$ & 1,543 & $8,509 \mathrm{E}-17$ \\
\hline ZBEDS & 1,543 & $6,016 \mathrm{E}-08$ \\
\hline MAPRE3 & 1,543 & $3,071 \mathrm{E}-18$ \\
\hline$A P B A 2 B P$ & 1,543 & $2,498 \mathrm{E}-18$ \\
\hline FKBPgL & 1,543 & $4,891 \mathrm{E}-18$ \\
\hline MXRA7 & 1,543 & $1,015 \mathrm{E}-11$ \\
\hline TNFSF14 & 1,543 & $8,301 \mathrm{E}-20$ \\
\hline C20orf194 & 1,542 & 9,917E-16 \\
\hline MSRB3 & 1,542 & $1,026 \mathrm{E}-16$ \\
\hline SURF1 & 1,541 & $3,603 \mathrm{E}-13$ \\
\hline PCYOXIL & 1,541 & $2,603 \mathrm{E}-14$ \\
\hline LRP11 & 1,541 & $4,626 \mathrm{E}-14$ \\
\hline ANO1 & 1,540 & $1,447 \mathrm{E}-20$ \\
\hline DDIT3 & 1,540 & $1,407 \mathrm{E}-11$ \\
\hline GSTM2 & 1,540 & $1,226 \mathrm{E}-15$ \\
\hline MACROD1 & 1,540 & $4,076 \mathrm{E}-15$ \\
\hline TPM1 & 1,539 & $1,558 \mathrm{E}-14$ \\
\hline PPAP2A & 1,538 & $4,175 \mathrm{E}-18$ \\
\hline C7orf20 & 1,538 & $3,932 \mathrm{E}-13$ \\
\hline AIRE & 1,538 & $3,992 \mathrm{E}-21$ \\
\hline TMEM16A & 1,537 & $7,633 \mathrm{E}-19$ \\
\hline CSNK1D & 1,537 & $3,315 \mathrm{E}-17$ \\
\hline UBE2G2 & 1,537 & $6,001 E-24$ \\
\hline ATP $7 B$ & 1,537 & $1,194 \mathrm{E}-14$ \\
\hline HSPA1B & 1,537 & $8,818 \mathrm{E}-17$ \\
\hline
\end{tabular}


Supplementary Table S4.9: continued

\begin{tabular}{|c|c|c|}
\hline POFUT2 & 1,537 & $5,739 \mathrm{E}-22$ \\
\hline TNFRSF18 & 1,536 & $1,686 \mathrm{E}-17$ \\
\hline IGFBP2 & 1,536 & $3,750 \mathrm{E}-11$ \\
\hline SGK & 1,536 & $2,479 \mathrm{E}-20$ \\
\hline PRRT2 & 1,536 & $2,113 \mathrm{E}-10$ \\
\hline GPD1L & 1,535 & $9,869 \mathrm{E}-18$ \\
\hline $\begin{array}{c}\text { DKFZp } 434 K 1 \\
91\end{array}$ & 1,535 & $3,824 \mathrm{E}-14$ \\
\hline ACSLI & 1,534 & $2,650 \mathrm{E}-12$ \\
\hline MIR21 & 1,534 & $8,860 \mathrm{E}-14$ \\
\hline RPS15A & 1,534 & $8,797 \mathrm{E}-24$ \\
\hline SIDT2 & 1,534 & $4,186 \mathrm{E}-22$ \\
\hline RIN1 & 1,533 & $4,093 \mathrm{E}-15$ \\
\hline ALDH2 & 1,533 & $1,196 \mathrm{E}-11$ \\
\hline GOLGA3 & 1,533 & $2,280 \mathrm{E}-18$ \\
\hline CSRNP3 & 1,532 & $3,286 \mathrm{E}-19$ \\
\hline HELZ & 1,532 & $4,986 \mathrm{E}-14$ \\
\hline C8orf37 & 1,532 & $3,126 \mathrm{E}-16$ \\
\hline TRAPPCGB & 1,532 & $3,748 \mathrm{E}-23$ \\
\hline CRABP1 & 1,531 & $1,271 \mathrm{E}-12$ \\
\hline GCAT & 1,531 & $8,273 \mathrm{E}-15$ \\
\hline DLG4 & 1,531 & $3,653 \mathrm{E}-15$ \\
\hline SCARNA13 & 1,531 & $1,009 \mathrm{E}-16$ \\
\hline CCDC 84 & 1,530 & $8,882 \mathrm{E}-19$ \\
\hline RADS1C & 1,530 & $5,928 \mathrm{E}-17$ \\
\hline PDIA3P & 1,530 & $1,208 \mathrm{E}-11$ \\
\hline COL17A1 & 1,529 & $5,820 \mathrm{E}-14$ \\
\hline NUDT1 & 1,529 & $4,192 \mathrm{E}-16$ \\
\hline RCAN1 & 1,528 & $7,631 \mathrm{E}-19$ \\
\hline COL9A2 & 1,528 & $8,728 \mathrm{E}-14$ \\
\hline ZNF860 & 1,527 & $5,579 \mathrm{E}-12$ \\
\hline DHRS13 & 1,527 & $9,251 \mathrm{E}-13$ \\
\hline MT3 & 1,526 & $8,366 \mathrm{E}-15$ \\
\hline TYRO3 & 1,525 & $1,221 \mathrm{E}-16$ \\
\hline
\end{tabular}

\begin{tabular}{|c|c|c|}
\hline RAB11FIP2 & 1,525 & $9,735 \mathrm{E}-15$ \\
\hline DNAJB2 & 1,525 & $6,183 \mathrm{E}-18$ \\
\hline CDЗEAP & 1,524 & $1,698 \mathrm{E}-27$ \\
\hline CTGLF3 & 1,524 & $1,209 \mathrm{E}-15$ \\
\hline PGM3 & 1,524 & $1,482 \mathrm{E}-10$ \\
\hline$B A X$ & 1,524 & $4,753 \mathrm{E}-16$ \\
\hline C21orf57 & 1,523 & $1,484 \mathrm{E}-12$ \\
\hline CPT2 & 1,523 & $3,376 \mathrm{E}-20$ \\
\hline SIPR3 & 1,523 & $1,659 \mathrm{E}-15$ \\
\hline$R B C K 1$ & 1,523 & $2,189 \mathrm{E}-16$ \\
\hline MBTD1 & 1,523 & $1,397 \mathrm{E}-09$ \\
\hline CCDC92 & 1,522 & $1,976 \mathrm{E}-28$ \\
\hline SLCBOA7 & 1,522 & $2,064 \mathrm{E}-14$ \\
\hline SIPAI & 1,522 & $9,412 \mathrm{E}-28$ \\
\hline MTX3 & 1,522 & $6,876 \mathrm{E}-13$ \\
\hline$A C Y 1$ & 1,522 & $3,954 \mathrm{E}-12$ \\
\hline $\begin{array}{c}\text { NCRNAOOOOB } \\
5\end{array}$ & 1,521 & $1,202 \mathrm{E}-16$ \\
\hline SKIV2L & 1,521 & $4,719 \mathrm{E}-17$ \\
\hline MAP1LC3B & 1,520 & $1,582 \mathrm{E}-15$ \\
\hline CCNE1 & 1,520 & $9,661 \mathrm{E}-17$ \\
\hline RASSF2 & 1,520 & $8,215 \mathrm{E}-12$ \\
\hline SLC22A5 & 1,519 & $2,786 \mathrm{E}-13$ \\
\hline PTPLA & 1,519 & $2,602 \mathrm{E}-11$ \\
\hline TGFBR2 & 1,519 & $7,025 \mathrm{E}-15$ \\
\hline GPR37 & 1,518 & $8,869 \mathrm{E}-09$ \\
\hline WDR74 & 1,518 & $5,220 \mathrm{E}-10$ \\
\hline PSMC4 & 1,518 & $4,249 \mathrm{E}-18$ \\
\hline C11orf35 & 1,517 & $1,473 \mathrm{E}-14$ \\
\hline EXT1 & 1,517 & $1,922 \mathrm{E}-16$ \\
\hline SH3BGRL3 & 1,516 & $1,653 \mathrm{E}-22$ \\
\hline PSMD7 & 1,516 & $5,058 \mathrm{E}-23$ \\
\hline MMP1 & 1,516 & $5,395 E-12$ \\
\hline ESYT1 & 1,516 & $1,197 \mathrm{E}-24$ \\
\hline
\end{tabular}

\begin{tabular}{|c|c|c|}
\hline AIM1L & 1,516 & $4,057 \mathrm{E}-15$ \\
\hline PTKG & 1,515 & $3,060 \mathrm{E}-18$ \\
\hline HIST2H $2 A B$ & 1,515 & $1,105 \mathrm{E}-12$ \\
\hline C9orf130 & 1,515 & $3,516 \mathrm{E}-17$ \\
\hline $\mathrm{NQO} 2$ & 1,514 & $1,089 \mathrm{E}-16$ \\
\hline SLC25A18 & 1,514 & $4,277 \mathrm{E}-07$ \\
\hline FL32252 & 1,514 & $2,930 \mathrm{E}-11$ \\
\hline TOM1 & 1,513 & $1,019 \mathrm{E}-18$ \\
\hline ANKRD $30 B$ & 1,513 & $7,370 E-19$ \\
\hline MiR185 & 1,512 & $9,308 \mathrm{E}-10$ \\
\hline ATXN1 & 1,512 & $1,401 \mathrm{E}-13$ \\
\hline PNMA1 & 1,512 & $1,180 \mathrm{E}-17$ \\
\hline C17orf101 & 1,511 & $2,517 \mathrm{E}-13$ \\
\hline UNC84A & 1,511 & $6,631 \mathrm{E}-13$ \\
\hline ISYNAI & 1,511 & $4,388 \mathrm{E}-17$ \\
\hline ENO3 & 1,511 & $8,437 \mathrm{E}-15$ \\
\hline CENTG3 & 1,511 & $2,646 \mathrm{E}-14$ \\
\hline YEATS2 & 1,511 & $7,683 E-21$ \\
\hline $15 G 20$ & 1,511 & $7,607 \mathrm{E}-16$ \\
\hline$C X C L 1$ & 1,511 & $2,394 \mathrm{E}-06$ \\
\hline PHLDA1 & 1,511 & $6,575 \mathrm{E}-18$ \\
\hline PHACTR3 & 1,510 & $4,242 \mathrm{E}-20$ \\
\hline ZCWPW1 & 1,510 & $5,339 \mathrm{E}-20$ \\
\hline CYTH3 & 1,510 & $1,548 \mathrm{E}-13$ \\
\hline KDMSB & 1,509 & $1,490 \mathrm{E}-12$ \\
\hline ACADVL & 1,509 & $3,285 \mathrm{E}-15$ \\
\hline TTLL11 & 1,509 & $2,069 \mathrm{E}-17$ \\
\hline PPP1R1B & 1,508 & $2,719 \mathrm{E}-20$ \\
\hline LRPAP1 & 1,508 & $3,049 \mathrm{E}-20$ \\
\hline PARVA & 1,508 & $3,425 \mathrm{E}-17$ \\
\hline PACSIN1 & 1,508 & $8,168 \mathrm{E}-15$ \\
\hline TNFRSF14 & 1,508 & $1,363 \mathrm{E}-15$ \\
\hline PCYOX1 & 1,507 & $2,915 \mathrm{E}-16$ \\
\hline
\end{tabular}

\begin{tabular}{|c|c|c|}
\hline CNO & 1,507 & $6,142 \mathrm{E}-12$ \\
\hline TERC & 1,507 & $1,282 \mathrm{E}-16$ \\
\hline FU44342 & 1,507 & $2,218 \mathrm{E}-11$ \\
\hline SPHK1 & 1,507 & $2,002 \mathrm{E}-13$ \\
\hline ZNF251 & 1,506 & $9,175 \mathrm{E}-09$ \\
\hline$D G K A$ & 1,506 & $5,429 \mathrm{E}-16$ \\
\hline MCAM & 1,506 & $8,525 \mathrm{E}-13$ \\
\hline MAST1 & 1,506 & $1,071 \mathrm{E}-10$ \\
\hline UBXNG & 1,505 & $1,611 \mathrm{E}-15$ \\
\hline C6orf70 & 1,505 & $1,282 \mathrm{E}-11$ \\
\hline DOCK1O & 1,505 & $2,562 \mathrm{E}-13$ \\
\hline ANKRD23 & 1,505 & $4,286 \mathrm{E}-12$ \\
\hline SLC35E1 & 1,504 & $1,056 \mathrm{E}-07$ \\
\hline RN7SK & 1,504 & $1,331 \mathrm{E}-18$ \\
\hline OSTM1 & 1,503 & $1,676 \mathrm{E}-14$ \\
\hline DENR & 1,503 & $3,173 \mathrm{E}-16$ \\
\hline BHLHB2 & 1,503 & $9,986 \mathrm{E}-19$ \\
\hline GMIP & 1,502 & $1,141 \mathrm{E}-13$ \\
\hline TECPR1 & 1,501 & $5,208 \mathrm{E}-15$ \\
\hline ACADM & 1,501 & $1,304 \mathrm{E}-18$ \\
\hline SSTR2 & 1,500 & $3,261 \mathrm{E}-13$ \\
\hline COMMD3 & 1,500 & $1,079 \mathrm{E}-17$ \\
\hline NEU1 & 1,500 & $6,344 \mathrm{E}-15$ \\
\hline KLF4 & 1,500 & $1,588 \mathrm{E}-14$ \\
\hline GPR126 & 1,500 & $2,377 \mathrm{E}-12$ \\
\hline TMEM127 & 0,668 & $2,671 \mathrm{E}-15$ \\
\hline$G 3 B P 2$ & 0,668 & $5,150 \mathrm{E}-11$ \\
\hline PPA1 & 0,668 & $1,728 \mathrm{E}-21$ \\
\hline DUSP4 & 0,668 & $5,322 \mathrm{E}-14$ \\
\hline$\angle Y 6 G 5 C$ & 0,668 & $1,602 \mathrm{E}-10$ \\
\hline FAM110A & 0,667 & $1,893 \mathrm{E}-17$ \\
\hline WDFY1 & 0,667 & $1,205 \mathrm{E}-20$ \\
\hline RAB25 & 0,667 & $1,962 \mathrm{E}-15$ \\
\hline
\end{tabular}


CHAPTER 4

Supplementary Table S4.9: continued

\begin{tabular}{|c|c|c|}
\hline FLL20444 & 0,667 & $3,672 \mathrm{E}-19$ \\
\hline $\begin{array}{c}\text { RP11- } \\
529 / 10.4\end{array}$ & 0,667 & $6,214 \mathrm{E}-16$ \\
\hline STX5 & 0,667 & $1,465 \mathrm{E}-20$ \\
\hline LSM3 & 0,667 & $6,318 \mathrm{E}-18$ \\
\hline ITGA1O & 0,667 & $4,147 \mathrm{E}-12$ \\
\hline FAM131A & 0,667 & $1,337 \mathrm{E}-13$ \\
\hline WDR43 & 0,667 & $4,567 \mathrm{E}-14$ \\
\hline PRMT3 & 0,667 & $1,237 \mathrm{E}-15$ \\
\hline C1orf57 & 0,666 & $3,224 \mathrm{E}-17$ \\
\hline LASIL & 0,666 & $6,814 \mathrm{E}-17$ \\
\hline C7orf 49 & 0,666 & $3,704 \mathrm{E}-13$ \\
\hline PLAGL2 & 0,666 & $1,577 \mathrm{E}-17$ \\
\hline LDOC1 & 0,666 & $8,935 \mathrm{E}-17$ \\
\hline PPP4R1 & 0,666 & $1,315 \mathrm{E}-16$ \\
\hline PIGQ & 0,665 & $4,158 \mathrm{E}-19$ \\
\hline C14orf126 & 0,665 & $5,142 \mathrm{E}-12$ \\
\hline$T D G$ & 0,665 & $4,475 \mathrm{E}-14$ \\
\hline GRPR & 0,665 & $1,017 \mathrm{E}-12$ \\
\hline$B L M$ & 0,665 & $1,247 \mathrm{E}-16$ \\
\hline NUP88 & 0,665 & $3,774 \mathrm{E}-18$ \\
\hline PNKD & 0,665 & $1,353 \mathrm{E}-16$ \\
\hline RPL34 & 0,665 & $1,918 \mathrm{E}-14$ \\
\hline FUCA2 & 0,665 & $2,236 \mathrm{E}-15$ \\
\hline$A G K$ & 0,665 & $3,007 \mathrm{E}-11$ \\
\hline RPS7 & 0,665 & $1,107 \mathrm{E}-18$ \\
\hline EPM $2 A \mid P 1$ & 0,665 & $7,543 \mathrm{E}-17$ \\
\hline MED4 & 0,665 & $1,263 \mathrm{E}-12$ \\
\hline$D P P 4$ & 0,664 & $9,339 \mathrm{E}-15$ \\
\hline C13orf3 & 0,664 & $4,776 \mathrm{E}-19$ \\
\hline CLTA & 0,664 & $2,045 \mathrm{E}-14$ \\
\hline Clorf85 & 0,664 & $3,235 \mathrm{E}-25$ \\
\hline FASTK & 0,664 & $5,512 \mathrm{E}-11$ \\
\hline SRF & 0,664 & $9,039 \mathrm{E}-17$ \\
\hline
\end{tabular}

\begin{tabular}{|c|c|c|}
\hline$D D \times 21$ & 0,664 & $1,755 \mathrm{E}-14$ \\
\hline HEATR7A & 0,664 & $3,251 \mathrm{E}-12$ \\
\hline TRO & 0,664 & $1,543 \mathrm{E}-12$ \\
\hline C9orf69 & 0,664 & $1,061 \mathrm{E}-18$ \\
\hline C6orf108 & 0,663 & $1,040 \mathrm{E}-23$ \\
\hline KCNF1 & 0,663 & $3,285 \mathrm{E}-13$ \\
\hline$S F 3 A 3$ & 0,663 & $4,206 \mathrm{E}-23$ \\
\hline POLRBF & 0,663 & $9,013 \mathrm{E}-18$ \\
\hline ARV 1 & 0,663 & $3,701 \mathrm{E}-15$ \\
\hline UBE2E1 & 0,663 & $9,402 \mathrm{E}-14$ \\
\hline CENPO & 0,662 & $1,188 \mathrm{E}-13$ \\
\hline STAT1 & 0,662 & $4,774 \mathrm{E}-15$ \\
\hline OAS1 & 0,662 & $2,389 \mathrm{E}-09$ \\
\hline COPZ1 & 0,662 & $2,002 \mathrm{E}-14$ \\
\hline GPBP1 & 0,662 & $2,231 \mathrm{E}-14$ \\
\hline ADRBK1 & 0,662 & $1,089 \mathrm{E}-22$ \\
\hline NTSDC3 & 0,661 & $3,781 \mathrm{E}-21$ \\
\hline ERCCGL & 0,661 & $2,343 \mathrm{E}-10$ \\
\hline$C S$ & 0,661 & $7,246 \mathrm{E}-23$ \\
\hline FCGR2A & 0,661 & $1,583 \mathrm{E}-11$ \\
\hline HAUSB & 0,661 & $1,779 \mathrm{E}-07$ \\
\hline TNFAIP1 & 0,661 & $1,526 \mathrm{E}-14$ \\
\hline PRDX2 & 0,660 & $1,428 \mathrm{E}-15$ \\
\hline TAF12 & 0,660 & $2,043 \mathrm{E}-10$ \\
\hline KIAAO0O2O & 0,660 & $1,111 \mathrm{E}-14$ \\
\hline$J O S D 1$ & 0,660 & $4,227 \mathrm{E}-15$ \\
\hline IPGKI & 0,660 & $1,782 \mathrm{E}-12$ \\
\hline CACYBP & 0,660 & $4,243 \mathrm{E}-10$ \\
\hline TBLIX & 0,660 & $4,882 \mathrm{E}-23$ \\
\hline $5 T \times 8$ & 0,660 & $1,034 \mathrm{E}-22$ \\
\hline C10orf76 & 0,659 & $6,087 \mathrm{E}-16$ \\
\hline PGAM1 & 0,659 & $6,759 \mathrm{E}-11$ \\
\hline HSPD1 & 0,659 & $2,413 \mathrm{E}-29$ \\
\hline
\end{tabular}

\begin{tabular}{|c|c|c|}
\hline THAP1O & 0,658 & $1,168 \mathrm{E}-14$ \\
\hline PKIB & 0,658 & $5,969 \mathrm{E}-14$ \\
\hline$X Y \angle B$ & 0,658 & $2,356 \mathrm{E}-16$ \\
\hline TEAD4 & 0,658 & $7,761 \mathrm{E}-22$ \\
\hline NANP & 0,658 & $4,951 \mathrm{E}-13$ \\
\hline MSHG & 0,658 & $9,682 \mathrm{E}-22$ \\
\hline MRE11A & 0,658 & 4,447E-16 \\
\hline EXOSC8 & 0,658 & $5,706 \mathrm{E}-08$ \\
\hline DERA & 0,658 & $1,316 \mathrm{E}-14$ \\
\hline C1orf43 & 0,657 & $2,097 \mathrm{E}-10$ \\
\hline UNC84B & 0,657 & $1,158 \mathrm{E}-11$ \\
\hline NAP1LI & 0,657 & $1,836 \mathrm{E}-14$ \\
\hline PHB2 & 0,657 & $8,125 \mathrm{E}-17$ \\
\hline C11orf60 & 0,657 & $3,579 \mathrm{E}-18$ \\
\hline TRIM68 & 0,657 & $2,238 \mathrm{E}-20$ \\
\hline$A P 2 B 1$ & 0,657 & $1,723 \mathrm{E}-19$ \\
\hline MPRIP & 0,657 & $1,571 \mathrm{E}-11$ \\
\hline MMS19 & 0,656 & $2,052 \mathrm{E}-12$ \\
\hline CEPT1 & 0,656 & $6,661 \mathrm{E}-17$ \\
\hline MED2O & 0,656 & $5,711 \mathrm{E}-23$ \\
\hline SLC25A28 & 0,656 & $4,205 \mathrm{E}-22$ \\
\hline CTSA & 0,656 & $2,532 \mathrm{E}-15$ \\
\hline DUS2L & 0,656 & $1,774 \mathrm{E}-19$ \\
\hline SPATA2L & 0,656 & $8,415 \mathrm{E}-15$ \\
\hline GCSH & 0,656 & $9,754 \mathrm{E}-17$ \\
\hline CYB561D1 & 0,655 & 1,193E-19 \\
\hline WDR12 & 0,655 & $3,100 \mathrm{E}-10$ \\
\hline UCK2 & 0,655 & $2,342 \mathrm{E}-08$ \\
\hline TIMM $8 A$ & 0,655 & $1,570 \mathrm{E}-14$ \\
\hline NOP56 & 0,655 & $1,485 \mathrm{E}-17$ \\
\hline$G C A$ & 0,655 & $1,050 \mathrm{E}-14$ \\
\hline MTCP1 & 0,655 & $3,288 \mathrm{E}-19$ \\
\hline IPOS & 0,654 & $2,891 \mathrm{E}-18$ \\
\hline
\end{tabular}

\begin{tabular}{|c|c|c|}
\hline SAPS1 & 0,654 & $8,471 \mathrm{E}-14$ \\
\hline$C D C A 2$ & 0,654 & $1,434 \mathrm{E}-17$ \\
\hline OSTC & 0,653 & $2,626 \mathrm{E}-17$ \\
\hline C12orf49 & 0,653 & $1,519 \mathrm{E}-11$ \\
\hline NCAPD3 & 0,653 & $1,996 \mathrm{E}-15$ \\
\hline CDK2 & 0,653 & $4,367 \mathrm{E}-19$ \\
\hline$|F| 44 L$ & 0,653 & $3,370 \mathrm{E}-14$ \\
\hline C11orf48 & 0,652 & $4,230 \mathrm{E}-18$ \\
\hline SPRYD4 & 0,652 & $5,662 \mathrm{E}-18$ \\
\hline CBWD3 & 0,652 & $3,660 \mathrm{E}-15$ \\
\hline CSRP2 & 0,652 & $9,150 \mathrm{E}-12$ \\
\hline STOML2 & 0,652 & $1,440 \mathrm{E}-27$ \\
\hline RFC2 & 0,652 & $2,472 \mathrm{E}-14$ \\
\hline$A B \mid 3 B P$ & 0,651 & $5,361 \mathrm{E}-20$ \\
\hline$\angle P X N$ & 0,651 & $4,204 \mathrm{E}-19$ \\
\hline$S D C 1$ & 0,650 & $1,313 \mathrm{E}-13$ \\
\hline GMPS & 0,650 & $9,782 \mathrm{E}-20$ \\
\hline EIF $2 C 1$ & 0,650 & $8,400 \mathrm{E}-14$ \\
\hline MKRN2 & 0,650 & $2,556 \mathrm{E}-14$ \\
\hline XPO6 & 0,650 & $1,676 \mathrm{E}-13$ \\
\hline MLST8 & 0,650 & $1,170 \mathrm{E}-14$ \\
\hline $00 \times 39$ & 0,650 & $4,625 \mathrm{E}-16$ \\
\hline RPL21 & 0,650 & $1,179 \mathrm{E}-20$ \\
\hline DNASE1L1 & 0,650 & $8,255 \mathrm{E}-16$ \\
\hline FBXW4 & 0,649 & $5,140 \mathrm{E}-13$ \\
\hline WOR18 & 0,649 & $9,095 \mathrm{E}-16$ \\
\hline MET & 0,649 & $2,859 \mathrm{E}-21$ \\
\hline$A S B 9$ & 0,648 & $4,490 \mathrm{E}-21$ \\
\hline UBE2F & 0,648 & $7,622 \mathrm{E}-22$ \\
\hline KIAA0494 & 0,648 & $1,570 \mathrm{E}-16$ \\
\hline SFRSG & 0,648 & $2,715 \mathrm{E}-21$ \\
\hline$X B P 1$ & 0,648 & $1,557 \mathrm{E}-11$ \\
\hline UBE $2 N$ & 0,648 & $4,017 \mathrm{E}-13$ \\
\hline
\end{tabular}


Supplementary Table S4.9: continued

\begin{tabular}{|c|c|c|}
\hline MRPS6 & 0,648 & $9,276 \mathrm{E}-18$ \\
\hline XRCC3 & 0,648 & $1,269 \mathrm{E}-12$ \\
\hline RUVBLI & 0,648 & $6,690 \mathrm{E}-17$ \\
\hline UBL7 & 0,648 & $2,062 \mathrm{E}-18$ \\
\hline GLIPR1 & 0,648 & $2,832 \mathrm{E}-14$ \\
\hline MLFIIP & 0,648 & $3,373 \mathrm{E}-22$ \\
\hline TMEM 48 & 0,648 & $1,481 \mathrm{E}-15$ \\
\hline TULP4 & 0,648 & $4,357 \mathrm{E}-14$ \\
\hline NEIL3 & 0,647 & $6,343 \mathrm{E}-10$ \\
\hline KIF18A & 0,647 & $3,326 \mathrm{E}-12$ \\
\hline MEIS2 & 0,647 & $1,598 \mathrm{E}-15$ \\
\hline PAK1/P1 & 0,647 & $4,513 \mathrm{E}-17$ \\
\hline$N M B$ & 0,646 & $1,475 \mathrm{E}-14$ \\
\hline DHRS11 & 0,646 & $5,150 \mathrm{E}-13$ \\
\hline SLC25A11 & 0,646 & $4,999 \mathrm{E}-13$ \\
\hline$C D C P 1$ & 0,646 & $2,253 \mathrm{E}-21$ \\
\hline CHORDC1 & 0,646 & $1,985 \mathrm{E}-11$ \\
\hline ZNF519 & 0,646 & $1,299 \mathrm{E}-18$ \\
\hline LRFN3 & 0,645 & $6,215 \mathrm{E}-18$ \\
\hline HPRT1 & 0,645 & $1,073 \mathrm{E}-11$ \\
\hline TUBA1B & 0,645 & $2,899 \mathrm{E}-13$ \\
\hline MYLIP & 0,645 & $2,377 \mathrm{E}-17$ \\
\hline CCDC56 & 0,645 & $1,983 \mathrm{E}-22$ \\
\hline EFHD2 & 0,645 & $3,168 \mathrm{E}-19$ \\
\hline PLXNA1 & 0,644 & $1,409 \mathrm{E}-14$ \\
\hline RANGAP1 & 0,644 & $2,368 \mathrm{E}-31$ \\
\hline BCL2L13 & 0,644 & $8,735 \mathrm{E}-20$ \\
\hline C2orf 47 & 0,644 & $5,176 \mathrm{E}-08$ \\
\hline SEHIL & 0,644 & $1,011 \mathrm{E}-11$ \\
\hline POLE & 0,644 & $2,411 \mathrm{E}-15$ \\
\hline MGC4294 & 0,644 & $9,262 \mathrm{E}-18$ \\
\hline LZIC & 0,644 & $5,309 \mathrm{E}-17$ \\
\hline RPA3 & 0,643 & $5,404 \mathrm{E}-15$ \\
\hline
\end{tabular}

\begin{tabular}{|c|c|c|}
\hline CGI-96 & 0,643 & $9,044 \mathrm{E}-19$ \\
\hline E2F7 & 0,643 & $2,320 \mathrm{E}-17$ \\
\hline$S D H C$ & 0,642 & $1,091 \mathrm{E}-27$ \\
\hline SLFN11 & 0,642 & $1,131 \mathrm{E}-09$ \\
\hline ATGS & 0,642 & $2,248 \mathrm{E}-19$ \\
\hline C14orf124 & 0,642 & $7,095 \mathrm{E}-15$ \\
\hline IFI6 & 0,642 & $5,145 \mathrm{E}-06$ \\
\hline AMMECR1L & 0,641 & $1,287 \mathrm{E}-15$ \\
\hline GPR89B & 0,641 & $1,675 \mathrm{E}-10$ \\
\hline C6orf136 & 0,641 & $5,869 \mathrm{E}-20$ \\
\hline GPN3 & 0,641 & $6,462 \mathrm{E}-11$ \\
\hline RNPS1 & 0,641 & $9,029 \mathrm{E}-19$ \\
\hline ARHGAP11B & 0,641 & $4,675 \mathrm{E}-19$ \\
\hline UBEAB & 0,641 & $1,460 \mathrm{E}-18$ \\
\hline TM4SF19 & 0,641 & $3,562 \mathrm{E}-23$ \\
\hline IRS1 & 0,641 & $4,325 \mathrm{E}-18$ \\
\hline HSPC111 & 0,640 & $3,363 \mathrm{E}-22$ \\
\hline GNG11 & 0,640 & $1,692 \mathrm{E}-18$ \\
\hline SLC45A3 & 0,640 & $4,186 \mathrm{E}-20$ \\
\hline IMPA2 & 0,640 & $1,857 \mathrm{E}-19$ \\
\hline VPS24 & 0,640 & $8,125 \mathrm{E}-15$ \\
\hline CHMP4C & 0,639 & $9,371 \mathrm{E}-12$ \\
\hline ZNF469 & 0,639 & $2,305 \mathrm{E}-17$ \\
\hline C17orf63 & 0,639 & $5,095 \mathrm{E}-14$ \\
\hline CCDC99 & 0,639 & $2,984 \mathrm{E}-16$ \\
\hline CTSL2 & 0,639 & $1,010 \mathrm{E}-23$ \\
\hline ZNF695 & 0,639 & $4,506 \mathrm{E}-17$ \\
\hline TXNDC15 & 0,638 & $1,340 \mathrm{E}-14$ \\
\hline$T B C 1 D 13$ & 0,638 & $5,007 \mathrm{E}-24$ \\
\hline FRAG1 & 0,638 & $1,049 \mathrm{E}-16$ \\
\hline MTA1 & 0,638 & $1,416 \mathrm{E}-16$ \\
\hline UBEZLZ & 0,638 & $3,988 \mathrm{E}-21$ \\
\hline RSLID1 & 0,638 & $1,065 \mathrm{E}-20$ \\
\hline
\end{tabular}

\begin{tabular}{|c|c|c|}
\hline RNF220 & 0,638 & $2,372 \mathrm{E}-18$ \\
\hline$E 2 F 5$ & 0,637 & $1,837 \mathrm{E}-14$ \\
\hline FAM120A & 0,637 & $7,623 \mathrm{E}-23$ \\
\hline NRBF2 & 0,637 & $1,013 \mathrm{E}-18$ \\
\hline SLC41A3 & 0,637 & $1,739 \mathrm{E}-21$ \\
\hline$X R C C G B P 1$ & 0,637 & $2,210 \mathrm{E}-16$ \\
\hline POP5 & 0,637 & $7,630 \mathrm{E}-19$ \\
\hline CRYL1 & 0,637 & $8,346 \mathrm{E}-19$ \\
\hline WDR75 & 0,637 & $4,637 \mathrm{E}-20$ \\
\hline ССТGP1 & 0,637 & $1,788 \mathrm{E}-23$ \\
\hline GEMING & 0,636 & $1,709 \mathrm{E}-18$ \\
\hline GINS4 & 0,636 & $5,499 \mathrm{E}-15$ \\
\hline COMMD2 & 0,636 & $7,092 \mathrm{E}-21$ \\
\hline REXO1 & 0,636 & $4,195 \mathrm{E}-25$ \\
\hline RNASEH2A & 0,635 & $8,657 \mathrm{E}-22$ \\
\hline RIPK2 & 0,635 & $1,164 \mathrm{E}-21$ \\
\hline C10orf26 & 0,635 & $3,419 \mathrm{E}-14$ \\
\hline$R A P 2 C$ & 0,635 & $1,231 \mathrm{E}-13$ \\
\hline MRPL3O & 0,635 & $9,972 \mathrm{E}-12$ \\
\hline SLC7AS & 0,635 & $6,916 \mathrm{E}-23$ \\
\hline SRPK1 & 0,634 & $1,283 \mathrm{E}-13$ \\
\hline ZNF668 & 0,634 & $3,464 \mathrm{E}-18$ \\
\hline KLF11 & 0,634 & $9,526 \mathrm{E}-18$ \\
\hline ALDH7A1 & 0,634 & $3,517 \mathrm{E}-18$ \\
\hline PELP1 & 0,634 & $1,276 \mathrm{E}-13$ \\
\hline NCAPG2 & 0,634 & $4,144 \mathrm{E}-21$ \\
\hline MAD2L1BP & 0,633 & $2,986 \mathrm{E}-14$ \\
\hline SHARPIN & 0,633 & $1,326 \mathrm{E}-10$ \\
\hline CCNE2 & 0,633 & $4,611 \mathrm{E}-16$ \\
\hline NUP37 & 0,633 & $4,092 \mathrm{E}-23$ \\
\hline$G B P 2$ & 0,633 & $4,518 \mathrm{E}-13$ \\
\hline TEX261 & 0,633 & $3,277 \mathrm{E}-18$ \\
\hline RBM15B & 0,633 & $2,427 \mathrm{E}-18$ \\
\hline
\end{tabular}

\begin{tabular}{|c|c|c|}
\hline FAM171A1 & 0,633 & $7,728 \mathrm{E}-24$ \\
\hline томм34 & 0,633 & $7,442 \mathrm{E}-19$ \\
\hline$S H 2 B 3$ & 0,633 & $4,531 \mathrm{E}-09$ \\
\hline$B Z W 2$ & 0,633 & $6,903 \mathrm{E}-24$ \\
\hline GLTP & 0,632 & $6,453 \mathrm{E}-16$ \\
\hline NOC3L & 0,632 & $1,659 \mathrm{E}-18$ \\
\hline WASF2 & 0,631 & $6,097 \mathrm{E}-17$ \\
\hline IPO9 & 0,631 & $3,622 \mathrm{E}-15$ \\
\hline SLC35AS & 0,631 & $3,516 \mathrm{E}-12$ \\
\hline$D K C 1$ & 0,631 & $5,105 \mathrm{E}-19$ \\
\hline PCGF2 & 0,631 & $3,569 \mathrm{E}-17$ \\
\hline ATPSL & 0,630 & $1,077 \mathrm{E}-13$ \\
\hline TEAD2 & 0,630 & $2,639 \mathrm{E}-23$ \\
\hline C22orf13 & 0,630 & $3,970 \mathrm{E}-25$ \\
\hline PRPF4 & 0,630 & $1,978 \mathrm{E}-26$ \\
\hline$S P C 25$ & 0,630 & $3,426 \mathrm{E}-15$ \\
\hline NAV2 & 0,630 & $2,765 \mathrm{E}-10$ \\
\hline ASH2L & 0,630 & $1,770 \mathrm{E}-16$ \\
\hline PATE3 & 0,630 & $3,455 \mathrm{E}-17$ \\
\hline MRTO4 & 0,629 & $6,905 \mathrm{E}-17$ \\
\hline$A R M C 6$ & 0,629 & $4,189 \mathrm{E}-24$ \\
\hline$C L C C 1$ & 0,629 & $1,324 \mathrm{E}-14$ \\
\hline CITED4 & 0,629 & $3,521 \mathrm{E}-17$ \\
\hline CSNK2A2 & 0,628 & $5,219 \mathrm{E}-18$ \\
\hline CARM1 & 0,628 & $1,515 \mathrm{E}-22$ \\
\hline CDC34 & 0,628 & $1,848 \mathrm{E}-19$ \\
\hline MCAT & 0,628 & $8,103 \mathrm{E}-14$ \\
\hline C11orf24 & 0,628 & $4,253 \mathrm{E}-15$ \\
\hline FAM117B & 0,628 & $8,378 \mathrm{E}-18$ \\
\hline$\pi L$ & 0,627 & $9,258 \mathrm{E}-16$ \\
\hline CLASP2 & 0,627 & $3,274 \mathrm{E}-23$ \\
\hline MGC70857 & 0,627 & $8,679 \mathrm{E}-15$ \\
\hline SNORA76 & 0,627 & $3,750 \mathrm{E}-12$ \\
\hline
\end{tabular}


CHAPTER 4

Supplementary Table S4.9: continued

\begin{tabular}{|c|c|c|}
\hline FAM $32 A$ & 0,626 & $1,126 \mathrm{E}-16$ \\
\hline BTBD1O & 0,626 & $3,861 \mathrm{E}-15$ \\
\hline MRPL37 & 0,626 & $2,576 \mathrm{E}-23$ \\
\hline HCLS1 & 0,625 & $1,897 \mathrm{E}-23$ \\
\hline ORCGL & 0,625 & $1,182 \mathrm{E}-14$ \\
\hline CGGBP1 & 0,625 & $1,749 \mathrm{E}-17$ \\
\hline GABPB2 & 0,625 & $8,120 \mathrm{E}-09$ \\
\hline TNFSF12 & 0,625 & $4,854 \mathrm{E}-17$ \\
\hline RRP15 & 0,625 & $2,115 \mathrm{E}-21$ \\
\hline$C B F B$ & 0,625 & $1,863 \mathrm{E}-18$ \\
\hline RPS23 & 0,624 & $1,954 \mathrm{E}-15$ \\
\hline CHAF1A & 0,624 & $6,205 \mathrm{E}-17$ \\
\hline$R S R C 1$ & 0,624 & $8,846 \mathrm{E}-19$ \\
\hline NUP205 & 0,624 & 7,604E-24 \\
\hline SLC25A22 & 0,624 & $2,451 \mathrm{E}-25$ \\
\hline KIAA1524 & 0,623 & $1,953 \mathrm{E}-22$ \\
\hline OAS3 & 0,623 & $2,110 \mathrm{E}-11$ \\
\hline Clorf112 & 0,623 & $3,223 \mathrm{E}-16$ \\
\hline STK 40 & 0,623 & $3,488 \mathrm{E}-23$ \\
\hline C16orf 75 & 0,623 & $1,355 \mathrm{E}-17$ \\
\hline MPST & 0,622 & $3,345 \mathrm{E}-15$ \\
\hline SLC25A13 & 0,622 & $1,095 \mathrm{E}-16$ \\
\hline RALY & 0,622 & $8,275 \mathrm{E}-21$ \\
\hline RAVERI & 0,621 & $4,671 \mathrm{E}-16$ \\
\hline PARP1 & 0,621 & $1,005 E-20$ \\
\hline PKIA & 0,621 & $4,166 \mathrm{E}-24$ \\
\hline POLR3G & 0,621 & $1,325 \mathrm{E}-14$ \\
\hline YEATS4 & 0,620 & $5,542 \mathrm{E}-12$ \\
\hline CASPG & 0,620 & $4,678 \mathrm{E}-10$ \\
\hline NASP & 0,620 & $4,968 \mathrm{E}-18$ \\
\hline C20orf 72 & 0,620 & $9,007 \mathrm{E}-22$ \\
\hline THOCG & 0,620 & $6,119 \mathrm{E}-23$ \\
\hline ZNF787 & 0,619 & $3,775 \mathrm{E}-26$ \\
\hline
\end{tabular}

\begin{tabular}{|c|c|c|}
\hline BTG3 & 0,619 & $1,755 \mathrm{E}-16$ \\
\hline SCAMP3 & 0,619 & $5,489 \mathrm{E}-20$ \\
\hline $\mid T G B 1 B P 1$ & 0,619 & $9,093 \mathrm{E}-17$ \\
\hline AKR1B1O & 0,619 & $1,049 \mathrm{E}-20$ \\
\hline THUMPD2 & 0,619 & $6,360 \mathrm{E}-20$ \\
\hline CSE1L & 0,619 & $4,909 \mathrm{E}-13$ \\
\hline SAE1 & 0,618 & $1,159 \mathrm{E}-30$ \\
\hline MCM7 & 0,618 & $1,055 \mathrm{E}-23$ \\
\hline CDK6 & 0,618 & $1,128 \mathrm{E}-22$ \\
\hline 15615 & 0,618 & $5,295 \mathrm{E}-12$ \\
\hline THOC4 & 0,617 & $1,467 \mathrm{E}-11$ \\
\hline CORO1C & 0,617 & $1,005 \mathrm{E}-19$ \\
\hline IFITM3 & 0,616 & $5,422 \mathrm{E}-14$ \\
\hline SSSCA1 & 0,616 & $3,782 \mathrm{E}-17$ \\
\hline GLTPD1 & 0,616 & $5,709 \mathrm{E}-18$ \\
\hline ATL3 & 0,616 & $2,887 \mathrm{E}-21$ \\
\hline NDC8O & 0,616 & $8,759 \mathrm{E}-26$ \\
\hline MYC & 0,616 & $5,726 \mathrm{E}-19$ \\
\hline F8A1 & 0,616 & $1,203 \mathrm{E}-18$ \\
\hline CXCL16 & 0,616 & $1,162 \mathrm{E}-21$ \\
\hline H1FO & 0,616 & $4,359 \mathrm{E}-19$ \\
\hline$D C P S$ & 0,615 & $8,299 \mathrm{E}-20$ \\
\hline CHES1 & 0,615 & $2,385 \mathrm{E}-22$ \\
\hline DHRS 1 & 0,615 & $2,763 \mathrm{E}-20$ \\
\hline MRPS27 & 0,615 & $4,595 \mathrm{E}-13$ \\
\hline ANKRDSO & 0,615 & $1,735 \mathrm{E}-20$ \\
\hline BYSL & 0,615 & $2,127 \mathrm{E}-26$ \\
\hline HSPE1 & 0,614 & $1,998 \mathrm{E}-03$ \\
\hline PHC2 & 0,614 & $3,071 \mathrm{E}-17$ \\
\hline WDHDI & 0,614 & $1,908 \mathrm{E}-17$ \\
\hline$E I F 3 M$ & 0,614 & $2,926 \mathrm{E}-18$ \\
\hline UTP18 & 0,614 & $1,139 \mathrm{E}-08$ \\
\hline HPS1 & 0,613 & $6,116 \mathrm{E}-22$ \\
\hline
\end{tabular}

\begin{tabular}{|c|c|c|}
\hline LGTN & 0,613 & $1,975 \mathrm{E}-22$ \\
\hline RPLP1 & 0,612 & $6,097 \mathrm{E}-26$ \\
\hline ACN & 0,612 & $4,140 \mathrm{E}-22$ \\
\hline$C D C 42$ & 0,611 & $5,584 \mathrm{E}-18$ \\
\hline$G \angle A$ & 0,611 & $6,689 \mathrm{E}-24$ \\
\hline C8orf30B & 0,611 & $9,919 \mathrm{E}-19$ \\
\hline LMAN2 & 0,611 & $4,364 \mathrm{E}-12$ \\
\hline$I T C H$ & 0,611 & $1,063 \mathrm{E}-19$ \\
\hline YWHAQ & 0,611 & $5,849 \mathrm{E}-24$ \\
\hline ITPRIP & 0,611 & $7,787 E-19$ \\
\hline C20orf 27 & 0,610 & $1,051 \mathrm{E}-29$ \\
\hline DPM3 & 0,610 & $3,428 \mathrm{E}-18$ \\
\hline$T T C 27$ & 0,610 & $7,413 \mathrm{E}-24$ \\
\hline PRSS3 & 0,610 & $4,609 \mathrm{E}-19$ \\
\hline ILF3 & 0,610 & $7,062 \mathrm{E}-20$ \\
\hline POPDC3 & 0,610 & $3,254 \mathrm{E}-13$ \\
\hline CENPK & 0,610 & $2,831 \mathrm{E}-19$ \\
\hline FIGNL1 & 0,609 & $1,347 \mathrm{E}-18$ \\
\hline DPAGT1 & 0,609 & $2,535 \mathrm{E}-13$ \\
\hline SNHGG & 0,608 & $3,188 \mathrm{E}-17$ \\
\hline NCLN & 0,608 & $2,744 \mathrm{E}-19$ \\
\hline PERP & 0,608 & $2,709 \mathrm{E}-13$ \\
\hline RPIA & 0,608 & $1,262 \mathrm{E}-19$ \\
\hline BANF1 & 0,607 & $1,120 \mathrm{E}-26$ \\
\hline KIF15 & 0,607 & $1,544 \mathrm{E}-22$ \\
\hline WDR77 & 0,606 & $9,638 \mathrm{E}-15$ \\
\hline$D E P D C 1 B$ & 0,606 & $1,246 \mathrm{E}-16$ \\
\hline NDUFAB 1 & 0,606 & $2,334 \mathrm{E}-24$ \\
\hline TMEM97 & 0,605 & $1,113 \mathrm{E}-20$ \\
\hline NOB1 & 0,605 & $7,664 \mathrm{E}-14$ \\
\hline MCM4 & 0,605 & $2,080 \mathrm{E}-16$ \\
\hline SMUG1 & 0,605 & $1,282 \mathrm{E}-22$ \\
\hline GULP1 & 0,605 & $3,404 \mathrm{E}-13$ \\
\hline
\end{tabular}

\begin{tabular}{|c|c|c|}
\hline$S F 3 B 4$ & 0,605 & $2,895 \mathrm{E}-25$ \\
\hline CD320 & 0,604 & $5,569 \mathrm{E}-27$ \\
\hline EIF5A & 0,604 & $5,005 \mathrm{E}-33$ \\
\hline SPC24 & 0,604 & $4,242 \mathrm{E}-26$ \\
\hline DYM & 0,604 & $2,377 \mathrm{E}-16$ \\
\hline TGFB1/1 & 0,604 & $4,458 \mathrm{E}-26$ \\
\hline HNRNPC & 0,604 & $7,010 \mathrm{E}-20$ \\
\hline GTF3C6 & 0,604 & $3,733 \mathrm{E}-16$ \\
\hline C16orf59 & 0,603 & $4,403 \mathrm{E}-18$ \\
\hline PPP1R11 & 0,603 & $1,541 \mathrm{E}-15$ \\
\hline LPPR2 & 0,603 & $8,730 \mathrm{E}-17$ \\
\hline KIAA1712 & 0,603 & $5,954 \mathrm{E}-17$ \\
\hline MRPS16 & 0,602 & $3,432 \mathrm{E}-23$ \\
\hline MED22 & 0,602 & $2,101 \mathrm{E}-23$ \\
\hline PLK1 & 0,602 & $6,625 \mathrm{E}-12$ \\
\hline ABHDS & 0,602 & $2,208 \mathrm{E}-20$ \\
\hline CD151 & 0,602 & $9,244 \mathrm{E}-28$ \\
\hline NR2C2AP & 0,602 & $7,251 \mathrm{E}-21$ \\
\hline SNRPF & 0,601 & $1,689 \mathrm{E}-27$ \\
\hline$F C R L B$ & 0,601 & $7,475 \mathrm{E}-22$ \\
\hline FARS2 & 0,601 & $3,998 \mathrm{E}-19$ \\
\hline ECE2 & 0,601 & $6,333 \mathrm{E}-23$ \\
\hline ZNF395 & 0,600 & $3,106 \mathrm{E}-22$ \\
\hline FAM111A & 0,600 & $8,057 \mathrm{E}-19$ \\
\hline VRK1 & 0,600 & $1,347 \mathrm{E}-20$ \\
\hline THOP1 & 0,600 & $2,530 \mathrm{E}-23$ \\
\hline SNORA12 & 0,599 & $4,213 \mathrm{E}-17$ \\
\hline MRPS26 & 0,599 & $4,201 \mathrm{E}-30$ \\
\hline RPSGKB2 & 0,599 & $3,190 \mathrm{E}-18$ \\
\hline UCHLSIP & 0,599 & $4,784 \mathrm{E}-28$ \\
\hline IRFI & 0,599 & $2,198 \mathrm{E}-22$ \\
\hline DCAF7 & 0,599 & $1,073 \mathrm{E}-25$ \\
\hline KIF22 & 0,598 & $2,093 \mathrm{E}-16$ \\
\hline
\end{tabular}


Supplementary Table S4.9: continued

\begin{tabular}{|c|c|c|}
\hline$G P X 1$ & 0,598 & $8,766 \mathrm{E}-19$ \\
\hline POM121C & 0,598 & $1,080 \mathrm{E}-25$ \\
\hline MUL1 & 0,597 & $2,095 \mathrm{E}-22$ \\
\hline ZMAT2 & 0,597 & $3,840 \mathrm{E}-29$ \\
\hline TMBIM4 & 0,596 & $2,150 \mathrm{E}-31$ \\
\hline C3orf10 & 0,596 & $2,436 \mathrm{E}-21$ \\
\hline MRPL1 & 0,596 & $1,012 \mathrm{E}-17$ \\
\hline NUP62 & 0,596 & $6,858 \mathrm{E}-24$ \\
\hline TFDP 1 & 0,596 & $4,000 E-15$ \\
\hline TrW3 & 0,596 & $1,175 \mathrm{E}-18$ \\
\hline COPS7A & 0,595 & $4,743 \mathrm{E}-17$ \\
\hline GNA11 & 0,594 & $3,842 \mathrm{E}-21$ \\
\hline MCMG & 0,594 & $8,048 \mathrm{E}-26$ \\
\hline NUP35 & 0,593 & $1,586 \mathrm{E}-20$ \\
\hline BARD1 & 0,593 & $1,071 \mathrm{E}-25$ \\
\hline PFAS & 0,592 & $9,434 \mathrm{E}-24$ \\
\hline RRS1 & 0,592 & $6,695 \mathrm{E}-22$ \\
\hline 102 & 0,592 & $1,801 \mathrm{E}-22$ \\
\hline MGST2 & 0,592 & $4,971 \mathrm{E}-28$ \\
\hline PTMS & 0,592 & $3,747 \mathrm{E}-25$ \\
\hline RNF144A & 0,591 & $8,342 \mathrm{E}-17$ \\
\hline MED25 & 0,591 & $3,611 \mathrm{E}-35$ \\
\hline $\mathrm{DH} \times 37$ & 0,591 & $4,645 \mathrm{E}-22$ \\
\hline ATP5G1 & 0,590 & $1,601 \mathrm{E}-22$ \\
\hline MRPL48 & 0,590 & $1,609 \mathrm{E}-24$ \\
\hline GPR81 & 0,589 & $2,110 \mathrm{E}-18$ \\
\hline HJURP & 0,589 & $3,122 \mathrm{E}-21$ \\
\hline C17orf 93 & 0,589 & $2,658 \mathrm{E}-17$ \\
\hline SLCSAG & 0,589 & $1,591 \mathrm{E}-23$ \\
\hline$D T L$ & 0,588 & $8,442 \mathrm{E}-16$ \\
\hline$A D C Y_{3}$ & 0,588 & $3,550 \mathrm{E}-21$ \\
\hline TMEM123 & 0,588 & $5,163 \mathrm{E}-21$ \\
\hline HSPBAP1 & 0,588 & $1,436 \mathrm{E}-21$ \\
\hline
\end{tabular}

\begin{tabular}{|c|c|c|}
\hline MRPS35 & 0,587 & 9,596E-19 \\
\hline SH3GL1 & 0,586 & $3,709 \mathrm{E}-20$ \\
\hline HMBS & 0,586 & $1,033 \mathrm{E}-19$ \\
\hline POLR3C & 0,586 & $4,842 \mathrm{E}-24$ \\
\hline $\operatorname{cox} \times 10$ & 0,586 & $1,356 \mathrm{E}-23$ \\
\hline C8orf55 & 0,586 & $3,037 \mathrm{E}-30$ \\
\hline B3GALT6 & 0,585 & $1,421 \mathrm{E}-24$ \\
\hline TUBA1A & 0,585 & $2,759 \mathrm{E}-20$ \\
\hline GMNN & 0,584 & $6,585 \mathrm{E}-16$ \\
\hline PAXIP1 & 0,584 & $6,558 \mathrm{E}-25$ \\
\hline RPL28 & 0,584 & $1,644 \mathrm{E}-15$ \\
\hline GPR110 & 0,583 & $7,234 \mathrm{E}-25$ \\
\hline PRNP & 0,583 & $2,143 \mathrm{E}-25$ \\
\hline GPSM2 & 0,583 & $4,294 \mathrm{E}-28$ \\
\hline NRM & 0,582 & $5,939 \mathrm{E}-17$ \\
\hline TOMM $40 \mathrm{~L}$ & 0,582 & $9,128 \mathrm{E}-24$ \\
\hline TMEM216 & 0,582 & $8,502 E-21$ \\
\hline BUB1B & 0,582 & $5,588 \mathrm{E}-17$ \\
\hline PSMG4 & 0,581 & $2,024 \mathrm{E}-24$ \\
\hline ATPGVODI & 0,581 & $7,178 \mathrm{E}-22$ \\
\hline$P E C R$ & 0,581 & $7,197 \mathrm{E}-31$ \\
\hline CENPM & 0,580 & $3,665 \mathrm{E}-25$ \\
\hline$C D C 2 O$ & 0,580 & $5,396 \mathrm{E}-25$ \\
\hline CWF19L1 & 0,579 & $9,587 \mathrm{E}-22$ \\
\hline ZDHHCS & 0,579 & $2,972 \mathrm{E}-21$ \\
\hline ABHD14A & 0,579 & $1,367 \mathrm{E}-28$ \\
\hline SNORD 31 & 0,578 & $7,036 \mathrm{E}-17$ \\
\hline AP $3 M 2$ & 0,578 & $6,300 E-27$ \\
\hline CDK5 & 0,578 & $1,026 \mathrm{E}-13$ \\
\hline CENPL & 0,578 & $1,551 \mathrm{E}-17$ \\
\hline ZDHHC8 & 0,577 & $3,776 \mathrm{E}-18$ \\
\hline KIAA1522 & 0,577 & $1,908 \mathrm{E}-18$ \\
\hline BRIX1 & 0,577 & 9,967E-18 \\
\hline
\end{tabular}

\begin{tabular}{|c|c|c|}
\hline CDKN2B & 0,577 & $1,432 \mathrm{E}-23$ \\
\hline SLC25A3 & 0,577 & $2,684 \mathrm{E}-21$ \\
\hline KNTC1 & 0,576 & $3,412 \mathrm{E}-21$ \\
\hline TUBв & 0,576 & $2,830 \mathrm{E}-29$ \\
\hline HMMR & 0,576 & $9,758 \mathrm{E}-17$ \\
\hline STMN3 & 0,576 & $2,027 \mathrm{E}-31$ \\
\hline PAQR4 & 0,575 & $9,892 \mathrm{E}-22$ \\
\hline CCDC28A & 0,575 & $8,369 \mathrm{E}-21$ \\
\hline$C C D C 5$ & 0,574 & $2,017 \mathrm{E}-15$ \\
\hline CENPF & 0,574 & $1,516 \mathrm{E}-23$ \\
\hline C8orf33 & 0,574 & $4,557 \mathrm{E}-27$ \\
\hline $\mathrm{COQ}_{3}$ & 0,573 & $2,452 \mathrm{E}-22$ \\
\hline CDIPT & 0,573 & $2,099 \mathrm{E}-18$ \\
\hline DSN1 & 0,572 & $1,001 \mathrm{E}-12$ \\
\hline TRIM4 & 0,572 & $1,097 \mathrm{E}-24$ \\
\hline WDR4 & 0,572 & $4,740 \mathrm{E}-23$ \\
\hline TXNIP & 0,571 & $5,238 \mathrm{E}-28$ \\
\hline RFC5 & 0,571 & $3,182 \mathrm{E}-19$ \\
\hline$C D C 7$ & 0,571 & $1,350 \mathrm{E}-17$ \\
\hline ADNP2 & 0,571 & $2,518 \mathrm{E}-18$ \\
\hline KIF4A & 0,570 & $2,303 E-21$ \\
\hline SFXN4 & 0,570 & $2,879 \mathrm{E}-25$ \\
\hline WDR67 & 0,568 & $2,698 \mathrm{E}-33$ \\
\hline NOP16 & 0,568 & $8,397 \mathrm{E}-25$ \\
\hline MED16 & 0,568 & $2,028 \mathrm{E}-15$ \\
\hline METAP1 & 0,567 & $3,889 \mathrm{E}-23$ \\
\hline ALDH1B1 & 0,567 & $1,272 \mathrm{E}-11$ \\
\hline ARLGIP1 & 0,567 & $4,504 \mathrm{E}-23$ \\
\hline PIGC & 0,567 & $1,413 \mathrm{E}-19$ \\
\hline$\pi K$ & 0,567 & $3,407 \mathrm{E}-16$ \\
\hline C11orf83 & 0,566 & $2,420 \mathrm{E}-24$ \\
\hline TUBB3 & 0,566 & $3,323 \mathrm{E}-24$ \\
\hline Clorf135 & 0,565 & $2,190 \mathrm{E}-31$ \\
\hline
\end{tabular}

\begin{tabular}{|c|c|c|}
\hline RHOG & 0,565 & $7,785 \mathrm{E}-29$ \\
\hline FOXM1 & 0,565 & $3,944 \mathrm{E}-23$ \\
\hline UBQLN4 & 0,565 & $2,331 \mathrm{E}-17$ \\
\hline MAPK13 & 0,565 & $9,565 \mathrm{E}-23$ \\
\hline LYAR & 0,565 & $7,137 \mathrm{E}-23$ \\
\hline RRAGB & 0,564 & $3,483 \mathrm{E}-25$ \\
\hline TMEM145 & 0,564 & $1,160 \mathrm{E}-21$ \\
\hline RFWD3 & 0,564 & $1,980 \mathrm{E}-29$ \\
\hline PHB & 0,563 & $4,031 \mathrm{E}-31$ \\
\hline MED3O & 0,563 & $1,782 \mathrm{E}-19$ \\
\hline LRRC47 & 0,563 & $3,523 \mathrm{E}-27$ \\
\hline CTDSP2 & 0,562 & $5,088 \mathrm{E}-28$ \\
\hline TRIP6 & 0,562 & $2,451 \mathrm{E}-15$ \\
\hline MTHFD1 & 0,561 & $2,748 \mathrm{E}-25$ \\
\hline ACTLGA & 0,561 & $1,250 \mathrm{E}-16$ \\
\hline RAD54L & 0,561 & $8,287 \mathrm{E}-27$ \\
\hline SURF 4 & 0,561 & $9,759 \mathrm{E}-26$ \\
\hline BACE2 & 0,560 & $5,516 \mathrm{E}-34$ \\
\hline GTSE1 & 0,558 & $3,072 \mathrm{E}-26$ \\
\hline C11orf67 & 0,558 & $7,133 \mathrm{E}-27$ \\
\hline$B C L 7 C$ & 0,558 & $3,895 \mathrm{E}-24$ \\
\hline RASL11A & 0,558 & $5,759 \mathrm{E}-16$ \\
\hline HMGB1L1 & 0,558 & $3,645 \mathrm{E}-10$ \\
\hline HSBP 1 & 0,557 & $3,929 \mathrm{E}-28$ \\
\hline ANLN & 0,557 & $5,203 \mathrm{E}-26$ \\
\hline CKAPS & 0,557 & $1,089 \mathrm{E}-22$ \\
\hline DEK & 0,556 & $9,878 \mathrm{E}-27$ \\
\hline$P X N$ & 0,555 & $6,586 \mathrm{E}-28$ \\
\hline ETV4 & 0,555 & $1,513 \mathrm{E}-19$ \\
\hline UBN1 & 0,555 & $1,184 \mathrm{E}-15$ \\
\hline DNAJC9 & 0,554 & $2,067 \mathrm{E}-26$ \\
\hline ZNHIT2 & 0,553 & $3,201 \mathrm{E}-19$ \\
\hline$D C K$ & 0,553 & $6,797 \mathrm{E}-16$ \\
\hline
\end{tabular}


CHAPTER 4

Supplementary Table S4.9: continued

\begin{tabular}{|c|c|c|}
\hline EXTLZ & 0,553 & $7,530 \mathrm{E}-21$ \\
\hline C14orfio6 & 0,552 & $4,804 \mathrm{E}-24$ \\
\hline TMEM19 & 0,552 & $1,444 \mathrm{E}-19$ \\
\hline ARHGAP1 & 0,551 & $3,711 \mathrm{E}-23$ \\
\hline WDR51A & 0,551 & $1,138 \mathrm{E}-31$ \\
\hline SNORD96A & 0,550 & $5,448 \mathrm{E}-19$ \\
\hline$S A C 3 D 1$ & 0,550 & $5,727 \mathrm{E}-25$ \\
\hline KIAA0114 & 0,550 & $2,015 \mathrm{E}-26$ \\
\hline IMPDH2 & 0,550 & $4,786 \mathrm{E}-18$ \\
\hline Clorf 86 & 0,549 & $2,131 \mathrm{E}-28$ \\
\hline$B E X 1$ & 0,549 & $5,436 \mathrm{E}-21$ \\
\hline CDCA4 & 0,549 & $4,479 \mathrm{E}-27$ \\
\hline TSGA14 & 0,548 & $1,057 \mathrm{E}-21$ \\
\hline LMNB2 & 0,548 & $1,335 \mathrm{E}-28$ \\
\hline SLMAP & 0,548 & $4,516 \mathrm{E}-24$ \\
\hline CKAP2L & 0,547 & $4,575 \mathrm{E}-29$ \\
\hline TFCP2 & 0,547 & $1,179 \mathrm{E}-22$ \\
\hline HAS3 & 0,546 & $6,291 \mathrm{E}-18$ \\
\hline LMNB1 & 0,546 & $4,229 \mathrm{E}-18$ \\
\hline FSCN1 & 0,545 & $1,203 \mathrm{E}-28$ \\
\hline EMG1 & 0,545 & $1,914 \mathrm{E}-26$ \\
\hline ASPM & 0,544 & $1,451 \mathrm{E}-24$ \\
\hline MAP4K4 & 0,544 & $6,161 \mathrm{E}-20$ \\
\hline SRM & 0,544 & $2,864 \mathrm{E}-17$ \\
\hline POLD1 & 0,544 & $1,048 \mathrm{E}-23$ \\
\hline COX7AZL & 0,543 & $5,226 \mathrm{E}-25$ \\
\hline BFAR & 0,542 & $1,014 \mathrm{E}-21$ \\
\hline MAF1 & 0,542 & $3,808 \mathrm{E}-26$ \\
\hline EXOSCg & 0,541 & $7,738 \mathrm{E}-33$ \\
\hline RACGAP1 & 0,541 & $5,622 \mathrm{E}-24$ \\
\hline EEF1E1 & 0,541 & $5,536 \mathrm{E}-29$ \\
\hline$N R G N$ & 0,541 & $7,212 \mathrm{E}-18$ \\
\hline$A Q P 11$ & 0,540 & $2,812 \mathrm{E}-19$ \\
\hline
\end{tabular}

\begin{tabular}{|c|c|c|}
\hline DUT & 0,540 & $2,390 \mathrm{E}-29$ \\
\hline KATNB1 & 0,539 & $1,494 \mathrm{E}-26$ \\
\hline APOBEC $3 B$ & 0,538 & $7,132 \mathrm{E}-21$ \\
\hline UBA52 & 0,538 & $6,081 E-27$ \\
\hline TMEM126A & 0,538 & $1,330 \mathrm{E}-24$ \\
\hline VEGFC & 0,538 & $3,645 E-21$ \\
\hline$S L C 25 A 6$ & 0,537 & $6,796 \mathrm{E}-23$ \\
\hline BDNF & 0,537 & $2,386 \mathrm{E}-24$ \\
\hline MLLT11 & 0,535 & $2,436 \mathrm{E}-24$ \\
\hline C13orf34 & 0,535 & $2,508 \mathrm{E}-16$ \\
\hline UBIAD1 & 0,535 & $2,779 \mathrm{E}-28$ \\
\hline HN1 & 0,535 & $2,570 E-13$ \\
\hline ALS2CR4 & 0,534 & $5,981 E-25$ \\
\hline GART & 0,534 & $4,732 \mathrm{E}-33$ \\
\hline C15orf23 & 0,533 & $4,262 \mathrm{E}-28$ \\
\hline NEDD8 & 0,532 & $1,226 \mathrm{E}-10$ \\
\hline CHAF1B & 0,531 & $3,373 \mathrm{E}-26$ \\
\hline ECT2 & 0,530 & $5,781 \mathrm{E}-18$ \\
\hline BOLA3 & 0,530 & $7,106 \mathrm{E}-24$ \\
\hline MCM2 & 0,530 & $3,091 \mathrm{E}-24$ \\
\hline TWIST1 & 0,529 & $1,905 E-24$ \\
\hline STEAP1 & 0,528 & $1,431 \mathrm{E}-25$ \\
\hline POLR1D & 0,528 & $7,356 \mathrm{E}-29$ \\
\hline IRAKI & 0,528 & $8,637 \mathrm{E}-23$ \\
\hline PRR11 & 0,527 & $1,270 \mathrm{E}-19$ \\
\hline APEX1 & 0,526 & $4,919 \mathrm{E}-34$ \\
\hline INCENP & 0,526 & $2,577 \mathrm{E}-36$ \\
\hline CCTEA & 0,525 & $3,035 E-20$ \\
\hline KCTD1O & 0,525 & $2,642 \mathrm{E}-20$ \\
\hline PITXI & 0,525 & $1,301 \mathrm{E}-28$ \\
\hline C16orf52 & 0,524 & $1,142 \mathrm{E}-20$ \\
\hline NDE1 & 0,524 & $1,539 \mathrm{E}-18$ \\
\hline TIMM9 & 0,524 & $3,017 \mathrm{E}-21$ \\
\hline
\end{tabular}

\begin{tabular}{|c|c|c|}
\hline BUB1 & 0,524 & $7,920 \mathrm{E}-23$ \\
\hline PSMG1 & 0,524 & $2,360 E-26$ \\
\hline HNRPAIP4 & 0,523 & $1,542 \mathrm{E}-21$ \\
\hline HEATR2 & 0,522 & $8,741 E-23$ \\
\hline SAAL1 & 0,522 & $4,576 \mathrm{E}-36$ \\
\hline HAUS4 & 0,521 & $1,930 \mathrm{E}-25$ \\
\hline PITPNCI & 0,521 & $5,554 \mathrm{E}-23$ \\
\hline CHEK1 & 0,521 & $8,774 \mathrm{E}-26$ \\
\hline ARLGIPG & 0,520 & $1,451 \mathrm{E}-19$ \\
\hline TMEM109 & 0,519 & $3,636 \mathrm{E}-34$ \\
\hline PLK4 & 0,519 & $5,407 E-19$ \\
\hline C19orf 48 & 0,518 & $1,980 \mathrm{E}-29$ \\
\hline CLPTM1 & 0,518 & $5,942 E-24$ \\
\hline PFKL & 0,517 & $2,098 \mathrm{E}-20$ \\
\hline PHF19 & 0,517 & $2,081 \mathrm{E}-32$ \\
\hline LRRC2O & 0,517 & $2,529 \mathrm{E}-23$ \\
\hline$C D C A 3$ & 0,516 & $6,917 \mathrm{E}-34$ \\
\hline$A L G 3$ & 0,516 & $1,955 \mathrm{E}-31$ \\
\hline CENPE & 0,515 & $2,530 \mathrm{E}-23$ \\
\hline GGCT & 0,515 & $8,358 \mathrm{E}-27$ \\
\hline C13orf37 & 0,515 & $6,712 \mathrm{E}-30$ \\
\hline DPH2 & 0,513 & $8,925 \mathrm{E}-30$ \\
\hline PTGES2 & 0,512 & $1,153 \mathrm{E}-30$ \\
\hline NETO2 & 0,511 & $1,607 \mathrm{E}-21$ \\
\hline CENPB & 0,511 & $8,130 \mathrm{E}-30$ \\
\hline UNG & 0,508 & $6,003 \mathrm{E}-22$ \\
\hline KIF 11 & 0,508 & $1,324 \mathrm{E}-20$ \\
\hline$H M G B 2$ & 0,508 & $3,151 \mathrm{E}-26$ \\
\hline POLA2 & 0,507 & $2,206 \mathrm{E}-23$ \\
\hline NXTI & 0,507 & $4,039 E-31$ \\
\hline$C X C L 6$ & 0,506 & $7,709 \mathrm{E}-21$ \\
\hline FANCG & 0,506 & $1,894 \mathrm{E}-36$ \\
\hline HRASLSB & 0,505 & $5,477 \mathrm{E}-23$ \\
\hline
\end{tabular}

\begin{tabular}{|c|c|c|}
\hline FAMG4A & 0,505 & $2,638 \mathrm{E}-27$ \\
\hline HNRNPAO & 0,505 & $4,346 \mathrm{E}-22$ \\
\hline ZNF362 & 0,505 & $9,126 \mathrm{E}-25$ \\
\hline POLA1 & 0,504 & $9,147 \mathrm{E}-33$ \\
\hline ZNF689 & 0,504 & $1,354 \mathrm{E}-34$ \\
\hline FBXOS & 0,502 & $3,975 \mathrm{E}-21$ \\
\hline$R F C 4$ & 0,501 & $6,749 \mathrm{E}-29$ \\
\hline$S N X 3$ & 0,500 & $1,429 \mathrm{E}-38$ \\
\hline ERAL1 & 0,499 & $3,785 \mathrm{E}-32$ \\
\hline B4GALT3 & 0,499 & $3,950 \mathrm{E}-17$ \\
\hline RNF144 & 0,498 & $1,630 \mathrm{E}-35$ \\
\hline$E 2 F 2$ & 0,498 & $5,575 \mathrm{E}-24$ \\
\hline PPM1G & 0,498 & $7,370 \mathrm{E}-39$ \\
\hline PTPMT1 & 0,498 & $8,062 \mathrm{E}-25$ \\
\hline POLQ & 0,498 & $8,090 \mathrm{E}-27$ \\
\hline NDUFA3 & 0,496 & $1,254 \mathrm{E}-34$ \\
\hline CDC25A & 0,496 & $4,144 \mathrm{E}-33$ \\
\hline EIF4EBP2 & 0,495 & $2,891 \mathrm{E}-25$ \\
\hline PDLIM1 & 0,495 & $1,304 \mathrm{E}-44$ \\
\hline ТОММ4O & 0,494 & 9,590E-39 \\
\hline RRM1 & 0,494 & $1,249 \mathrm{E}-33$ \\
\hline SNHG1 & 0,494 & $5,857 \mathrm{E}-24$ \\
\hline$X R C C 5$ & 0,494 & $5,266 \mathrm{E}-26$ \\
\hline RBM9 & 0,493 & $6,310 \mathrm{E}-29$ \\
\hline RRM2 & 0,493 & $2,243 \mathrm{E}-25$ \\
\hline CKS1B & 0,493 & $1,300 \mathrm{E}-26$ \\
\hline NUP107 & 0,493 & $4,807 E-33$ \\
\hline C16orf35 & 0,492 & $1,297 \mathrm{E}-28$ \\
\hline MMACHC & 0,492 & $1,406 \mathrm{E}-24$ \\
\hline BTBD2 & 0,492 & $9,017 \mathrm{E}-39$ \\
\hline ARHGAP24 & 0,491 & $4,203 E-26$ \\
\hline RTN4 & 0,491 & $9,892 \mathrm{E}-19$ \\
\hline TMEM27 & 0,490 & $3,313 \mathrm{E}-30$ \\
\hline
\end{tabular}


Supplementary Table S4.9: continued

\begin{tabular}{|c|c|c|}
\hline $\cos 1$ & 0,490 & $6,823 \mathrm{E}-27$ \\
\hline MELK & 0,490 & $1,983 \mathrm{E}-28$ \\
\hline LXN & 0,489 & $8,188 \mathrm{E}-25$ \\
\hline BCL2L12 & 0,489 & $3,699 \mathrm{E}-29$ \\
\hline MICB & 0,487 & $4,452 \mathrm{E}-33$ \\
\hline NFIX & 0,486 & $7,476 \mathrm{E}-42$ \\
\hline CKS2 & 0,486 & $6,455 \mathrm{E}-22$ \\
\hline KIF 14 & 0,486 & $7,008 \mathrm{E}-24$ \\
\hline$T P X 2$ & 0,485 & $3,927 \mathrm{E}-33$ \\
\hline UBE2I & 0,484 & $3,438 \mathrm{E}-29$ \\
\hline$C C N G 1$ & 0,484 & $4,566 \mathrm{E}-25$ \\
\hline C3orf14 & 0,483 & $9,121 \mathrm{E}-28$ \\
\hline NR1H2 & 0,483 & $6,843 \mathrm{E}-23$ \\
\hline DSCC1 & 0,483 & $1,721 \mathrm{E}-18$ \\
\hline PIGN & 0,482 & $1,613 \mathrm{E}-28$ \\
\hline GGPC3 & 0,482 & $7,892 \mathrm{E}-25$ \\
\hline$C L E C 2 D$ & 0,482 & $1,451 \mathrm{E}-14$ \\
\hline DIMT1L & 0,482 & $3,999 \mathrm{E}-36$ \\
\hline PLSCR1 & 0,482 & $2,787 \mathrm{E}-22$ \\
\hline PIGT & 0,482 & $1,960 \mathrm{E}-37$ \\
\hline SLC25A19 & 0,481 & $1,964 \mathrm{E}-39$ \\
\hline NUSAP1 & 0,480 & $1,632 \mathrm{E}-18$ \\
\hline C9orf30 & 0,479 & $3,601 \mathrm{E}-19$ \\
\hline KATNALI & 0,479 & $4,218 \mathrm{E}-29$ \\
\hline CCNA2 & 0,476 & $1,751 \mathrm{E}-21$ \\
\hline MESP1 & 0,475 & $4,508 \mathrm{E}-31$ \\
\hline RPL13A & 0,474 & $1,937 \mathrm{E}-28$ \\
\hline RHBDF2 & 0,474 & $2,943 \mathrm{E}-28$ \\
\hline$C B \times 6$ & 0,473 & $8,475 \mathrm{E}-38$ \\
\hline SDHAF2 & 0,473 & $1,507 \mathrm{E}-32$ \\
\hline MRPS3O & 0,472 & $6,717 \mathrm{E}-27$ \\
\hline EXOSC6 & 0,472 & $2,131 \mathrm{E}-21$ \\
\hline ATPGVOE2 & 0,471 & $1,206 \mathrm{E}-35$ \\
\hline
\end{tabular}

\begin{tabular}{|c|c|c|}
\hline QTRT1 & 0,471 & $2,291 \mathrm{E}-13$ \\
\hline MRPL36 & 0,470 & $2,261 \mathrm{E}-40$ \\
\hline KIFCI & 0,470 & $3,458 \mathrm{E}-31$ \\
\hline$B A G 3$ & 0,470 & $3,100 \mathrm{E}-32$ \\
\hline KIF 23 & 0,469 & $1,773 \mathrm{E}-21$ \\
\hline CEP55 & 0,469 & $1,207 \mathrm{E}-28$ \\
\hline ATPGVOC & 0,469 & $1,307 \mathrm{E}-31$ \\
\hline MNS1 & 0,468 & $8,125 \mathrm{E}-20$ \\
\hline SUPTAH1 & 0,468 & $1,438 \mathrm{E}-34$ \\
\hline RGS7 & 0,467 & $7,271 \mathrm{E}-26$ \\
\hline C2orf7 & 0,466 & $4,139 \mathrm{E}-26$ \\
\hline$R F C 3$ & 0,465 & $3,426 \mathrm{E}-25$ \\
\hline FAM $36 A$ & 0,463 & $7,203 \mathrm{E}-19$ \\
\hline OIPS & 0,463 & $7,069 \mathrm{E}-43$ \\
\hline FEN1 & 0,461 & $7,602 \mathrm{E}-24$ \\
\hline RADS4B & 0,461 & $4,492 \mathrm{E}-25$ \\
\hline FANCI & 0,460 & $7,419 \mathrm{E}-27$ \\
\hline ATAD2 & 0,460 & $1,361 \mathrm{E}-15$ \\
\hline C16orf 33 & 0,459 & $6,052 \mathrm{E}-28$ \\
\hline PRIMI & 0,459 & $3,689 \mathrm{E}-22$ \\
\hline CENPA & 0,458 & $1,660 \mathrm{E}-30$ \\
\hline VARS & 0,458 & $1,522 \mathrm{E}-35$ \\
\hline PLCXD3 & 0,458 & $1,613 \mathrm{E}-27$ \\
\hline CCNB1 & 0,457 & $9,141 \mathrm{E}-19$ \\
\hline$C C D C 86$ & 0,456 & $8,547 \mathrm{E}-20$ \\
\hline UBE2T & 0,456 & $2,281 \mathrm{E}-36$ \\
\hline$C D C A B$ & 0,454 & $2,012 \mathrm{E}-36$ \\
\hline$K I F 2 O B$ & 0,454 & $7,287 \mathrm{E}-29$ \\
\hline C17orf53 & 0,452 & $5,671 \mathrm{E}-34$ \\
\hline ТТYн3 & 0,452 & $3,358 \mathrm{E}-30$ \\
\hline ANKRD22 & 0,452 & $1,746 \mathrm{E}-27$ \\
\hline ZNF358 & 0,451 & $6,022 \mathrm{E}-28$ \\
\hline ANPEP & 0,448 & $1,969 \mathrm{E}-26$ \\
\hline
\end{tabular}

\begin{tabular}{|c|c|c|}
\hline TOP2A & 0,448 & $1,845 \mathrm{E}-34$ \\
\hline CDKN2C & 0,447 & $8,658 \mathrm{E}-31$ \\
\hline HZAFX & 0,446 & $2,155 \mathrm{E}-28$ \\
\hline TRAPPC1 & 0,445 & $2,603 \mathrm{E}-37$ \\
\hline TTF2 & 0,445 & $2,233 \mathrm{E}-23$ \\
\hline NHP2 & 0,443 & $1,161 \mathrm{E}-37$ \\
\hline$R B B P 8$ & 0,443 & $2,177 \mathrm{E}-37$ \\
\hline TYMS & 0,440 & $5,352 \mathrm{E}-31$ \\
\hline SUV39H1 & 0,440 & $5,239 \mathrm{E}-36$ \\
\hline PBK & 0,439 & $2,424 \mathrm{E}-34$ \\
\hline$P G D$ & 0,437 & $1,297 \mathrm{E}-36$ \\
\hline GLOD4 & 0,436 & $6,203 \mathrm{E}-29$ \\
\hline TIMELESS & 0,435 & $3,922 \mathrm{E}-41$ \\
\hline SMARCD1 & 0,433 & $1,585 \mathrm{E}-32$ \\
\hline NUP85 & 0,433 & $5,026 \mathrm{E}-27$ \\
\hline EHD1 & 0,433 & $6,715 \mathrm{E}-30$ \\
\hline DDX54 & 0,432 & $9,889 \mathrm{E}-29$ \\
\hline NGRN & 0,431 & $3,341 \mathrm{E}-32$ \\
\hline $\mathrm{CDH} 11$ & 0,431 & $4,352 \mathrm{E}-33$ \\
\hline TMEM54 & 0,430 & $1,746 \mathrm{E}-31$ \\
\hline NCAPG & 0,428 & $1,083 \mathrm{E}-29$ \\
\hline$E M P 1$ & 0,428 & $2,063 \mathrm{E}-28$ \\
\hline TMEM189 & 0,427 & $1,306 \mathrm{E}-21$ \\
\hline PAK4 & 0,427 & $2,481 \mathrm{E}-20$ \\
\hline CDK4 & 0,426 & $3,404 \mathrm{E}-40$ \\
\hline GINS3 & 0,425 & $1,479 \mathrm{E}-28$ \\
\hline CENPN & 0,424 & $1,992 \mathrm{E}-19$ \\
\hline CDT1 & 0,423 & $9,144 \mathrm{E}-40$ \\
\hline CDKN3 & 0,423 & $3,720 \mathrm{E}-41$ \\
\hline$\angle C P 1$ & 0,420 & $8,422 \mathrm{E}-33$ \\
\hline HAS2 & 0,420 & $1,009 \mathrm{E}-31$ \\
\hline CLDN11 & 0,417 & $3,104 \mathrm{E}-29$ \\
\hline ATPSSL & 0,415 & $2,198 \mathrm{E}-33$ \\
\hline
\end{tabular}

\begin{tabular}{|c|c|c|}
\hline REPIN1 & 0,414 & $5,385 E-39$ \\
\hline SLC35A4 & 0,414 & $2,146 \mathrm{E}-27$ \\
\hline |FRD2 & 0,413 & $1,356 \mathrm{E}-28$ \\
\hline ZWILCH & 0,412 & $5,696 \mathrm{E}-21$ \\
\hline MAD2L1 & 0,412 & $7,439 \mathrm{E}-29$ \\
\hline KIF $20 A$ & 0,408 & $2,080 \mathrm{E}-40$ \\
\hline C12orf48 & 0,407 & $7,638 \mathrm{E}-43$ \\
\hline CDCA7 & 0,406 & $7,914 \mathrm{E}-43$ \\
\hline DAP & 0,404 & $6,056 \mathrm{E}-44$ \\
\hline UHRF1 & 0,404 & $3,891 \mathrm{E}-39$ \\
\hline PPIL1 & 0,403 & $5,025 \mathrm{E}-32$ \\
\hline CABLES1 1 & 0,403 & $1,713 \mathrm{E}-31$ \\
\hline PRC1 & 0,403 & $1,335 \mathrm{E}-32$ \\
\hline JMJDS & 0,398 & $5,442 E-30$ \\
\hline$C D C 2$ & 0,398 & $1,450 \mathrm{E}-26$ \\
\hline TROAP & 0,398 & $1,509 \mathrm{E}-35$ \\
\hline SHISA2 & 0,397 & $8,118 \mathrm{E}-29$ \\
\hline$M D K$ & 0,395 & $8,950 \mathrm{E}-41$ \\
\hline CLCN7 & 0,394 & $3,268 \mathrm{E}-41$ \\
\hline SEPN1 & 0,391 & $3,638 \mathrm{E}-44$ \\
\hline FAM 830 & 0,389 & $6,301 \mathrm{E}-35$ \\
\hline POLE2 & 0,388 & $3,287 \mathrm{E}-23$ \\
\hline AURKA & 0,388 & $1,687 \mathrm{E}-25$ \\
\hline KIF2C & 0,387 & $8,351 \mathrm{E}-37$ \\
\hline NTSR1 & 0,386 & $1,959 \mathrm{E}-34$ \\
\hline TRIP13 & 0,386 & $1,013 \mathrm{E}-30$ \\
\hline CCNB2 & 0,385 & $8,758 \mathrm{E}-34$ \\
\hline C11orf82 & 0,385 & $4,625 \mathrm{E}-34$ \\
\hline HMGA1 & 0,384 & $1,568 \mathrm{E}-41$ \\
\hline EPN1 & 0,380 & $1,228 \mathrm{E}-45$ \\
\hline RRP7A & 0,379 & $4,868 \mathrm{E}-37$ \\
\hline RAD51AP1 & 0,374 & $6,956 \mathrm{E}-24$ \\
\hline CDC45L & 0,372 & $1,402 \mathrm{E}-34$ \\
\hline
\end{tabular}


CHAPTER 4

Supplementary Table S4.9: continued

\begin{tabular}{|c|c|c|}
\hline CYBSR3 & 0,372 & $7,446 \mathrm{E}-29$ \\
\hline TMEM158 & 0,371 & $1,107 \mathrm{E}-28$ \\
\hline HIST1H4C & 0,370 & $4,163 \mathrm{E}-45$ \\
\hline FOXQ1 & 0,368 & $3,404 \mathrm{E}-38$ \\
\hline ENOPH1 & 0,365 & $8,211 \mathrm{E}-23$ \\
\hline ZWINT & 0,361 & $1,864 \mathrm{E}-30$ \\
\hline SLC2A4RG & 0,358 & $1,410 \mathrm{E}-30$ \\
\hline CIRBP & 0,358 & $2,520 \mathrm{E}-36$ \\
\hline C6orf173 & 0,356 & $1,941 \mathrm{E}-29$ \\
\hline
\end{tabular}

\begin{tabular}{|c|c|c|}
\hline PDCD6 & 0,354 & $1,527 \mathrm{E}-28$ \\
\hline ASF1B & 0,350 & $4,948 \mathrm{E}-33$ \\
\hline POLE3 & 0,350 & $1,692 \mathrm{E}-31$ \\
\hline SLC35F2 & 0,349 & $1,572 \mathrm{E}-30$ \\
\hline FZD8 & 0,348 & $1,683 \mathrm{E}-38$ \\
\hline HADH2 & 0,347 & $1,318 \mathrm{E}-29$ \\
\hline C5Orf46 & 0,344 & $9,388 \mathrm{E}-47$ \\
\hline HEBP1 & 0,341 & $2,759 \mathrm{E}-36$ \\
\hline DLGAP5 & 0,332 & $2,964 \mathrm{E}-29$ \\
\hline
\end{tabular}

\begin{tabular}{|c|c|c|}
\hline MGC87042 & 0,328 & $1,107 \mathrm{E}-26$ \\
\hline AURKB & 0,327 & $1,454 \mathrm{E}-24$ \\
\hline CALB2 & 0,322 & $2,929 \mathrm{E}-29$ \\
\hline TPP1 & 0,318 & $3,612 \mathrm{E}-40$ \\
\hline PTTG1 & 0,318 & $1,056 \mathrm{E}-28$ \\
\hline CDCA5 & 0,316 & $2,138 \mathrm{E}-54$ \\
\hline COMMD4 & 0,314 & $1,665 \mathrm{E}-28$ \\
\hline NPM3 & 0,310 & $4,553 \mathrm{E}-35$ \\
\hline HSD17B10 & 0,303 & $4,055 \mathrm{E}-41$ \\
\hline
\end{tabular}

\begin{tabular}{|c|c|c|}
\hline GINS2 & 0,300 & $4,185 \mathrm{E}-42$ \\
\hline TK1 & 0,293 & $3,815 \mathrm{E}-32$ \\
\hline SET & 0,280 & $4,783 \mathrm{E}-39$ \\
\hline PTTG3P & 0,263 & $1,726 \mathrm{E}-37$ \\
\hline LGALS3BP & 0,261 & $2,709 \mathrm{E}-27$ \\
\hline DYNLRB1 & 0,248 & $2,020 \mathrm{E}-35$ \\
\hline AHCY & 0,222 & $8,607 \mathrm{E}-54$ \\
\hline
\end{tabular}


Supplementary Table S4.10A: Functional annotation of genes differentially regulated upon L1CAM knockdown in PC-3 cells

\begin{tabular}{|c|c|c|c|c|}
\hline Functional annotation & Genes & p-value & z-score* & \# Genes' \\
\hline Differentiation of cells & $\begin{array}{l}\text { TGFBR2, IL1B, IL6, EPOR, LIF, HBEGF, } \\
\text { RTN4, NGF, IL23A, GRB2 }\end{array}$ & 2.47E-09 & 3.188 & 136 \\
\hline Interphase & $\begin{array}{l}\text { TGFBR2, ID2, CDKN1C, CDk2, RBBP8, AR, } \\
\text { BIRC5, CDk4, TCF3, CDC2, E2F5 }\end{array}$ & $1.01 \mathrm{E}-07$ & -2.396 & 33 \\
\hline $\begin{array}{l}\text { Colony formation of } \\
\text { tumor cell lines }\end{array}$ & $\begin{array}{l}\text { KPNA2, IFITM3, CYR61, KRT19, SEMA3B, } \\
\text { HPGD, MDK, RASD1, E2F5, GRB2 }\end{array}$ & $3.72 \mathrm{E}-06$ & -2.247 & 24 \\
\hline Invasion of cancer cells & $\begin{array}{l}\text { S100P, AHCY, IL6, KLK6, ITGB4, CTSL, } \\
\text { ITGA1, PLAUR, FERMT2, GDF15 }\end{array}$ & $1.58 \mathrm{E}-05$ & 2.354 & 13 \\
\hline Cell death & $\begin{array}{l}\text { ADM, TOP2A, IL1B, AR, PTHLH, TGM2, } \\
\text { DUSP1, DDIT4, TNFRSR6B, PDGFB }\end{array}$ & 1.63E-05 & -2.082 & 43 \\
\hline
\end{tabular}

Top 10 differentially expressed genes in our dataset that were annotated to a function. A gene was selected when its annotation to the indicated function was based on at least two findings in the Ingenuity knowledge base. *Activation z-score is a measure of predicted change (increase or decrease) of the process. †Total number of genes supporting a specific functional annotation.

Supplementary Table S4.10B: Canonical pathway analysis of genes differentially regulated upon L1CAM knockdown in PC-3 cells

\begin{tabular}{lccc}
\hline Ingenuity Canonical Pathways & p-value & z-score* & \# Genes† \\
\hline ATM Signaling & $5.21 \mathrm{E}-07$ & 1.633 & $33(80)$ \\
Interferon Signaling & $1.75 \mathrm{E}-06$ & 3.317 & $11(36)$ \\
PPAR Signaling & $4.25 \mathrm{E}-05$ & -3.357 & $16(95)$ \\
Pancreatic Adenocarcinoma Signaling & $5.66 \mathrm{E}-04$ & 2.53 & $16(118)$ \\
VDR/RXR Activation & $9.53 \mathrm{E}-04$ & 2 & $8(789)$ \\
\hline
\end{tabular}

Significantly enriched canonical pathways across the dataset of commonly regulated genes between T/E III and $\mathrm{VI}$ are shown. *Activation z-score is a measure of predicted change (activated or reduced) of the process. +Number of genes in the dataset, which are represented in the pathway. Numbers in brackets depict the total number of genes in the pathway in the reference gene set. 


\section{REFERENCES}

1. Guate JL, Escaf S, Menendez CL, del Valle M and Vega JA. Neuroendocrine cells in benign prostatic hyperplasia and prostatic carcinoma: effect of hormonal treatment. Urol Int. 1997; 59(3):149-153.

2. Lapuk AV, Wu C, Wyatt AW, McPherson A, McConeghy BJ, Brahmbhatt S, Mo F, Zoubeidi A, Anderson S, Bell RH, Haegert A, Shukin R, Wang Y, Fazli L, Hurtado-Coll A, Jones EC, et al. From sequence to molecular pathology, and a mechanism driving the neuroendocrine phenotype in prostate cancer. J Pathol. 2012; 227(3):286-297.

3. Miyoshi Y, Uemura H, Kitami K, Satomi Y, Kubota Y and Hosaka M. Neuroendocrine differentiated small cell carcinoma presenting as recurrent prostate cancer after androgen deprivation therapy. BJU Int. 2001; 88(9):982-983.

4. Burchardt T, Burchardt M, Chen MW, Cao Y, de la Taille A, Shabsigh A, Hayek O, Dorai T and Buttyan R. Transdifferentiation of prostate cancer cells to a neuroendocrine cell phenotype in vitro and in vivo. J Urol. 1999; 162(5):1800-1805.

5. Germann M, Wetterwald A, Guzman-Ramirez N, van der Pluijm G, Culig Z, Cecchini MG, Williams ED and Thalmann GN. Stem-like cells with luminal progenitor phenotype survive castration in human prostate cancer. Stem Cells. 2012; 30(6):1076-1086.

6. Stratton M, Evans DJ and Lampert IA. Prostatic adenocarcinoma evolving into carcinoid: selective effect of hormonal treatment? J Clin Pathol. 1986; 39(7):750-756.

7. Wang HT, Yao YH, Li BG, Tang Y, Chang JW and Zhang J. Neuroendocrine Prostate Cancer (NEPC) progressing from conventional prostatic adenocarcinoma: factors associated with time to development of NEPC and survival from NEPC diagnosis-a systematic review and pooled analysis. J Clin Oncol. 2014; 32(30):3383-3390.

8. Gillessen S, Omlin A, Attard G, de Bono JS, Efstathiou E, Fizazi K, Halabi S, Nelson PS, Sartor O, Smith MR, Soule HR, Akaza H, Beer TM, Beltran H, Chinnaiyan AM, Daugaard G, et al. Management of patients with advanced prostate cancer: recommendations of the St Gallen Advanced Prostate Cancer Consensus Conference (APCCC) 2015. Ann Oncol. 2015; 26(8):1589-1604.

9. Beltran H, Rickman DS, Park K, Chae SS, Sboner A, MacDonald TY, Wang Y, Sheikh KL, Terry S, Tagawa ST, Dhir R, Nelson JB, de la Taille A, Allory Y, Gerstein MB, Perner S, et al. Molecular characterization of neuroendocrine prostate cancer and identification of new drug targets. Cancer Discov. 2011; 1(6):487-495.

10. Epstein JI, Amin MB, Beltran H, Lotan TL, Mosquera JM, Reuter VE, Robinson BD, Troncoso P and Rubin MA. Proposed morphologic classification of prostate cancer with neuroendocrine differentiation. Am J Surg Pathol. 2014; 38(6):756-767.

11. Qi J, Pellecchia M and Ronai ZA. The Siah2-HIF-FoxA2 axis in prostate cancer - new markers and therapeutic opportunities. Oncotarget. 2010; 1(5):379-385.

12. Hirano D, Jike T, Okada Y, Minei S, Sugimoto S, Yamaguchi K, Yoshikawa T, Hachiya T, Yoshida T and Takimoto Y. Immunohistochemical and ultrastructural features of neuroendocrine differentiated carcinomas of the prostate: an immunoelectron microscopic study. Ultrastruct Pathol. 2005; 29(5):367-375.

13. Bonkhoff $\mathrm{H}$, Stein $\mathrm{U}$ and Remberger $\mathrm{K}$. Endocrine-paracrine cell types in the prostate and prostatic adenocarcinoma are postmitotic cells. Hum Pathol. 1995; 26(2):167-170.

14. Sauer CG, Roemer A and Grobholz R. Genetic analysis of neuroendocrine tumor cells in prostatic carcinoma. Prostate. 2006; 66(3):227-234.

15. Lotan TL, Gupta NS, Wang W, Toubaji A, Haffner MC, Chaux A, Hicks JL, Meeker AK, Bieberich CJ, De Marzo AM, Epstein JI and Netto GJ. ERG gene rearrangements are common in prostatic small cell carcinomas. Mod Pathol. 2011; 24(6):820-828.

16. Hansel DE, Nakayama M, Luo J, Abukhdeir AM, Park BH, Bieberich CJ, Hicks JL, Eisenberger M, Nelson WG, Mostwin JL and De Marzo AM. Shared TP53 gene mutation in morphologically and phenotypically distinct concurrent primary small cell neuroendocrine carcinoma and adenocarcinoma of the prostate. Prostate. 2009; 69(6):603-609. 
17. Huang J, Yao JL, di Sant'Agnese PA, Yang Q, Bourne PA and Na Y. Immunohistochemical characterization of neuroendocrine cells in prostate cancer. Prostate. 2006; 66(13):1399-1406.

18. Bonkhoff $\mathrm{H}$, Stein $\mathrm{U}$ and Remberger K. Multidirectional differentiation in the normal, hyperplastic, and neoplastic human prostate: simultaneous demonstration of cell-specific epithelial markers. Hum Pathol. 1994; 25(1):42-46.

19. Wyatt AW, Mo F, Wang K, McConeghy B, Brahmbhatt S, Jong L, Mitchell DM, Johnston RL, Haegert A, Li E, Liew J, Yeung J, Shrestha R, Lapuk AV, McPherson A, Shukin R, et al. Heterogeneity in the inter-tumor transcriptome of high risk prostate cancer. Genome Biol. 2014; 15(8):426.

20. Brase JC, Johannes M, Mannsperger H, Falth M, Metzger J, Kacprzyk LA, Andrasiuk T, Gade S, Meister M, Sirma H, Sauter G, Simon R, Schlomm T, Beissbarth T, Korf U, Kuner R, et al. TMPRSS2-ERG -specific transcriptional modulation is associated with prostate cancer biomarkers and TGF-beta signaling. BMC cancer. 2011; 11:507.

21. Weischenfeldt J, Simon R, Feuerbach L, Schlangen K, Weichenhan D, Minner S, Wuttig D, Warnatz HJ, Stehr H, Rausch T, Jager N, Gu L, Bogatyrova O, Stutz AM, Claus R, Eils J, et al. Integrative genomic analyses reveal an androgen-driven somatic alteration landscape in early-onset prostate cancer. Cancer Cell. 2013; 23(2):159-170.

22. Tranchevent LC, Capdevila FB, Nitsch D, De Moor B, De Causmaecker P and Moreau Y. A guide to web tools to prioritize candidate genes. Brief Bioinform. 2011; 12(1):22-32.

23. Taylor BS, Schultz N, Hieronymus H, Gopalan A, Xiao Y, Carver BS, Arora VK, Kaushik P, Cerami E, Reva B, Antipin Y, Mitsiades N, Landers T, Dolgalev I, Major JE, Wilson M, et al. Integrative genomic profiling of human prostate cancer. Cancer Cell. 2010; 18(1):11-22.

24. Castro F, Dirks WG, Fahnrich S, Hotz-Wagenblatt A, Pawlita M and Schmitt M. High-throughput SNPbased authentication of human cell lines. Int J Cancer. 2013; 132(2):308-314.

25. Schmitt M and Pawlita M. High-throughput detection and multiplex identification of cell contaminations. Nucleic Acids Res. 2009; 37(18):e119.

26. Ratz L, Laible M, Kacprzyk LA, Wittig-Blaich SM, Tolstov $Y$, Duensing $S$, Altevogt $P$, Klauck SM and Sultmann H. TMPRSS2:ERG gene fusion variants induce TGF-beta signaling and epithelial to mesenchymal transition in human prostate cancer cells. Oncotarget. 2017; 8(15):25115-25130.

27. Pfaffl MW. A new mathematical model for relative quantification in real-time RT-PCR. Nucleic Acids Res. 2001; 29(9):e45.

28. Tsai H, Morais CL, Alshalalfa M, Tan HL, Haddad Z, Hicks J, Gupta N, Epstein JI, Netto GJ, Isaacs WB, Luo J, Mehra R, Vessella RL, Karnes RJ, Schaeffer EM, Davicioni E, et al. Cyclin D1 Loss Distinguishes Prostatic Small-Cell Carcinoma from Most Prostatic Adenocarcinomas. Clin Cancer Res. 2015; 21(24):5619-5629.

29. Duggan A, Madathany T, de Castro SC, Gerrelli D, Guddati K and Garcia-Anoveros J. Transient expression of the conserved zinc finger gene INSM1 in progenitors and nascent neurons throughout embryonic and adult neurogenesis. J Comp Neurol. 2008; 507(4):1497-1520.

30. Mellitzer G, Bonne S, Luco RF, Van De Casteele M, Lenne-Samuel N, Collombat P, Mansouri A, Lee J, Lan M, Pipeleers D, Nielsen FC, Ferrer J, Gradwohl G and Heimberg H. IA1 is NGN3-dependent and essential for differentiation of the endocrine pancreas. EMBO J. 2006; 25(6):1344-1352.

31. Goto Y, De Silva MG, Toscani A, Prabhakar BS, Notkins AL and Lan MS. A novel human insulinomaassociated cDNA, IA-1, encodes a protein with "zinc-finger" DNA-binding motifs. J Biol Chem. 1992; 267(21):15252-15257.

32. Mertz KD, Setlur SR, Dhanasekaran SM, Demichelis F, Perner S, Tomlins S, Tchinda J, Laxman B, Vessella RL, Beroukhim R, Lee C, Chinnaiyan AM and Rubin MA. Molecular characterization of TMPRSS2-ERG gene fusion in the $\mathrm{NCl}-\mathrm{H} 660$ prostate cancer cell line: a new perspective for an old model. Neoplasia. 2007; 9(3):200-206.

33. Bello D, Webber MM, Kleinman HK, Wartinger DD and Rhim JS. Androgen responsive adult human prostatic epithelial cell lines immortalized by human papillomavirus 18. Carcinogenesis. 1997; 18(6):1215-1223.

34. Wiedenmann B, Franke WW, Kuhn C, Moll R and Gould VE. Synaptophysin: a marker protein for neuroendocrine cells and neoplasms. Proc Natl Acad Sci U S A. 1986; 83(10):3500-3504. 
35. Ballas N, Grunseich C, Lu DD, Speh JC and Mandel G. REST and its corepressors mediate plasticity of neuronal gene chromatin throughout neurogenesis. Cell. 2005; 121(4):645-657.

36. Katsetos CD, Legido A, Perentes E and Mork SJ. Class III beta-tubulin isotype: a key cytoskeletal protein at the crossroads of developmental neurobiology and tumor neuropathology. J Child Neurol. 2003; 18(12):851-866; discussion 867.

37. Maness PF and Schachner M. Neural recognition molecules of the immunoglobulin superfamily: signaling transducers of axon guidance and neuronal migration. Nat Neurosci. 2007; 10(1):19-26.

38. Huszar M, Pfeifer M, Schirmer U, Kiefel H, Konecny GE, Ben-Arie A, Edler L, Munch M, Muller-Holzner E, Jerabek-Klestil S, Abdel-Azim S, Marth C, Zeimet AG, Altevogt P and Fogel M. Up-regulation of L1CAM is linked to loss of hormone receptors and E-cadherin in aggressive subtypes of endometrial carcinomas. J Pathol. 2010; 220(5):551-561.

39. Held-Feindt J, Schmelz S, Hattermann K, Mentlein R, Mehdorn HM and Sebens S. The neural adhesion molecule L1CAM confers chemoresistance in human glioblastomas. Neurochem Int. 2012; 61(7):11831191.

40. Trasino SE, Harrison EH and Wang TT. Androgen regulation of aldehyde dehydrogenase $1 \mathrm{~A} 3$ (ALDH1A3) in the androgen-responsive human prostate cancer cell line LNCaP. Exp Biol Med (Maywood). 2007; 232(6):762-771.

41. Le Magnen C, Bubendorf L, Rentsch CA, Mengus C, Gsponer J, Zellweger T, Rieken M, Thalmann GN, Cecchini MG, Germann M, Bachmann A, Wyler S, Heberer M and Spagnoli GC. Characterization and clinical relevance of ALDHbright populations in prostate cancer. Clin Cancer Res. 2013; 19(19):5361-5371.

42. Casanova-Salas I, Masia E, Arminan A, Calatrava A, Mancarella C, Rubio-Briones J, Scotlandi K, Vicent MJ and Lopez-Guerrero JA. MiR-187 Targets the Androgen-Regulated Gene ALDH1A3 in Prostate Cancer. PLoS One. 2015; 10(5):e0125576.

43. Gomes IM, Arinto P, Lopes C, Santos CR and Maia CJ. STEAP1 is overexpressed in prostate cancer and prostatic intraepithelial neoplasia lesions, and it is positively associated with Gleason score. Urol Oncol. 2014; 32(1):53 e23-59.

44. Ihlaseh-Catalano SM, Drigo SA, de Jesus CM, Domingues MA, Trindade Filho JC, de Camargo JL and Rogatto SR. STEAP1 protein overexpression is an independent marker for biochemical recurrence in prostate carcinoma. Histopathology. 2013; 63(5):678-685.

45. Cox ME, Deeble PD, Lakhani S and Parsons SJ. Acquisition of neuroendocrine characteristics by prostate tumor cells is reversible: implications for prostate cancer progression. Cancer Res. 1999; 59(15):38213830.

46. Deeble PD, Murphy DJ, Parsons SJ and Cox ME. Interleukin-6- and cyclic AMP-mediated signaling potentiates neuroendocrine differentiation of LNCaP prostate tumor cells. Mol Cell Biol. 2001; 21(24):84718482.

47. Cox ME, Deeble PD, Bissonette EA and Parsons SJ. Activated 3',5'-cyclic AMP-dependent protein kinase is sufficient to induce neuroendocrine-like differentiation of the LNCaP prostate tumor cell line. J Biol Chem. 2000; 275(18):13812-13818.

48. Mosquera JM, Beltran H, Park K, MacDonald TY, Robinson BD, Tagawa ST, Perner S, Bismar TA, Erbersdobler A, Dhir R, Nelson JB, Nanus DM and Rubin MA. Concurrent AURKA and MYCN gene amplifications are harbingers of lethal treatment-related neuroendocrine prostate cancer. Neoplasia. 2013; 15(1):1-10.

49. Lee JK, Phillips JW, Smith BA, Park JW, Stoyanova T, McCaffrey EF, Baertsch R, Sokolov A, Meyerowitz JG, Mathis C, Cheng D, Stuart JM, Shokat KM, Gustafson WC, Huang J and Witte ON. N-Myc Drives Neuroendocrine Prostate Cancer Initiated from Human Prostate Epithelial Cells. Cancer Cell. 2016; 29(4):536-547.

50. Otto SJ, McCorkle SR, Hover J, Conaco C, Han JJ, Impey S, Yochum GS, Dunn JJ, Goodman RH and Mandel G. A new binding motif for the transcriptional repressor REST uncovers large gene networks devoted to neuronal functions. J Neurosci. 2007; 27(25):6729-6739.

51. Bruce AW, Donaldson IJ, Wood IC, Yerbury SA, Sadowski MI, Chapman M, Gottgens B and Buckley NJ. Genome-wide analysis of repressor element 1 silencing transcription factor/neuron-restrictive silencing factor (REST/NRSF) target genes. Proc Natl Acad Sci U S A. 2004; 101(28):10458-10463. 
52. Kallunki P, Edelman GM and Jones FS. Tissue-specific expression of the L1 cell adhesion molecule is modulated by the neural restrictive silencer element. J Cell Biol. 1997; 138(6):1343-1354.

53. Altevogt P, Doberstein K and Fogel M. L1CAM in human cancer. Int J Cancer. 2016; 138(7):1565-1576.

54. Sung SY, Wu IH, Chuang PH, Petros JA, Wu HC, Zeng HJ, Huang WC, Chung LW and Hsieh CL. Targeting L1 cell adhesion molecule expression using liposome-encapsulated siRNA suppresses prostate cancer bone metastasis and growth. Oncotarget. 2014; 5(20):9911-9929.

55. Doberstein K, Milde-Langosch K, Bretz NP, Schirmer U, Harari A, Witzel I, Ben-Arie A, Hubalek M, MullerHolzner E, Reinold S, Zeimet AG, Altevogt $P$ and Fogel M. L1CAM is expressed in triple-negative breast cancers and is inversely correlated with androgen receptor. BMC cancer. 2014; 14:958.

56. Ayala R, Shu T and Tsai LH. Trekking across the brain: the journey of neuronal migration. Cell. 2007; 128(1):29-43.

57. Zhao S and Frotscher M. Go or stop? Divergent roles of Reelin in radial neuronal migration. Neuroscientist. 2010; 16(4):421-434.

58. Kawabe $\mathrm{H}$ and Brose $\mathrm{N}$. The role of ubiquitylation in nerve cell development. Nat Rev Neurosci. 2011; 12(5):251-268.

59. Sekine K, Kawauchi T, Kubo K, Honda T, Herz J, Hattori M, Kinashi T and Nakajima K. Reelin controls neuronal positioning by promoting cell-matrix adhesion via inside-out activation of integrin alpha5beta1. Neuron. 2012; 76(2):353-369.

60. Lee GH and D'Arcangelo G. New Insights into Reelin-Mediated Signaling Pathways. Front Cell Neurosci. 2016; 10:122.

61. D'Arcangelo G, Homayouni R, Keshvara L, Rice DS, Sheldon M and Curran T. Reelin is a ligand for lipoprotein receptors. Neuron. 1999; 24(2):471-479.

62. Farkas LM, Haffner C, Giger T, Khaitovich P, Nowick K, Birchmeier C, Paabo S and Huttner WB. Insulinoma-associated 1 has a panneurogenic role and promotes the generation and expansion of basal progenitors in the developing mouse neocortex. Neuron. 2008; 60(1):40-55.

63. Rosenbaum JN, Guo Z, Baus RM, Werner H, Rehrauer WM and Lloyd RV. INSM1: A Novel Immunohistochemical and Molecular Marker for Neuroendocrine and Neuroepithelial Neoplasms. Am J Clin Pathol. 2015; 144(4):579-591.

64. Lan MS, Russell EK, Lu J, Johnson BE and Notkins AL. IA-1, a new marker for neuroendocrine differentiation in human lung cancer cell lines. Cancer Res. 1993; 53(18):4169-4171.

65. Chen C, Breslin MB and Lan MS. Ectopic expression of a small cell lung cancer transcription factor, INSM1 impairs alveologenesis in lung development. BMC Pulm Med. 2016; 16:49.

66. Berruti A, Mosca A, Porpiglia F, Bollito E, Tucci M, Vana F, Cracco C, Torta M, Russo L, Cappia S, Saini A, Angeli A, Papotti M, Scarpa RM and Dogliotti L. Chromogranin A expression in patients with hormone naive prostate cancer predicts the development of hormone refractory disease. J Urol. 2007; 178(3 Pt 1):838-843; quiz 1129.

67. Rapa I, Ceppi P, Bollito E, Rosas R, Cappia S, Bacillo E, Porpiglia F, Berruti A, Papotti M and Volante M. Human ASH1 expression in prostate cancer with neuroendocrine differentiation. Mod Pathol. 2008; 21(6):700-707.

68. Fujino K, Motooka Y, Hassan WA, Ali Abdalla MO, Sato Y, Kudoh S, Hasegawa K, Niimori-Kita K, Kobayashi H, Kubota I, Wakimoto J, Suzuki M and Ito T. Insulinoma-Associated Protein 1 Is a Crucial Regulator of Neuroendocrine Differentiation in Lung Cancer. Am J Pathol. 2015; 185(12):3164-3177.

69. Bishop JL, Thaper D, Vahid S, Davies A, Ketola K, Kuruma H, Jama R, Nip KM, Angeles A, Johnson F, Wyatt AW, Fazli L, Gleave ME, Lin D, Rubin MA, Collins CC, et al. The Master Neural Transcription Factor BRN2 Is an Androgen Receptor-Suppressed Driver of Neuroendocrine Differentiation in Prostate Cancer. Cancer Discov. 2017; 7(1):54-71.

70. Liu WD, Wang HW, Muguira M, Breslin MB and Lan MS. INSM1 functions as a transcriptional repressor of the neuroD/beta2 gene through the recruitment of cyclin D1 and histone deacetylases. Biochem J. 2006; 397(1):169-177. 
71. Jia S, Ivanov A, Blasevic D, Muller T, Purfurst B, Sun W, Chen W, Poy MN, Rajewsky N and Birchmeier C. Insm1 cooperates with Neurod1 and Foxa2 to maintain mature pancreatic beta-cell function. EMBO J. 2015; 34(10):1417-1433.

72. Osipovich AB, Long Q, Manduchi E, Gangula R, Hipkens SB, Schneider J, Okubo T, Stoeckert CJ, Jr., Takada $S$ and Magnuson MA. Insm1 promotes endocrine cell differentiation by modulating the expression of a network of genes that includes Neurog3 and Ripply3. Development. 2014; 141(15):2939-2949.

73. Gupta A, Wang Y, Browne C, Kim S, Case T, Paul M, Wills ML and Matusik RJ. Neuroendocrine differentiation in the 12T-10 transgenic prostate mouse model mimics endocrine differentiation of pancreatic beta cells. Prostate. 2008; 68(1):50-60.

74. Jia S, Wildner $\mathrm{H}$ and Birchmeier $\mathrm{C}$. Insm1 controls the differentiation of pulmonary neuroendocrine cells by repressing Hes1. Dev Biol. 2015; 408(1):90-98.

75. George J, Lim JS, Jang SJ, Cun Y, Ozretic L, Kong G, Leenders F, Lu X, Fernandez-Cuesta L, Bosco G, Muller C, Dahmen I, Jahchan NS, Park KS, Yang D, Karnezis AN, et al. Comprehensive genomic profiles of small cell lung cancer. Nature. 2015; 524(7563):47-53.

76. Chen C, Breslin MB and Lan MS. INSM1 increases N-myc stability and oncogenesis via a positivefeedback loop in neuroblastoma. Oncotarget. 2015; 6(34):36700-36712.

77. De Smaele E, Fragomeli C, Ferretti E, Pelloni M, Po A, Canettieri G, Coni S, Di Marcotullio L, Greco A, Moretti M, Di Rocco C, Pazzaglia S, Maroder M, Screpanti I, Giannini G and Gulino A. An integrated approach identifies Nhlh1 and Insm1 as Sonic Hedgehog-regulated genes in developing cerebellum and medulloblastoma. Neoplasia. 2008; 10(1):89-98.

78. dilorio PJ, Moss JB, Sbrogna JL, Karlstrom RO and Moss LG. Sonic hedgehog is required early in pancreatic islet development. Dev Biol. 2002; 244(1):75-84.

79. Watkins DN, Berman DM, Burkholder SG, Wang B, Beachy PA and Baylin SB. Hedgehog signalling within airway epithelial progenitors and in small-cell lung cancer. Nature. 2003; 422(6929):313-317.

80. Roubaud G, Liaw BC, Oh WK and Mulholland DJ. Strategies to avoid treatment-induced lineage crisis in advanced prostate cancer. Nat Rev Clin Oncol. 2017; 14(5):269-283.

81. Mounir Z, Lin F, Lin VG, Korn JM, Yu Y, Valdez R, Aina OH, Buchwalter G, Jaffe AB, Korpal M, Zhu P, Brown $M$, Cardiff RD, Rocnik JL, Yang $Y$ and Pagliarini R. TMPRSS2:ERG blocks neuroendocrine and luminal cell differentiation to maintain prostate cancer proliferation. Oncogene. 2015; 34(29):3815-3825.

82. Akamatsu S, Wyatt AW, Lin D, Lysakowski S, Zhang F, Kim S, Tse C, Wang K, Mo F, Haegert A, Brahmbhatt S, Bell R, Adomat H, Kawai Y, Xue H, Dong X, et al. The Placental Gene PEG10 Promotes Progression of Neuroendocrine Prostate Cancer. Cell Rep. 2015; 12(6):922-936.

83. Zhang $T$, Liu WD, Saunee NA, Breslin MB and Lan MS. Zinc finger transcription factor INSM1 interrupts cyclin D1 and CDK4 binding and induces cell cycle arrest. J Biol Chem. 2009; 284(9):5574-5581.

84. Lukaszewicz Al and Anderson DJ. Cyclin D1 promotes neurogenesis in the developing spinal cord in a cell cycle-independent manner. Proc Natl Acad Sci U S A. 2011; 108(28):11632-11637.

85. Jongsma J, Oomen MH, Noordzij MA, Van Weerden WM, Martens GJ, van der Kwast TH, Schroder FH and van Steenbrugge GJ. Kinetics of neuroendocrine differentiation in an androgen-dependent human prostate xenograft model. Am J Pathol. 1999; 154(2):543-551.

86. Grobholz R, Griebe M, Sauer CG, Michel MS, Trojan L and Bleyl U. Influence of neuroendocrine tumor cells on proliferation in prostatic carcinoma. Hum Pathol. 2005; 36(5):562-570.

87. Grigore AD, Ben-Jacob E and Farach-Carson MC. Prostate cancer and neuroendocrine differentiation: more neuronal, less endocrine? Front Oncol. 2015; 5:37.

88. DaSilva JO, Amorino GP, Casarez EV, Pemberton B and Parsons SJ. Neuroendocrine-derived peptides promote prostate cancer cell survival through activation of IGF-1R signaling. Prostate. 2013; 73(8):801812.

89. Yuan TC, Veeramani S, Lin FF, Kondrikou D, Zelivianski S, Igawa T, Karan D, Batra SK and Lin MF. Androgen deprivation induces human prostate epithelial neuroendocrine differentiation of androgen-sensitive LNCaP cells. Endocr Relat Cancer. 2006; 13(1):151-167. 
90. Deeble PD, Cox ME, Frierson HF, Jr., Sikes RA, Palmer JB, Davidson RJ, Casarez EV, Amorino GP and Parsons SJ. Androgen-independent growth and tumorigenesis of prostate cancer cells are enhanced by the presence of PKA-differentiated neuroendocrine cells. Cancer Res. 2007; 67(8):3663-3672.

91. Bonkhoff H, Wernert N, Dhom G and Remberger K. Relation of endocrine-paracrine cells to cell proliferation in normal, hyperplastic, and neoplastic human prostate. Prostate. 1991; 19(2):91-98.

92. Yang JC, Ok JH, Busby JE, Borowsky AD, Kung HJ and Evans CP. Aberrant activation of androgen receptor in a new neuropeptide-autocrine model of androgen-insensitive prostate cancer. Cancer Res. 2009; 69(1):151-160.

93. Tsapakidis K, Vlachostergios PJ, Voutsadakis IA, Befani CD, Patrikidou A, Hatzidaki E, Daliani DD, Moutzouris $\mathrm{G}$, Liakos $P$ and Papandreou CN. Bortezomib reverses the proliferative and antiapoptotic effect of neuropeptides on prostate cancer cells. Int J Urol. 2012; 19(6):565-574.

94. Tzelepi V, Zhang J, Lu JF, Kleb B, Wu G, Wan X, Hoang A, Efstathiou E, Sircar K, Navone NM, Troncoso P, Liang S, Logothetis CJ, Maity SN and Aparicio AM. Modeling a lethal prostate cancer variant with smallcell carcinoma features. Clin Cancer Res. 2012; 18(3):666-677.

95. Wang Q, Li W, Zhang Y, Yuan X, Xu K, Yu J, Chen Z, Beroukhim R, Wang H, Lupien M, Wu T, Regan MM, Meyer CA, Carroll JS, Manrai AK, Janne OA, et al. Androgen receptor regulates a distinct transcription program in androgen-independent prostate cancer. Cell. 2009; 138(2):245-256.

96. Liu LL, Xie N, Sun S, Plymate S, Mostaghel E and Dong X. Mechanisms of the androgen receptor splicing in prostate cancer cells. Oncogene. 2014; 33(24):3140-3150.

97. Hornberg E, Ylitalo EB, Crnalic S, Antti H, Stattin P, Widmark A, Bergh A and Wikstrom P. Expression of androgen receptor splice variants in prostate cancer bone metastases is associated with castrationresistance and short survival. PLoS One. 2011; 6(4):e19059.

98. Hu R, Lu C, Mostaghel EA, Yegnasubramanian S, Gurel M, Tannahill C, Edwards J, Isaacs WB, Nelson PS, Bluemn E, Plymate SR and Luo J. Distinct transcriptional programs mediated by the ligand-dependent full-length androgen receptor and its splice variants in castration-resistant prostate cancer. Cancer Res. 2012; 72(14):3457-3462.

99. Bruce AW, Lopez-Contreras AJ, Flicek P, Down TA, Dhami P, Dillon SC, Koch CM, Langford CF, Dunham I, Andrews RM and Vetrie D. Functional diversity for REST (NRSF) is defined by in vivo binding affinity hierarchies at the DNA sequence level. Genome Res. 2009; 19(6):994-1005.

100. Svensson C, Ceder J, Iglesias-Gato D, Chuan YC, Pang ST, Bjartell A, Martinez RM, Bott L, Helczynski L, Ulmert D, Wang Y, Niu Y, Collins $C$ and Flores-Morales A. REST mediates androgen receptor actions on gene repression and predicts early recurrence of prostate cancer. Nucleic Acids Res. 2014; 42(2):9991015.

101. Martin D, Kim YH, Sever D, Mao CA, Haefliger JA and Grapin-Botton A. REST represses a subset of the pancreatic endocrine differentiation program. Dev Biol. 2015; 405(2):316-327.

102. Martin D and Grapin-Botton A. The Importance of REST for Development and Function of Beta Cells. Front Cell Dev Biol. 2017; 5:12.

103. Kreisler A, Strissel PL, Strick R, Neumann SB, Schumacher U and Becker CM. Regulation of the NRSF/REST gene by methylation and CREB affects the cellular phenotype of small-cell lung cancer. Oncogene. 2010; 29(43):5828-5838.

104. Schafer MK and Altevogt P. L1CAM malfunction in the nervous system and human carcinomas. Cell Mol Life Sci. 2010; 67(14):2425-2437.

105. Virtanen C, Ishikawa Y, Honjoh D, Kimura M, Shimane M, Miyoshi T, Nomura H and Jones MH. Integrated classification of lung tumors and cell lines by expression profiling. Proc Natl Acad Sci U S A. 2002; 99(19):12357-12362.

106. Seigel GM, Hackam AS, Ganguly A, Mandell LM and Gonzalez-Fernandez F. Human embryonic and neuronal stem cell markers in retinoblastoma. Mol Vis. 2007; 13:823-832.

107. Wang Q, Lu J, Yang C, Wang X, Cheng L, Hu G, Sun Y, Zhang X, Wu M and Liu Z. CASK and its target gene Reelin were co-upregulated in human esophageal carcinoma. Cancer Lett. 2002; 179(1):71-77. 


\section{CHAPTER 4}

108. Qin X, Lin L, Cao L, Zhang X, Song X, Hao J, Zhang Y, Wei R, Huang X, Lu J and Ge Q. Extracellular matrix protein Reelin promotes myeloma progression by facilitating tumor cell proliferation and glycolysis. Sci Rep. 2017; 7:45305.

109. Perrone G, Vincenzi B, Zagami M, Santini D, Panteri R, Flammia G, Verzi A, Lepanto D, Morini S, Russo A, Bazan V, Tomasino RM, Morello V, Tonini G and Rabitti C. Reelin expression in human prostate cancer: a marker of tumor aggressiveness based on correlation with grade. Mod Pathol. 2007; 20(3):344-351.

110. Park TJ and Curran T. Crk and Crk-like play essential overlapping roles downstream of disabled-1 in the Reelin pathway. J Neurosci. 2008; 28(50):13551-13562.

111. Leemhuis J and Bock HH. Reelin modulates cytoskeletal organization by regulating Rho GTPases. Commun Integr Biol. 2011; 4(3):254-257.

112. Ballif BA, Arnaud $L$ and Cooper JA. Tyrosine phosphorylation of Disabled-1 is essential for Reelinstimulated activation of Akt and Src family kinases. Brain Res Mol Brain Res. 2003; 117(2):152-159.

113. Caplin NJ, O'Leary P, Bulsara M, Davis EA and Jones TW. Subcutaneous glucose sensor values closely parallel blood glucose during insulin-induced hypoglycaemia. Diabet Med. 2003; 20(3):238-241.

114. Qi J, Nakayama K, Cardiff RD, Borowsky AD, Kaul K, Williams R, Krajewski S, Mercola D, Carpenter PM, Bowtell D and Ronai ZA. Siah2-dependent concerted activity of HIF and FoxA2 regulates formation of neuroendocrine phenotype and neuroendocrine prostate tumors. Cancer Cell. 2010; 18(1):23-38.

115. D'Arcangelo G, Miao GG, Chen SC, Soares HD, Morgan JI and Curran T. A protein related to extracellular matrix proteins deleted in the mouse mutant reeler. Nature. 1995; 374(6524):719-723.

116. Kiefel $\mathrm{H}$, Pfeifer M, Bondong S, Hazin J and Altevogt P. Linking L1CAM-mediated signaling to NF-kappaB activation. Trends Mol Med. 2011; 17(4):178-187. 
Chapter 5

General discussion 
At the time of diagnosis, PCa will frequently present as organ-confined disease or with locoregional spread and most tumors will persist as indolent clinical condition [1, 2]. The individual risk to develop clinically significant and potentially lethal disease is not recognized by histological grading alone. The heterogeneous clinical course that is observed among PCa cases is determined by complex and dynamic genomic aberrations. The biological and clinical significance of those molecular aberrations is not well understood limiting the availability of prognostic markers for risk stratification in current clinical practice. Simultaneously, a broader spectrum of therapeutic targets in addition to ADT is required to improve the clinical management of metastatic PCa [3]. An ideal situation would be if the molecular subtypes of PCa that are characterized by distinct genomic alterations, could be treated differently and specifically. Far away from personalized treatment, all PCa patients are treated rather by the same therapeutics. The only FDAapproved targeted therapy in PCa is currently sipuleucel-T, an autologous cellular immunotherapy containing PAP-activated peripheral blood mononuclear cells indicated for the treatment of asymptomatic or minimally symptomatic MCRPC [4]. A better understanding of the contribution of molecular alterations to the biological characteristics of PCa is essential to identify novel markers for risk assessment and targets for improved therapeutic management.

The aim of the studies compiled in this thesis was to identify candidate driver genes of aggressive PCa and to provide a functional and mechanistic evaluation of these candidates in prostate cancer cell lines. The role of the TMPRSS2:ERG gene fusion, the most frequent genomic aberration in $\mathrm{PCa}$, was studied in detail. Detection of the TMPRSS2:ERG gene fusion has currently no prognostic or therapeutic implications in routine clinical management. Several clinical trials are currently evaluating the predictive value of the TMPRSS2:ERG gene fusion alone (NCT02588404) or in combination with the PTEN deletion (NCT02573636) for failure of hormonal therapy, and for response to enzalutamide (NCT02288936). The analysis of T/E-induced molecular mechanisms identified resistance mechanisms with potential implications for existing treatment regimens. ERG was shown to bind to cytoplasmatic $\beta$-tubulin thereby reducing the availability of microtubules for taxane binding [5]. In DU145-ERG overexpressing xenografts, reduced taxane-induced apoptosis was observed compared to the DU145-GFP expressing control mice [5]. T/E fusion-positive CRPC patients showed reduced sensitivity to taxane-based chemotherapy suggesting a role for the TMPRSS2:ERG fusion as potential predictive marker [5].

When identifying driver alterations in cancer, the 'druggability', i.e. the ability to identify a druglike ligand that can modulate the activity of the target with a therapeutic benefit to the patient [6], is of major interest. Transcription factors are generally considered as difficult to target [7]. The evaluation of the druggability of ERG is limited to the in vitro and preclinical setting. The small molecule YK-4-279 (an ETS-family inhibitor) was shown 
to inhibit VCaP and LNCaP prostate cancer cell motility and invasion in vitro [8] and in vivo [9]. In a murine model of Ewing sarcoma, a disease characterized by high occurrence of chromosomal translocations between the EWSR1 gene and various members of the ETS-family, YK-4-279 was able to inhibit transcriptional activity of the EWS-FLI1 fusion protein [10]. In neuroblastoma cells, YK-4-279 induced apoptosis by inhibition of mitosis [11]. However, no clear genotype underlying the YK-4-279 sensitivity could be identified, suggesting that YK-4-279 interrupts key protein interactions required for controlled mitosis and proliferation of cancers cells [11]. The di-(thiophene-phenylamidine) compound DB1255 was identified as an ERG/DNA binding inhibitor by interacting with part of the ERG-binding site thereby modulating ERG-regulated genes [12]. Recently, liposomal nanoparticles packaged with squalene-conjugated siRNA against TMPRSS2:ERG (siRNA-SQ NPS) conferred strong antitumoral activity and were suggested as alternative treatment approach to antiandrogen therapy with flutamide in VCaP cells [13].

An alternative approach under evaluation is to target ERG interacting proteins, such as PARP1, DNA protein kinases (DNA-PK), and HDAC1. In T/E overexpressing cells PARP1 inhibition induced increased vulnerability of prostate cancer cells to low-dose radiation $[14,15]$. In the preclinical setting, T/E overexpressing xenografts were sensitized to growth arrest by inhibiting PARP1 suggesting that tumors respond to treatment with PARP1-inhibitors [14]. Recent studies showed that PCa patients with inherited mutations in BRCA1/2 and ataxia-telangiectasia mutated (ATM, a DNA-PK), who generally have a shorter survival, clinically responded to the PARP1 inhibitor olaparib $[16,17]$. Inhibition of DNA-PK was able to reduce ERG transcriptional activity [14] and a phase I trial currently investigates the dual inhibition of DNA-PK and mTOR, an effector of PI3K signaling, in MCRPC patients using PSA response as secondary objective (clinicaltrials.gov: NCT02833883). HDAC1 inhibition reduced the expression of ERG-associated genes in VCaP cells [18] and diverse HDAC inhibitors are currently tested in clinical trials (NCT00878436, NCT01075308, and NCT01174199).

Taylor et al. previously showed that four key cancer pathways are affected in PCa and suggested those signaling pathways as basis for drug development [19]. In this thesis, we present the identification of novel driver mechanism that could be used for drug development in PCa extending the list of key cancer pathways in TMPRSS2:ERG fusionpositive PCa subtypes. First, the TGF- $\beta / B M P$ and $W N T / \beta$-catenin signaling pathways as molecular determinants underlying T/E-mediated EMT in PCa cells were identified. Of note, the type I TGF- $\beta$ receptor ALK1 as well as the WNT receptor FZD4 were identified as the mediators of transcriptional changes leading to EMT in T/E overexpressing cells. Activation of TGF- $\beta$-ALK1-p38 signaling promoting EMT in T/E expressing cells provides a rational basis for ALK1-blocking agents (which are currently already tested in clinical studies in various malignancies $[20,21]$ ) to inhibit progression of T/E-positive PCa. The 
soluble recombinant ALK1-Fc fusion protein dalantercept is currently evaluated as inhibitor of angiogenesis by binding of BMP9 and -10, and was shown to have antitumor activity in diverse refractory solid tumors in phase 1 studies (NCT00996957, NCT02024087) or phase 2 trials (NCT01642082, NCT01727336, NCT01720173).

This work further confirmed the previously reported finding that loss of cell adhesion and EMT in T/E overexpressing cells are associated with FZD4-induced activation of WNT signaling [22]. The druggability of the WNT-signaling pathway has for long been topic of discussion due to its complexity regarding ligand binding, downstream responses and signaling crosstalk, as well as its role in homeostasis and stem cell mechanisms raising substantial concerns. Among the targeted therapies, the selective Frizzled signaling pathway inhibitors (vantictumab against FZD7, ipafricept against FZD8) are currently tested in combination with taxane-based chemotherapies in HER2negative breast cancer (NCT01973309), pancreatic cancer (NCT02005315, NCT02050178), NSCLC (NCT01957007), and ovarian cancer (NCT02092363). Although FZD4 is currently not addressed in clinical trials, these results support the feasibility of FZD4-targeted therapy in the future. The correlation between FZD4 hypomethylation and mRNA upregulation, although preliminary, represents another level of druggability in T/E fusion-positive tumors by methylation-modifying agents.

Second, we identified INSM1 as transcriptional regulator of a neuroendocrine network in prostate cancer cell lines and further highlighted the integration of Reelin signaling in this regulatory network involving INSM1, LICAM and REST. Taking advantage of its tissue-restricted expression pattern and re-activation in NE tumors, INSM1 has gained attention regarding its role in suicide gene therapy approaches for tumor-specific systemic treatment in small cell lung cancer and neuroblastoma [23, 24]. Linking the INSM1 promoter to a toxic transgene, such as herpes simplex virus thymidine kinase (HSV-TK), ganciclovir treatment resulted in increased cell death in vitro $[23,25]$ and tumor regression in vivo $[24,25]$. Since shared gene signatures have previously been identified between different NE tumors, application of this method to diverse tumors with NE features has been suggested $[24,26]$. These findings, though preliminary, present a potential strategy for targeted systemic therapy in NE tumors that could be implicated in NEPC as well. INSM1 promoter constructs have further been proposed as diagnostic and disease monitoring tool to identify NE tumors by using a luciferase reporter vector that can detect the presence of NE tumors in vivo [24, 27]. These findings could have future implications for the management of NEPC. For example, the eligibility of INSM1 for the identification of patients that are more likely to develop NEPC could be analysed in future studies. Selecting those patients is of importance for the consideration whether they could benefit from a chemotherapy-based treatment regimen rather than ADT. 


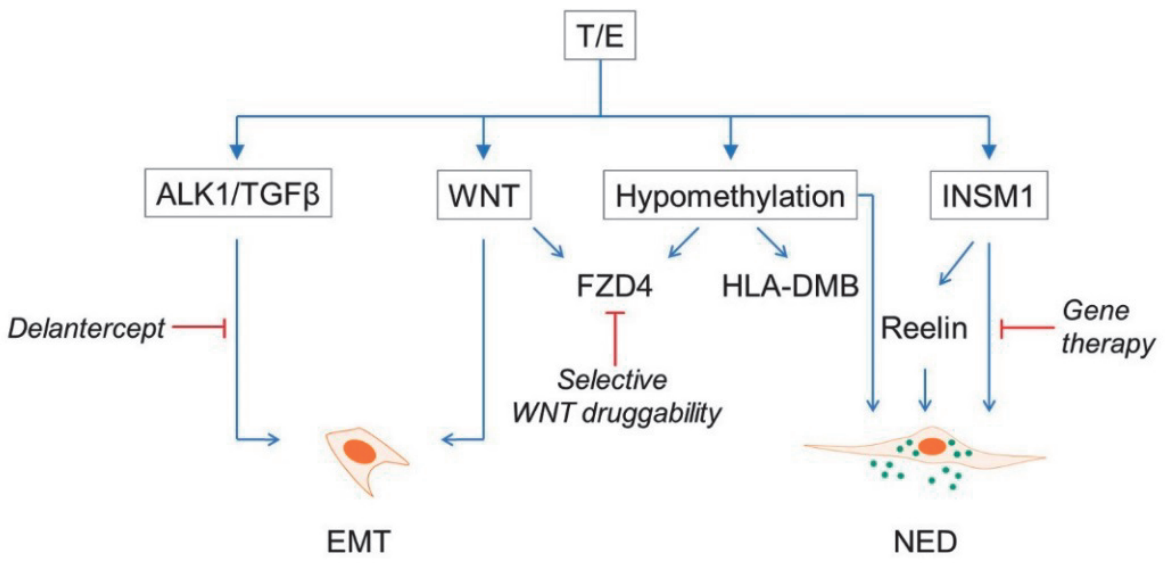

Figure 5.1: Summarizing model of the T/E-induced molecular mechanisms. This figure highlights the factors and mechanisms that are induced by $T / E$ overexpression in prostate cancer cells. Further, potential implementations for treatment strategies are depicted (red arrow).

The molecular characterization of INSM1 in prostate cancer cell lines presented in this work provided a molecular basis for further analysis of the clinical relevance of INSM1 as target in NEPC. This is supported by the progress regarding INSM1 in gene therapy. We highlighted remarkable similarities in signaling pathways between NEPC and wellknown models of NE tumors, such as small cell lung cancer, suggesting that insights into the mechanisms of NEPC might be derived from the molecular pathology of those NE cancers. Of note, the current National Comprehensive Cancer Network (NCCN) guidelines on PCa recommend the consultation of the specific guidelines for small cell lung cancer for management of small cell carcinoma of the prostate [28]. This knowledge could guide the emphasis of future research.

In conclusion, the work in this thesis accomplished the identification of novel drivers in the development of aggressive PCa at the molecular level of the tumor cells that point towards future strategies for clinical diagnosis and treatment. 


\section{REFERENCES}

1. Penney KL, Stampfer MJ, Jahn JL, Sinnott JA, Flavin R, Rider JR, Finn S, Giovannucci E, Sesso HD, Loda M, Mucci LA and Fiorentino M. Gleason grade progression is uncommon. Cancer Res. 2013; 73(16):51635168.

2. Miller DC, Hafez KS, Stewart A, Montie JE and Wei JT. Prostate carcinoma presentation, diagnosis, and staging: an update form the National Cancer Data Base. Cancer. 2003; 98(6):1169-1178.

3. Georgi B, Korzeniewski N, Hadaschik B, Grullich C, Roth W, Sultmann H, Pahernik S, Hohenfellner M and Duensing S. Evolving therapeutic concepts in prostate cancer based on genome-wide analyses (review). Int J Oncol. 2014; 45(4):1337-1344.

4. Institute NC. FDA Approval for Sipuleucel-T.

5. Galletti G, Matov A, Beltran H, Fontugne J, Miguel Mosquera J, Cheung C, MacDonald TY, Sung M, O'Toole S, Kench JG, Suk Chae S, Kimovski D, Tagawa ST, Nanus DM, Rubin MA, Horvath LG, et al. ERG induces taxane resistance in castration-resistant prostate cancer. Nat Commun. 2014; 5:5548.

6. Verdine GL and Walensky LD. The challenge of drugging undruggable targets in cancer: lessons learned from targeting BCL-2 family members. Clin Cancer Res. 2007; 13(24):7264-7270.

7. Fontaine F, Overman $\mathrm{J}$ and Francois M. Pharmacological manipulation of transcription factor proteinprotein interactions: opportunities and obstacles. Cell Regen (Lond). 2015; 4(1):2.

8. Rahim S, Beauchamp EM, Kong Y, Brown ML, Toretsky JA and Uren A. YK-4-279 inhibits ERG and ETV1 mediated prostate cancer cell invasion. PLoS One. 2011; 6(4):e19343.

9. Rahim S, Minas T, Hong SH, Justvig S, Celik H, Kont YS, Han J, Kallarakal AT, Kong Y, Rudek MA, Brown ML, Kallakury B, Toretsky JA and Uren A. A small molecule inhibitor of ETV1, YK-4-279, prevents prostate cancer growth and metastasis in a mouse xenograft model. PLoS One. 2014; 9(12):e114260.

10. Lamhamedi-Cherradi SE, Menegaz BA, Ramamoorthy V, Aiyer RA, Maywald RL, Buford AS, Doolittle DK, Culotta KS, O'Dorisio JE and Ludwig JA. An Oral Formulation of YK-4-279: Preclinical Efficacy and Acquired Resistance Patterns in Ewing Sarcoma. Mol Cancer Ther. 2015; 14(7):1591-1604.

11. Kollareddy M, Sherrard A, Park JH, Szemes M, Gallacher K, Melegh Z, Oltean S, Michaelis M, Cinatl J, Jr., Kaidi A and Malik K. The small molecule inhibitor YK-4-279 disrupts mitotic progression of neuroblastoma cells, overcomes drug resistance and synergizes with inhibitors of mitosis. Cancer Lett. 2017; 403:7485.

12. Nhili R, Peixoto P, Depauw S, Flajollet S, Dezitter X, Munde MM, Ismail MA, Kumar A, Farahat AA, Stephens CE, Duterque-Coquillaud M, David Wilson W, Boykin DW and David-Cordonnier MH. Targeting the DNA-binding activity of the human ERG transcription factor using new heterocyclic dithiophene diamidines. Nucleic Acids Res. 2013; 41(1):125-138.

13. Urbinati G, de Waziers I, Slamic M, Foussigniere T, Ali HM, Desmaele D, Couvreur P and MassaadMassade L. Knocking Down TMPRSS2-ERG Fusion Oncogene by siRNA Could be an Alternative Treatment to Flutamide. Mol Ther Nucleic Acids. 2016; 5:e301.

14. Brenner JC, Ateeq B, Li Y, Yocum AK, Cao Q, Asangani IA, Patel S, Wang X, Liang H, Yu J, Palanisamy N, Siddiqui J, Yan W, Cao X, Mehra R, Sabolch A, et al. Mechanistic rationale for inhibition of poly(ADPribose) polymerase in ETS gene fusion-positive prostate cancer. Cancer Cell. 2011; 19(5):664-678.

15. Chatterjee P, Choudhary GS, Sharma A, Singh K, Heston WD, Ciezki J, Klein EA and Almasan A. PARP inhibition sensitizes to low dose-rate radiation TMPRSS2-ERG fusion gene-expressing and PTEN-deficient prostate cancer cells. PLoS One. 2013; 8(4):e60408.

16. Na R, Zheng SL, Han M, Yu H, Jiang D, Shah S, Ewing CM, Zhang L, Novakovic K, Petkewicz J, Gulukota K, Helseth DL, Jr., Quinn M, Humphries E, Wiley KE, Isaacs SD, et al. Germline Mutations in ATM and BRCA1/2 Distinguish Risk for Lethal and Indolent Prostate Cancer and are Associated with Early Age at Death. Eur Urol. 2017; 71(5):740-747.

17. Fong PC, Boss DS, Yap TA, Tutt A, Wu P, Mergui-Roelvink M, Mortimer P, Swaisland H, Lau A, O'Connor MJ, Ashworth A, Carmichael J, Kaye SB, Schellens JH and de Bono JS. Inhibition of poly(ADP-ribose) polymerase in tumors from BRCA mutation carriers. N Engl J Med. 2009; 361(2):123-134. 
18. Bjorkman M, Iljin K, Halonen P, Sara H, Kaivanto E, Nees M and Kallioniemi OP. Defining the molecular action of HDAC inhibitors and synergism with androgen deprivation in ERG-positive prostate cancer. Int J Cancer. 2008; 123(12):2774-2781.

19. Taylor BS, Schultz N, Hieronymus H, Gopalan A, Xiao Y, Carver BS, Arora VK, Kaushik P, Cerami E, Reva B, Antipin Y, Mitsiades N, Landers T, Dolgalev I, Major JE, Wilson M, et al. Integrative genomic profiling of human prostate cancer. Cancer Cell. 2010; 18(1):11-22.

20. Vecchia L, Olivieri C and Scotti C. Activin Receptor-like kinase 1: a novel anti-angiogenesis target from TGF-beta family. Mini Rev Med Chem. 2013; 13(10):1398-1406.

21. Bendell JC, Gordon MS, Hurwitz HI, Jones SF, Mendelson DS, Blobe GC, Agarwal N, Condon CH, Wilson D, Pearsall AE, Yang Y, McClure T, Attie KM, Sherman ML and Sharma S. Safety, pharmacokinetics, pharmacodynamics, and antitumor activity of dalantercept, an activin receptor-like kinase-1 ligand trap, in patients with advanced cancer. Clin Cancer Res. 2014; 20(2):480-489.

22. Gupta S, Iljin K, Sara H, Mpindi JP, Mirtti T, Vainio P, Rantala J, Alanen K, Nees M and Kallioniemi O. FZD4 as a mediator of ERG oncogene-induced WNT signaling and epithelial-to-mesenchymal transition in human prostate cancer cells. Cancer Res. 2010; 70(17):6735-6745.

23. Pedersen N, Pedersen MW, Lan MS, Breslin MB and Poulsen HS. The insulinoma-associated 1: a novel promoter for targeted cancer gene therapy for small-cell lung cancer. Cancer Gene Ther. 2006; 13(4):375-384.

24. Akerstrom V, Chen C, Lan MS and Breslin MB. Modifications to the INSM1 promoter to preserve specificity and activity for use in adenoviral gene therapy of neuroendocrine carcinomas. Cancer Gene Ther. 2012; 19(12):828-838.

25. Tseng AW, Chen C, Breslin MB and Lan MS. Tumor-specific promoter-driven adenoviral therapy for insulinoma. Cell Oncol (Dordr). 2016; 39(3):279-286.

26. Akerstrom V, Chen C, Lan MS and Breslin MB. Adenoviral insulinoma-associated protein 1 promoterdriven suicide gene therapy with enhanced selectivity for treatment of neuroendocrine cancers. Ochsner J. 2013; 13(1):91-99.

27. Breslin MB LM. (2012). Modified INSM1-promoter for neuroendocrine tumor therapy and diagnostics. In: College BOSOLSUAAAM, ed. (Louisiana United States

28. Network NCC. (05/26/16). Prostate Cancer (Version 3.2016). 

Valorisation 
Valorisation in its original sense means the creation of economic value. In biomedical research, valorisation aims to assess the contribution of scientific knowledge to industrial activities and its application as potential products or services with societal benefit. This chapter is meant to position the scientific results from the preceding chapters in the context of social utilisation and to generate potential health care returns in appreciation of public investments.

\section{Social relevance}

Getting the diagnosis of 'cancer' is a significant and dramatic incident for patients and their relatives. Prostate cancer (PCa) frequently shows an indolent clinical course with a 2.5-3\% lifetime risk of dying from progressive disease [1]. However, risk stratification remains a major clinical question. Since clinicopathologic criteria are insufficient to efficiently distinguish between indolent and aggressive tumors, patients experience uncertainty about the risk of disease progression, which means an additional burden to them. Knowledge about the molecular profiles of an individual tumor and its potential to progress could provide clinicians with valuable information about the clinical course and support treatment recommendations. Proper counseling and involvement in therapy planning, especially of patients that could be considered for conservative management, positively affects patient's satisfaction after treatment [2]. Reducing overtreatment of patients with insignificant disease on the one hand would decrease comorbidity as a consequence of the PCa treatment, such as a surgical procedure, with benefit for the quality of life and reduction of health care costs. The accurate selection of patients that need aggressive treatment on the other hand would improve prognosis by avoding a delay until initiation of a potentially effective treatment.

\section{Scientific and clinical relevance}

PCa is the most prevalent non-cutaneous malignancy accounting for $15 \%$ of the cancers diagnosed in men [3]. Depending on risk estimation, different treatment options are possible. During the decision-making process towards radical treatment versus conservative management, clinicians use various prediction tools to determine patients that are at increased risk for disease progression. Those tools are based on clinicopathologic variables. However, PCa is a genomically complex disease. The molecular mechanisms and implications for clinical outcome of distinct genomic aberrations are yet poorly understood. Identification of the molecular profiles that promote aggressive tumor biology is therefore essential to support the prediction of progressive disease, and to recommend aggressive treatment to patients that will most likely benefit from it.

In the studies compiled in this doctoral thesis, novel targets have been identified that provide insights into the molecular mechanisms of TMPRSS2:ERG fusion-positive PCa. Defining tumors by their individual genetic constitution, rather than histopathological patterns could lead to more accurate risk stratification. 
Detection of the TMPRSS2:ERG gene fusion has currently no prognostic or therapeutic implications in routine clinical management. Determination of the gene fusion status could direct the selection of patients for clinical trials that are most likely to benefit from a molecularly targeted therapy reducing the number of required patients to randomize and potentially increasing the chance of success of drug effectiveness testing (targeted design). This could further create an economically valuable strategy to control public investments into scientific research.

We suggest that the TGF- $\beta$-ALK1 receptor-mediated signaling pathway in TMPRSS2:ERG positive tumors could be a promising candidate for future evaluation as therapy target in PCa. However, targeted therapy approaches are vulnerable to intrinsic resistance due to redundancy in signaling pathways in cancer cells [4]. Since ERG-mediated signaling deployed a second route, the FZD4-WNT signaling pathway, inhibition of both pathways could be considered as a combined concept to inhibit tumor activity. The identification of the two molecular determinants of epithelial-to-mesenchymal transition (EMT) in TMPRSS2:ERG positive tumors is therefore promising basis for future therapeutic approaches.

Recognition of therapy resistance is important to avoid disease progression. Functional characterization of biological processes involved in therapy resistance could identify novel targets to improve clinical management. INSM1 was identified as promising regulator of a neuroendocrine (NE) phenotype in PCa cells. The power of INSM1 lies in its specific overexpression in NE tumors. Since prostate cancers with NE characteristics are less likely to respond to hormonal agents, detection of INSM1 overexpression could be valuable in counseling patients towards a chemotherapeutic treatment or enrolment in a clinical trial [5]. 


\section{REFERENCES}

1. Howlader N NA, Krapcho M, Miller D, Bishop K, Kosary CL, Yu M, Ruhl J, Tatalovich Z, Mariotto A, Lewis DR, Chen HS, Feuer EJ, Cronin KA (eds). (2017). SEER Cancer Statistics Review, 1975-2014. National Cancer Institute. Bethesda, MD, USA).

2. Shariat SF, Kattan MW, Vickers AJ, Karakiewicz PI and Scardino PT. Critical review of prostate cancer predictive tools. Future Oncol. 2009; 5(10):1555-1584.

3. Ferlay J, Steliarova-Foucher E, Lortet-Tieulent J, Rosso S, Coebergh JW, Comber H, Forman D and Bray F. Cancer incidence and mortality patterns in Europe: estimates for 40 countries in 2012. Eur J Cancer. 2013; 49(6):1374-1403.

4. Stenvang J, Kumler I, Nygard SB, Smith DH, Nielsen D, Brunner N and Moreira JM. Biomarker-guided repurposing of chemotherapeutic drugs for cancer therapy: a novel strategy in drug development. Front Oncol. 2013; 3:313.

5. Mosquera JM, Beltran H, Park K, MacDonald TY, Robinson BD, Tagawa ST, Perner S, Bismar TA, Erbersdobler A, Dhir R, Nelson JB, Nanus DM and Rubin MA. Concurrent AURKA and MYCN gene amplifications are harbingers of lethal treatment-related neuroendocrine prostate cancer. Neoplasia. 2013; 15(1):1-10. 
Summary 


\section{SUMMARY}

The general introduction illustrates the challenges of prostate cancer (PCa) research and states the aims of my doctoral thesis. PCa is the most prevalent non-cutaneous malignancy accounting for $15 \%$ of the cancers diagnosed in men. It is the second leading cause of cancer-related death in men in Western countries. Family history and increasing age are the most important risk factors, with a 10 -years risk of $5.50 \%$ to develop PCa for men aged 70 years. PCa frequently shows an indolent clinical course with a 2.5$3 \%$ lifetime risk of dying from PCa. Since clinicopathologic criteria are insufficient to efficiently distinguish between slow growing and progressive tumors, there is uncertainty about the individual risk of aggressive disease. Identifying biomarkers that predict clinically aggressive disease is a current challenge for PCa research. Those markers could be valuable to reduce overtreatment of insignificant disease on the one hand and select patients that are at risk of progressive disease and need aggressive treatment on the other hand. PCa is usually suspected based on elevated PSA value and abnormal result from digital rectal examination (DRE), but PSA level is not a direct surrogate for tumor stage. Definitive diagnosis requires histopathological evaluation of prostate biopsy cores that are classified according to the Gleason grading system. The dilemma with the Gleason score is that it does not reflect the diversity of genetic aberrations. Therefore, patients with with the same histological pattern can develop heterogeneous clinical outcomes.

My work aimed to identify novel molecular mechanisms of aggressive PCa. The focus was on the molecular and cellular consequences of ERG overexpression upon TMPRSS2:ERG (T/E) variant expression.

Chapter 1 provides a detailed overview about the distinct genetic and molecular aberrations that impacts the heterogeneity of PCa. The majority of prostate cancers are adenocarcinomas arising from multifocal hyperplasia of luminal secretory cells. These cells display continuous histomorphological aberrations ranging from low-grade dysplasia to 'carcinoma in situ', collectively described as prostatic intraepithelial neoplasia (PIN). PCa is characterized by a complex pathology with multiple histological foci that can harbor diverse genetic and molecular alterations. The spectrum of genomic aberrations, including point mutations, copy number alterations, structural rearrangements and DNA methylation changes, reflect distinct molecular subtypes. Major signaling pathways that are most commonly altered in PCa, including androgen receptor (AR), PTEN-PI3K/AKT, Ras/Raf/MEK/ERK and the retinoblastoma protein (pRB) signaling, are increasingly affected in metastatic tumors. Further in metastatic PCa, a large portion of the genome can be affected by deletions suggesting increased genomic instability with disease progression.

Androgens play a central role in PCa development and progression to metastatic disease. Blocking of the AR signaling pathway by androgen deprivation therapy (ADT) belongs to the initial treatment options of advanced-stage PCa. However, most cancers will relapse and progress to castration-resistant prostate cancer (CRPC). Neuroendo- 
crine (NE) differentiation is a highly aggressive disease manifestation distinguished from adenocarcinoma by NE marker expression and unresponsiveness to hormone therapy.

Long-term androgen receptor signaling can induce DNA double-strand breaks driving the generation of chromosomal rearrangements. In PCa, gene fusions involving the ETStranscription factors have been described. The TMPRSS2:ERG (T/E) gene fusion is the most prevalent genomic alteration in PCa present in approximately $50 \%$ of all PCa cases. This gene fusion, resulting from the fusion of the transcription factor ERG to the androgen responsive gene TMPRSS2, leads to upregulation of ERG protein and activation of downstream target genes. The expression of fusion mRNAs from distinct T/E variants is associated with clinicopathological parameters. However, the underlying molecular processes resulting from expression of $\mathrm{T} / \mathrm{E}$ gene fusion variants remain unclear.

In chapter 2, the molecular alterations and functional implications caused by the T/E gene fusion were analysed. Using a doxycycline (Dox)-inducible overexpression LNCaP cell model (LNCaP-T/E), we showed that the TGF- $\beta /$ BMP as well as the WNT/ $\beta$-catenin signaling pathways are important regulators of $\mathrm{T} / \mathrm{E}$-mediated epithelial-to-mesenchymal transition (EMT) in PCa cells. Induction of T/E expression resulted in augmented secretion of TGF- $\beta 1$ and $-\beta 2$, and increased expression of $A L K 1$, a member of the TGF- $\beta$ receptor family. ALK1 inhibition in T/E expressing cells blocked p38 phosphorylation and reduced the expression of the TGF- $\beta$ target genes VIM, MMP1, CDH2, and SNAI2. Induction of $T / E$ expression further resulted in increased cellular migratory and invasive potential. We suggest that ALK1-mediated TGF- $\beta$ signaling is a novel oncogenic mechanism in T/E positive PCa and provide a rational basis for ALK1-blocking agents in T/E positive PCa. The soluble recombinant ALK1-Fc fusion protein dalantercept is currently evaluated in various malignancies. It was shown to have antitumor activity in diverse refractory solid tumors in phase 1 (NCT00996957, NCT02024087) or phase 2 trials (NCT01642082, NCT01727336, NCT01720173) as discussed in chapter 5.

Further in chapter 2, we confirmed that WNT/ $\beta$-catenin signaling and EMT in T/E expressing cells is mediated by the Frizzled receptor FZD4. Inhibition of FZD4 led to reduced phosphorylation of p38. Strikingly, we observed upregulation of miR-503 exclusively in $\mathrm{T} / \mathrm{E}$ variant $\mathrm{VI}$ overexpressing cells. Overexpression of miR-503 was able to repress SMAD7, a known negative regulator of TGF- $\beta$ and WNT/ $\beta$-catenin signaling. MiR-503mediated repression of SMAD7 therefore appears to be a way to escape the inhibitory effect of SMAD7 on TGF- $\beta$ and WNT/ $\beta$-catenin signaling. Inhibition of FZD4-mediated signaling is currently not addressed in clinical trials. However, support for the feasibility of FZD4-targeted therapy is provided from the testing of selective Frizzled signaling pathway inhibitors against FZD7 (vantictumab) and FZD8 (ipafricept) in ongoing clinical trials in HER2-negative breast cancer (NCT01973309), pancreatic cancer (NCT02005315), non-small cell lung cancer (NCT01957007), and ovarian cancer (NCT02092363).

We explored the epigenetic alterations induced by the T/E gene fusion in chapter 3 . Upon T/E overexpression, we found a global hypomethylation profile. Those differen- 
tially methylated $\mathrm{CpG}$ sites were mostly located in gene bodies. An integrative analysis on epigenetic and gene expression changes in LNCaP-T/E cells demonstrated that T/E overexpression drives upregulation of FZD4 and $H L A-D M B$ that could be correlated with loss of DNA methylation. However, the relation of DNA hypomethylation and mRNA upregulation, as well as the mechanistic exploration of the T/E-induced epigenetic changes remain unclear from the present analysis. In addition to the discussion in chapter 2, the correlation between FZD4 hypomethylation and mRNA upregulation, although preliminary, represents a basis for future research on the 'druggability' in T/E fusionpositive tumors.

In chapter 4, we identified the transcription factor INSM1 as a regulator of neuroendocrine (NE) differentiation in prostate cancer cell lines. Neuroendocrine prostate cancer (NEPC) is a highly aggressive variant of advanced PCa, often occurring with conventional adenocarcinoma. A correlation between INSM1 and the T/E gene fusion was observed in patient samples and cell lines. In cell culture experiments, ERG induced the expression of INSM1 and the NE markers TUBB3, SCG3, ASCL1. These data indicate that the $T / E$ gene fusion could be associated with NEPC. The tissue-restricted expression pattern and established role in neuronal and endocrine tissues of INSM1 could be of advantage in the histological detection of NE differentiation in PCa and targeted therapy of NEPC. Re-expression of INSM1 in NE tumors gained attention regarding its role in suicide gene therapy as tumor-specific treatment in small cell lung cancer and neuroblastoma. INSM1 promoter constructs have further been proposed as diagnostic and disease monitoring tool for NE tumors in vivo. In addition to previous studies showing shared gene signatures between different NE tumors, the present study highlighted remarkable similarities in genetic and molecular aberrations between NEPC and well-known models of NE tumors, such as the Reelin signaling pathway, in chapter 4. This suggests that insights into the mechanisms of NEPC can be derived from the molecular mechanisms of known NE cancers and the suicide gene therapy could find application as targeted strategy for NEPC.

In conclusion, novel markers for refined risk stratification of progressive disease outcome and prediction of treatment response are needed. Several tissue-based multigene expression assays for the prediction of aggressive PCa are available for clinical application. Their routine implementation is currently hampered by intrinsic challenges of PCa research, such as heterogeneity, multifocality, and a small sample volume in prostate biopsy. Genetic instability increases the complexity of somatic genomic alterations leading to a specific combination of driver mutations in a tumor. However, molecular pathology is an emerging field in PCa as a growing number of targets with known correlation to tumor biology are recognized, such as $A R$ splice variants. Further, differentiation markers of neuroendocrine manifestation, such as INSM1 or LICAM, may predict poor responsiveness to ADT. Current studies on novel molecular targets are discussed in chapter 5 . Individual genetic aberrations could be interrogated by next generation sequencing and may find application for a personalized approach in clinical practice. Molecular and genetic analysis of biopsy cores is currently not included in the PCa guidelines. In future, it may complement the diagnosis of PCa as it has already been im- 
plemented in other tumor entities, such as breast cancer, melanoma and, most recently, lung cancer. Simultaneously, a broader spectrum of therapeutic targets in addition to ADT is required to improve the clinical management of metastatic PCa. The functional and mechanistic evaluation of genetic markers, as presented in this doctoral thesis, is the basis for the development of novel drug targets and treatment strategies, and could guide the emphasis of future research. 

Nederlandse samenvatting 


\section{NEDERLANDSE SAMENVATTING}

De algemene introductie schetst de uitdagingen van prostaatkankeronderzoek en licht de doelen van mijn proefschrift toe. Prostaatkanker is de meest voorkomende nietcutane maligniteit en maakt 15\% van alle kankervormen in mannen uit. Het is tevens de één na belangrijkste doodsoorzaak door kanker in mannen in de Westerse wereld. Een positieve familiegeschiedenis en toenemende leeftijd zijn de belangrijkste risicofactoren, het 10-jaarsrisico voor mannen van 70 jaar om prostaatkanker te ontwikkelen is $5.50 \%$. Prostaatkanker vertoont vaak een langzaam groeiend beloop met een $2.5-3 \%$ leeftijdsrisico om eraan te overlijden. De klinisch-pathologische criteria volstaan echter niet om tussen langzaam groeiende en progressief verlopende tumoren te onderscheiden, zodat er onzekerheid bestaat ten opzichte van het individuele risico op een agressief groeiende tumor. Eén van de uitdagingen voor het prostaatkankeronderzoek is de identificatie van biomarkers die een agressief ziekteverloop kunnen voorspellen. Met behulp van deze markers zou enerzijds overbehandeling van klinisch niet-relevante tumoren voorkomen worden. Anderzijds zouden patiënten geselecteerd kunnen worden die een verhoogd risico op ziekteprogressie hebben en een agressieve behandeling nodig hebben. De verdenking op prostaatkanker ontstaat op basis van een verhoogde PSA waarde en een afwijkend resultaat tijdens digitaal rectaal onderzoek. De hoogte van de PSA waarde is echter geen directe marker voor het tumorstadium. De definitieve diagnose vereist histopathologisch onderzoek van biopsiecoupes van de prostaat die volgens het Gleason score-systeem geclassificeerd worden. De heterogeniteit van de genetische en moleculaire afwijkingen bij prostaatkanker heeft tot gevolg dat patiënten met dezelfde Gleason score een zeer uiteenlopend klinisch beloop kunnen ontwikkelen.

Het doel van dit proefschrift was het identificeren van nieuwe moleculaire mechanismen van het agressieve prostaatcarcinoom. De focus werd gelegd op de moleculaire en cellulaire gevolgen van de ERG overexpressie in TMPRSS2:ERG (T/E) varianten.

Hoofdstuk 1 geeft een gedetailleerd overzicht over de diverse genetische en moleculaire afwijkingen die van invloed zijn op de heterogeniteit van prostaatkanker. De meeste prostaatkankers zijn adenocarcinomen, die door multifocale hyperplasie van luminale secretoire cellen ontstaan. Deze cellen vertonen continue histomorfologische veranderingen, die van laaggradige dysplasie tot 'carcinoma in situ' rijken, samengevat als prostaat intra-epitheliale neoplasie (PIN). Prostaatkanker wordt gekenmerkt door een complexe pathologie met multipele histologische foci, die uiting zijn van een combinatie van diverse genetische en moleculaire afwijkingen. Het spectrum van genomische afwijkingen, zoals puntmutaties, copynumbervariatie, structurele rearrangements en DNA methyleringsveranderingen, spiegelt verschillende moleculaire subtypen weer. Signaalroutes die het vaakst afwijken, zijn de androgen receptor, PTEN-PI3K/Akt, Ras/Raf/MEK/ERK en het retinoblastoom protein (pRB). Deze routes zijn tevens vaker aangedaan in gemetastaseerde prostaatkanker. Verder zijn in het gemetastaseerde prostaatcarcinoom grote genomische gebieden gedeleteerd, wat op een verhoogde genetische instabiliteit in gevorderde prostaatkanker duidt. 
Androgenen spelen een centrale rol bij de ontwikkeling van prostaatkanker en progressie tot gemetastaseerde ziekte. Androgeen-deprivatie therapie (ADT) is de primaire behandeling van gevorderde prostaatkanker. Vaak treedt er onder deze behandeling echter een ziekterecidief en progressief beloop op. Neuroendocriene (NE) differentiatie is een zeer agressieve vorm van prostaatkanker, die onderscheiden wordt door expressie van NE markers en ongevoeligheid voor ADT. Langdurige blootstelling aan geactiveerde androgeen signaaltransductie kan leiden tot DNA dubbelstrengsbreuken, waardoor chromosomale rearrangements kunnen ontstaan. In prostaatkanker zijn genfusies van de ETS-transcriptiefactoren beschreven. De TMPRSS2:ERG (T/E) genfusie is de meest voorkomende genomische afwijking in prostaatkanker, aanwezig in rond 50\% van alle prostaattumoren. Deze genfusie ontstaat door fusie van het transcriptiefactor $E R G$ met het androgeen-sensitieve gen TMPRSS2 en leidt tot opregulatie van het ERG proteïne gevolgd door activatie van target genen. De expressie van fusie mRNAs van verschillende T/E varianten is geassocieerd met klinisch-pathologische parameters. De moleculaire veranderingen ten gevolge van expressie van $T / E$ genfusie-varianten zijn echter nog onvoldoende bekend.

In hoofdstuk 2 werden de moleculaire veranderingen en functionele gevolgen door expressie van de T/E genfusie onderzocht. Gebruikmakend van een doxycycline (Dox)induceerbaar overexpressie LNCaP cel model (LNCaP-T/E) werd aangetoond dat de TGF$\beta / B M P$ en de WNT/ $\beta$-catenin signaleringsroutes belangrijke regulatoren van de T/Egemedieerde epitheliale-tot-mesenchymale transitie (EMT) in prostaatkankercellen zijn. Inductie van T/E expressie resulteerde in een versterkte secretie van TGF- $\beta 1$ en - $\beta 2$, als een verhoogde expressie van ALK1, een receptor uit de TGF- $\beta$ familie. Inhibitie van ALK1 in T/E expresserende cellen leidde tot verminderde p38 fosforylering en verminderde expressie van de TGF- $\beta$ target genen VIM, MMP1, CDH2 en SNAI2. T/E expressie leidde ook tot een versterkte migratie en invasie van de cellen. ALK1-gemedieerde TGF- $\beta$ signalering is een nieuw oncogeen mechanisme in T/E positieve prostaatkanker en kan een basis zijn voor het testen van ALK1-blokkerende middelen in T/E positieve tumoren. Het oplosbare recombinante ALK1-Fc fusie eiwit dalantercept wordt momenteel onderzocht in diverse kankersoorten. In fase 1 (NCT00996957, NCT02024087) en fase 2 studies (NCT01642082, NCT01727336, NCT01720173) werd aangetoond dat dit middel anti-tumor activiteit in moeilijk behandelbare solide tumoren heeft, zoals besproken in hoofdstuk 5 .

We laten verder in hoofdstuk 2 zien dat de WNT/ $\beta$-catenin signalering in T/E expresserende cellen gemedieerd wordt door de Frizzled receptor FZD4. Remming van FZD4 leidde eveneens tot verminderder fosforylering van p38. Opvallend was verder dat het microRNA miR-503 enkel in T/E variant VI expresserende cellen verhoogd was. Overexpressie van miR-503 verminderde de expressie van SMAD7, een negatieve regulator van TGF- $\beta$ en WNT/ $\beta$-catenin signalering. MiR-503-gemedieerde repressie van SMAD7 kan een 'escape' route zijn om aan de remmende effecten van SMAD7 op TGF- $\beta$ en WNT/ $\beta$ catenin te ontsnappen. Therapeutische inhibitie van FZD4-gemedieerde signalering wordt momenteel niet getest in klinische studies. Aanleiding voor de haalbaarheid van een FZD4-gerichte therapie geven lopende studies die de selectieve Frizzled inhibitoren 
tegen FZD7 (vantictumab) en FZD8 (ipafricept) aan in HER2-negatieve borstkanker (NCT01973309), pancreaskanker (NCT02005315), niet-kleincellig longkanker (NCT01957007), en eierstokkanker (NCT02092363) onderzoeken.

In hoofdstuk 3 werden de epigenetische veranderingen ten gevolge van de T/E genfusie onderzocht. Door T/E overexpressie werd er een globale hypomethylering geobserveerd. De differentieel gemethyleerde CpG sites werden meestal in genlichamen gevonden. Een integratieve analyse van de epigenetische en genexpressie veranderingen in LNCaP-T/E cellen liet zien dat T/E overexpressie tot opregulatie van FZD4 en HLA-DMB leidde, die zou kunnen samenhangen met een verlies van DNA methylering. Er werd niet onderzocht of er een directe relatie tussen DNA methylering en mRNA opregulatie bestaat en wat de onderliggende mechanismen van de T/Egeïnduceerde epigenetische veranderingen zijn. Dit geeft aanleiding voor toekomstig onderzoek en zou kunnen bijdragen aan de behandelingsopties in T/E positieve tumoren.

In hoofdstuk 4 werd het transcriptiefactor INSM1 gevonden als regulator van een neuro-endocrine (NE) differentiatie in prostaatkanker cellijnen. Neuro-endocrine prostaatkanker (NEPC) is een zeer agressieve vorm van gevorderde prostaatkanker, die vaak met gewone adenocarcinomen optreedt. Zowel in patiënten monsters als in cellijnen werd er een correlatie tussen INSM1 en ERG expressie gezien. In cellcultuur experimenten leidde de overexpressie van ERG tot een verhoogde expressie van INSMI en van de NE markers TUBB3, SCG3 en ASCL1. Deze resultaten laten vermoeden dat de T/E genfusie geassocieerd is met NEPC. De weefselspecifieke expressie van INSM1 in neuronaal en endocrien weefsel zou van voordeel kunnen zijn bij de histologische detectie van NE differentiatie in prostaatkanker en gerichte behandeling van NEPC. Her-expressie van INSM1 in NE tumoren heeft aandacht gekregen voor zijn functie bij de 'suicide' gentherapie als tumor-specifieke behandeling in kleincellig longkanker en neuroblastoom. INSM1 promotor constructen werden voorgesteld als diagnostisch en ziektemonitoring tool voor NE tumoren in vivo. In de literatuur staat omschreven dat verschillende NE tumoren gelijkenissen in gensignaturen vertonen. De analyse in hoofdstuk 4 benadrukt eveneens opvallende overeenkomsten in de genetische en moleculaire afwijkingen van NEPC met bekende NE tumormodellen, zoals de Reelin signaleringsroute. Inzichten in de mechanismen van NEPC kunnen derhalve mogelijk afgeleid worden van de moleculaire mechanismen in andere NE tumoren. Verder geeft dit aanleiding voor de 'suicide' gentherapie als een potentiële strategie voor een gerichte therapie in NEPC.

Afsluitend geldt voor prostaatkanker dat nieuwe markers nodig zijn voor een verbeterde risicobeoordeling van een progressief ziekteverloop en predictie van de behandelingsrespons. Diverse weefsel-gebaseerde multigen expressie assays voor de predictie van agressieve prostaatkanker zijn beschikbaar voor de klinische toepassing. Echter wordt de implementatie ervan bemoeilijkt door de intrinsieke uitdagingen van prostaatkankeronderzoek, zoals heterogeniteit, multifocaliteit en beperkt monstervolume uit de prostaatbiopsie. Genetische instabiliteit verhoogt de complexiteit van somatische genomische afwijkingen die een specifieke combinatie van 'driver' mutaties in een tu- 
mor veroorzaken. De moleculaire pathologie is echter een snelgroeiend onderzoeksgebied en een toenemend aantal aan 'targets' wordt bekend die samenhangen met de tumorbiologie, zoals bijvoorbeeld $A R$ splice varianten. Bovendien zouden differentiatiemarkers die duiden op een NE manifestatie, zoals INSM1 of L1CAM, een ongevoeligheid op ADT kunnen voorspellen. Recente studies naar nieuwe moleculaire 'targets' worden besproken in hoofdstuk 5 .

De individuele genetische afwijkingen van een tumor kunnen geïdentificeerd worden door 'next generation sequencing' dat toegepast zou kunnen worden in een gepersonaliseerd aanpak in de kliniek. Een moleculaire en genetische analyse van biopsiemonsters is tegenwoordig niet opgenomen in de richtlijnen voor prostaatkanker. In toekomst zouden deze analyses echter een aanvulling bieden op de standaardbehandeling van prostaatkanker, zoals het reeds toegepast wordt in andere tumorvormen, namelijk borstkanker, melanoom en laatstelijk longkanker. Ook is er een breder spectrum van therapeutische 'targets' nodig als aanvulling op ADT om het klinische beleid van gemetastaseerde prostaatkanker te verbeteren. De functionele en mechanistische analyse van genetische markers, zoals het in dit proefschrift uitgewerkt werd, stelt de basis voor de ontwikkeling van nieuwe drug targets en behandelmogelijkheden en opent de deur voor toekomstig onderzoek. 



\section{Deutsche Zusammenfassung}




\section{DEUTSCHE ZUSAMMENFASSUNG}

Die allgemeine Einführung schildert die Schwierigkeiten der Prostatakrebsforschung und erläutert die Zielsetzungen meiner Doktorarbeit. Prostatakrebs ist die häufigste nichtkutane Krebserkrankung, die 15\% aller Krebsdiagnosen des Mannes ausmacht. Er ist außerdem die zweithäufigste krebsbedingte Todesursache unter Männern in westlichen Ländern. Eine familiäre Vorbelastung, sowie zunehmendes Alter sind die wichtigsten Risikofaktoren. Das 10-Jahres-Risiko für 70-jährige Männer an Prostatakrebs zu erkranken liegt bei 5,50\%. Die meisten Prostatakrebserkrankungen zeigen keine Tendenz zu einem aggressiven Verlauf und es besteht ein 2,5-3\% Lebenszeitrisiko an Prostatakrebs zu versterben. Allerdings sind die klinisch-pathologischen Kriterien unzureichend für eine genaue Differenzierung zwischen langsam wachsenden und progredient verlaufenden Tumoren. Daher besteht eine Unsicherheit bezüglich des individuellen Risikos für eine aggressiv wachsende Krebsform. Eine der Herausforderungen in der aktuellen Prostatakrebsforschung liegt in der Identifizierung von Markern, die einen aggressiven Krankheitsverlauf prognostizieren können. Mithilfe dieser Marker könnten einerseits Übertherapie der klinisch nicht-relevanten Formen reduziert und andererseits Patienten mit einem erhöhten Risiko für einen trotz lokaler Therapie progredienten Krankheitsverlauf identifiziert und behandelt werden. Der Verdacht auf Prostatakrebs entsteht aufgrund eines erhöhten PSA Wertes sowie eines auffälligen digital-rektalen Untersuchungsergebnisses. Die Höhe des PSA Wertes korreliert jedoch nicht direkt mit dem Tumorstadium. Zur Diagnosesicherung ist eine feingewebliche Untersuchung der Drüsenmorphologie an Stanzbiopsien erforderlich. Diese werden nach dem Gleason Scoring-System eingeteilt. Die Heterogenität der molekularbiologischen Veränderungen im Prostatakrebs führt jedoch dazu, dass Patienten mit der gleichen Gleason-Score einen sehr variablen klinischen Verlauf entwickeln können.

Das Ziel meiner Arbeit war es, neue Erkenntnisse zu gewinnen über die molekularen Mechanismen, die zu aggressiven Prostatakrebserkrankungen führen. Der Schwerpunkt meiner Arbeit lag dabei auf der Untersuchung der molekularen und zellulären Veränderungen, die aus der Überexpression von ERG in TMPRSS2:ERG (T/E) Varianten resultieren.

Kapitel 1 liefert eine detaillierte Übersicht über die verschiedenen genetischen und molekularbiologischen Veränderungen, die zur Heterogenität des Prostatakrebses beitragen. Die überwiegende Mehrheit aller Prostatakrebserkankungen sind Adenokarzinome, die durch multifokales Wachstum luminaler sekretorischer Zellen entstehen. Diese Zellen weisen kontinuierliche histomorphologische Veränderungen auf, die von niedriggradiger Dysplasie bis hin zu einem 'carcinoma in situ' reichen und zusammenfassend als intraepitheliale Prostataneoplasie (PIN) bezeichnet werden. Prostatakrebs ist gekennzeichnet von einer komplexen Pathologie mit mehreren histologische Fokussen, die Ausdruck einer Mischung von mehreren genetischen und molekularbiologischen Veränderungen sind. Das Spektrum der genomischen Aberrationen, wie z.B. Punktmutationen, Kopienzahlvariationen, strukturelles Rearrangement und DNA Methylierungsveränderungen, spiegelt unterschiedliche molekulare Subtypen wider. Die am 
häufigsten veränderten Signalwege sind die Signaltransduktion über Androgene, PTENPI3K/Akt, Ras/Raf/MEK/ERK und das Retinoblastom Protein (pRB). Diese sind vertärkt betroffen in metastasiertem Prostatakrebs. Auch sind im metastasierten Prostatakrebs große Genomabschnitte von Deletionen betroffen, was eine erhöhte genetische Instabilität in fortgeschrittenem Prostatakrebs vermuten lässt.

Androgene nehmen eine zentrale Rolle in der Entstehung und dem Fortschreiten von Prostatakrebs ein. Die hormonablative Behandlung gehört daher zu den primären Therapieoptionen des fortgeschrittenen Prostatakarzinom. Häufig tritt darunter jedoch ein Krankheitsrückfall und progressiver Verlauf hin zum kastrationsresistenten Prostatakrebs ein. Der neuroendokrine Prostatakrebs (NEPC) ist eine sehr aggressive Form des Prostatakrebses, die sich durch die Expression von neuroendokrinen (NE) Markern und fehlendem Ansprechen auf hormonablative Therapie vom Adenokarzinom unterscheidet.

Langfristig aktivierte Signaltransduktion über den Androgenrezeptor können zu Doppelstrangbrüchen der DNA führen und somit chromosomales „rearrangement" hervorrufen. Im Prostatakrebs wurden Genfusionen der ETS-Transkriptionsfaktoren beschrieben. Die T/E Genfusion ist die häufigste Genomveränderung im Prostatakrebs mit einer Prävalenz von 50\% aller Tumore. Diese Genfusion resultiert aus der Fusion des Transkriptionsfaktors ERG mit dem androgensensiblen Gen TMPRSS2 und begünstigt die Hochregulierung des ERG Proteins mit anschließender Aktivierung der ERG-Zielgene. Die Expression von Fusions-mRNA Molekülen von unterschiedlichen T/E Varianten ist assoziiert mit klinisch-pathologischen Parametern. Die molekularen Veränderungen, die als Folge der Expression von T/E Genfusionsvarianten auftreten, sind jedoch nicht ausreichend bekannt.

In Kapitel 2 wurden die molekularen Veränderungen und funktionellen Auswirkungen der T/E Genfusion untersucht. Unter Verwendung eines Doxycyclin (Dox)-induzierbarem Überexpressionsmodel in LNCaP Zellen (LNCaP-T/E) konnte belegt werden, dass der TGF- $\beta$ /BMP sowie der WNT/ $\beta$-catenin Signalweg wichtige Regulatoren der T/Evermittelten Epithelial-zu-Mesenchymal-Transition (EMT) in Prostatakrebszellen sind. Die Induktion der T/E Expression führte zur verstärkten Sekretion von TGF- $\beta 1$ und -2 sowie erhöhter Expression von ALK1, einem Rezeptor der TGF- $\beta$ Familie. ALK1 Hemmung in T/E exprimierenden Zellen blockierte die p38 Phosphorylierung und verringerte die Expression der TGF- $\beta$ Zielgene VIM, MMP1, CDH2 und SNAI2. T/E-Induktion führte auch zur verstärkten Zellmigration- und Invasion. Diese Ergebnisse deuten auf die ALK1vermittelte TGF- $\beta$ Signaltransduktion als onkogener Mechanismus in T/E positiven Prostatatumoren hin. Außerdem liefern diese Daten eine Grundlage für die Testung von ALK1-Inhibitoren bei der Behandlung von T/E positiven Prostatatumoren. Das lösliche rekombinante ALK1-FC Fusionsprotein Dalantercept wird zurzeit in verschiedenen Krebsarten getestet und zeigte bereits Antitumorwirkung in unterschiedlichen Therapierefraktären soliden Tumoren in Phase 1 (NCT00996957, NCT02024087) und Phase 2 Studien (NCT01642082, NCT01727336, NCT01720173), beschrieben in Kapitel 5. Des Weiteren konnten wir in Kapitel 2 erhärten, dass der WNT/ $\beta$-catenin Signalweg in T/E exprimierenden Zellen über den Frizzled Rezeptor FZD4 vermittelt wird. Die FZD4- 
Inhibition hatte eine Reduktion der p38 Phosphorylierung zur Folge. Interessanterweise wurde eine Hochregulierung der microRNA miR-503 ausschließlich in T/E Variant VI exprimierenden Zellen gefunden. Eine Überexpression der miR-503 führte zur Reduktion von SMAD7, da als negativer Rregulator der TGF- $\beta$ und WNT/ $\beta$-catenin Signalwege bekannt ist. Die miR-503-vermittelte Reduzierung von SMAD7 könnten ein 'escape' Mechanismus sein, der hemmenden Wirkung von SMAD7 auf TGF- $\beta$ und WNT/ $\beta$ catenin zu entkommen. Eine therapeutische Hemmung des FZD4-vermittelten Signalweges ist zurzeit nicht Gegenstand von klinischen Studien. Unterstützende Belege zur Möglichkeit einer FZD4-gezielten Therapie können abgeleitet werden von Studien, welche die selektiven Inhibitoren gegen FZD7 (Vantictumab) und FZD8 (Ipafricept) an HER2-negativen Brusttumoren (NCT01973309), Bauchspeicheldrüsenkrebs (NCT02005315), nicht-kleinzelligem Lungenkrebs (NCT01957007), und Eierstockkrebs (NCT02092363) testen.

In Kapitel 3 wurde eine Analyse der epigenetischen Veränderungen als Folge der T/E Genfusion durchgeführt. Durch Überexpression der T/E Varianten zeigte sich ein globales Hypomethylierungsmuster. Die differentiell methylierten CpG-Orte befanden sich überwiegend in Gen-Körper Regionen. Eine integrative Analyse der epigenetischen und Genexpressionsveränderungen in LNCaP-T/E Zellen wies auf eine T/E-induzierte Hochregulierung von FZD4 und HLA-DMB, die mit einem Verlust von DNA Methylierung einhergehen könnte. Ein direkter Zusammenhang zwischen DNA Hypomethylierung und mRNA Hochregulierung sowie eine Bestimmung der zugrundeliegenden Mechanismen der T/E-vermittelten epigenetischen Veränderungen konnte in der vorliegenden Analyse nicht erbracht werden. In Ergänzung zu den in Kapitel 2 aufgeführten Diskussionspunkten könnte ein Zusammenhang zwischen der FZD4 Hypomethylierung und mRNA Hochregulierung eine Basis sein für weitere Analysen zu der „druggability“ von T/E fusionspositiven Tumoren.

In Kapitel 4 wurde der Transkriptionsfaktor INSM1 als Regulator einer neuroendokrine (NE) Differenzierung in Prostatakrebszelllinien identifiziert. Der neuroendokrine Prostatakrebs (NEPC) ist ein hochaggressives Karzinom, welcher oft in Kombination mit dem klassischen Adenokarzinom auftritt. In Patientenproben und in Zelllinien konnte ein Zusammenhang zwischen INSM1 und der T/E Genfusion beobachtet werden. Experimentell führte die T/E Überexpression zur Hochregulierung von INSM1 sowie zur verstärkten Expression von den NE Markern TUBB3, SCG3, ASCL1. Dies deutete daraufhin, dass die T/E Genfusion mit NEPC assoziiert sein könnte. Die gewebespezifische Expression und etablierte Funktion von INSM1 in neuronalem und endokrinem Gewebe könnten von Vorteil sein bei der histologischen Diagnose von neuroendokrinem Prostatakrebs und als spezifisches, target' in der gezielten Therapie des NEPC. Die ReExpression von INSM1 in NE Tumoren erhielt Aufmerksamkeit in der, suicide' Gentherapie als tumorspezifische Behandlung des kleinzelligen Lungenkrebses und Neuroblastoms. INSM1 Promoter-Konstrukte könnten potentiell Anwendung finden in der Diagnose und Verlaufskontrolle von NE Tumoren in vivo. In Ergänzung zu vorangegangen Studien, die auf beachtliche Ähnlichkeiten der Gensignaturen verschiedener NE Tumore hinweisen, zeigte auch die vorliegende Arbeit, insbesondere Kapitel 4, Übereinstim- 
mungen in den genetischen und molekularbiologischen Veränderungen zwischen NEPC und bekannten NE Tumormodellen, wie zum Beispiel die Reelin Signaltransduktion. Dies lässt vermuten, dass weitere Erkenntnisse über die Mechanismen des NEPC abgeleitet werden könnten von den molekularpathologischen Mechanismen anderer NE Tumore und dass die ,suicide' Gentherapie eine potentielle Strategie der gezielten Therapie im NEPC sein könnte.

Abschließend gilt für Prostatakrebserkrankungen, dass Marker für die verfeinerte Risikoabschätzung eines progredienten Tumorverlaufs benötigt werden. Verschiedene gewebsbasierte Multi-Genexpressionstests für die Einschätzung des aggressiven Prostatakrebses stehen bereits zur Verfügung. Ihre standardisierte Anwendung wird allerdings erschwert von den bekannten Herausforderungen der Prostatakrebsforschung, wie Heterogenität, Multifokalität und das eingeschränkte Probenvolumen aus der Stanzbiopsie. Die genetische Instabilität im Prostatakrebs erhöht die Komplexität der somatisch genomischen Aberrationen, welche zu spezifischen Kombinationen von ,driver' Mutationen in einem Tumor führen. Die molekulare Pathologie ist jedoch ein schnell wachsendes Forschungsfeld, immer mehr, targets' werden entdeckt, die mit einer aggressiven Tumorbiologie korrelieren, wie zum Beispiel AR Spleißvarianten und Differenzierungsmarker einer neuroendokrinen Manifestation (zum Beispiel INSM1 oder L1CAM). Letztere könnten zum Beispiel eine Einschätzung des Therapieansprechens auf eine hormonablative Behandlung ermöglichen. Aktuelle Studien zu neuen molekularen 'targets' werden in Kapitel 5 besprochen. Individuelle genetische Veränderungen können durch next generation sequencing erhoben werden und Anwendung finden für einen personalisierten Ansatz in der klinischen Praxis. Die molekularbiologische und genetische Klassifizierung am Biopsiematerial ist aktuell kein Bestandteil der Prostatakrebsrichtlinien. Sie könnte in Zukunft jedoch Einfluss haben auf die Standardtherapie des Prostatakrebses, wie es bereits am Beispiel des Brustkrebses, Melanoms und kürzlich auch des Lungenkrebses umgesetzt wurde. Gleichzeitig ist ein breiteres Spektrum an therapeutischen ,targets' (in Ergänzung zur hormonablativen Therapie) dringend notwendig, damit die Behandlungsmaßnahmen für metastasierten Prostatakrebserkrankungen verbessert werden. Die funktionelle und mechanistische Untersuchung von genetischen Markern, wie in der vorliegenden Promotionsarbeit erarbeitet wurde, ist die Basis für die Entwicklung von neuen Diagnoseverfahren und könnte die Ausrichtung zukünftiger Forschungsvorhaben beeinflussen. 



\section{ACKNOWLEDGEMENTS}

Most of the time, working on my thesis has been both a challenge and a pleasure. Always, collaborating with my mentors and colleagues has been a very special privilege. This part is about expressing my gratitude towards a number of people who have played a key part in my professional and personal life in the past years. Finishing my thesis with these notes of thanks is actually the nicest part, because it makes me rembering all the good things that happened.

With this, my first thank you goes to Holger Sültmann, for supervising my research: I cannot say how much I benefited from your scientific expertise and broad experience. Your constructive support and criticism helped me a lot to grow professionally and personally. You provided most valuable input that helped me constantly reflect on my research and to deal with all obstacles that came along the way. Under your supervision, I finally grew from a student to a reseacher.

I am more than thankful to Frans Ramaekers, who has been my first and most important mentor from my first days as a young A-KO on to the final revision of this thesis. Thank you for being a constant source of inspiration and motivation. I will not forget your visits to Heidelberg; after our TAC meetings, you always found the time for a friendly chat in a local pub.

Another big thank you goes to my co-supervisors Sabine Klauck and Peter Altevogt.

Sabine, you provided me the best possible support in terms of organizing my work and myself. Your eye for details has helped me to deliver results in a professional and productive manner. Your ingenious solutions saved many experiments and turned them into a success.

Peter, thank you for being such a inspiring mentor and coach. When I first came to Heidelberg, your warm hospitality made my start as a researcher in your group together with Uwe, Nico, Kai and Natalie an entirely pleasant and positive and experience. Your endless experience in so many different fields contributed to actually all subjects of my research. Your overwhelming enthusiasm about a promising result was very motivating and contagious to me. Sometimes, you knew better about the message of my results than I did.

I would also like to thank the members of the Assessment committee, Prof. Manon van Engeland, Prof. Jack Schalken, Prof. Sascha Pahernik, and Prof. Marc Vooijs, and Supervisory committee for investing the time and efforts to read this thesis and for giving me encouraging feedback. And also Ralf Bischoff, as a member of my Thesis Advisory Committee, you have given very valuable input which I am most thankful for.

Thank you, Toon Van Gorp, for opening many doors for me to my PhD studies and for bein such a reliable contact person in Maastricht. 
Working with my lab group at the DKFZ in Heidelberg - the awesome B063 - has been a rewarding professional experience and a wonderful time of my personal life. Thank you, Sabrina, Simon, Uwe, Steffen, Julia, Arlou, Sebastian, Doreen, Anja, Sabrina M., and Simone, thank you for all the laughing during lunch time, for the riddles, games and radio music that shortened hours of incubation time; for barbecues and selfmade Glühwein in the lab kitchen. With you, even the annual lab cleaning was fun. Sabrina and Simon, thank you for trembling with me for the countless qPCRs, migration assays or Western blots, and for being there for me when I got stuck in a huge cell culture experiment or when one of the machines did not wanted to work.

I was always happy about a distraction from the lab work by pub crawling with Noemi, Micha, Uwe, Kay, Kathrin any many others. Thank you for all the nights in O'Reilleys or the French corner pub that we did not want to end. Lisa, what a pleasure that I met you during my remaining months in Heidelberg at the $\mathrm{PhD}$ retreat. It was such a fun dancing with you all night long.

And I found more welcome distraction with my wind quintet Kristina, Christa, Martin and Renate, as well as with the Collegium Musicum Orchestra in Mannheim. Thank you for the nice chats. Playing with you gave my thoughts a break from research. And after some exciting pieces I was refreshed to return to the lab life. Timmy and Karolina, thank your for being loyal visitors of our concerts in Mannheim.

Kevin, David and Caro, thank you for your friendship and for your encouraging words that kept me going my way.

Helmut and Annette, thank you for your genuine interest in my research, and for your support with proofreading the German summary.

Alex, Tali, and Nora, while you live remotely, I still feel that we are close whenever we manage to meet. Thank you for this!

My dear family: my parents, Edda and Michael, with your support and your love I have made it so far. My sisters and my brother, Saskia, Mirjana, and Nicolai, thank you for your patience and your confidence in me. Christian, Tim, and Hans, Judith, and André, for me it is a big gift having you as part of our family. Tante Schmitzi, thank you for your love and care.

And finally, a very special thank you to Tobias. Thank you for all the moments we can share, your advice, patience, especially during this last, most stressful year, and your love. 


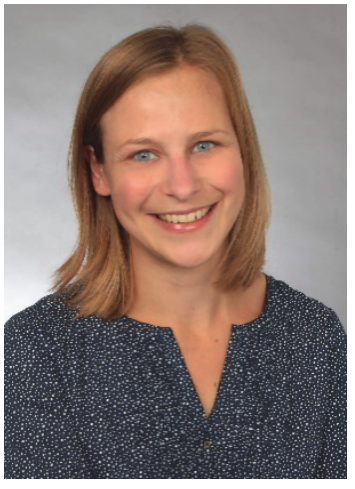

\section{CURRICULUM VITAE}

Leonie Ratz was born on the 23rd of March 1987 in Cologne, Germany. After finishing her pre-university education (Abitur) at the Kaiserin-Augusta School in Cologne in 2004, she pursued her bachelor studies in 'Molecular Life Sciences' at the Maastricht University in the Netherlands.

Her fascination about the combination of scientific research and medical care encouraged her to enroll in the master program 'Medical Doctor and Clinical Resarcher' (A$\mathrm{KO})$ at Maastricht University. After finishing her studies, she performed a scientific internship at the German Cancer Research Center (DKFZ) in Heidelberg, Germany. In 2013, she started her PhD studies in the field of cancer genome research under supervision of Prof. H. Sültmann and in collaboration with Prof. F.C.S. Ramaekers at GROW, Maastricht University. During her PhD research, Leonie worked on the identification of novel driver genes in aggressive prostate cancer with special emphasis on the role of the TMPRSS2:ERG gene fusion. She now works as resident physician at the department of Gynecology and Obstetrics in the Augustinian hospital in Cologne. 


\section{PUBLICATION LIST}

J.M.A. Pickl, D. Heckmann, L. Ratz, S.M. Klauck, H. Sültmann. Novel RNA Markers in Prostate Cancer: Functional Considerations and Clinical Translation. Biomed Res Int. 2014: 765207.

L. Ratz, P. Altevogt, S. M. Klauck and H. Sültmann. The biology of aggressive prostate cancer: Implications for innovative diagnostics and therapy. In preparation for submission as review.

L. Ratz, M. Laible, L.A. Kacprzyk, S.M. Wittig-Blaich, Y. Tolstov, S. Duensing, P. Altevogt, S.M. Klauck, and H. Sültmann. TMPRSS2:ERG gene fusion variants induce TGF- $\beta$ signaling and epithelial to mesenchymal transition in prostate cancer cells. Oncotarget. 2017; 8(15):25115-25130.

L. Ratz, S. Bauer, P. Altevogt, S. M. Klauck and H. Sültmann. INSM1 induces a neuroendocrine phenotype in prostate cancer cells. TMPRSS2:ERG overexpression induces changes in the epigenetic signature of human prostate cancer cells. In preparation.

L. Ratz, P. Altevogt, S. M. Klauck and H. Sültmann. INSM1 induces a neuroendocrine phenotype in prostate cancer cells. In preparation. 